\title{
R\&D internationalisation and knowledge transfer : impact on MNEs and their home countries
}

Citation for published version (APA):

Criscuolo, P. (2004). R\&D internationalisation and knowledge transfer : impact on MNEs and their home countries. [Doctoral Thesis, Maastricht University]. Datawyse / Universitaire Pers Maastricht. https://doi.org/10.26481/dis.20041222pc

Document status and date:

Published: 01/01/2004

DOI:

$10.26481 /$ dis.20041222pc

Document Version:

Publisher's PDF, also known as Version of record

\section{Please check the document version of this publication:}

- A submitted manuscript is the version of the article upon submission and before peer-review. There can be important differences between the submitted version and the official published version of record.

People interested in the research are advised to contact the author for the final version of the publication, or visit the DOI to the publisher's website.

- The final author version and the galley proof are versions of the publication after peer review.

- The final published version features the final layout of the paper including the volume, issue and page numbers.

Link to publication

\footnotetext{
General rights rights.

- You may freely distribute the URL identifying the publication in the public portal. please follow below link for the End User Agreement:

www.umlib.nl/taverne-license

Take down policy

If you believe that this document breaches copyright please contact us at:

repository@maastrichtuniversity.nl

providing details and we will investigate your claim.
}

Copyright and moral rights for the publications made accessible in the public portal are retained by the authors and/or other copyright owners and it is a condition of accessing publications that users recognise and abide by the legal requirements associated with these

- Users may download and print one copy of any publication from the public portal for the purpose of private study or research.

- You may not further distribute the material or use it for any profit-making activity or commercial gain

If the publication is distributed under the terms of Article $25 \mathrm{fa}$ of the Dutch Copyright Act, indicated by the "Taverne" license above, 


\title{
R\&D Internationalisation and Knowledge Transfer:
}

\author{
Impact on MNEs and their Home Countries
}

\section{PROEFSCHRIFT}

ter verkrijging van de graad van doctor aan

$$
\text { de Universiteit Maastricht, }
$$

op gezag van de Rector Magnificus, Prof. Mr. G.P.M.F. Mols

volgens het besluit van het College van Decanen, in het openbaar te verdedigen

op woensdag 22 december 2004 om 10.00 uur

\section{Paola Criscuolo}


Promotor

Prof. Dr. Bart Verspagen, Technische Universiteit Eindhoven

Co-promotor

Prof. R. Narula, University of Reading

Beoordelingscommissic:

Prof. Dr. L.L.G. Soete, voorzitter

Prof. Dr. J. Hagedoorn

Prof. Dr. R. Veugelers, Katholieke Universiteit Leuven 


\section{ACKNOWLEDGEMENTS}

Like any other PhD candidate. I owe a significant debt to a wide range of people. But the list of those I want to thank is even longer than usual, both because this thesis has been researched and written in a number of different institutions and because I came across so many people, most of who have now become my friends, who have been willing to help me in my quest.

First of all. I want to thank my two supervisors Prof. Rajneesh Narula and Prof. Bart Verspagen (in alphabetical order!), who, in very different ways, have guided me through the long and tortuous process of writing my doctoral dissertation. Rajneesh introduced me, a macrocconomist by training, to the field of international business and has provided me, with many ideas and opportunities to meet a large number of the most important researchers in this area. He has encouraged me to exploit the potential synergies between the economics and the management literatures and has continuously supported me emotionally (and also financially) without any regard to his telephone bill! Bart is at the root of my interest in patents and patent citations. I owe him a great deal for providing me with most the data analysed in this thesis and for having shared with me his invaluable knowledge on how to handle them, on how to construct meaningful indicators and, above all, on how to interpret the results. He has always been able to find time for intense discussion in Eindhoven to help me solve critical problems. Despite sometimes being a man of few words, what he has said has counted. The careful reader will see that the fingerprints of both supervisors have been left throughout the following pages.

I am also greatly indebted to Pari Patel, who first offered me the possibility of working with him at SPRU (University of Sussex) three years ago. I am very grateful to him for teaching me how to deal with patent data and for all his efforts in trying to keep me at the Freeman Centre where I carried out most the work that forms this thesis. At Sussex I benefited from very valuable comments and suggestions on a multitude of subjects from Virginia Acha, Stefano Brusoni. Eugenia Cacciatori. Pablo D’Este. Aldo Geuna. Elisa Giuliani, Anabel Marin. Piera Morlacehi, Andrea Prencipe, Ed Steinmueller, and Nick von Tunzelmann. Special thanks go to Gustavo Crespi and Lionel Nesta for their immense willingness and patience in helping me solving econometric and STATA issucs.

I wish to thank all the researchers and R\&D managers at AstraZeneca, Aventis, GSK, Novartis. Roche, and Schering for allowing me to interview them and for providing me with 
invaluable insights into their R\&D organisations and their secondment experiences. Without their contributions Chapter 6 could not have been written. I also very much appreciate Wilfred Schoenmakers and Pari Patel letting me using their patent database without which 1 could not have carried out the analysis presented in Chapters 4 and 5 . Chapter 4 benefited also from the extremely useful insights given by Bend Bettels on the patent examination process at the European Patent Office.

The ideas and the results developed in the chapters of this thesis have been presented in various workshops and conferences. I would like to thank the members of three Europeanfunded projects (AITEG, SETI and MESIAS), with which I have been involved at various stages, for their comments at workshops in Rome, London, Madrid, and Bruges. Earlier versions of Chapters 5 and 7 have benefited from very useful remarks received from the participants and discussants of the $28^{\text {th }}$ EIBA conference in Athens in December 2002 and the AIB conference in Monterey in July 2003. Chapter 6 was much improved by the suggestions of participants at the conference in honour of Keith Pavitt held at SPRU in November 2003 and the $29^{\text {th }}$ EIBA conference in Copenhagen in December 2003. In particular I want to thank Daniele Archibugi, John Cantwell. Davide Castellani, Marva Corley, Gabriela Dutrenit, Simona Iammarino, Jakob Edler, Michael Enright. Tony Frost, Jose Molero, Guido Reger, Francesca Sanna Randaccio, Grazia Santangclo. Maria Savona, Matias Ramircz, Paulina Ramirez, Reinhilde Veugelers, and Antonello Zanfei. In addition to those who already mentioned I am grateful to Bill Green, Bronwyn Hall, John Van Reenen, and Joc Hilbe for offering many valuable suggestions and comments on econometric and statistical techniques and to Cynthia Little for clcaning the manuscript of spelling mistakes and improving my English all round.

I also wish to thank the various institutions that have provided me with the perfect environment to carry out my rescarch. MERIT at the University of Maastricht - of course the place where I started my PhD (especially Wilma Coenegrachts. Robin Cowan, Corien Gijsbers. Hugo Hollanders, Silvana de Sanctis, and, last but not least, Luc Socte for taking care of me when $I$ first moved there and for continuing to help me with all sort of issues after I left): the School of Management and Organisational Psychology at Birkbeck College (especially Jonathan Michic, Christine Oughton, Telly Tolentino, and Jenny Cook) where I was a visiting $\mathrm{PhD}$ student for one year and where I have lectured for the past three years: ECIS at the University of Eindhoven for allowing me to use their facilities during my numerous meetings with my supervisor; and the Innovation Studies Centre at Imperial 
College, where I am working now as a research associate, for allowing me time to deal with the printing of the thesis and the organisation of the defence.

The research for this dissertation was sponsored by Mediocredito Central (Marco Fanno fellowship from September 1999 to June 2001) and by the European Commission (Maric Curie fellowship from October 2002 to October 2003). This latter grant allowed me to spend one year at SPRU, to carry out the case study presented in Chapter 6, and to participate to a number of conferences. I also gratefully acknowledge the Royal Economic Society for its financial support of my participation in the AIB conference.

Finally, I want to express my deepest gratitude to all my friends (first among others Alessandro Nuvolari for his warm and repeated 'steam-powered' hospitality in Eindhoven, the 'SPRU crowd', Elad Harrison, Camilla Noonan, and Pedro Martinez Lara), to my parents, Vanda and Antonio, my sisters, Alberta and Chiara, and Chiara's boyfriend, Dr. Pratik Roy (who also looked after my health), for their patience, understanding and moral support over the many years that this research has taken. I am particularly indebted to my sister Chiara, who in the last five years has shared with me the ups and downs of writing a $\mathrm{PhD}$ thesis, for her help with econometric issues and for being there when I needed to vent all my frustrations.

Last, but not least, a special word of thanks goes to my husband, Fergal Shortall. Not only has he supported me financially and emotionally in the numerous moments of discouragement, but he has also advised me on several technical issues and above all has had the patience to read every single thing I have been able to come up with. His contribution has significantly improved both the form and the content of this book. At this stage he knows as much as I do about multinationals, patents and patent citations...

This thesis is dedicated to him. 


\section{TABLE OF CONTENTS}

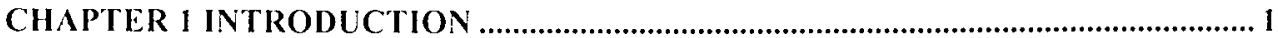

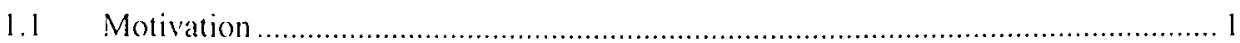

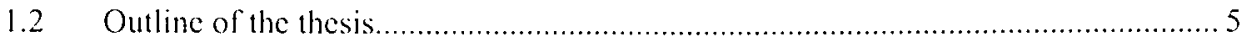

\section{CHAPTER 2 R\&D SPILLOVERS AND MNES: AN OVERVIEW OF THE}

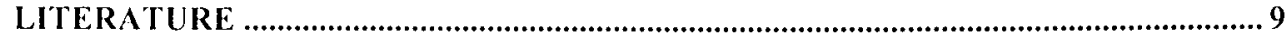

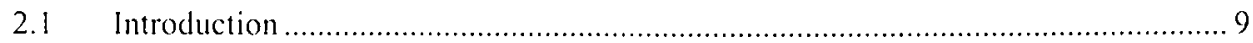

2.2 Geographical and social dimension of R\&D spillovers .................................. 10

2.2.1 Local embeddedness................................................................................ II

2.2.2 Empirical evidence of localised knowledge spillovers................................... 13

2.2.3 Empirical evidence of the social dimension of knowledge spillovers ................ I8

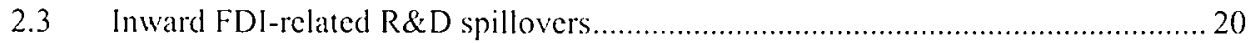

2.3.1 Technological spillovers chamnels ........................................................ 2l

2.3.2 Conditions favouring the realisation of spillover potential .............................22

2.3.3 Empirical evidence on the conditions favouring invard FDI-related spillovers. 29

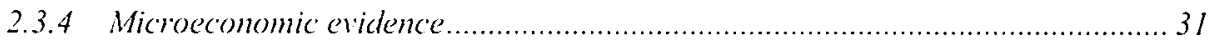

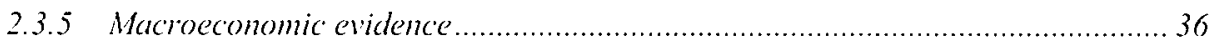

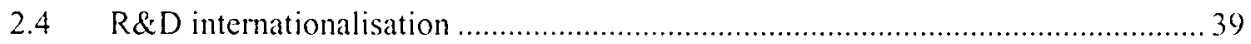

2.4.1 Home-based angmenting and home-based exploiting activities ......................... 39

2.4.2 Recent empirical studies on R\&D internationalisation ................................ 42

2.4.3 Results from R\&D and patent data studies ................................................. 43

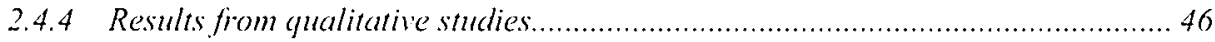


2.5 Conclusions

\section{CHAPTER 3 THE HOME COUNTRY EFFECTS OF OUTWARD FDI: REVERSE}

3.1 Introduction...... 51

3.2 Private effects of outward FDI: intra-firm reverse technology transfer 53

3.2.1 Estimating the effect on firm profitability and productivity. 55

3.2.2 Estimating the impact on the firm knowledge base. 60

3.2.3 Knowledge transfer within the MNE. 61

3.2.4 Estimating the impact of knowledge characteristics and a subsidiary's embeddedness in the internal and external network 65

3.3 Public effects of outward FDI: inter-firm RTT 69

3.3.1 Conditions for the occurrence of inter-firm RTT: local embeddedness of MNEs 72

3.3.2 Empirical evidence 75

3.3.3 Evidence using the international R\&D spillovers framework 76

3.3.4 Testing for inter-firm RTT using patent citations. 82

3.4 Conclusions 83

CHAPTER 4 SOME METHODOLOGICAL ISSUES: A COMPARISON OF USPTO AND EPO PATENTS AND PATENT CITATIONS 86

4.1 Introduction 86

4.2 Patents as technological indicators. 87

4.2.1 The home advantage effect. 88

4.3 Main differences between the USPTO and EPO systems. 91 
4.4 R\&D internationalisation indicators: USPTO vs. EPO databases

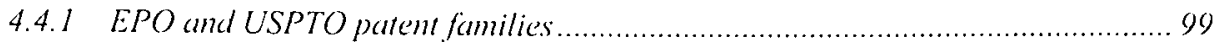

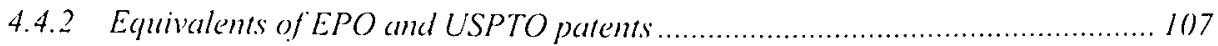

4.4.3 Empirical model ................................................................................. 115

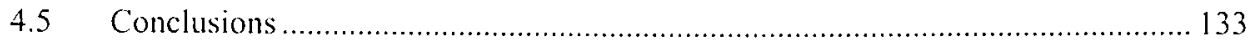

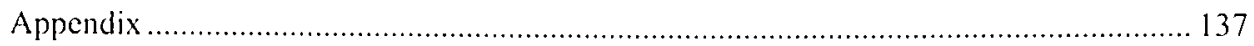

CHAPTER 5 ASSET-EXPLOITING AND ASSET-AUGMENTING R\&D ACTIVITIES

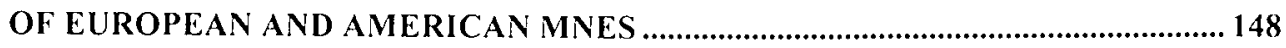

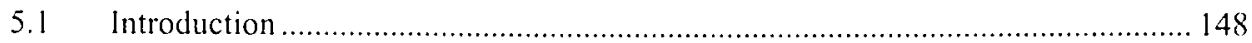

5.2 MNEs' Asset-exploiting and asset-augmenting R\&D activities: a 'macro'

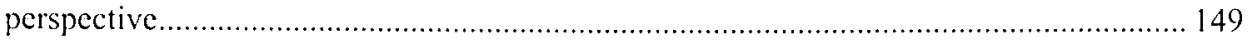

5.3 Patent citations: a proxy for knowledge flows ........................................... 154

5.3.1 Differences between EPO and USPTO patent citations data ....................... 158

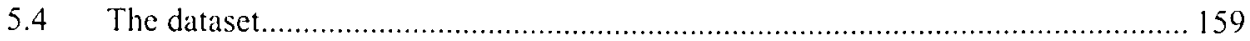

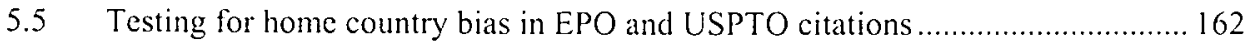

5.5.1 Geographical distribution of backward citations ......................................... 166

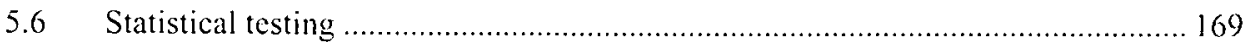

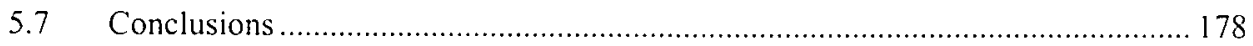

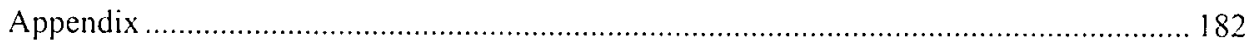

CHAPTER 6 KNOWLEDGE TRANSFER INSIDE THE GLOBAL R\&D NETWORK: THE CASE OF EUROPEAN PHARMACEUTICAL COMPANIES ........................... 186

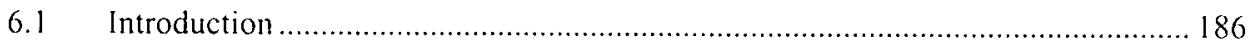

6.2 The emergence of integrated R\&D networks structures .................................... 188 
6.3 Research and development in the pharmaceutical industry 195

6.4 Methodology 198

6.5 The integrated R\&D network: centres of excellence for drug discovery..... 202

6.6 Socialisation mechanisms employed to achieve knowledge transfer and integration 209

6.6.I The role of international assignments.....

6.7 Conclusion

\section{CHAPTER 7 INTER-FIRM REVERSE TECHNOLOGY TRANSFER THE CASE OF}

7.1 Introduction

7.2 Description of the database 220

7.2.1 The patenting profile of US subsidiaries. 221

7.2.2 A descriptive look at the citations data. 224

7.3 Empirical model 227

7.4 Econometrics results 234

7.5 Conclusion..... 243

Appendix 245

CHAPTER 8 SUMMARY AND CONCLUSIONS. 251

8.1 Introduction 251

8.2 Principal Research Findings. 251

8.2.1 Assessing the limitations of patent and patent-citation indicators in the analysis of $R \& D$ internationalisation. 
8.2.2 Identifing the extent of asset-angmenting and asset-exploiting R\&D activities

8.2.3 The impact of R\&D internationalisation on the organisation of innovative active

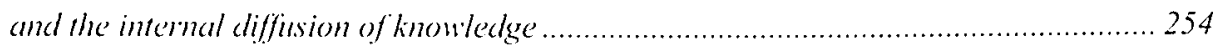

8.2.4 Testing for the presence of inter-firm reverse technologl transfer.................. 255

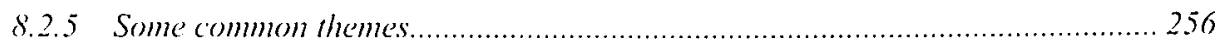

8.3 Limitations of the study and suggestions for further research ........................ 257

8.4 Implications for economic and technology management policy.....................259

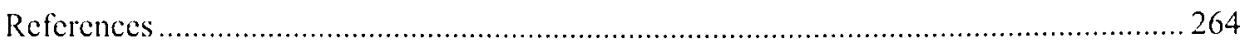




\section{LIST OF TABLES}

TABLEE 1.1 COSTS AND BENIHITS OF INTERNATIONALISATION OF R\&D ................................ 3

TABLL 2.I OVIRVILW OF THE IVVIDIENCE ON LOCALISED KNOWLEDGE SPILLOVERS AND ON THEIR SOCIAL DIMINSION

TABLE 2.2 ECONOMI:TRIC STUIDES TESTING FOR THIE DETERMINANTS OF INWARD FDI-RELATID

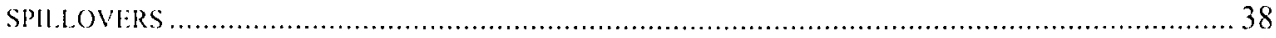

TABLE: 2.3 INTERNATIONALISATION OF R\&D AS SHOWN BY PATENT DATA...........................45

TABLE 3.1 OVERVIEW OF IEMPIRICAL STUDIES ON THE IMPACT OF INTRA-FIRM RTT ON FIRMS' PROI)UCTIVITY

TABIF 3.2 OVERVIEW OF THE IEMPIRICAL CONTRIBUTIONS ON THE DETERMINANTS OF INTRAHIRM RTT

TABIF 3.3 ECONOMETRIC STUDIES TESTING FOR FDI CHANNELS IN THE INTERNATIONAL THCHNOLOGY TRANSFER PROCESS.

TABLE 4.I DISTRIBUTION OF THE 131 FIRMS IN THE SAMPLE AND THEIR USPTO AND EPO PATENTS BLETWELN 1989-2000 BY NATIONALITY AND PRINCIPAL PRODUCT GROLP.

TABLE 4.2 COMPARING SHARES OF PATENTING ACTIVITIES AT HOME, IN THE US AND IN THE EU USING EPO APPLICATIONS AND USPTO GRANTED PATINTS 1989-2000. 96

TABLE 4.3 PATENT FAMILY DIFINITIONS: AN EXAMPLE: 100

TABLE 4.4 SIZE OF PATENT FAMILIES 1989-2000.. 102

TABLL 4.5 PATENT FAMILIES OF USPTO GRANTED PATENTS 1989-2000 103

TABLE 4.6 PATIENT FAMILIES OF EPO APPLICATIONS 1989-2000. 106

TABLE 4.7 SECTORAL AND GEOGRAPHICAL DISTRIBUTION OF SHARES OF EPO GRANTED/USPTO EQUIVALIENT PATENTS OWNED BY EU MNES

TABLE 4.8 SECTORAL AND GIEOGRAPHICAL DISTRIBUTION OF SHARES OF EPO GRANTED/USPTO EQUIVALLNT PATENTS OWNED BY US MNES

TABLE 4.9 DESCRIPTIVI: STATISTICS

TABLI: 4.10 EMPIRICAL ESTIMATES FROM THE PROBIT MODEL FOR THE SAMPLE OF EPO PATENTS

TABLE 4.1I SECTORAL ESTIMATES FROM THE PROBIT MODEL FOR THE SAMPLE OF EPO GRANTED PATENTS

TABLE 4.12 ESTIMATES FROM THE PROBIT MODEL FOR THE SAMPLE OF EPO GRANTED PATENTS, BY TECHNOLOGY FIELD .

TABLE 4. 13 SECTORAL ESTIMATES FROM THE PROBIT MODEL FOR THE SAMPLE OF EPO GRANTED PATENTS OWNED BY EU MNES.

TABLE 4. 14 ESTIMATES FROM THE: PROBIT MODEL FOR THE SAMPLE OF EU MNE-OWNED EPO GRANTED PATENTS BY TECHNOLOGY FIELDS

TABLE 4. 5 EMPIRICAL ESTIMATES FROM THE PROBIT MODEL FOR THE SAMPLE OF USPTO PATENTS

TABLE 4.16 SECTORAL ESTIMATES FROM THE PROBIT MODEL FOR THE SAMPLE OF USPTO PATENTS AND EPO GRANTED EQUIVALENTS 
TABI.I 4.17 ESTIMATES FROM THE PROBIT MODHI. FOR THE SAMPLE OF USPTO PATENTS AND EPO GRANTED R:QUIVALENTS BY TI:CHNOLOGY FIELDS

TABLE: A4-1 LIST OF MNES IN THE SAMPII:

TABLE A4-2 DESCRIPTION OF PATENT FAMILIES OF USPTO PATENTS GRANTED BETWEEN 1989 AND 2000

TABLE A4-3 DI:SCRIPTION OF PATENT FAMILIIS OF EPO APPLICATIONS BETWEEN 1989 AND 2000

TABLE A4-4 SICTORAL AND GIOOGRAPHICAL DISTRIBUTION OF SHARE OF EPO/USPTO EQUIVALENT PATIENS OWNED BY EU MNES BETWIEN 1989-99 USING A FRACTIONAL COUNT METHOD FOR BOTH EPO AND USPTO PATENTS

TABLE: A4-5 SECTORAL AND GEOGRAPHICAL DISTRIBUTION OF SHARE OF EPO/USPTO FQUIVALIENT PATENTS OWNED BY US MNES BETWEEN 1989-99 USING A FRACTIONAL COUNT METHOD FOR BOTH EPO AND USPTO PATENTS

TABLE: A4-6 SECTORAL AND GEOGRAPHICAL DISTRIBUTION OF SHARE OF EPO APPLICATIONS/USPTO BQUIVALENT PATENTS OWNED BY EU MNES.

TABLE A4-7 SECTORAL AND GEOGRAPHIICAL DISTRIBUTION OF SHARE OF EPO APPLICATIONS/USPTO EQUIVALENT PATENTS OWNED BY US MNES.

TABLE A4-8 CLASSIFICATION OF EPO PATENTS IN TECHNOLOGICAL FIELDS AND SUIB-FIELDS 146 TABLE 5.I SECTORAL DISTRIBUTION OF MNES IN THE DATABASE ..................................... 160

TABLE 5.2 EPO APPLICATIONS BY AFFILIATES, 1985-87 AND 1995-97. 161

TABLE 5.3 TOP 3 TECHNICAL FIELDS FOR FOREIGN AFFILIATES BY SECTOR OVER THE PERIOD 1977-2000 COMPUTED USING EPO APPLICATIONS

TABLE 5.4 DESCRIPTIVE STATISTICS OF BACKWARD CITATIONS OF EPO/USPTO EQUIVALENT PATENTS

TABLE 5.5 GEOGRAPHICAL DISTRIBUTION OF THE CITATIONS MADE BY EPO/USPTO EQUIVALENTS TO PATENTS FILED IN EACH PATENT OFFICE

TABLE 5.6 GEOGRAPHICAL ORIGIN OF PATENTS CITED BY US AFFILIATES OF EU MNES (19772000).

TABLE 5.7 GEOGRAPHICAL ORIGIN OF PATENTS CITED BY EU AFFILIATES OF US MNES (19772000)

TABLE 5.8 DESCRIPTIVE STATISTICS OF CITATION RATES

TABLE 5.9 TESTING THE RELATIVE PROPENSITY TO ENGAGE IN ASSET-EXPLOITING AND ASSETAUGMENTING ACTIVITIES BY EU MNES

TABLE 5.10 TESTING THE RELATIVE PROPENSITY TO ENGAGE IN ASSET-EXPLOITING AND ASSETAUGMENTING ACTIVITIES BY US MNES

TABLE 5.11 TESTING THE RELATIVE EXTENT OF ASSET-EXPLOITATION ACTIVITIES BY EU MNES AND US MNES.

TABLE 5.12 TESTING THE RELATIVE EXTENT OF ASSET-AUGMENTING ACTIVITIES BY EU MNES AND US MNES. 178

TABLE A5-I TOP 3 TECHNICAL FIELDS FOR FOREIGN AFFILIATES BY SECTOR OVER THE PERIOD 1977-2000 COMPUTED USING USPTO PATENTS GRANTED 
TABLE A5-2 DI:SCRIPTIVE STATISTICS FOR TIE CITATION RATES COMPLTED ON THE BASIS OF PATENTS REGROUPED IN TECHNOLOGICAL FIELDS

TABLI: A5-3 TESTING THE RELATIVE PROPENSITY TO ENGAGE IN ASSET-EXPLOITING AND ASSETAUGMENTING ACTIVITIES BY EU MNES

TABLE A5-4 TESTING THE RELATIVI PROPISNSITY TO ENGAAGE IN ASSET-EXPLOITING AND ASSETAUGMIENTING ACTIVITIES BY US MNES

TABLE A5-5 TESTING THE RELATIVE EXTENT OF ASSET-EXPLOITATION ACTIVITIES BY EU MNES AND US MNES

TABLF: A5-6 TESTING THE REI ATIVE EXTENT OF ASSET-AUGMENTING ACTIVITIES BY EU MNES AND US MNES

TABLE 6.1 BASIC FEATURES OF INTERNATIONAL R\&D ORGANISATIONS 189

TABLI: 6.2 DESCRIPTION OF THI: INTIERVIIEWED COMPANIES 199

TABLI: 6.3 GIGOGRAPIICAL DISTRIBUTION OF R\&D CENTRES AND THEIR SPECIALISATION .... 206

TABLE 7.1 PHI-SQUARE MEASURES BETWEEN US SUBSIDIARIES AND HEAdQUARTERS OF MOST

TI: 'HNOLOGICALLY ACTIVE MNES

TABLE 7.2 SPECIALISATION OF US SUBSIDIARIES' PATINTING ACTIVITIES 224

TABLI: 7.3 DESCRIPTIVE STATISTICS OF CITATIONS MADE BY EU-INVENTED PATENTS TO US SUBSSIDIARIES' PATENTS (EXCLUDING INTRA-FIRM CITATIONS) 227

TABLE 7.4 AN EXAMPLE OF HOW THE CITATION COUNT VARIABLE IS DERIVED. 229

TABLI: 7.5 SUMMARY STATISTICS 233

TABLE 7.6 ESTIMATES FROM THE CITATION COUNT MODEL 237

TABLF 7.7 ESTIMATES FROM THE NEGATIVF BINOMIAL MODEL FOR THE SAMPLES OF CHEMICAL AND PHARMACI:UTICAL PATENTS 242

TABLE A7-1 LIST OF COMPANIES IN THE SAMPLE. 249

TABLE A7-2 CORRILLATION MATRIX 250 


\section{LIST OF FIGURES}

FIGURE 4.1 AN ILLUSTRATION OF TIIE EPO/USPTO SHARLS OF EQUIVALFNT PATENTS ......... 111

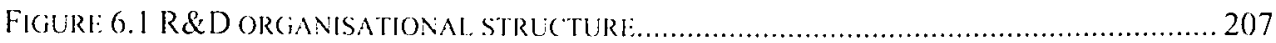

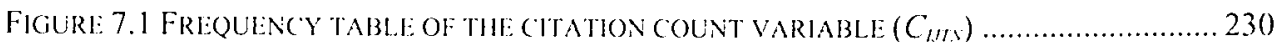

FIGURE 7.2 HISTOGRAM OF THE PRIEDICTIONS OF THE TRUNCATED POISSON MOIDEL............... 235

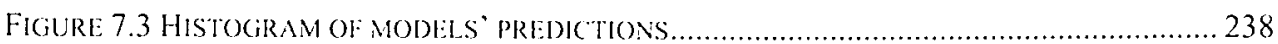




\section{CHAPTER 1 \\ INTRODUCTION}

\subsection{Motivation}

The topics addressed in this thesis form part of a wide-ranging debate on the consequences of globalisation for the world economy. Whereas most of the controversy surrounds the effects of the internationalisation of production on developing countries (sec for example Bhagwati 2004), I will analyse instead the impact that the internationalisation of research and development has had, not on developing countries, but on multinationals themselves and on their home countries. This phenomenon has raised no less concern among policy makers (ETAN 1998, OECD 1999, OTA 1993. OTA 1994) but has not loomed as large in the minds of the general public.

Since the pioneering work of Hymer (1960) on the reasons for the existence of multinational enterprises (MNEs), rescarchers have looked to their ability to transfer and exploit knowledge across borders as a central explanation for their competitive advantage. And, indeed, MNEs play a dominant role in the innovation activities of their home countrics and control a vast proportion of the world's stock of advanced technologies. In 1999, for instance, three MNEs (Akzo Nobel, DSM and Philips) spent the equivalent of $75 \%$ of all Dutch business-financed R\&D. In the same year Glaxo SmithKline, British Aerospace, and GEC together invested an amount equal to $60 \%$ of total UK business-financed R\&D expenditure. And the concentration among a relatively small number of MNEs is also a feature of the innovation systems of many other countries.

Historically R\&D has been one of the last aspects of corporate activity to take on a global dimension since the economies of scale associated with research activities tend to favour centralisation (Cantwell 1989). But as production became more globalised, more research began to be undertaken abroad to adapt products to local conditions. Even this limited dilution of technological sovereignty alarmed some policy makers. In the early 1970 s the US government became worried that increasing amounts of overseas investment by America's largest and most powerful MNEs might contribute both to the decline of US technological 
leadership through the export of technology and to growth in unemployment (Caves 1974a).' During the same period European policy makers feared that Europe, the recipient of much of this investment, would be dominated by the subsidiaries of US-based MNEs and that European companies might not develop sufficient scale and scope to compete internationally (Scrvan-Schreiber 1968).

More recently, despite core technology development remaining largely rooted in the parent operations of MNEs, which are themselves embedded in national and often sub-national innovation systems, there has been some evidence that foreign subsidiaries increasingly tap into the knowledge generated in centres of excellence around the world and actively engage in the creation of technological assets (e.g. Florida 1997, Kuemmerle 1996). This new phenomenon has caused concern among policy makers of both net recipient and net source countries (sce Table 1.1). Governments of net recipient countries fear that foreign-owned firms may act as 'Trojan horses' (Dunning 1986) since they may reduce the national technology and production base while keeping the core of their innovative activities in their home countries. These concerns were expressed in the US, particularly in relation to the activities of Japanese MNEs (Kogut and Chang 1991, OTA 1993, 1994). Vernon (1992) eloquently captures the key aspect of this debate:

Some of the principal arguments against foreign direct investment are about its effects on research and development activities in the United States... Some cases seem to fit the mould of a rapacious foreign investor, buying up the crown jewels of US science and engineering, and carrying them off to distant locations. (p. 14-15) ${ }^{2}$

Similarly countries that are net sources of foreign $R \& D$ investment have become worried that the internationalisation of R\&D may erode the domestic knowledge base, both because foreign affiliates may export technology developed at home and because fewer R\&D activities are undertaken at home. Concerns about a possible 'hollowing-out' (ETAN 1998,

\footnotetext{
${ }^{\prime}$ During this period the US government implemented a number of programmes, both voluntary and mandatory. to restrict capital outflows. These programmes allowed individual firms the freedom to transfer technology as they wished, subject only to two constraints: that national security would not be impaired and that payments would be made so as to satisfy the US tax authorities (i.e. no transfer pricing) (Adler 1971). Similar policies were implemented in Sweden in the mid 1980 s when capital markets were liberalised. Here the regulation required firms to ask the permission of the Contral Bank of Sweden to invest abroad. Permission was only granted if the firm could demonstrate that the investment would have a positive effect on exports. According to Swedenborg (1985) investment in foreign R\&D activities could not fulfil this requirement. at least not in a direct way, and the Central Bank was reluctant to grant permission for the relocation of R\&D abroad, on the basis that it would have been beneficial to keep the more advanced and innovative production in Sweden.
}

2 Quoted in Frost (1998). 
OECD 1999) of national technology have been expressed by the European Commission (Europcan Commission 2002):

Multinational companies account for the greater share of business $R \& D$ expenditure. Increasingly, they tend to invest on the basis of a global analysis of possible locations. A worrying trend in this respect is the growing concentration of transnational R\&D expenditure in the US, suggesting a decline in the global attractiveness of the EU as a location for R\&D as compared to the case in the US. (p. 7)

Table 1.1 Costs and benefits of internationalisation of $R \& D$

\begin{tabular}{|l|l|l|}
\hline & Potential costs & Potential benefits \\
\hline $\begin{array}{l}\text { Multinational } \\
\text { company }\end{array}$ & $\begin{array}{l}\text { Reduced economies of scale and scope. } \\
\text { disadvantage of being outsider in the host } \\
\text { country innovation system: increased } \\
\text { obstacles in the internal knowledge } \\
\text { transfer due to inter-unit geographical } \\
\text { and technological distance; leakage of } \\
\text { key teclmology to foreign competitors. }\end{array}$ & $\begin{array}{l}\text { Access to foreign pockets of } \\
\text { excellence; greater efficiency in } \\
\text { production and innovation not only } \\
\text { for the forcign subsidiary but for the } \\
\text { rest of the organisation (intra-firm } \\
\text { reverse technology transfer). }\end{array}$ \\
\hline $\begin{array}{l}\text { Recipient } \\
\text { country }\end{array}$ & $\begin{array}{l}\text { Loss of control over domestic innovative } \\
\text { capacity; potential damage to the } \\
\text { technological competitiveness of } \\
\text { domestic firms through intensified } \\
\text { competition for limited specialised } \\
\text { resources. }\end{array}$ & $\begin{array}{l}\text { Upgrading of domestic innovative } \\
\text { capacity: integration in the } \\
\text { international community: strengthen } \\
\text { of agglomeration cffects in domestic } \\
\text { clusters (specialisation gains). }\end{array}$ \\
\hline $\begin{array}{l}\text { Source } \\
\text { country }\end{array}$ & $\begin{array}{l}\text { Erosion of domestic innovative capacity } \\
\text { technology export, hollowing out' of } \\
\text { domestic research base); employment } \\
\text { losses. }\end{array}$ & $\begin{array}{l}\text { Improve overall innovative } \\
\text { performance of domestic companies } \\
\text { (inter-firm reverse technology } \\
\text { transfer); increase specialisation and } \\
\text { international competitiveness in high- } \\
\text { tech sectors. }\end{array}$ \\
\hline
\end{tabular}

If these are the concerns of policy makers, the relocation of R\&D activities abroad is not a straightforward process for MNEs cither (see Table 1.1). Geographical dispersion of innovative activities may lead to inefficiencies if economies of scope and scale, which could otherwise be realised were research efforts concentrated in a single location, are not fully captured. By spreading R\&D activities across different countries the firm also increases the costs and reduces the efficiency of internal technology transfer because of greater inter-unit distance. Another potential cost associated with the adoption of a geographically dispersed R\&D network is increased divergence in technological specialisation, which in turn reduces their firms' capacities to assimilate the knowledge produced by other units within the organisation. Furthermore there is the possibility that in undertaking R\&D activities abroad, foreign competitors may appropriate key innovations and in so doing compromise the MNE's competitive advantage and profit potential. Finally, there are potential costs and inefficiencies 
arising from the fact that foreign subsidiaries, if they are greenficld investments, will be outsiders in the host country innovation and productive system.

If these are the potential losses involved in R\&D internationalisation, there are also significant potential benefits. Chicf among these is that foreign subsidiaries can access more quickly and more easily specialised knowledge generated in centres of excellence around the world, which can then be exploited by the rest of the organisation.

The internationalisation of R\&D by domestic MNEs thus raises issues for both managers and policy makers. At the micro level R\&D managers are faced with the challenge of sourcing advanced knowledge from dispersed locations and leveraging it in their operations worldwide. This implies the adoption of mechanisms for the transfer and the integration of knowledge within the organisation. At the macro level policy makers must in the first instance evaluate the nature and extent of the R\&D activity that has been relocated abroad. They may be indifferent to the simple adaptation of products developed at home to suit local tastes, but must be attentive to the transfer of more substantive R\&D investment. Even then, the issue is not so much the extent of the R\&D performed abroad, but the extent to which the domestic economy benefits from it, if at all. Indeed foreign subsidiaries' innovative efforts may represent an opportunity to enhance domestic technological competitiveness if what is absorbed abroad spills over to other home country firms.

The academic literature has addressed the micro issues, at least in part. The R\&D internationalisation literature, on the one hand, has gathered evidence on the different motivations for carrying out $R \& D$ abroad, but has implicitly assumed that the existence of a dispersed network of R\&D facilities naturally implies free transfer of knowledge within the organisation (e.g. Gassmann and von Zedtwitz 1999). On the other hand, the strategic management literature has recently become interested in the process of knowledge integration, but has thus far confined itself to theoretical issues (c.g. Almeida et al. 2002, Grant 1996) rather than how it is achieved in practice.

Notwithstanding the political relevance of the potential reverse knowledge flow from $R \& D$ activities performed abroad, the macro issues have not received explicit research attention in the academic literature. The R\&D internationalisation literature has generally regarded the home country as the source of an MNE's technological advantage (e.g. Sölvell et al. 1991) and thus that internationalisation entails only an outflow of knowledge. It has therefore assumed away the policy issues mentioned above. The FDI literature instead has mainly 
examined the impact of outward FDI (meaning, primarily, foreign production) on homecountry employment and balanee of payments, disregarding any effects on the technology base. Thus there has been as yet little direct investigation of this reverse technology transfer process (Globerman et al. 2000 is one notable exception).

This thesis aims to fill in these gaps in the literature in two ways. First, it will use a case study approach to assess how MNEs organise their international R\&D laboratories and achicve knowledge diffusion. Meeting this challenge is crucial if an MNE is to reap the benefits of a geographically dispersed R\&D network. Second, it will evaluate the extent to which foreign stibsidiaries build on local sources of knowledge (what Dunning and Narula 1995 call assetaugmenting' activity) and furthermore whether new technologies created abroad spill over to the rest of the multinational's home country (what I shall call 'inter-firm reverse technology transfer').

These macro issues will be addressed using patents and patent citation analysis, tools commonly used in innovation studies and exploited by both the literature on localised knowledge spillovers (Jaffe et al. 1993) and by studies of the technological sourcing behaviour of foreign subsidiaries (Almeida 1996, Frost 1998). The advantages and disadvantages of patent indicators have been widely acknowledged and discussed in the literature (Archibugi 1992, Basberg 1987, Griliches 1990, Pavitt 1985). However, when they are used for measuring the R\&D internationalisation strategies of MNEs one particular limitation needs to be borne in mind, namely that domestic applicants, proportionate to their innovative activities, tend to file more patents in their home country than foreign applicants do (the so called 'home advantage' effect). As a result in making international comparisons of innovative activities - be it at the level of the country or of the firm - one cannot rely on any particular patent office's data because the analysis can be biased towards domestic inventive activities. A secondary theme of this thesis will be gauging the extent of this effect and whether it is equally present in the two principal patent offices whose data are used in the R\&D internationalisation literature, the United States Patent Office (USPTO) and the European Patent Office (EPO).

\subsection{OUTLINE OF THE THESIS}

This thesis is divided into seven further chapters. The next two chapters review the literature in the areas described above; Chapters 4-7 cover the empirical analysis. 
Chapter 2 conducts a broad survey of the theoretical and empirical literature on the R\&D spillovers generated by foreign affiliates' activities in host countries and of that on the R\&D internationalisation process. It first defines the basic concept of spillovers focusing on the existing empirical analysis of their geographical and social dimensions. This section introduces the concept of local embeddedness, which will be developed further in the following chapter in relation to the activities of MNEs. The chapter goes on to review theoretical and empirical studies, both at the micro and macro level, on inward-FDI related spillovers. This survey aims to identify the main factors determining the occurrence of these spillovers, namely the host country's absorptive capacity, the technological gap between foreign and domestic firms, forcign subsidiaries' technological behaviour, and their degrec of host-country embeddedness. The chapter concludes with a review of the different motivations driving R\&D investment abroad and presents recent empirical evidence on the R\&D internationalisation process.

Chapter 3 lays out the theoretical framework of the reverse technology transfer process by providing a synthesis of the literatures reviewed in the previous chapter. It begins by presenting the main arguments and empirical evidence reported by the FDI literature supporting the existence of the positive effect that foreign investment has on the home part of the multinational (intra-firm reverse technology transfer). I investigate this process further by reviewing those studies in the intemational business literature that have highlighted the determinants of this reverse knowledge flow. The focus then shifts to the investigation of inter-firm reverse technology transfer and, by building on the inward-FDI-related spillovers literature (although moving the focus from the host country to the home country and from forcign production to foreign research activities), this chapter formulates the main theoretical argument of the thesis. In particular it will argue that the main factor favouring the realisation of technology-related externalities stemming from the activities of MNEs is the high degree of cmbeddedness that MNEs have in their home countries. Finally, a detailed survey of those existing empirical studics that are more or less directly related to this phenomenon is carried out.

Chapter 4 sets the stage for the empirical chapters that follow by discussing important methodological issues concerning the use of patent indicators in assessing MNEs' internationalisation strategies. Specifically, it investigates the extent of the "home advantage" effect present in both the USPTO and the EPO data by analysing the patents filed in these two patent offices by 131 European, US, and Japanese MNEs operating in high-tech sectors. I start 
by comparing internationalisation indicators built using USPTO data with those built using EPO data. Then by examining the patent families of both EPO and USPTO datasets (patents protecting the same invention in different patent offices), I evaluate to what extent MNEs seek to protect their inventions in both patent offices and whether this varies depending on where the invention occurs. Finally l use a probit model to identify the determinants of the decision to seek patent protection in both patent offices. I draw conclusions from this about the relative validity of the two datasets for analysing MNEs ${ }^{\circ} \& D$ internationalisation strategies.

Chapter 5 evaluates the nature of the R\&D investment carried out by European MNEs in the US and by American MNEs in Europe. First, I argue that any given R\&D facility`s capacity to exploit and/or augment technological competences is a function not just of its own resources, but also of the efficiency with which it can utilise complementary resources associated with the particular local innovation system. Just as asset-augmenting activities require proximity to the economic units (and thus the innovation system) from which they seek to learn, asset-exploiting activities draw on the parent's technological resources as well as on the other assets of the home location's innovation system. Second, following the work of Almedia (1996) and Frost (2001), I carry out a patent citation analysis at the sectoral level to quantify the relative asset augmenting and exploiting character of R\&D located abroad. Furthermore I explore to what extent the 'home advantage' effect highlighted in the previous chapter affects the inference about foreign subsidiaries' technological sourcing behaviour that can be drawn from patent citation analysis. The outcome of this chapter has some important policy implications since it shows that Europe does not attract much asset-augmenting R\&D investment by US MNEs, while the US has greater success with European MNEs.

Moving the focus from the sector to the firm, Chapter 6 explores in more detail how and why MNEs organise their R\&D activities across borders. I take as a case study six of the largest European pharmaceutical companies, European rather than American because of the results presented in the previous chapter and the pharmaceutical industry in particular because it is generally believed to be especially internationalised. I will argue that the adoption of a new, scientific-deductive method in the drug discovery process has made possible the carrying out of research in relatively small experimental units that are highly specialised and geographically dispersed. Drug development instead remains concentrated in a small number of large units, which operate in relative isolation from one another. In such an organisational structure, foreign subsidiaries capture and leverage knowledge from pockets of excellence around the world, actively contributing as much as the home part of the multinational to the 
creation of new technological assets. However the adoption of this R\&D organisation can hinder the transfer and integration of knowledge. This chapter also examine the mechanisms in place to ensure the diffusion and cross-fertilisation of technical knowledge inside the organisation, focusing mainly on a particular 'social' mechanism, namely the international assigmment of researchers. From in-depth interviews with R\&D managers and scientists it will emerge that mobility of researchers is one of the possible ways in which knowledge sharing can be achieved. The creation of personal relationships and increased communication, both among R\&D facilities and among researchers, is often facilitated by the exchange of personnel. Nonetheless secondments are not often used and are not always used to this end. International assigmments appear mostly to be employed to reduce the level of inter-unit attrition and to favour the personal development of researchers.

While Chapter 6 examines the impact of R\&D internationalisation on the firm, Chapter 7 explores the effects of this process on the MNEs' home country. By drawing on the evolutionary theory of the multinational and on the concept of embeddedness. I will test for the presence of inter-firm reverse technology transfer. This I do by analysing the citations received by patents granted to US subsidiarics of 24 European chemical and pharmaceutical MNEs over the period 1980-99. After controlling for competing explanations for the observed citation rate in a multivariate count data model, different sectoral patterns emerge: while chemical MNEs act as a channel for the transmission of knowledge developed abroad to other home country firms, be they purely domestic or active internationally, pharmaceutical MNEs do not. An important implication of these results is that the increasing trend in the transfer of R\&D activities abroad may not be completely detrimental to the home country's knowledge base. Indeed, the relocation of research activities to centres of excellence can have positive feed back effects.

The final chapter begins with a summary of the preceding chapters and underlines their findings. It then suggests further directions for research in these areas and tackles some policy implications arising from the empirical results of the thesis. 


\section{CHAPTER 2}

\section{R\&D SPILLOVERS AND MNES: AN OVERVIEW OF THE LITERATURE}

\subsection{INTRODUCTION}

This chapter contains an overvicw of the three theoretical and empirical strands of literature that I have tried to integrate in this thesis: first, the literature on localised knowledge spillovers, second, the literature on foreign direct investment (FDI), and, third. the international business literature on R\&D internationalisation. The first set of contributions has focused on the importance of geography in explaining firms' innovative performance and its implications for conomic clustering. The second stream of literature on inward FDI analyses the technological impact of MNE's productive activitics in host countries. It is therefore largely concerned with what happens outside the multinational company. The third body of litcrature on R\&D internationalisation examines MNEs' motivations for undertaking innovative activities outside their home country and in doing so it analyses both within firm knowledge flows and host country location advantages. These strands of the literature complement each other in that they present similar theoretical concepts, namely the existence of knowledge spillovers and the concept of embeddedness.

Theoretical and empirical contributions to the geographical dimension of knowledge spillovers provide some basic concepts and evidence for understanding the technological impact of an MNE's presence in a host country. This body of literature identifies the channels for inter-firm knowledge spillovers, e.g. labour mobility and demonstration effects. It highlights that these are spatially bounded because they are transmitted by personal interaction and rooted in particular social contexts, i.c. they are locally embedded. The concept of embeddedness emerges also as a determinant of FDI-related spillovers although within this literature the focus is mainly on producer-supplier relationships (backward linkages) and producer-customer relationships (forward linkages), since they are the main host-country players involved in the productive activities of foreign affiliates. In the R\&D internationalisation literature the concept of embeddedness has been developed in connection with the emerging paradigm of R\&D integrated network structures, i.e. with the idea that the competitive strength of the multinational relies on the ability of subsidiaries to assimilate 
knowledge from pockets of excellence around the world. Foreign affiliates need to become integrated in the host country innovation system in order to establish trust-based relationships with local players if they want to get aceess to local knowledge sources. This type of knowledge is difficult to acquire from a distance due to its tacit nature and because it is related to agglomeration effects.

The remainder of this chapter is structured as follows. The next section reviews empirical studies on the geographical and social dimension of R\&D spillovers focusing not only on their results, but also on the different methods used to measure knowledge spillovers. Section 2.3 provides a critical overview of the theoretical and empirical contributions on inward FDIrelated R\&D spillovers. This is far from being a comprehensive review on existing studies on this topic. It will rather concentrate on those contributions that have identified and examined the different factors determining the occurrence of these spillovers. Section 2.4 contains a survey of the theoretical explanations of why firms undertake R\&D activities abroad and provides a review of more recent empirical investigations on the R\&D internationalisation process. Section 2.5 summarises and concludes.

\subsection{GEOGRAPHICAL AND SOCIAL DIMENSION OF R\&D SPILLOVERS}

Externalities arise from the production of knowledge because it is non-rival in consumption, meaning that a firm's use of it does not affect the use by other firms, and it is partially cxcludable, i.c. it is not possible to prevent other firms from using the knowledge once it is made available. The seminal work by Griliches (1979) identifies two types of potential positive externalities from R\&D activities: rent and knowledge spillovers. Rent spillovers occur when the price of an input does not reflect the quality improvements derived from innovative activities. ${ }^{3}$ More broadly, pecuniary spillovers encompass shifts both in price and market structure, the benefits (rents or profits) of which cannot be extracted by the initiating party. This form of pecuniary externality arises for example from trade in intermediate goods and from the entry of multinational companies into host country markets (as I discuss later in this chapter). Knowledge spillovers are unintended transfers of knowledge, where the owner of such knowledge cannot prevent others from making use of it, and they include: departure of key scientists or engineers; informal know-how sharing (Von Hippel 1987); unintended leakage of information at conferences or trade fairs; imitation of products or technological

\footnotetext{
As argued by Griliches, since these types of spillovers take place when goods are traded, they cannot be considered "real' externalities as they are mainly due to measurement errors of economic transactions.
} 
secrets through reverse engineering or product inspection: patent information: industrial espionage: scientific literature. Therefore while rent spillovers arise from the transaction of goods, knowledge spillovers arise from the imperfect appropriability of knowledge, i.e. from its public-good nature. Although in theory the distinction between these two types of externalities is clear cut, in practice they may occur simultancously and thus empirically it is difficult to disentangle between the two dimensions.

Some of these knowledge spillover channels are more effective when the two parties involved in the unintended exchange of knowledge are near to each other. Inter-firm worker mobility tends to be geographically confined, because of the presence of social ties, risk aversion and localisation sunk costs (Breschi and Lissoni 2001). Informal know-how sharing takes place because of the expectation of its being reciprocated (Von Hippel 1987) and these exchanges are more easily organised in a context of physical proximity (Malmberg 1997). Imitation can be more sucessful if the use of a particular technology or product can be demonstrated in the local environment (see the demonstration effect in section 2.3.1). In general the importance of local proximity for the transmission of knowledge spillovers can be attributed to the tacit nature of knowledge. In this context the distinction between information and knowledge is crucial. Information can be easily codified and can be transferred from person to person and from location to location. Knowledge, especially in its tacit form, is difficult to codify and to transfer, because it is context specific and person embodied. Von Hippel (1994) demonstrates that when knowledge is context specific, informal, uncodified and tacit it is best transmitted through face-to-face contacts and repeated interaction, and can be acquired only through physical proximity. He also finds that the problem-solving activity must be located near the knowledge relevant for the innovation process to minimise the costs of transmitting what he defines as 'sticky knowledge'. Although the use of information and communication technology (ICT) has reduced the costs and increased the specd of transferring information across borders, transferring tacit knowledge remains difficult and costly especially over long distances. As Morgan (2004) states: 'virtual proximity may well be a surrogate for physical proximity in the context of standardised transactions but not in the context of transactions which are high in complexity, ambiguity and tacitness' (p. 5).

\subsubsection{Local embeddedness}

Thus proximity matters because it lowers the cost and eases the transfer of tacit and complex knowledge, which can be transferred mainly through personal interaction and mobility of 
people embodying this knowledge. ${ }^{4}$ Physical proximity also facilitates personal interaction through the presence of a common, cultural and social context. The effectiveness with which knowledge, and in particular tacit knowledge, can be shared is in fact improved by the presence of a "shared language', common norms, values, and expectations. A lack of common social and cultural understanding can in fact hinder interaction between proximate actors, because of the high trust and understanding needed to transfer tacit knowledge. As observed by Lundvall (1992) 'when cultural differences are present, certain types of messages will be difficult to transmit and decode. ... Cultural differences between users and producers may block the interaction'.

According to the regional innovation system approach (Braczyk et al. 1998, Cooke 1992), the 'region-statc' is the geographical scale best suited for the emergence of the physical, social, cultural and institutional context conducive to knowledge sharing and interactive learning. In addition a region provides external economies for firms involved in interactive learning by providing a concentration of demand for specialised labour, the presence of specialised intermediate industries, and knowledge spillovers (Marshall 1891). Within this literature innovation activities are perceived to be determined by the way in which firms interact with their environment. that is, with the local network of firms and institutions regulated by institutional structures and social and political values. This network perspective of the systemic approach to innovation builds on the social network model developed within the sociology literature, and the work of Granovetter (1985). In particular Granovetter argues that most individual behaviours are closely embedded in networks of interpersonal relationships, which crucially depend on trust. There are three key elements in these trust-based relationships (Gordon and McCann 2000). First, firms within the network are willing to engage in risky cooperative and joint venture projects without fear of opportunism. Sccond, firms may reorganise their relationships within the network without having to worry about retaliation. Third, firms may act as a group in order to support and achieve a common and mutually beneficial objective. The strength of these trust-based relationships in a social network is defined as embeddedness. 'Embeddedness [refers to the] fact that economic action and outcomes, like all social action and outcomes, are affected by actors' dyadic relations and

\footnotetext{
However the importance of spatial proximity has been questioned by the concept of communities of practice (Brown and Duguid 1996, Wenger 1998) or epistemic communities (Breschi and Lissoni 2001). These communities comprise a number of individuals who share a common interest, experience, and language and who are bound together by the obligation of reciprocate knowledge exchanges. The existence of these types of communities challenges the significance of physical proximate since relational proximity ... can be achieved at a distance', it does not need (continuous) spatial proximity and does not in any way implicate. a priori. local clustering or any of the other properties of place' (Amin 2000 p. 14 ).
} 
by the structure of overall network of relations' (Grabher 1993, p. 4). The social network model of industrial clusters recognises the importance of embeddedness and social integration in the creation and maintenance of agglomerations. In fact Cooke et al. (1998) defines a regional innovation system as a system in which firms and other organisations are systematically engaged in interactive learning through an institutional milieu characterised by embeddedness' (p.1581). The notion of embeddedness within this literature is related to the social aspect of knowledge exchanges between firms and institutions. As pointed out by Lyons (2000): ' $\ldots$ embeddedness of firms is expected to strengthen the milieu by developing a sense of common industrial purpose and social consensus; common ways of perceiving economic and technical problems and solutions; and the development of extensive institutional and informal support that cncourages innovation. skill formation and the circulation among firms' (p. 893).

Although Granovetter's notion of social networks and embeddedness is not inherently spatially bounded, according to Lyons (2000) and Gordon and McCann (2000). physical proximity is consistent with his formulation. They argue that trust-based relationships emerge from repeated interactions, which can be facilitated by personal contacts and geographical proximity. And their strength, i.c. embeddedness, depends on prior events which lead to a sense of common interests and whose development is facilitated by physical proximity. If proximity enhances personal contacts and this facilitates interaction and trust, embeddedness is likcly to emerge in places with a high concentration of firms.

\subsubsection{Empirical evidence of localised knowledge spillovers}

A number of empirical contributions, summarised in Table 2. I, which focus on different processes and use different methodologies, have shown that knowledge spillovers tend to be geographically bounded. A group of studies has tested the geographical reach of spillovers generated by academic research by estimating a firm's knowledge production function. This function includes as arguments, in addition to internal R\&D efforts, both a term measuring spillovers from university research and an index of geographical coincidence of corporate and academic research, the latter of which should capture the geographical dimension of spillovers. Jaffe (1989) was the first to apply this approach. He analysed corporate patenting activity at the level of US states and found, after controlling for both R\&D inputs and the size of the state, that it is influenced by the R\&D spending of the local university. But geographic proximity within the state between a university and a corporate R\&D unit does not seem to have a strong impact on corporate innovative performance. However this method does not 
really capture the geographical dimension of spillovers; instead it measures the effect of spatial agglomeration of research within the state on the innovation output of the same state. Moreover as acknowledged by the same author: spillovers mechemisms have not been modelled' (p. 968 , cmphasis in the original text).

Another line of research has instead focused on the analysis of knowledge-intensive industries and their tendency to geographically cluster. As shown by Audretsch and Feldman (1996) firms operating in these industries tend to exhibit a greater propensity to geographically concentrate their production activities. Audretsch and Feldman also find a significant tendency for them to cluster their innovative activities, after controlling for the spatial concentration of production. On the one hand these results seem to support the localised nature of knowledge spillovers. Innovative activities in these knowledge-intensive industries take place within a close geographical area in order to benefit from knowledge spillovers generated by industry and academic research efforts or by the mobility of skilled workers. On the other hand these findings also show that one of the factors behind the agglomeration of innovative efforts is the availability of specialised inputs. If these resources represent important inputs to their innovation process, firms will benefit from concentrating their R\&D activities within a certain region. However the existence of these knowledge spillovers is more assumed than demonstrated (Breschi and Lissoni 2001).

Another empirical framework used to analyse the local reach of knowledge spillovers has been proposed by Jaffe et al. (1993). In this seminal and influential study the authors propose the use of patent citations as a proxy for knowledge flows. They analyse, using the address of the inventor, the geographical origin (at the country, state and metropolitan area level) of the citations received by a sample of USPTO patents granted to academic institutions and by a sample of similar patents - in terms of technological and temporal profile - granted to firms. After controlling for the geographical clustering of patenting activity, ${ }^{6}$ they find that citations

\footnotetext{
"A similar econometric approach has been subsequently applied by Acs el al. (1992) who have used innovations counts. instead of patents, as a measure of corporate innovative output. Their results seem to reinforee Jaffe's findings since they find a stronger significant effect of the geographic coincidence between corporate and university rescarch centres. Acset al. (1994) conduct a similar exercise dividing the sample of firms in large and small firms and find that the geographic coincidence index is significant only for small firms. which scems to suggest that smaller firms are drawing more heavily on academic research efforts because they camnot afford high level of internal $R \& D$ investment.

"This is done by matching each patent citing the academic (firm)"s patent with a control patent. This control patent has a similar technological and temporal profile to the citing patent. but it is not itself cited by the academic (firm s) patent. The frequency with which the control patent and the academic (firms) patent originate from the same geographical region represents the benchmark against which the co-localisation of the academic (tim) 's citations patlern is measured.
} 
to both corporate and university patents are more likely to come from the same state and from the same metropolitan area. In addition their results seem to show that the effect of geographical localisation 'fades with time', i.e. as the innovation loses in novelty the proximity of knowledge sources secms to matter less, and the output of academic research does not appear to diffuse more quickly than corporate innovations.

A number of studies have subsequently applied a similar methodology to analyse the geographical dimension of knowledge spillovers (see for example Maurseth and Verspagen 2002, Verspagen and Schoenmakers 2000) and their results scem to support their localised nature also within the European context. ${ }^{7}$ However patent citation analysis suffers from the same limitation that affects the knowledge production function method, i.c. it does not identify what are the channels through which spillovers occur. The other interesting observation concerning these studies is that they show that codified knowledge flows, which are captured by patent citations, are spatially bounded. This seems to go against the common belief that codified knowledge should be easily transferred across geographical distances. What this may suggest is that tacit knowledge plays a significant role in the interpretation, use and assimilation of codified knowledge (Howells 2002).

Another series of studies examines the localisation of spillovers focusing directly on one of the mechanisms through which R\&D spillovers occur: labour mobility. The basic assumption behind these studies is that workers cmbody specialised knowledge which can be transferred to other firms as they change their job. A general limitation of these studies is that they do not really test whether the firm that employs the workers embodying the specialised knowledge and technical expertise show an increase in productive or innovative performance. In other words, as pointed out by Breschi and Lissoni (2001). mobility of workers may just contribute to shifting knowledge from one firm to another, but not to its actual diffusion. ${ }^{\circledR}$ On a more

\footnotetext{
"Maurseth and Verspagen (2002) propose a variant of Jaffe et al.'s methodology which they adopt to analyse the geographical proximity effect within European regions using patents applied to the EPO. In this study citation counts between pairs of regions are regressed against both a measure of geographical distance between regions and a number of control variables. such as the technology gap and congruence between regions. the number of patents originating from the citing and cited region. This approach has the advantage of comtrolling not only for the geographical distribution of the cited patents. as was done in Jaffe's work. but also for the distribution of citing patents. The results of this study show that the number of citations declines with distance.

"The study by Dahl (2002) on the mobility of engineers in two Danish high-tech clusters is a step forward in this direction. Using a very rich labour market dataset, the author is able to follow engineers as they move between firms in the clusters and also to examine their annual earnings. These data show that mobile engincers exhibit above average growth in their amual earnings with respect to immobile engineers. This could be considered as indirect evidence of spillovers through labour mobility since higher wages may reflect higher productivity levels attained through past labour experience.
} 
semantic level, labour mobility may give rise to rent spillovers since the firm which is employing the scientist or the engineer enters in a contractual agreement with them. which tends to compensate only in part for their past experience (Breschi and Lissoni 2003, Stolpe 2002).

Zucker et al. (1998) analyse the geographical distribution of US biotechnology starts-up and finds that. after controlling for the presence of top universities, the pool of skilled workers, and the availability and cost of financial resourees, their emergence is explained by the presence of star scientists, as identified by their publishing record in genetic sequencing. However this evidence was stronger at the beginning of the life cycle of this industry when the knowledge involved in the DNA recombination was very complex and tacit. Audretsch and Stephan (1996) deal with a similar issue using a database linking biotechnology firms with their specific scientific advisors. They find that university scientists who were founders or were chair of a firm's scientific advisory board were much more likely to be locally linked to the firm than other affiliated scientists, indicating that those scientists intimately involved in the transfer of knowledge achieve this through face-to-face interaction.

The evidence reported in these two studies seems to suggest that the localised mobility of academic scientists embodying specialised tacit knowledge in the biotechnology industry explains the localised nature of knowledge spillovers. However the localised nature of knowledge spillovers through this channel may just be the result of a particular institutional and social context that supports inter-firm labour mobility, as is the case in Silicon Valley (Breschi and Lissoni 2001). This point elcarly emerges from the study by Almeida and Kogut (1999). They track the movement of key engineers in US semiconductor clusters and show that knowledge flows, measured by patent citations, tend to be localised only in certain regions, particularly in Silicon Valley, characterised by high levels of intra-regional mobility of talented engineers." Knowledge spillovers through labour mobility appear to be related to the existence of broader social institutions that support a viable flow of ideas within the spatial confines of regional economies' (Almeida and Kogut p. 916).

\footnotetext{
"In an examination of labour mobility patterns among semiconductor engineers, Angel (1991) found that these engineers moved around the US. However, if they moved to Silicon Valley their mobility continued. but from then on their mobility was confined to the Silicon Valley.
} 
Table 2.1 Overview of the evidence on localised knowledge spillovers and on their social dimension

\begin{tabular}{|c|c|c|c|c|c|}
\hline \multicolumn{6}{|c|}{ Geographical dimension of knowledge spillovers } \\
\hline Authors & Sample & Period & Methodology & Main results & Issues \\
\hline $\begin{array}{l}\text { Jalfe } \\
(1989)\end{array}$ & $\begin{array}{l}\text { Corporate } \\
\text { USPTO patent } \\
\text { data of } 29 \text { US } \\
\text { states }\end{array}$ & $\begin{array}{l}1972- \\
77 . \\
1979 \\
1981\end{array}$ & $\begin{array}{l}\text { Knowledge } \\
\text { production } \\
\text { function }\end{array}$ & $\begin{array}{l}\text { Spillovers from } \\
\text { academic research to } \\
\text { corporate R\&D units are } \\
\text { not geographically } \\
\text { localised }\end{array}$ & \multirow{3}{*}{$\begin{array}{l}\text { They measure the } \\
\text { effect of spatial } \\
\text { agglomeration of } \\
\text { research within the } \\
\text { state on the } \\
\text { innovation output } \\
\text { of the same state } \\
\text { Spillovers } \\
\text { mechanisms are } \\
\text { not modelled }\end{array}$} \\
\hline $\begin{array}{l}\text { Acset al. } \\
(1992)\end{array}$ & $\begin{array}{l}\text { Corporate } \\
\text { innovation count } \\
\text { of US states }\end{array}$ & 1982 & $\begin{array}{l}\text { Knowledge } \\
\text { production } \\
\text { function }\end{array}$ & $\begin{array}{l}\text { Spillover effects } \\
\text { facilitated by geographic } \\
\text { proximity between } \\
\text { academic and corporate } \\
\text { research labs }\end{array}$ & \\
\hline $\begin{array}{l}\text { Acs et al. } \\
(1994)\end{array}$ & $\begin{array}{l}\text { Corporate } \\
\text { imnovation count } \\
\text { of US states }\end{array}$ & 1982 & $\begin{array}{l}\text { Knowledge } \\
\text { production } \\
\text { function }\end{array}$ & $\begin{array}{l}\text { Localised spillover } \\
\text { effects from academic } \\
\text { rescarch to corporatc } \\
\text { research only significant } \\
\text { for small firms. }\end{array}$ & \\
\hline $\begin{array}{l}\text { Jaffe el al. } \\
(1993)\end{array}$ & $\begin{array}{l}\text { Patents granted } \\
\text { by the USPTO } \\
\text { to US university } \\
\text { and firms }\end{array}$ & $\begin{array}{l}1975 . \\
1980\end{array}$ & $\begin{array}{l}\text { Patent citation } \\
\text { analysis }\end{array}$ & $\begin{array}{l}\text { Knowledge spillovers } \\
\text { geographically localised } \\
\text { both at the level of the } \\
\text { US state and } \\
\text { metropolitan area }\end{array}$ & \multirow{2}{*}{$\begin{array}{l}\text { They capture only } \\
\text { codified } \\
\text { knowledge flows } \\
\text { Spillovers } \\
\text { mechanisms are } \\
\text { not modelled }\end{array}$} \\
\hline $\begin{array}{l}\text { Maurseth } \\
\text { and } \\
\text { Verspagen } \\
(2002)\end{array}$ & $\begin{array}{l}\text { Patents applied } \\
\text { for to the EPO } \\
\text { by inventors in } \\
112 \text { European } \\
\text { regions }\end{array}$ & $1979-96$ & $\begin{array}{l}\text { Patent citation } \\
\text { analysis }\end{array}$ & $\begin{array}{l}\text { Geographical distance } \\
\text { hinders knowledge } \\
\text { spillovers }\end{array}$ & \\
\hline $\begin{array}{l}\text { Audretsch } \\
\text { and } \\
\text { Stephan } \\
(1996)\end{array}$ & $\begin{array}{l}54 \text { US } \\
\text { biotechnology } \\
\text { lims and their } \\
\text { academic } \\
\text { advisors }\end{array}$ & $1990-92$ & $\begin{array}{l}\text { Labour } \\
\text { mobility }\end{array}$ & $\begin{array}{l}\text { Academic scientists } \\
\text { founders of / chicf } \\
\text { advisors to } \\
\text { biotechnology firms } \\
\text { more likely to be located } \\
\text { in the proximity of these } \\
\text { firms }\end{array}$ & \multirow{3}{*}{$\begin{array}{l}\text { Inventors } \\
\text { mobility } \\
\text { embodying tacit } \\
\text { and specialised } \\
\text { knowledge may } \\
\text { not give rise to } \\
\text { inter-firm } \\
\text { knowledge } \\
\text { diffusion } \\
\text { Localised } \\
\text { knowledge } \\
\text { spillovers through } \\
\text { this channel may } \\
\text { be the result of } \\
\text { specificity of the } \\
\text { local labour } \\
\text { market }\end{array}$} \\
\hline $\begin{array}{l}\text { Zucker et } \\
\text { al. (1998) }\end{array}$ & $\begin{array}{l}\text { Regional } \\
\text { distribution of } \\
\text { US } \\
\text { biotechnology } \\
\text { starts-up }\end{array}$ & $1976-89$ & $\begin{array}{l}\text { Labour } \\
\text { mobility }\end{array}$ & $\begin{array}{l}\text { Emergence of } \\
\text { biotechnology start-ups } \\
\text { is explained by location } \\
\text { of star scientists }\end{array}$ & \\
\hline $\begin{array}{l}\text { Almeida } \\
\text { and Kogut } \\
(1999)\end{array}$ & $\begin{array}{l}\text { Highly cited } \\
\text { USPTO patents } \\
\text { in } \\
\text { semiconductors } \\
\text { from } 12 \text { US } \\
\text { regions }\end{array}$ & $\begin{array}{l}1980 . \\
1985\end{array}$ & $\begin{array}{l}\text { Labour } \\
\text { mobility and } \\
\text { patent citation } \\
\text { analysis }\end{array}$ & $\begin{array}{l}\text { Localised knowledge } \\
\text { spillovers associated } \\
\text { with intra regional } \\
\text { mobility of top inventors }\end{array}$ & \\
\hline $\begin{array}{l}\text { Rosenkopf } \\
\text { and } \\
\text { Almeida } \\
(2003)\end{array}$ & $\begin{array}{l}\text { Patents granted } \\
\text { by USPTO to } 74 \\
\text { semiconductor } \\
\text { firms }\end{array}$ & $1990-95$ & \begin{tabular}{|l|} 
Labour \\
mobility and \\
patent citation \\
amalysis
\end{tabular} & $\begin{array}{l}\text { Knowledge flows } \\
\text { associated with } \\
\text { inventors mobility do } \\
\text { not depend on } \\
\text { geographical distance }\end{array}$ & $\begin{array}{l}\text { Inventors } \\
\text { mobility may not } \\
\text { give rise to imer- } \\
\text { firm knowledge } \\
\text { diffusion }\end{array}$ \\
\hline
\end{tabular}




\begin{tabular}{|c|c|c|c|c|c|}
\hline \multicolumn{6}{|c|}{ Social dimension of knowledge spillovers } \\
\hline Authors & Sample & Period & Methodology & Main results & Issues \\
\hline $\begin{array}{l}\text { Stolpe } \\
(20(02)\end{array}$ & $\begin{array}{l}\text { Patents granted } \\
\text { by USPTO on } \\
\text { the liquid crystal } \\
\text { technology }\end{array}$ & $1975-95$ & $\begin{array}{l}\text { Labour } \\
\text { mobility and } \\
\text { patent citation } \\
\text { analysis }\end{array}$ & $\begin{array}{l}\text { Knowledge spillovers } \\
\text { are related to past } \\
\text { collaborative experience } \\
\text { among inventors }\end{array}$ & $\begin{array}{l}\text { The social } \\
\text { network of } \\
\text { inventors is not } \\
\text { qualified or } \\
\text { quantified }\end{array}$ \\
\hline \begin{tabular}{|l|} 
Lissoni and \\
Breschi \\
$(2003)$
\end{tabular} & $\begin{array}{l}\text { Patents applied } \\
\text { for to the I:PO } \\
\text { by Italian } \\
\text { inventors }\end{array}$ & $1987-89$ & $\begin{array}{l}\text { Social network } \\
\text { and patent } \\
\text { citation } \\
\text { analyses }\end{array}$ & $\begin{array}{l}\text { Social ties among } \\
\text { inventors explains } \\
\text { knowledge spillovers }\end{array}$ & $\begin{array}{l}\text { Small and country } \\
\text { specific sample }\end{array}$ \\
\hline \begin{tabular}{|l|} 
Singh \\
$(2004 b)$
\end{tabular} & $\begin{array}{l}\text { USPTO patents } \\
\text { granted to } 3000) \\
\text { firms }\end{array}$ & $1986-95$ & \begin{tabular}{|l|} 
Social network \\
and patent \\
citation \\
analyses
\end{tabular} & $\begin{array}{l}\text { Social ties among } \\
\text { inventors explains } \\
\text { knowledge spillovers }\end{array}$ & \\
\hline
\end{tabular}

The US semiconductor industry is also the object of analysis in the study by Rosenkopf and Almeida (2003) who investigate whether firms exploit alliances and labour mobility as a means to acquire knowledge beyond their local context. This analysis is based on a sample of patents granted to 74 semiconductor firms from which the authors extract information on the mobility of inventors and on the geographical distribution of cited patents. They show that inter-firm knowledge flows, measured by the number of patent citations, are positively and significantly affected by geographical proximity and inventors' mobility. However the interaction term of the labour mobility variable with geographical distance is not significant. This secms to suggest that inter-firm knowledge flows associated with inventors' mobility do not depend on geographic proximity. Therefore this study qualifies the results of Almeida and Kogut showing that labour mobility can be a means for accessing knowledge in geographically and technologically distant contexts.

\subsubsection{Empirical evidence of the social dimension of knowledge spillovers}

Another promising line of research within this approach has tried to connect the geographical localisation of spillovers with the existence of social ties between mobile inventors. These recent studies, summarised in Table 2.1, represent a step towards opening the 'black box' of localised knowledge spillovers since they propose an explanation for their occurrence. The assumption is that inventors who have worked together in the past establish social relationships that allow the sharing of information after their collaborative project has terminated or when they are not longer part of the same organisation. The study by Stolpe (2002) on knowledge diffusion in liquid crystal technology is one of the first in this direction. Replicating the exercise carried out by Jaffe et al. (1993), the author shows that localised 
spillovers are determined, among other factors, by the existence of prior collaborative relationships between citing and cited inventors (as documented in patent data either through joint filing of a third patent or joint affiliation with the same organisation). This seems to suggest that social ties among inventors resulting from past collaborative experience can promote knowledge diffusion. Similar results are reached by Breschi and Lissoni (2003) on a sample of EPO patents applied for by Italian inventors. In this study the social linkages between inventors are measured by using social network analysis techniques which allow the social distance among inventors to be assessed. Repeating Jaffe et al.'s (1993) exercise, they find that localised knowledge spillovers are almost entirely explained by geographically concentrated social networks of inventors. This implies that hiring workers from competitors and other firms seems to be a key means to access such a network', confirming the results of Rosenkopf and Almeida's (2003) study. Singh (2004b) describes similar findings on a much broader sample of USPTO patents taking accoumt not only of the existence of the social ties among inventors, but also of their strength. Singh shows that higher social proximity among inventors leads to a higher intensity of citation, i.c. both greater knowledge diffusion and social links help explain the spillovers localisation effect. This result implies that knowledge diffusion between socially connected inventors does not depend on them being geographical proximate. Agarwal et al. (2003) reach the same conclusion, although not using social network analysis techniques. They show that mobile inventors continue disproportionately to cite patents from their city of origin even after moving to a new city, which seems to confirm the existence of what they define as 'enduring social capital', i.e. the effect of social ties appears to persist not only over time, but also across space.

Overall these studies contribute to the literature on knowledge spillovers in two ways. On the one hand they offer a quantitative evaluation of the importance of the social dimension of localised knowledge diffusion, which was already reported in a number of case studies of regional clusters (see for example the studies by Saxenian 1990, 1994 on the semiconductor cluster in Silicon Valley) and implicit in the concept of embeddedness. These studies showed that spatial proximity reduces the cost and increases the frequency of personal contacts giving rise to social relationships between the individuals in a network through which knowledge can diffuse. On the other hand they also identify labour mobility as a channel for transferring knowledge across borders through the creation of social relationships. A recent case study on the emergence of semiconductor clusters in Taiwan (Saxenian and Jinn-Yuh 2001) has in fact shown the significant role of international technological communities which bridge the 
Silicon Valley and the Hsinchu (Taiwan) clusters. An increase in the number of US-educated engineers constantly travelling across the Pacific has helped build fruitful relationships with the network of firms and institutions in Silicon Valley and maintain a constant flow of technical knowledge between the two clusters.

\subsection{INWARD FDI-RELATED R\&D SPILLOVERS}

MNEs are believed to play a very important role in the international diffusion of technology. In fact technology is probably the most important proprictary asset that allows firms to become multinational and to be able to compete sucessfully in foreign markets (Dunning 1977, Hymer 1960). Foreign subsidiaries are receivers of technology from the headquarters and these technology flows create a potential for spillovers to host country firms. Caves (1974b) distinguishes among three different sources of beneficial effects from the presence of MNEs in the host country. First, the increase in market competition due to the entry of a foreign subsidiary can increase allocative efficiency and decrease the excess profits realised by local firms. Second, domestic firms in monopolistic markets may increase their level of technical efficiency or X-efficiency, either through the competitive pressure exerted by foreign affiliates or through demonstration effects. Finally, the entry of MNEs' subsidiaries can speed up the transfer and diffusion of technology in the local market and henec foster host country technological development. Therefore the effects of MNEs' presence on domestic firms' productivity occur via two channels: the increase of competitive pressure and technology transfer.

As pointed out by Marin and Bell (2003), productivity spillovers stemming from competitive pressures may not imply the adoption of technology introduced or diffused by foreign affiliates and therefore they should not be considered 'genuine' technological spillovers. Morcover productive spillovers resulting from this channel can be of a negative nature through a 'market stealing effect': more productive foreign firms may crowd out domestic firms in the local market and force them up to the average cost curve and so reduce their productivity (Aitken and Harrison 1999). In general technological spillovers occur when there is a non-market mediated technology transfer - intentional or unintentional - between foreign subsidiaries and domestic firms, while productivity spillovers are said to take place when the entry or the presence of MNEs' affiliates leads to productivity or efficiency benefits for local firms. 


\subsubsection{Technological spillovers channels}

Genuine technological spillovers can occur in three ways: through demonstration effects, labour mobility, and backward and forward linkages. First, domestic firms may learn about technologies used by foreign affiliates and adopt them through imitation and reverse engineering. This 'demonstration effect' argument assumes that in the absence of FDI domestic firms may find it difficult or costly to gather the information necessary for implementing a new technology. Geographical proximity is clearly a key element of the demonstration effect and may be crucial for those developing countries not integrated into the world economy that cannot otherwise see the application of more advanced technologies. However, through this channel foreign subsidiaries increase the set of technologies available to domestic firms, but do not guarantee the actual adoption of these new technologies. Das (1987) takes into consideration this demonstration effect in his price-leadership model which analyses the transfer of technology from the parent company to its foreign affiliates. In this model domestic firms can become more efficient by 'learning from watching', but the increase in efficiency is positively related to the foreign subsidiaries' scales of operation. Das shows that despite these technology leakages the multinational benefits from transferring tecimology to its foreign units. There are no empirical studies supporting the existence of this demonstration effect, although, as reported by Blömstrom and Kokko (1998), there is indirect evidence of this phenomenon. The lack of empirical analysis has to do with the fact that it is very difficult to disentangle the effects of increased competition and demonstration on the imitation and adoption of new technologies.

Second, spillovers can occur when workers and managers previously employed and/or trained by MNEs move to a domestic firm or set up their own businesses. In this case the knowledge embodied in workers is transferred from foreign subsidiaries to domestic firms. Fosfuri et al. (2001) have analysed this channel in a game-theory model which tries to identify the conditions under which technological spillovers arise. They find that this channel works if the multinational and the domestic firm do not operate in competing sectors and if the host country's absorptive capacity is high (an issue that 1 will address later in this section). Indirect empirical evidence of this technology transfer mechanism is offered by a few studies showing that foreign subsidiaries provide more training than domestic firms (see for example Sousa 2001 ) and that an increase in FDI promotes higher wages in domestic firms (Lipsey and Sjöholm 2001). The study by Görg and Strobl (2002) provides direct empirical evidence of the positive impact that labour mobility has on host firms' productivity. This study uses the information contained in a panel dataset of firms from Ghana which contains information on 
the work history of their owners. The authors find that firms with entrepreneurs with previous working experience in foreign multinationals have higher productivity than other local firms, after controlling for the level of education achieved by the entrepreneur.

Third, the presence of foreign subsidiaries may benefit the host country cconomy through the creation of linkages with local suppliers (backward linkages) and customers (forward linkages). Although multinational companies may try to minimise technology leakage, they have incentives to improve the productivity of their local suppliers through for example personnel training. As pointed out by Lall (1980) spillovers through backward linkages can emerge as a result of direct transfer of knowledge from foreign customers to local suppliers in the form of technical assistance for improving the quality of their products, buying raw materials or adopting new organisational methods. In addition the higher requirements regarding quality standards and delivery time imposed by multinational companies may stimulate local suppliers to upgrade their production processes. Finally, if foreign subsidiaries do not crowd out domestic competitors and do not divert demand from domestic inputs to imported inputs, domestic suppliers can benefit from potential economies of scales.

\subsubsection{Conditions favouring the realisation of spillover potential}

However the occurrence of technological spillovers depends on a number of interrelated factors: the host country firms' technology gap vis-à-vis foreign subsidiaries, domestic firms' absorptive capacity, foreign subsidiaries' productive and technological activities, foreign subsidiaries' host country embeddedness, and the intellectual property rights (IPR) regime.

The relationship between the technology gap and the incidence of FDI spillovers was first formalised by Findlay (1978) in his North-South model of technology diffusion. Findlay builds on the 'advantage of backwardness' hypothesis put forward by Gerschenkron (1962) who assumed that, as long as the gap is not so large to impede any learning process, the greater the relative disparity between the advanced and backward region the faster the catching up rate. Findlay extends this argument to the case of FDI from 'advanced' regions to 'backward' regions: the greater the gap between foreign and domestic firms the greater the scope for technological spillovers. Together with this hypothesis Findiay assumes that technology diffuses like a contagious disease. i.e. technologies are diffused through personal contact between the two parties. This contagious effect implies that the diffusion is faster the greater the foreign presence in the host country. As a result, domestic firms in the South will 
catch up faster if the technology gap with the North is wide and the foreign share in the host country capital stock is large.

A positive relationship between the technology gap and spillovers is also assumed in Wang and Blömstrom's (1992) duopoly model with differentiated goods. In this model spillovers are not only automatically triggered by MNE presence, but are also endogenously determined by strategic interaction between foreign and domestic firms. In particular, Wang and Blömstrom show that some spillovers, directly proportional to the size of the technology gap, always occur regardless of the host country firm's learning efforts, as in Findlay's model. But at the same time the more resources local firms invest in learning activities the greater the incentive will be for foreign subsidiaries to import more advanced technologies and thus the greater the scope for technological spillovers and, ultimately, the smaller the gap. In this model technology transfer is assumed to be costly and the cost is a function of the complexity of the technology to be transferred, as shown by the seminal empirical studies of Teece (1976). Since profitability of foreign firms depends on their superior technological advantage and technology transfer is costly, if domestic firms do not exert any competitive pressure on foreign subsidiaries they will not import newer technologies. As a result a large foreign presence may coexist with slow technology transfer and the transfer of 'old' technologies' (Wang and Blömstrom 1992, p. 138). The most interesting implication of this model is that technology transfer via FDI is positively related to the local firms' learning investment, an aspect to which I will refer later in this section.

However there are opposing views in the literature on the relationship between the technology gap and spillovers. The 'technological accumulation hypothesis', as defined by Cantwell (1989), assumes that the lower the technology gap between domestic and foreign firms the higher the ability of clomestic firms to capture the benefits created by MNE presence. This argument builds on the concept of 'localised technical progress' presented by Atkinson and Stiglitz (1969) and further developed by Lapan and Bardhan (1977) who stated that 'technical advances applicable to the factor-proportions of capital rich developed countries are hardly of any use in improving the techniques of Jow capital-intensity in less developed countries" (p.585). Therefore the higher the gap the lower the potential for spillovers due to lack of what Abramovitz (1986) defines as 'technological congruence'. Cantwell (1989), in his study of the impact of US multinationals in Europe between 1955-75, finds in fact that host country firms with a small technology gap are the ones benefiting most from the MNE presence. 
affected by the international technological situation. The concept of absorptive capacity shares some commonality with the definition of human eapital $\cdots$ being both related to learning activities - but there are also other elements. apart from availability of suitably qualified workers, that determine a country's ability to assimilate forcign developed technologies. Absorptive eapacity depends on the aceessibility of foreign technology through trade and FDI. and on the existence of appropriate incentives to implement new technologies. In fact. absorptive capacity accumulates only if an effort to internalise external knowledge is exerted and in particular if prior knowledge has been applied to the solution of problems ( Kim 1995). A proxy for a country's absorptive capacity should therefore include not only human capital indicators (better if specifically related to technical and enginecring education attainments, see the study by Lankhuizen 1998), but also the degree of a country's openness to trade and FDI, the level of infrastructure, the property-rights regime (see Rogers 2004 for an attempt in this direction).

Another important related aspect in determining the occurrence of FDI-related spillovers is the type of activities that foreign subsidiaries decide to undertake in host countries, which in turn is a function of the level of the host country development. While it is normally assumed that foreign subsidiaries share the same technological capabilities as the parent company, in reality subsidiaries can evolve independently from the headquarters according to their choices and to the domestic environment (Birkinshaw and Hood 1998). Subsidiaries can develop their technological capabilities by building on the host country technological advantage and they can become as important as the headquarters as a source of new technological assets. But at the same time and to the same extent, subsidiaries' technological upgrading can be limited by the host country's degree of technological development. When local firms are technologically backward, MNEs will tend to engage themselves in low-value added activities and, as postulated by Wang and Blömstrom (1992), they will not transfer advanced technologies to these foreign subsidiaries, thus reducing the scope for spillovers. The type of activities that foreign firms undertake in a host economy is strictly connected with the motives that have in the first place prompted MNEs to invest abroad. Firms may undertake direct investment abroad to avail themselves of natural resources (resource-based FDI), to exploit the host country market (market-secking investment), to restructure existing foreign production through rationalisation (efficiency-seeking investment), or to acquire and create new assets. The first three motives can be classified as being asset-exploiting in nature while the last is asset-augmenting. As argued by Narula and Dunning (2000). different levels of host country 
development will attract different amounts of FDI and different types of MNE activity depending on the host economy's comparative advantage. Less developed countries due to their low level of productivity and underdeveloped infrastructure will attract very limited FDI and this will mainly be of the resource-secking type. In contrast asset-augmenting FDI mainly lakes place among industrialised countries. This implies that the occurrence of technological spillovers is contingent upon the host country's characteristics, in terms of the location advantages that it is able to offer to MNEs. which in turn determines the FDI motives and therefore the activities that foreign subsidiaries undertake.

An additional factor determining the incidence of FDl-related spillovers is the degree of cmbeddedness of foreign subsidiarics in the host cconomy (UNCTAD 2001). If forcign subsidiaries operate in isolation and import most of their inputs, there is little scope for technological spillovers. As mentioned above, it is through the creation of backward and forward linkages that tangible and intangible assets can be transferred from foreign subsidiaries to domestic suppliers and customers. As shown by both a number of case studies reviewed by Belderbos et al. (2001), and the empirical evidence found in his study, it is not only host country characteristics such as market size. technological development. infrastructure, availability of proximate domestic suppliers, and local content regulations that are important determinants of backward linkages, but also certain foreign affiliates' characteristics such as their market orientation (domestic ws export), their age, and their mode of establishment (greenficld us acquisition). In particular, domestic market-oriented foreign affiliates tend to use local inputs because the quality and technical requirements may be lower and they can be met by local suppliers. Export-oriented affiliates may instead be more inclined to source their intermediate products from abroad often from other units of the multinational company. Acquired subsidiaries or subsidiaries established through joint ventures are more likely to source locally than greenfield subsidiaries, and in particular newly established greenfield subsidiaries. As observed by Belderbos et al. (2001), acquired subsidiaries are already embedded in the host economy; therefore they may already have developed stable relationships with local suppliers which may continue to be exploited under the new ownership.

Rodriguez-Clare (1996) was the first to develop a formal model of linkages which are measured by analysing the job creating impact of multinational companies on local suppliers. Specifically the linkage effect is measured by a linkage coefficient which is equal to the ratio of new employment generated in upstream industries by a firm to the labour employed 
directly by that firm. A positive linkage effect arises if multinationals have a higher linkage coefficient than domestic firms. In this model it is assumed that positive linkage effects are more likely if communication costs between home and host country are high and if the home and host country are more similar in terms of the variety of intermediate goods produced, in other words, if there is a small technology gap between the two countries. In this model the MNE's presence may lead to the production of a larger variety of intermediate goods through backward linkages that allow the economy to gain a competitive advantage in the production of more sophisticated final goods. Because of these effects the host country may reach higher productivity and wage levels. However backward linkages may also lead to negative spillover effects. These can occur when local supply of intermediates is poor and MNEs import most of their inputs and limit their domestic activities to hiring labour, lcading to a reduction in input variety and specialisation. Thus the activity of foreign affiliates in developing countries may take place without linkages with host country firms creating 'enclaves economies within developing countries'.

While Rodriguez-Clare focuses on the impact on the labour market, in their model Markusen and Venable (1999) measure the linkage effect with an input-output coefficient which is equal to the share of intermediate goods required by the downstream industry. If the input-output coefficient is higher for multinational companies than for host country firms, then multinational companies source intermediate goods from local suppliers more than their domestic counterparts. According to this model the presence of multinational firms has two contrasting effects on the host economy. On the one hand competitive pressures exerted by multinational firms may crowd out host country firms in the final goods sector. On the other hand the entry of multinationals may increase demand for domestically produced intermediate goods through a linkage effect which causes an expansion of domestic production of intermediate products, increased profits and entry into this sector. This entry leads to a fall in the price of intermediate goods favouring both domestic and foreign firms in the final goods sector (forward linkage effect).

Another factor affecting the scope for technological spillovers from FDI is the host country's intellectual property right (IPR) regime. Although other host country regulatory regimes (such as tax and investment regulations), trade policies, and competition rules also affect FDI decisions, the host country IPR regime is the most important policy variable in determining not only the amount of FDI, but also the technology content of the activities that foreign firms undertake. This issue has recently become prominent on the international political agenda 
with the implementation of the Agrecment on Trade-Related Aspects of Intellectual Property Rights (TRIPs) which entails a minimum level of protection for all categories of property rights and requires the development of effective enforcement measures. ${ }^{10}$ The relationship between FDI and IPR is ambiguous. On the one hand a weak IPR protection system can increase the probability of imitation thus reducing the amount of FDI a country receives and increasing exports. On the other hand stronger IPR protection may indeed encourage more FDI but at the same time may make licensing more attractive and therefore have a negative effect on FDI. However survey studies by Mansfield (1994) have shown that the effect of IPR regimes varies across industries and is a function of the type of investment project. In particular the role of IPRs was considered important by 100 major US firms with international operations in 1991 in the pharmaceutical and chemicals industries and it was less relevant for investment in distribution and sales." In a more recent study Smith (2001) analyses the relationship between the IPR regime and US exports, sales of forcign affiliates, and licensing fees in 50 developed and developing countries in 1989. She finds significant evidence that a better-enfored IPR system has on average a positive effect on affiliate sales and licence payments in countries with strong imitative capabilities. But at the same time a stronger IPR regime shifts activity away from exports and FDI and towards licensing. In addition she finds that patent rights strongly and positively affect the inflows of knowledge, measured as R\&D expenditures undertaken by affiliates. This evidence is stronger for countries with greater absorptive capacity. These results seem to suggest that the enforement of property rights may favour intemational technology transfer through inward FDI-related spillovers and licensing in those developing countries that have achieved a certain level of absorptive capacity. However since tougher IPR protection makes technology licensing more attractive, domestic firms may get access to older technologies. A study by Mansfield et al. (1979) shows in fact that firms tend to transfer newer technologies abroad through their subsidiaries rather than licensing agrements. Therefore overall the net impact of stronger IPR protection on

\footnotetext{
11" The main changes brought in by the TRIPs agreenent conceming the patent system are that World Trade Organization (WTO) members may no longer exclude any ficld of technology from patentability (in most developing countries certain products such as pharmaceuticals, living material. food and beverages used to be excluded from patentability): the patent protection must extend for 20 years from the application filing date (in most developing countries the duration of patents used to vary between 5 and 20 years depending on the technological sector): the use of compulsory licensing by governments is restricted and can only be applied if adequate compensation is granted: patem holders camot be obliged to produce the invented produet or use the patented invention in the production process in the country which has granted the patent.

1 These results are contirmed by a recent econometric study by Smarzynska (2003a) based on data from questionnaires sent to forejgn investors in Eastern Europe and the former Soviet Union. The author finds that weak IPR protection delers FDI in drugs, cosmetics \& health care products: chemicals: machinery \& equipment: and electrical equipment and encourages MNEs to establish distribution facilities rather than to engage in local production.
} 
technology transfer via FDI is ambiguous and it only affects the spillover potential not the actual realisation of these spillovers. ${ }^{12}$

In summary. FDI-related R\&D spillovers are determined by the degree of foreign subsidiaries" embeddedness in the host economy, by the technology gap between the foreign subsidiaries and the host country firms, by the level of domestic firms' absorptive capacity, by the type of technological activity that these firms are undertaking and by the enforement of IPR protection. All these factors are mutually reinforcing and interrelated and all contribute to the realisation of spillover potential.

\subsubsection{Empirical evidence on the conditions favouring inward FDI-related spillovers}

In this section I review some of the empirical evidence on the spillover effects deriving from the activities of MNEs, concentrating on the studies that have investigated the conditions for their occurrence. It does not pretend to be an exhaustive revicw of all the existing studies on inward FDI-related spillovers. Rather the aim of this section is to provide an overall picture of the significance of these determinants both at the micro and macro levels and the methods used to assess their impact on the host economy. I structure the survey according to the level of aggregation used to carry out the analysis: firm and sectoral level, and country level.

Firm and industry level studies focus on whether the presence of MNEs affects domestic firms' productivity, measured either as labour productivity or total factor productivity (TFP). These studies generally involve regressing domestic firms' productivity on a variable capturing MNE presence in the same sector, e.g. the share of employment in foreign-owned firms or the share of output produced by foreign subsidiaries, and a number of other variables controlling for host market characteristics such as the level of host market competition, technology gap, and absorptive capacity. In this framework, FDI-related spillovers arise if the coefficient on the variable measuring MNEs' presence turns out to be positive and statistically significant. These studies are therefore testing for the presence of horizontal spillovers, i.e. the impact on domestic firms' productivity in the same sector.

The recent survey by Görg and Strobl (2001) shows that earlier studics based on industry level cross-sectional data find a statistically significant horizontal spillovers effect both in

\footnotetext{
12 So far the overall effect of the implementation of the TRIPs agrement has not been systematically investigated because, although the agrement came into force on the I January 1996, developing countries were granted a transition period of four years. In addition. the agreement contemplates an additional five year period for introducing product patents in areas of technology that were not protected at the date of the application of the agreement.
} 
host developed countries (Caves 19746 for Australia. Globerman 1979 for Canada) and developing countries (Blömstrom 1986. Blömstrom and Persson 1983, Kokko 1994 in Mexico). However firm-level panel data studies. like the seminal investigation by Haddad and Harrison (1993) with data from Moroceo, tend to find that the presence of foreign subsidiaries reduces, instead of increases, domestic firms' productivity. Görg and Strobl conclude that cross-sectional studies overestimate the spillover effects of MNEs because they are not able to control for firm or sector specific fixed effects, which instead may affect the relationship between domestic firms' productivity and MNEs. Controlling for these unobservable and time-invariant factors is extremely important because multinational companies are driven towards relatively high-productivity sectors, which implies that the observed positive relationship between forcign presence and domestic productivity may not be related to the occurrence of spillovers. Once this identification problem is solved with the use of panel data techniques, empirical findings seem to point towards a negative or non-significant impact of MNEs on domestic firms' productivity operating in the same industry. In a recent survey of studies using panel data sets, Görg and Greenaway (2003) find that only six studies for industrialised countries and none for developing countries report positive within-industry spillover effects.

Negative or neutral effects from MNE presence can be explained by a lack of absorptive capacity on the part of host country firms, their relative technological backwardness with respect to foreign subsidiaries and their technological activities. Another explanation for the failure to find any evidence of positive spillovers is due to the fact that spillovers from FDI are more likely to be vertical than horizontal in nature. In other words, spillovers may occur through backward and forward linkage effects, that is, through contacts with domestic suppliers and customers. The approach used in testing for vertical spillovers consists in estimating host country suppliers' production functions which include, apart from production inputs - such as labour, capital, material inputs - three other variables capturing the extent of foreign presence in the same industry (horizontal linkages), in the downstream industry (backward linkages), and in the upstream industry (forward linkages). Positive and significant coefficients on the variables proxying both backward and forward linkages are then interpreted as an indication of FDI-related vertical spillovers. Following Markusen and Venables's (1999) model, backward (forward) linkages are measured by a variable capturing the foreign presence in the upstream (downstream) industry weighted by the input-output coefficient. 
Studies at the country level have tested the importance of FDI as a channel for technology transfer within the context of both endogenous growth models and international R\&D spillovers. In the first approach. FDI, measured by the stock or flow of inward FDI, is one of the explanatory variables of the host country's GDP or total factor productivity (TFP) growth rate. In the second approach the TFP of a country is a function of domestic and forcign R\&D investment. ${ }^{13}$ Foreign R\&D cxpenditure can affect domestic productivity growth mainly through three channels: trade, inward FDI and outward FDI. I review these studies in the next chapter where I consider the impact of outward FDI as a channel for international technology diffusion.

\subsubsection{Microeconomic evidence}

\section{Technology gap}

The approach adopted to test the impact of the technology gap on the incidence of FDI spillovers is to divide the sample of firms according to different levels of gap and then to compare the sign and the statistical significance of the spillovers variable across the subsamples. The study by Kokko (1994) applies this methodology to a cross-section of firms in Mexico. Kokko divides the industries into groups with lower and higher technology gaps using three different proxies: the average spent on patent fees per employee in each industry, the average capital intensity of foreign affiliates, and the labour productivity gap between local and foreign firms. ${ }^{1+}$ Across every different proxy measure Kokko finds that the spillover effect is positive and significant for the sub-sample with small technology gaps, which supports the 'technological accumulation hypothesis'. However what seems to inhibit the occurrence of spillovers is the coincidence of a large technology gap and a strong foreign presence - a situation that Kokko describes as an industrial 'enclave'. This evidence supports the idea that, when the technology gap is very wide, MNEs may crowd out domestic firms and operate in complete isolation, thus reducing the possibility that local firms might benefit from the MNEs' presence, as postulated in the backward linkage model of Rodriguez-Clare (1996). Kokko et al. (1996) repeat the analysis for a cross-section of Uruguayan manufacturing plants. They find evidence of positive spillover effects for the group of domestic firms with small technology gap vis-à-vis foreign affiliates (proxied by the

\footnotetext{
1. This methodology was first implemented to assess trade-related international R\&D spillovers (Coe and Helpman 1995. Coe et al. 1997. Gittleman and Wolff 1995, Mohen 1995, see Verspagen 1994).

is As noted by Sjöholm (1999), the first wo proxies capture expected differences in technology complexity rather than observed differences. The last proxy measures instead the observed differences between domestic and foreign firms, which may however be related to differences in capital intensity or scale of production. rather than differences in technology.
} 
difference between the firms' labour productivity and the average labour productivity in foreign firms). However these results and those obtained by Kokko (1994) may be affected by an identification bias which arises from examining productivity levels in a cross-section data set. Furthermore, as demonstrated by Hanson (2000), the inference drawn from econometric estimates obtained using an exogenous sample splitting technique may be affected by the invalidity of the standard asymptotic confidence intervals.

Sjöholm (1999) applies the same methodology for a sample of Indonesian manufacturing firms in 1980 and 1991, but tests for the impact of the presence of MNEs on domestic firms' productivity growth rather than levels. In this study the technology gap for each industry, proxied by the difference in labour productivity between domestic and foreign plants, is estimated after controlling for capital intensity and scale of production. The cut-off value used for dividing the sample into low and high technology gap is not arbitrarily chosen, but is estimated as an intercept parameter in the regression of the technology gap measure. The results seem also to support the 'technological accumulation hypothesis': host country firms with small technology gaps vis-à-vis foreign subsidiaries register an increase in their productivity growth rate. However this evidence should be interpreted with caution since the methodology for splitting the sample does not avoid the econometric problems pointed out above. Another limitation of this study is that it does not consider the role of domestic firms' absorptive capacity together with the technology gap.

\section{Absorptive capacity}

One of the methods adopted for testing the role of absorptive capacity in determining the incidence of spillovers is to introduce in the regression an interaction term between FDI and absorptive capacity. This is the approach adopted by Kinoshita (2000) in his study of the effects of FDI in a panel of firms in the Czech Republic between 1995 and 1998. The author finds no positive effect on domestic firms' productivity growth even after controlling for domestic firms' R\&D expenditure. However there is a positive effect if the FDI variable is interacted with domestic firms' absorptive capacity (proxied by their R\&D intensity). This evidence supports the hypothesis that the spillover effects from MNEs' activities are conditional on host firms' absorptive capacities. However, as pointed out by Girma (2003), this approach, i.e. the use of an interaction term, implicitly imposes the a priori restriction that there is a linear relationship between MNE presence and absorptive capacity. As I have already observed, there may be a non-linear relationship between these two variables, since 
domestic firms can benefit from MNE presence only if a certain minimum level of absorptive capacity has been achicved.

The study by (iirma (2003) tries to take account of this different configuration in a large panel data set of UK firms covering 1989-99. Both linear and quadratic interaction term specifications are estimated using as a proxy for absorptive capacity the average domestic firm's productivity in cach industry. Girma also examines the impact of both the FDI motivation and geographical distance on the occurrence of spillovers. Following Kogut and Chang (1991), the author assumes that MNEs' activities in a sector are asset-augmenting (asset-exploiting) if the host country sectoral R\&D intensity is greater (smaller) than the sectoral R\&D intensity in the MNEs' home country. Separate analyses are carried out for the sample of firms in sectors where MNEs are either asset-exploiting or asset-augmenting. One would expect that spillover effects are less likely when FDI is motivated by the desire to acquire technological assets from the host country, since foreign subsidiaries will tend to be technological laggards with respect to domestic firms. The opposite holds true for assetexploiting FDI. The empirical evidence confirms this assumption: across different econometric specifications, firms in sectors characterised by asset-augmenting FDI do not experience faster productivity growth rates. However one should keep in mind that the proxies used for capturing the different FDI motivations implicitly assume that foreign affiliates reflect the technological advantage or disadvantage of their home countries as well as displaying homogenous technological bchaviour across foreign affiliates operating in the same sector.

Girma's estimates from the model with the linear specification term between absorptive capacity and FDI presence confirm the results obtained by Kinoshita (2000): higher levels of absorptive capacity reinforce the spillover effect from both asset-exploiting and assetaugmenting $\mathrm{FDI}$. But the quadratic specification reveals an inverted-U shaped relationship between absorptive capacity and MNE presence in sectors where asset-exploiting activities are prevalent. This implies that inward FDI-related spillovers increase with absorptive capacity, but at a decreasing rate, i.e. the externalities effect of FDI on domestic firms with an already high absorptive capacity is less significant. The author is also able to identify a threshold level of absorptive capacity below which FDI-induced productivity spillovers do not occur. Finally this study shows that productivity spillovers have a geographical dimension, in other words, that their effect is stronger within the host region than outside it. Although this study presents firm-level evidence of the presence of an absorptive capacity 
threshold-level effect, which was previously found in macroeconomics analysis, it uses only a rough measure for this variable. It also implicitly assumes that high levels of absorptive capacity correspond to low technology gaps between domestic and foreign firms without testing for the role of both variables in the incidence of spillovers (p. 21 ).

Castellani and Zanfei (2003b) introduce both the technology gap and the absorptive capacity variable, proxied by the productivity of the average domestic firm, from a panel of firms in France. Spain and Italy. In this study the impact of both variables on the occurrence of spillovers is analysed using a linear interaction model. Castellani and Zanfei do not find significant spillover effects for French firms, find negative spillover effects for Spanish firms and positive spillover effects for Italian firms. However their results show that high gaps are conducive to positive and significant productivity spillovers, which supports the catching up hypothesis put forward by Findlay (1978). Domestic firms' absorptive capacity in contrast does not have any statistically significant impact. Furthermore a threshold level of the technology gap is identified, below which no positive effect from the presence of FDI is registered. These results are in contrast with the findings of previous studies reviewed in this section that have analysed the role of these two variables separately. But at the same time they suggest the existence of a non-linear relationship between spillovers and technology gaps as postulated in Perez's (1997) model.

\section{Foreign subsidiaries technological behaviour}

The technological behaviour of foreign subsidiaries is investigated in Chung's (2001) study on FDl-related spillovers in the US. The distinction between asset-atgmenting and assetexploiting is however based on host industry competition level rather than on the relative R\&D intensity between host and home country, as in Gima (2003). Chung assumes that high levels of competition will force domestic and foreign firms to adopt an innovative strategy and therefore highly competitive industries will attract only those MNEs with an assetaugmenting strategy. Less competitive industries will attract foreign affiliates that can, with their pre-cxisting capabilities, overcome the high barriers to entry characterising these industries. The results confirm the findings of Girma (2003): productivity increases via FDI are only registered in industries with low levels of competition, i.e. when subsidiaries carry out asset-cxploiting activities. However in both studies (this and the one by Girma), foreign subsidiaries technological behaviour is only assumed and not directly examined. 
The studies by Marin and Bell (2003) and Narula and Marin (2003) present a direct analysis of foreign subsidiaries' innovative activitics using data from innovation surveys conducted in Argentina. This data set allows the authors to investigate the impact of host country firms' absorptive eapacity in determining the incidence of spillovers. They use different proxies for this variable, including R\&D intensity, training, number of engineers over total employment, payments for licences and royalty fees, investment both in ICT and in imported technologies, and the firm's innovation strategy. Following Kokko (1994), the authors divide the sample of firms into two groups with lower and higher absorptive capacity using different proxies, and then compare the sign and the statistical significance level of the spillover variable across the sub-samples. Overall the results seem to point towards an insignificant impact of host country firms' absorptive capacity, as in Castellani and Zanfei (2003b). However, high levels of domestic training and investment in both ICT and equipment for innovation appear to be associated with higher productivity growth connected with rapid FDI growth. The failure of domestic firms to benefit from the presence of MNEs cannot be attributed to the lack of absorptive or technological capacity, but id due to the type of innovative activities that foreign subsidiaries decide to undertake. Domestic firms in sectors where foreign affiliates are technologically active, that is, when they display a high level of R\&D expenditure, training. investment in capital-embodied technologies, products and process innovations, experience positive and significant spillovers. Spillovers effects are negative and significant in sectors where foreign subsidiaries are technologically passive.

\section{Host country embeddedness: backward and forward linkages}

Although there are a number of case studies and much empirical evidence describing the conditions and the extent of foreign affiliates' supply linkages with local producers (UNCTAD 2001, Bclderbos et al. 2001), econometric studies on productivity spillovers effect via backward linkages are scant. Blalock and Gertler (2003) apply the production function empirical framework described in Section 2.3 .3 to a panel of Indonesian manufacturing plants, although considering only backward linkages. They find evidence of positive vertical externalities, but there is no indication of spillovers to domestic firms operating in the same sector (horizontal spillovers). Smarzynska (2003b) applies a similar framework to a panel of Lithuanian firms and investigates both the presence of backward and forward linkages. She finds that firms' productivity is positively correlated with foreign presence in downstream industries. However in this study there is no evidence of spillovers occurring through horizontal and forward linkages. Furthermore this study reveals that this effect is stronger for 
joint foreign and domestic ownership but is not significant for wholly forcign-owned affiliates.

From the firm level studies whose findings are summarised in Table 2.2, it appears that there is mixed evidence on the type of relationship between FDI-related spillovers on the one hand, and both host country firms' absorptive capacity and the technology gap on the other, due mostly to the different measures used for capturing absorptive capacity and to the different econometric specifications adopted. However what seems to emerge from these studies is the existence of threshold level effects and non-linearity in the two relationships (absorptive capacity-FDI spillovers and technology gap-FDI spillovers). Instead there seems to be unequivocal evidence that the type of technological activities foreign subsidiaries undertake is an important determinant of whether or not domestic firms benefit from FDI in the same sector. In addition the recent studies that have examined the potential for vertical (interindustry) spillovers find evidence suggesting that these types of externalities may be more important than intra-industry spillovers.

\subsubsection{Macroeconomic evidence}

There are very few macrocconomic studies that have analysed the determinants of FDI-related spillovers (see Table 2.2 for a summary). The seminal study by Borensztein et al. (1998) shows that financial FDI flows from OECD countries have led to higher levels of domestic investment in 69 developing countries and higher per-capita income growth in those developing countries that have attained a certain minimum level of absorptive capacity, measured by the level of schooling. The impact of absorptive capacity is tested by introducing an interaction term of FDI and secondary school attainment. Therefore, as pointed out by Borensztein et al, a linear relationship between these two variables is imposed a priori. In addition, as the authors acknowledge, these results, based on FDI data from balance of payments statistics, are a poor proxy for MNEs' activities in host countries since they include financial transactions that may not give rise to real activities.

$\mathrm{Xu}$ (2000) tries to overcome this shortcoming using data on the value added activities of US MNEs' subsidiaries in 40 countries during the period 1966-94. He is also able to capture the technology intensity of US subsidiaries using data on royalties and licence payments. Xu assumes that higher spending on royaltics and payments by foreign subsidiaries corresponds with greater technology diffusion to domestic firms. $\mathrm{Xu}$ finds a positive correlation between host country TFP growth and presence of US foreign subsidiaries. However this effect is 
stronger in countries than in less developed countries. Results based on the sample of less developed countries indicate that the presence of US MNEs' subsidiaries has a positive impact on host country TFP, but that their technological intensity does not have a significant effect, i.e. they are not a source of technology diffusion to domestic firms. This can be attributed to the fact that these countries do not have enough human capital to attract technology-intensive FDI and to absorb technology spillovers generated by the foreign subsidiaries' activities. In particular Xu finds that a country needs to reach a level of human capital equivalent to 1.9 years of male secondary school attainment to benefit from technological diffusion generated by US subsidiaries. This is a higher threshold than that obtained by Borenzstein et al. (1998), which explains the weak evidence for technology diffusion effects in Xu's sample of less developed countries.

Although both studies suffer from the limitation of using human capital indicators as a proxy for absorptive capacity, the evidence from them secms to support the existence of a threshold level of absorptive capacity as a condition for the occurrence of FDI-related spillovers. In addition, as has been done in firm level studies (Chung 2001, Girma 2003, and in particular Marin and Bell 2003), the study by $\mathrm{Xu}$ tries to incorporate the technological behaviour of foreign subsidiaries to better qualify the spillover potential of MNEs' activities. Microcconomic studies have been more successful in capturing the technological nature of foreign activities distinguishing between asset-exploiting activities and asset-augmenting activities, an issue that is at the centre of the empirical analysis of the R\&D internationalisation process reviewed in the next section. 
Table 2.2 Econometric studies testing for the determinants of inward FDI-related spillovers

\begin{tabular}{|c|c|c|c|c|c|c|c|}
\hline \multicolumn{8}{|c|}{ Microeconomic Studies: horizontal spillovers } \\
\hline Authors & Sample & Period & \multicolumn{3}{|c|}{ Determinants" } & \multirow[t]{2}{*}{ Main results } & \multirow[t]{2}{*}{ Issues } \\
\hline & & & TG & $\mathrm{AC}$ & TB & & \\
\hline $\begin{array}{l}\text { Kokko } \\
\text { (1994) }\end{array}$ & Mexico & 1970 & $v^{i}$ & & & $\begin{array}{l}\text { Positive spillovers to } \\
\text { local plants with small } \\
\text { technology gaps. } \\
\text { Negative spillovers } \\
\text { linked to larger gaps } \\
\text { and strong foreign } \\
\text { presence }\end{array}$ & \multirow[t]{2}{*}{$\begin{array}{l}\text { Cross- } \\
\text { sectional: } \\
\text { identification } \\
\text { problems } \\
\text { Exogenous } \\
\text { sample splitting } \\
\text { technique }\end{array}$} \\
\hline $\begin{array}{l}\text { Kokko et } \\
\text { al. }(1996)\end{array}$ & Uruguay & 1988 & $\lambda^{\prime}$ & & & $\begin{array}{l}\text { Positive spillovers to } \\
\text { local plants with small } \\
\text { technology gaps }\end{array}$ & \\
\hline $\begin{array}{l}\text { Sjöholm } \\
(1999)\end{array}$ & Indonesia & $1980-91$ & $\sqrt{ }$ & & & $\begin{array}{l}\text { Positive spillovers to } \\
\text { local plants with small } \\
\text { technology gaps }\end{array}$ & $\begin{array}{l}\text { Exogenous } \\
\text { sample splitting } \\
\text { technique } \\
\end{array}$ \\
\hline $\begin{array}{l}\text { Kinoshita } \\
(2000)\end{array}$ & $\begin{array}{l}\text { Czech } \\
\text { Republic }\end{array}$ & $1995-98$ & & $\sqrt{ }$ & & $\begin{array}{l}\text { Positive spillovers for } \\
\text { domestic firms with } \\
\text { high R\&D intensity }\end{array}$ & $\begin{array}{l}\text { Linear } \\
\text { specification } \\
\text { between } \mathrm{AC} \\
\text { and foreign } \\
\text { presence }\end{array}$ \\
\hline $\begin{array}{l}\text { Girma } \\
(2003)\end{array}$ & UK & $1989-99$ & & $\sqrt{ }$ & $\sqrt{ }$ & $\begin{array}{l}\text { Inverted U-shaped } \\
\text { relationship between } \\
\text { AC and foreign } \\
\text { presence. } \\
\text { Asset-cxploiting FDI } \\
\text { are more conducive to } \\
\text { positive spillovers than } \\
\text { asset-augmenting } \\
\text { activities }\end{array}$ & $\begin{array}{l}\text { Poor proxics } \\
\text { for } \mathrm{AC} \text { and } \\
\text { foreign } \\
\text { affiliates' } \\
\text { technological } \\
\text { activities }\end{array}$ \\
\hline $\begin{array}{l}\text { Castellani } \\
\text { and Zanfei } \\
(2003)\end{array}$ & $\begin{array}{l}\text { Italy, } \\
\text { Spain, } \\
\text { France }\end{array}$ & $1992-97$ & $\sqrt{ }$ & $\sqrt{ }$ & & $\begin{array}{l}\text { Positive spillovers to } \\
\text { firms with high } \\
\text { technology gaps. } \\
\text { AC does not have any } \\
\text { statistically significant } \\
\text { impact }\end{array}$ & $\begin{array}{l}\text { Poor proxy for } \\
\text { AC and linear } \\
\text { specification } \\
\text { between } A C \\
\text { and foreign } \\
\text { presence }\end{array}$ \\
\hline $\begin{array}{l}\text { Chung } \\
(2001)\end{array}$ & US & $1987-91$ & & & $\sqrt{ }$ & $\begin{array}{l}\text { Positive spillovers } \\
\text { associated with asset- } \\
\text { exploiting FDI } \\
\text { activities }\end{array}$ & $\begin{array}{l}\text { Subsidiaries' } \\
\text { technological } \\
\text { activities not } \\
\text { directly } \\
\text { measured }\end{array}$ \\
\hline $\begin{array}{l}\text { Marin and } \\
\text { Bell } \\
(2003)\end{array}$ & Argentina & $1992-96$ & & $\sqrt{ }$ & $\sqrt{ }$ & $\begin{array}{l}\text { Positive spillovers in } \\
\text { sectors characterised by } \\
\text { technological active } \\
\text { foreign firms. } \\
\text { AC does not have any } \\
\text { statistically significant } \\
\text { impact }\end{array}$ & $\begin{array}{l}\text { The impact of } \\
\text { AC and } \\
\text { technological } \\
\text { behaviour is } \\
\text { separately } \\
\text { analysed. } \\
\text { Exogenous } \\
\text { sample splitting } \\
\text { technique }\end{array}$ \\
\hline
\end{tabular}




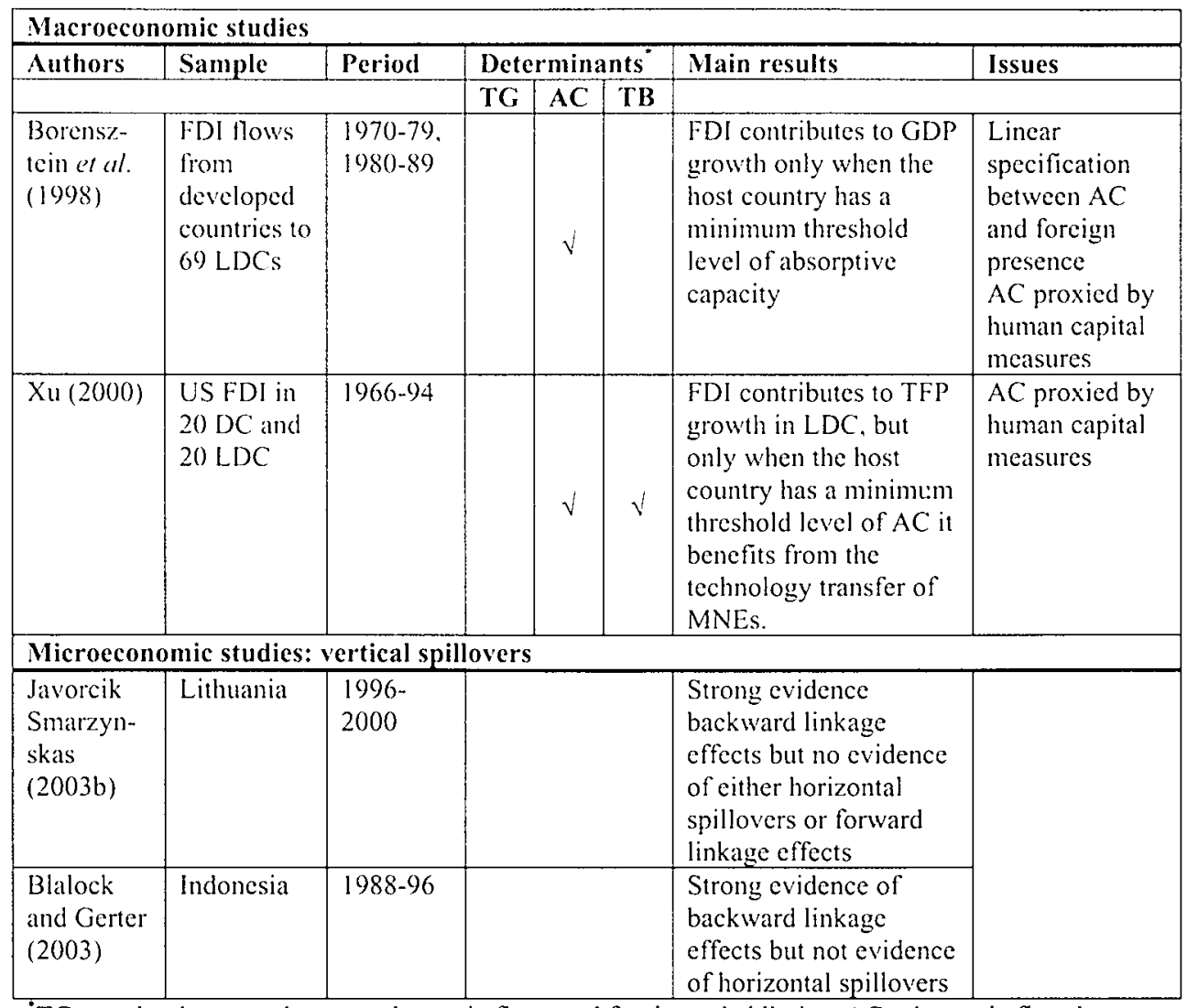

' $\mathrm{TG}=$ technology gap between domestic firms and foreign subsidiaries; $\mathrm{AC}=$ domestic firms" absorptive capacity; $\mathrm{TB}=$ technological behaviour of foreign subsidiaries; $\mathrm{LDC}=$ least developed countrics.

\subsection{R\&D INTERNATIONALISATION}

\subsubsection{Home-based augmenting and home-based exploiting activities}

Although the global generation of technology by European MNEs dates back to the interwar period (Cantwell 1995), little research on the topic had been carried out before the 1980s. The lack of interest in the location of R\&D activity by MNEs has to be attributed to the widespread belief that MNEs were concentrating innovation activity in their home countries. Empirical evidence to support this assumption was provided using data on US MNES. American companies were performing most of their R\&D at home where high demand and advanced technological resources and capabilities provided a constant stimulus to their innovation activities. European firms on the other hand, and especially from small countries, have historically shown a greater tendency to conduct both production and innovation 
activities abroad because of the lack of suitable supply and demand conditions in their domestic markets.

Early studies of the process of internationalisation of R\&D used as an analytical framework Vernon's (1966, 1977) product-cycle model. The original product-cycle model (1966) is based on the assumption that innovation is a demand-led process: it arises from a market stimulus. But according to this hypothesis, firms tend to be stimulated by the needs of the nearest market, the home market. The home market plays a dual role in this model: it is considered the source of innovations and at the same time it is the preferred location for R\&D activities. Innovating firms will therefore concentrate their R\&D efforts at home where they can benefit from both the availability of scientists and engineers with the required skills, and proximity to and, interaction with, potential customers. Economies of scale in R\&D activity and agglomeration effects, as well as the need for the coordination and control of expensive and risky investments are also reasons for keeping $R \& D$ and the initial stages of production in a common location (Vernon 1977). Therefore in this model internationalisation of production is limited to mature and standardised products and minor adaptive and development work would be the only R\&D to accompany foreign production.

Nevertheless, this model, with its demand-led interpretation of the innovation process and the important role it gives to proximity to local costumers, has contributed significantly to our understanding of why overseas $R \& D$ is undertaken. As firms increasingly locate production closer to their customers and suppliers they need R\&D laboratories to adapt the technologies and products developed at home to local conditions. The creation of such technical support laboratories', in Hood and Young's (1982) terms, is then supposed to accompany the later stages of the production process abroad. Indeed they seem to follow a linear progression based on the age, growth and relative size of the international production of the MNE (Lall 1979). In this type of R\&D facility technological knowledge tends to flow from the parent firm's laboratory to the foreign-based facility so that the technological advantage of the affiliate primarily reflects that of the home country (where the core innovation activities continuc to be concentrated) and foreign R\&D units tend to enhance the existing parentcompany technologies. This type of R\&D site has been termed 'home-base exploiting' (HBE) (Kuemmerle 1996) or 'asset-exploiting' (Dunning and Narula 1995).

However, as argued by Dunning and Narula (1995), the level and type of R\&D activity carried out in these types of laboratories is not only a function of the amount of foreign 
production undertaken, but is also dependent on the kinds of value-adding activities that the foreign affiliate is performing. Trade-supporting activities or minor assembly-type operations do not need to be responsive to demand-side considerations, while subsidiaries carrying out more technology-intensive, value-adding activities are more likely to set up R\&D facilities. In general, the more embedded the foreign subsidiary, and the greater the intensity of the valueadding activity, the greater the amount of R\&D activity. This leads to a duplication of its home-base activities, since the host location is acting as a substitute for activities it may have wished, ceteris paribus, to have undertaken at home (Zander 1999), but now finds that it can undertake more efficiently elsewhere. On the other hand, evidence clearly suggests that this is moderated by industry level effects (c.g. Lall 1979, Patel 1997). This type of foreign R\&D operation has usually supported the expansion of international production, not in high-tech product groups, but rather in sectors where adapting the product to serve the local market is important. .

From the mid-eightics to the early 1990s a number of studies reported an increasing trend in foreign R\&D activities. As already acknowledged by Vernon in a later contribution (1979), the product cycle became inappropriate for explaining the increase in R\&D investment abroad by US MNEs and needed to be modified to take account of the emergence of other markets outside the US with similar size and cost configuration. Cantwell (1995) further argued that the theoretical framework of the product cycle model cannot account for the importance of supply factors that appear to be driving some of the R\&D investment abroad. The new evidence gathered during this period showed in fact that MNEs were establishing foreign R\&D facilities in an attempt to tap into knowledge and technology sources in centres of scientific excellence. This strategy is based not only on the wish to reduce R\&D expenditure and to avoid duplication of R\&D activitics, but also to absorb technological spillovers, either from the local knowledge base (be they agglomeration effects or from public infrastructure), or from specific firms. These R\&D activities have been defined as 'home-base augmenting' (HBA) (Kuemmerle, 1996) or 'asset-secking' R\&D activity (Dunning and Narula, 1995). In such investments, firms aim either to improve their existing assets, or to acquire (and internalise) or create completely new technological assets by locating R\&D facilities abroad. Knowledge flows tend therefore to proceed firom the foreign laboratory to the central home laboratory. The assumption in such cases is that this provides access to location-specific advantages that are not as easily available in the home base and that may be associated with the presence of a lead market (Meyer-Krahmer and Reger 1999). Location decisions for this 
type of R\&D facility are based not only on the technological infrastructure of the host country, but also on the presence of other firms and institutions, which may create externalities that investing firms could absorb. As stated by Lall (1979):

'there may be certain benefits of 'agglomerations' in placing $R \& D$ in areas with advanced technology in relevant activity. Such benefits may result from spillovers of information from other R\&D units, access to trained personnel. established links with universities or government institutions, and the existence of an appropriate infrastructure for specific kinds of research' ( $p$. $321)$.

The HBA/HBE taxonomy implicitly attributes to the home country of the multinational a prominent role in shaping the firm's technological upgrading (Narula and Zanfei 2004). The home base model put forward by Porter $(1986,1990)$ and Sölvell, Zander and Porter (1991) $)^{15}$ assumes that the core and strategic manufacturing and R\&D functions are concentrated in the home country ${ }^{16}$ where the multinational firm benefits from strong linkages with suppliers, customers and research institutions. The home-base model does not exclude the possibility of 'tapping selectively' into foreign centres of excellence through home-base augmenting R\&D laboratories, but this activity is perceived as being marginal. According to this model the primary source of a company's international competitive advantage lies in the home country and foreign sources of advantage can supplement national sources but not substitute for them. The argument here is that MNEs are more embedded in their home countries than in other host countries, as I will discuss further in the next chapter.

Thus, to summarise, HBE activities are primarily associated with demand-based activities, with the internalisation of technological spillovers as a sccondary issue and involving knowledge transfers from the parent company to the foreign subsidiary. HBA activities, on the other hand, are primarily undertaken with the intention to acquire and internalise technological spillovers that are host location-specific and should give rise to a knowledge flow in the opposite direction, from the periphery to the centre.

\subsubsection{Recent empirical studies on $R \& D$ internationalisation}

A number of recent studies have analysed the internationalisation of $R \& D$ activities by multinational companies using different methods and databases. The empirical analyses carried out to assess this phenomenon fall into three categories. The first group focuses on the

\footnotetext{
15 The product-cycle model attributes to the home country a key role in determining firm-specific advantages. However the source of these advantages derives mainly from the demand conditions and no specific reference is made to the supply factors that play a role in Porter's diamond model.

${ }^{16}$ Although the home base does not have to be equivalent to the home country, it tends to coincide with it.
} 
relative volume, scope and geographical pattern of foreign R\&D using patent and R\&D expenditure data by foreign affiliates. The second group of studies includes those based on surveys and case-studies whose main research question is to investigate the firms' motivations in carrying out R\&D activities abroad and the specific activities that are performed in foreign research. The third group is a more recent stream of work that has examined knowledge sources of foreign R\&D units using patent citation analysis.

Each method provides different insights into the process of internationalisation of R\&D, although they have some shortcomings. Survey-based studies are able to offer a rich and detailed picture of a small number of cases, but they are mainly qualitative in nature and they can only provide a description of sector or location at a particular point in time. Patent analyses, apart from offering a quantitative description of the phenomenon, are able to examine the internationalisation of R\&D over a long time-span covering a larger sample of firms and sectors. The main disadvantages of using patent statistics are that they are not a satisfactory measure of the innovative activities in biotechnology and software and they are not able to account for the accumulation of uncodified knowledge in foreign locations. Patent citation analyses use the citations recorded in patent documents as an indicator of knowledge spillovers. This method can provide more insights into the process of technology sourcing of foreign R\&D sites; however as will be extensively discussed in the following chapters, patent citation analysis has several disadvantages.

\subsubsection{Results from $R \& D$ and patent data studies}

The study by Dalton ef al. (1999) examines the magnitude, scope, sectoral distribution and country of origin of foreign R\&D investment in the US as well as the trend and destination of FDI in R\&D by US MNEs. R\&D expenditure by foreign affiliates in the United States tripled between 1987 and 1997 , reaching a value of $\$ 19.7$ billion, which corresponds to almost $15 \%$ of total company-funded R\&D investment. The main reason for this increase was the wave of mergers and acquisitions (M\&A) in the American pharmaceutical and biotechnology sectors, both of which have a significant R\&D budget. What emerges from this study is that the internationalisation of R\&D is a phenomenon that occurs primarily between a small number of highly industrialised countries (Germany, Japan, and the United Kingdom), and mainly affects technology intensive sectors. Foreign companies have concentrated their R\&D efforts in the US in three industries (pharmaceuticals \& biotechnology. industrial chemicals, and electronic equipment) and in certain areas (such as Silicon Valley and greater Los Angeles, Detroit, and Princeton). US MNEs' investment in foreign R\&D facilities has increased from 
$\$ 5.2$ billion in 1987 to $\$ 14.1$ billion in 1997 an amount equal to $11 \%$ of total R\&D performed in the US. Most R\&D expenditure is concentrated in five countries (Ciemany, United Kingdom. Canada. France and fapan) and in four industries (phamaceuticals, automotives. computers, and electronic components).

A similat pattern of R\&D internationalisation is shown by the patenting activities of 546 of the largest American, lapanese, and European MNEs reported in a study that 1 carricd out with Parj Patel (Criscuolo and Patel 2003) (sec Table 2.3). Between 1996 and 2000, 28\% of patents granted to $\mathrm{EU}^{17}$ MNEs originate from subsidiaries outside the EU, while the share of patenting activities of US and Japanese MNEs originating from forcign locations is 9 and $4 \%$ respectively. Although European companies show on average a higher tendency to relocate their R\&D activities abroad with respect to their Japanese and American counterparts, the degree to which European companies have internationalised their activities varies considerably across countries. MNEs from smail countries, such as Belgium, the Netherlands, Sweden and Switzerland, are the most internationalised in their R\&D operations, while MNEs from large European countries (the exception being the UK) are less so. This study shows also that the US has attracted most of the foreign technological activities of European and Japanese MNEs. As shown by the figures in Table 2.3, there has been a modest increase in the last 15 years in internationalisation of technological activities. Most of the growth has been in MNEs from small European countries. At the sectoral level, EU MNEs in pharmaceuticals, electrical \& electronics, IT related activities, instrumentations, and food, drink \& tobacco appear to undertake more than half of their technological operations outside their home countries. The magnitude of these trends may however have been affected by the use of patent data from the USPTO, which possibly underestimates the forcign patenting activities of US MNEs and overestimate the patenting activities of EU and Japanese MNEs in the US. As 1 show in Chapter 4 , the bias can be quite substantial. Despite the growing internationalisation of R\&D activities. especially by EU MNEs, the results obtained in this study suggest that the home-based technological activities of large firms continue to have a big influence on the activities of their home countries. There appears to be no systematic relationship between national technological performance and internationalisation of corporate $R \& D$, either positive or negative, in the 1990s, confirming the results of an earlier study by Patel and Pavitt (1991) for the period up to the mid-80s.

\footnotetext{
${ }^{17}$ Belgium. Demmark. Finland. France, Germany, Italy, Netherlands, Norway. Sweden. Switzerland, and the UK are included.
} 
Table 2.3 Internationalisation of $R \& D$ as shown by patent data

\begin{tabular}{|l|cc|c|c|c|}
\hline \multirow{2}{*}{ Nationality } & \multicolumn{3}{|c|}{$\begin{array}{c}\text { \% share of USPTO patents } \\
\text { 1996-2000 }\end{array}$} & \multicolumn{2}{c|}{$\begin{array}{c}\text { Change between 1985- } \\
\text { 90 and 1996-2000 } \\
\text { (percentage point) }\end{array}$} \\
\cline { 2 - 6 } & Home & Abroad & in the US & Abroad & in the US \\
\hline Japan & 95.7 & 4.3 & 3.4 & 2.3 & -0.7 \\
US & 90.5 & 9.5 & & 0.5 & \\
Europe & 72.7 & $27.3^{\circ}$ & 25.1 & 5.9 & 4.9 \\
\hline \hline Belgium & 40.3 & 59.7 & 23.9 & 6.0 & 18.1 \\
France & 60.2 & 39.8 & 19.8 & 8.7 & 5.5 \\
Germany & 73.0 & 27.0 & 18.0 & 10.2 & 6.7 \\
Netherlands & 46.7 & 53.3 & 21.6 & -3.0 & -4.0 \\
Sweden & 50.1 & 49.9 & 33.4 & 5.8 & 16.1 \\
Switzerland & 31.7 & 68.3 & 34.0 & 13.4 & 10.7 \\
UK & 37.4 & 62.6 & 49.8 & 8.6 & 5.1 \\
\hline
\end{tabular}

Abroad here means outside those EU countries listed in footnote 16.

Source: adapted from Criscuolo and Patel (2003).

USPTO patent data have also been used by Patel and Vega (1999) to assess the nature of foreign R\&D activities on the basis of home and host country relative technological advantage. They distinguish among four different types of R\&D FDI motives (HBA. HBE, host-country exploiting and market secking) and they postulate that each of these different strategies is associated with different host country and firm relative technological advantage combinations. In particular the HBA strategy corresponds to a situation in which both the MNE and the host location show a relatively strong advantage in a particular technological field. ${ }^{18}$ HBE investment is undertaken to exploit a technological advantage that the firm has in its home market in a host location which is weak in that particular technological domain. The host country's and firm's relative technological advantages are calculated using the RTA (revealed technological advantage) index. The firm's RTA is derived using only patents both granted to the MNE and originating in the home country of the MNE. Therefore the assumption adopted in this study is that the MNE's R\&D internationalisation strategies are driven not by the home country's relative technological strengths and weaknesses compared with the host location, but instead by the firms' relative technological advantage developed in the home country. This is an important point because it implicitly denies the assumption of the home-based model that states that the whole home country innovation system is the source

\footnotetext{
Is According to Patel and Vega s taxonomy. when a company is relatively weak in a technological field and the host country is relatively specialised. FDI is classified as technology seeking. This seems however to reflect more closely the definition of HBA. i.e. undertaking R\&D activitics abroad to tap into local pockets of knowledge, than the one proposed by the authors.
} 
of MNE competitive advantage. Using a sample of 220 firms with the highest volume of patenting outside the home country between 1990-96. Patel and Vega find that the HBE strategy is one of the most frequently implemented strategies especially by firms in electronics and metals, while firms in chemicals, pharmaceuticals, mining, food, and materials are relative more engaged in $\mathrm{HBA}$ activities. Le Bas and Sicra (2002) conduct a similar analysis on the basis of patents applied by 350 firms to the EPO during 1994-96 and find stronger for of the HBA strategy: in 22 out of 30 technological fields this strategy dominates (for example in chemistry, phamaceuticals, biotechnology, and oil refining). Results on the basis of the nationality of the investing firm are quite different from those obtained by Patel and Vega (1999), which could be attributable to the different patent database used.

The study by Cantwell and Janne (1999) addresses a similar research question focusing on the international research strategy of 72 European MNEs active in three major industries (chemicals \& pharmaccuticals, metal products \& mechanical engineering, and clectrical equipment \& computing) and analysing their USPTO patents originating from European locations for the 1969-95 period. The authors want to test what is the role of the national capabilities of both home and host countries in shaping the technological behaviour of foreign subsidiaries. They find that European MNEs from leading centres in an industry tend to adopt a more diversified spectrum of technological activities abroad so as to acquire complementary assets and to specialise in each market in accordance with host location patterns of technological development. In contrast foreign subsidiaries with headquarters in lower order centres appear to exploit their technological assets replicating their home country's technological specialisation.

\subsubsection{Results from qualitative studies}

Early works based on surveys include Håkanson (1992) and Pearce and Singh (1992). Hakanson examines the impact of different host country characteristics on the location decisions of foreign R\&D units. The location pattern of 20 chemical and engineering Swedish MNEs seems to show that 'demand-related' are more important than 'supply-related' factors and that 'political' factors (such as trade barriers, the possibility of participating in government sponsored research programs) also play a role in determining the geographical location of forcign R\&D operations. The results of the study by Pearce and Singh (1992) based on a comprehensive sample of MNEs operating in 30 industries seems to confirm that most overseas R\&D units carry out asset exploiting type of activities. 
However, more recent surveys find substantial support for the increasing importance of 'supply-side' factors as motives for international decentralisation of R\&D. Florida (1997) surveys a sample of 207 R\&D facilities in the US in four technology sectors (electronics, automotive, chemicals \& materials, and biotechnology) with regard to the relative importance of their technology-oriented activities (HBA) and market oriented-activities (HBE). The findings of this study suggest that both types of activities are important in the overall activities of the sampled laboratories. However technology-oriented activities are relatively more significant, especially in R\&D units operating in biotechnology and pharmaceuticals, while R\&D sites in ehemicals and automotives secm to concentrate on tasks related to the support of manufacturing activities and the adaptation of products to local market conditions. The results for electronics are more mixed: both supply and demand considerations are considered important. The innovating performanee of the laboratories in the sample confirms that these sites are not mere 'listening posts', but are dedicated to the creation of new scientific and technological knowledge. The survey indicates also that one of most often implemented strategies for gaining access to localised knowledge is the recruitment of highquality scientists.

Some of Florida's results are confirmed by a more recent survey by Kuemmerle (1999). This study analyses the activities of 238 foreign R\&D facilities from 32 American, Japanese and European pharmaceuticals and electronics companies in different host countries over time, and investigates the motives, location characteristics, and mode of entry for R\&D facilitics abroad. What emerges from this study is that technology sourcing has increasingly become a motivation for establishing foreign R\&D laboratories. Kuemmerle found that $38 \%$ of laboratories in the sample could be classified as HBA. The location of foreign R\&D sites seems to match the distribution of the knowledge sources they build upon. When the purpose of R\&D is to try to gain access to localised knowledge, firms will establish centres in proximity to universities or national laboratories. When instead it is to support manufacturing and marketing activities, R\&D sites will be located near a lead market or within a cluster of competitors. Although in principle acquisition of a foreign laboratory could be a shortcut to localised knowledge, Kucmmerle found that greenfield investment is the dominant form of entry in both the case of HBA and HBE sites.

\subsubsection{Studies based on patent citations analysis}

Almeida (1996) was the first to apply Jaffe et al.'s (1993) patent citation methodology to investigate the technology sourcing activities of foreign affiliates. This method allows the 
author not only to assess whether, or to what extent. foreign subsidiaries draw on local sourees of knowledge, but also to what degree they contribute to the local knowledge base. Almeida analyses the citations included in a sample of major patents granted by the USPTO to MNEs in the US semiconductor industry and finds that forcign subsidiaries build on localised sources of knowledge. The patents eited by foreign affiliates are more likely to have originated in the US or in the same US State where they operate. Almeida finds also that foreign affiliates contribute to the regional knowledge base: the patents granted to these foreign firms are cited by other patents originating in the same region more frequently than one would expect.

Frost (1998, 2001) builds upon and extends the work of Almeida investigating both the geographic sources of forcign subsidiaries' innovation activitics across a much broader sample of MNEs operating in the US and the determinants of local technology sourcing. Results show that both the characteristics of the subsidiary, such as the amount and type of innovation activity carried out, and the technological specialisation of the home and host country are important in determining the geographic sources of innovation. Less innovative affiliates are more likely to build on the knowledge base of the parent company, while more innovative subsidiaries, being more embedded in the local context, tend to draw upon local sources of knowledge. Frost finds that foreign affiliates that devote much of their R\&D efforts to adapting technologies developed in the home country, i.c. HBE sites, are less likely to use technical ideas originating in the host country. Similarly when foreign affiliates perform R\&D activities in technical fields in which the home country has a technological advantage and the host country presents a technological disadvantage, they seem more likely to cite the home country's patents. The opposite case arises when foreign subsidiaries are active in technological fields in which the host country has a greater technological advantage with respect to the home country. However Frost does not discuss the knowledge flows from multinational subsidiaries to domestic firms, evidence of which was reported in Almeida's study. In a recent study based on USPTO patents granted to 4400 MNEs from six countries (US, Japan, Germany, France, UK and Canada) between 1986-95, Singh (Singh 2004a) finds that foreign subsidiaries cite host-country patents more often than do host-country inventors, suggesting that foreign subsidiaries gain more in terms of local knowledge than they contribute. These results are however moderated by industry and host country effects. Although this study brings new evidence on the technological behaviour of foreign subsidiaries operating outside the US and on the existence of bi-directional flows between 
domestic and foreign firms, it does not examine the factors determining the different knowledge flows under analysis.

From the recent empirical studies reviewed in this section one can draw three main conclusions. First MNEs, especially from small European countries, have substantially increased their foreign R\&D activities in the last decade, but this phenomenon is concentrated in a small number of industriatised countries and mostly in the US. Second, MNEs in the biotechnology, pharmaceutical and electronic industries make R\&D investments abroad to acquire and develop new technology, and in so doing they learn from local sources of knowledge. Third, home country technological advantages and host country technological characteristics influence the type of R\&D activity performed abroad and also the extent that foreign subsidiaries engage in two-way knowledge flows with domestic firms.

So far the existing empirical literature has analysed the learning behaviour and the technological sourcing of foreign subsidiaries and little attention has been given to analysing the impact that such imnovation activities have on the home part of the multinational company and on other firms in the home country. The next chapter will deal with this issue laying down the theoretical argument and reviewing the existing empirical evidence while Chapter 7 will test for the presence of this backward effect on the home country technological base.

\subsection{Conclusions}

This chapter has presented a survey of the three bodies of literatures - both theoretical and empirical - that contribute most directly to the research questions addressed in this thesis. Key aspects of the literature on localised knowledge spillovers have been critically reviewed, focusing on the empirical methods used to test for the geographical dimension of R\&D spillovers. From this set of contributions labour mobility emerges as one of the most important factors facilitating intra-firm knowledge diffusion. The R\&D spillovers transmitted through this channel are local in nature, since inter-firm worker mobility tends to be geographically confined, but at the same time has a social dimension, since knowledge is transferred through pre-existing social ties among mobile workers. Social proximity appears to persist not only over time but also across space. which explains why labour mobility can be a vehicle for international technology transfer. Most empirical studies on this issue have however focused on external patterns of knowledge transfers and little is known regarding to what extent labour mobility, and in particular researchers' mobility, facilitate internal knowledge transfers between distant units within the same organisation. An investigation of 
this phenomenon is needed in the light of the emergence of geographically dispersed $R \& D$ organisations that rely on the integration and diffusion of knowledge acquired and generated by specialised units.

In reviewing the literature on FDI-related spillovers I have tried to focus on those empirical and theoretical contributions that have explored the determinants of R\&D spillovers from foreign subsidiaries. Although there is still some divergence of views on the direction of causality between certain variables and on the incidence of spillovers, these studies generally concur in recognising that the technology gap between domestic firms and foreign affiliates, the host-country firm's absorptive capacity, the foreign subsidiaries' technological behaviour, and their degree of local embeddedness all play a role in determining the potential for learning. Because these multiple factors are strongly interconnected and that the relationship between certain factors and the spillover potential may be non-linear makes it difficult empirically to identify the effect of each one. I draw upon the evidence gathered by these studies in formulating a theoretical argument about the impact of foreign R\&D investment on home country firms. To develop this argument I aiso build on those empirical and theoretical contributions on R\&D internationalisation that have highlighted the different mandates that foreign R\&D units may have. 


\section{CHAPTER 3}

\section{THE HOME COUNTRY EFFECTS OF OUTWARD FDI: REVERSE TECHNOLOGY TRANSFER}

\subsection{INTRODUCTION}

Building on the bodies of literature on localised knowledge spillovers, inward FDI-related spillovers and R\&D internationalisation reviewed in the previous chapter, in this chapter I analyse the potential technological impact of outward FDI on the home country. This aspect of the R\&D internationalisation process until recently has been disregarded by both the FDI literature and the international business literature. On the one hand the studies on R\&D internationalisation consider the home country as a source of firms' technological advantage and, as such, the home country technology base plays a role in explaining the relocation of R\&D activities abroad. On the other hand the literature on outward FDI focuses mainly on the impact of overseas productive activities on the home country balance of payments and labour market. Earlier studies on the home country effect of FDI tried to provide an answer to the political debate that emerged during the 1960s, especially in the US, over the harmful consequences of outward FDI on exports and domestic employment (Lipscy 2002). ${ }^{19}$ The effects of outward FDI on trade and the balance of payments have also been the subject of several empirical studies, partly because they are indirectly connected to employment issues. Several contributions have tried to assess whether production abroad substitutes or complements exports by parent companies or other domestic firms. The effect of outward FDI on home country productivity and the home country knowledge base has so far received less attention. It is symptomatic that, in a recent survey, Lipsey (2002) does not mention a single study investigating either of these issues. As acknowledged by Blomström and Kokko (1998) the existing literature on the home country effects of FDI has seldom referred explicitly to spillovers' (p. 22, emphasis added).

However there are two sets of contributions that have analysed the private effects of outward FDI, that is, the effect that these investment activities have on the home part of the

\footnotetext{
14 The relocation of productive activities abroad may lead to a reduction in demand for domestic labour that could result in lower wages or higher unemployment. particularly for low-skilled workers, if overseas production is concentrated in low wage countries.
} 
multinational. The first group of studies, which belong to the FDI literature, examined both the impact of foreign R\&D activities and of outward FDI in general on MNE productivity (Barbal Navaretti and Castellani 2003, Barba Navaretti el al. 2002. Fors 1997. Mansficld and Romeo 1984. Reddawaly et al. 1968) and on MNEs" knowledge bases (Branstetter 2000). The second group of studies within the international business literature focused on measuring and qualifying reverse knowledge flows that are not related to R\&D activities in particular but rather to the activities of foreign affiliates in general (Frost 1998. Hakanson and Nobel 2000), Hakanson and Nobel 2001. Zhou and Frost 2003). These contributions analysed what Mansfield (1984) defines as 'reverse' technology transfer, i.e. the transfer of technology from foreign subsidiaries to the parent company. The emphasis here is on the multinational company and not on other home country firms and institutions; in other words, they investigated intra-firm reverse lechologl transfer. But, as pointed out by Globerman (1994). associated with these private effects of outward FDI there may also be some public effects, i.e. effects on the home country as a whole. if the benefits of these activities are not completely captured by the multinational firm. One of the obvious social benefits is improvement in the home country's technological performance and in intemational competitiveness more gencrally. Foreign activities of MNEs may provide access to foreign technologies and they can therefore represent a channel for transferring knowledge back to the home country. To explain the existence of this phenomenon which can be defined as inter-firm reverse tec/mology "ramsfer, one can think of channels similar to those considered in the inward FDI literature hrough which technology accumulated abroad can flow back to the home country. In formulating my argument on inter-firm reverse technologl transfer I therefore build on the literature on inward FDI-related spillovers, although moving the focus from the host country to the home country and from the foreign-located productive activities to research activities.

This chapter is organised as follows: section 3.2 reviews several distinct lines of investigation. both theoretical and empirical, on the intra-firm reverse technology transfer process. Section 3.3 examines the public effects of outward FDI and discusses the conditions under which foreign located R\&D activities are likely to benefit other firms in the multinational's home country. In this section I also review empirical studies that directly or indirectly have analysed this phenomenon. The final section summarises the existing contributions and presents the main rescarch questions of this thesis. 


\subsection{PRIVATE EFFECTS OF OUTW ARD FDI: INTRA-FIRN REVERSE TECHNOLOGY TRANSFER}

There are at least thee explanations proposed in the literature for the linkages between foreign investment and productivity gains. First, increases in productivity can derive from the reduction in production costs and the exploitation of host country comparative advantages that are nomally associated with vertical FDI (Helpman and Krugman 1985, Venables 1999). This type of investment involves the relocation of low value-added and labour-intensive stages of production to less developed countries, while the more skill-intensive activities are maintained in the home country. Second, productivity gains can arise from the exploitation of cconomies of scales that derive from horizontal investment, i.e. when multinational companies decide to replicate home country production in the host country. Investment of this kind tends to be attracted by large markets in developed countries and is undertaken when firms have large fixed costs (Markusen 1995, Markusen and Venables 1999). Exploitation of economies of scale and scope in production may also lead to higher R\&D investment (Mansfield et al. 1982). This is modelled by Markusen, (1984) who assumes that R\&D assets, a fixed cost, can be used as a joint input to all the MNE's plants and that therefore it can be considered a source of multi-plant economy of scale. Mansfield et al. (1982) finds that forcign affiliates' sales and overseas investment contribute to generating higher returns from R\&D. In particular they estimate that if firms were not allowed to use new technologies in foreign units, R\&D expenditure would fall by between $12 \%$ and $15 \%$. If foreign rents could not be camed, R\&D spending would fall by an average of 16 to $26 \%$. Third, when the main motive of foreign investment is to access knowledge and technology from the host country, in other words when MNEs establish asset-augmenting R\&D units, there are potential efficiency gains from the exploitation of technologies acquired abroad. As the empirical evidence reviewed in the previous chapter shows, knowledge spillovers are localised, meaning that firms operating near the knowledge sources are the first to learn about new technologies and products and the first to assimilate all the relevant knowledge. Foreign subsidiaries with an asset-augmenting or technology-sourcing mandate may therefore work as a transmission channel of host country knowledge back to units in the home country. Mansfield (1984) defines this process as 'reverse' technology transfer (RTT), i.e. the transfer of technology from forcign subsidiaries to the parent company. ${ }^{20}$ An example of this technology-transfer process is provided by Mansfield and Romeo (1984) who report:

\footnotetext{
2) This phenomenon, also called learning by imesting (Castellani 2001), is very much related to the recent literature on kemming by exporting (Bernard and Jensen 1999. Castellani 2002. Clerides et al. 1998. Maccarvie
} 


\begin{abstract}
'One of the prominent cases of "reverse' technology transfer is Tagamet, the anti-ulcers drug developed by SmithKline Beckman Corporation ... The basic idea and early work that eventually culminated in Tagamet came from SmithKline's British laboratory. Moreover, since the scientists who produced the original idea were there, the firm felt that it was logical not only to do research. but also to have a substantial elinical development there. In 1976. Tagamet was marketed in the United Kingdom: in 1977 it was marketed in the United States, Germany, France and C'anada' (p. 125)."
\end{abstract}

Although the first systematic study of this technology transfer process is the work by Mansfield and Romeo (1984), an attempt to define intra-firm RTT and to estimate its impact can also be found in a much earlier study by Reddaway et al. (1968).22 This report, commissioned by the Confederation of British Industry, mainly focused on assessing the impact on the UK balance of payments and export performance of direct investment abroad. In the early 1960s outward FDI became a source of increasing public concern in the UK because this period was characterised by declining exports and at the same time by an expansion of British manufacturing abroad. However the authors also attempt to measure the gains in efficiency deriving from what they call 'knowledge sharing', i.c. a two-way exchange of knowledge between the subsidiaries and the parent company. In defining this process they state:
'One of the economies of scale is that when knowledge has been secured much greater use is made of it, if it can be applied to a much bigger output ... Formally this point applies to all kinds of knowledge, stretching from the results of deliberate research at the one extreme to the sort of know-how which is acquired as a result of carrying on the day-to-day activities of the company. As a general proposition, this know-how is perhaps less likely to be useful to other plants operating in other countries, and may be more difficult to transmit effectively: but on occasions it can be of exceptional value, because an overseas plant operating in a different environment may pick up the benefits of practices which are in common use there, but have not been introduced in the U.K. Many companies attach exceptional value to what they learn from their American subsidiaries for this reason, because the atmosphere is one of keen competition: moreover the United States is ahcad of us on the road to higher real wages, and so frequently uses practices which we should have adopted but have not yet got around to introducing. $A$ process of moving staff between different countries will sometimes go some way towards passing round the fruits of this experience, but it obviously involves considerable costs ... There are other possibilities besides overseas investment as a means whereby a company can secure the benefit of overseas experience (e.g. the purchase of know-how from foreign firms). But is clearly true that knowledge can flow more freely and effectively where there is a common ownership, and there is an obvious economy if the same bit of research can be made to serve two or twenty different plants' (p. 308).

\footnotetext{
2002. Shaver and Solomon 2003).

${ }^{21}$ SmithKline Beckman Corporation is an American company formed by the merger of SmithKline Corporation with another American company (Beckman Instruments Inc.) in 1982. This company must not be confused with SmithKline Beecham ple the Anglo-American Company formed in 1989.

2 I am grateful to Nick von Tunzelmann for this reference.
} 
The Reddaway report acknowledges that there is greater learning potential from subsidiaries located in entres of exeellenee in the US and that the scope for knowledge sharing is higher when the research carried out in foreign subsidiaries is not limited to host country applications.". Mansficld (1984) and Mansfield and Romeo (1984) go further in stating the conditions for the occurrence of this reverse technology transfer process and list three factors that determine this knowledge flow:

1) the foreign subsidiary's R\&D function

2) the foreign subsidiary's R\&D intensity

3) the share of R\&D expenditure dedicated to research rather than to development activities.

As discussed in the previous chapter, forcign R\&D units can have different mandates: they can mainly adapt products to the local market or they can aceess knowledge localised in the host country and generate new knowledge that can be deployed by the rest of the organisation. It is in this latter that the potential for intra-firm RTT will be higher, since the knowledge generated by the subsidiary is relevant to, and can be applied by, the rest of the organisation. Asset-augmenting R\&D facilities will also show a higher R\&D intensity and a higher share of R\&D expenditure devoted to research than asset-exploiting units.

\subsubsection{Estimating the effect on firm profitability and productivity}

The empirical studies that have tried to estimate the impact of intra-firm RTT on firms' profits and productivity have adopted three different approaches. The first, used in the Reddaway report and based on survey data, consists of estimating, on the basis of the 'best guess' of MNE managers, the cost and benefits deriving from the exchange of formal and informal 'know-how' with foreign subsidiaries and then comparing the net gains from these knowledge sharing activities with the profits deriving from a hypothetical situation in which that particular forcign unit had not been established. In the approach proposed by Mansfield and Romeo (1984) and later applied by Fors (1997), the effect of foreign R\&D activities on the MNE productivity is calculated. This is done by estimating a Cobb-Douglas production function that includes both domestic and foreign R\&D expenditures. The third method is very similar in principle to the one adopted in the Reddaway Report. It consists of comparing the

\footnotetext{
2 Another significant comment in the Reddaway report is the fact that MNEs can be a more efficient vehicle than market-mediated transactions for transferring knowledge across borders, an issue that is being developed further in the knowledge management literature and that has been recently tested by $A$ meida ef al. (2002).
} 
productivity growth of firms that have engaged in foreign investment activities with the productivity growth of a sample of firms that have not invested abroad. While in the approach adopted in the Reddaway Report the counterfactual is a situation in which the internal source of knowledge flows was no longer available, in this approach the counterfactual analysis is based on a sample of domestic firms that have undertaken no foreign investment activities. In this section 1 review the results of these empirical studies, whose findings are summarised in Table 3.1. starting with the Reddaway report.

In estimating the impact of 'knowledge sharing' on UK MNEs' profits Reddaway and his coauthors asked the managers of 68 companies ${ }^{2+4}$ to provide estimates of the financial contribution from 'knowledge sharing' resulting from the exclusion of a particular foreign subsidiary as a source of knowledge. However, as acknowledged by the authors (see appendix $J$ of the final report), the estimates of the impact of outward FDI on the MNEs' profits may not be very accurate since they rely on predictions of accounting figures that are not normally reported in companies' financial statements. Therefore, rather than detailing the actual figures, I will summarise some of the evidence gathered in the study at country and sectoral levels. The authors found that companies in the chemical and food, drink \& tobaceo sectors benefit the most from the knowledge produced in their foreign subsidiaries. In the chemical sector these benefits derive from formal research activities carried out in foreign units, while for food, drink \& tobacco companies the greatest contribution comes from informal knowhow feedback. Across all sectors, US subsidiaries appear to be the source of most of these knowledge flows and companies seem to value very highly the informal 'know-how' from these subsidiaries.

While the Reddaway Report mainly tried to provide some empirical evidence in response to the political concerns on the effect of outward FDI on the UK balance of payments, the study by Manficld and Romeo (1984) attempted to address directly the impact of foreign R\&D expenditure on US MNEs. In particular the authors wanted to challenge the idea that the transfer of technology from the US parent company to foreign subsidiaries cntailed only an outflow of knowledge. During the 1970s in the US there was a quite lively political debate over the potential leakage of US technology to other countries through these overseas R\&D activities (see for example Caves 1974a). As a result Mansfield and Romeo carried out a

\footnotetext{
24 The companies in the sample operate in mining. food, drink \& tobacco, household products, chemicals. engineering $\&$ metals, vehicles \& components, textiles, paper, and building materials. Pharmaceutical companies were instead excluded from the analysis.
} 
survey of a random sample of 29 US MNEs in chemicals \& pharmaceuticals. petroleum, machinery, electrical equipment, instruments. and glass \& rubber industries in order to obtain data on the extent of technology transfer from R\&D facilitics located abroad (mainly in Europe and (anada). They found that about $47 \%$ of foreign R\&D expenditure in 1979 resulted in technologies that were transferred back to the US parent company. They also found quite a significant amount of heterogeneity in the percentage of R\&D investment with this characteristic, which can be explained by the different R\&D functions of each laboratory. The technology being transferred is in most cases embodied in new products and, based on a 'rougli estimate, the authors calculate that the overall contribution of this technological feedback during the 1970-79 period amounted to $4 \%$ of the total profits of US manufacturing firms in 1980. In addition the results show that the lag between when the transferred technology was first applied overseas and when it was subsequently applied in the US is on average less than one year. This reflects the importance of the US market in the marketing strategy of these firms and is confirmed by the fact that technologies with higher expected profits in the US are those that are transferred more quickly.

Finally Mansficld and Romeo attempted to quantify the contribution of foreign R\&D activities to worldwide MNE productivity growth by estimating a production function where total R\&D expenditure is disaggregated into domestic and foreign R\&D investment. The data used for estimating this model are taken from a smaller sample of 15 chemical and petroleum US MNEs between 1960-76. The ordinary least squared regression estimates show not only that foreign R\&D investment has a positive impact on the firms' TFP growth, but also that its contribution has a greater effect than the R\&D performed at home. Overall the evidence gathered in this study scems to support the reverse technology transfer hypothesis, although the estimates of the foreign R\&D contribution to firm's productivity growth may be affected by the small sample sizc.

These findings were not confirmed by Fors (1997) who, using a similar econometric framework, analyses the impact of overseas R\&D activities on the performance of 112 Swedish MNEs between 1965-90. However this study differs from Mansficld and Romeo's in two respects. First, it measures the contribution of foreign R\&D investment to output growth rather than TFP growth, and sccond, it assesses the impact of these activities on only the home part of the multinational rather than firm's overall productivity. The evidence reported in this study does not support the existence of a reverse technology transfer process, i.e. forcign R\&D expenditures do not have a significant impact on the home plant's output 
growth. However, Fors finds that there is a substantial flow of technology from the home part of the multinational to foreign subsidiaries: R\&D investment performed in the parent company increases foreign affiliates' productivity. These results are consistent with assetexploiting. but not with asset-augmenting activities. An explanation advanced by the author is that the positive feedback from the subsidiaries to the headquarters might be offset by a flow in the other direction. Also the author does not control for the technological development of the host country. Empirical evidence on R\&D internationalisation suggests that the relative degree of host country technological specialisation with respect to the home country is one of the determinants of the type of technological activities that foreign subsidiaries undertake. Furthermore the establishment of asset-augmenting units is a quite recent phenomenon, restricted to high-tech industries, and this may not be reflected in the data that Fors analysed. The survey carried out by Hakkanson (1992) on a sample of 20 Swedish chemical and enginecring MNEs shows that during the late 1980s foreign subsidiaries were mainly engaged in asset-exploiting activitics.

Unfortunately, because of the lack of reliable data on foreign affiliates' R\&D expenditure of MNEs from other home countries, there has been no systematic investigation of this process using the same empirical approach. However one way of overcoming this data limitation is to measure the feedback indirectly: instead of focusing only on foreign R\&D activities abroad, one could estimate the impact on firms' productivity of total overseas investment activity and then compare the productivity of these firms with that of domestic firms with no overseas subsidiaries. This approach would not discriminate among the different sources of productivity enhancement some of which may not be related to technology flows. In other words it would not identify the mechanisms by which foreign subsidiaries access host country knowledge. This approach follows very closely the methodology applied in the empirical literature on the effects of exports on firms' productivity (Bernard and Jensen 1999, Castellani 2002. Clerides et al. 1998, MacGarvic 2002, Shaver and Solomon 2003), which analyses the gains stemming from the acquisition of both knowledge and technology from supplying a foreign market. In applying this methodology two issues need to be addressed: how to select the sample of firms that have not invested abroad and how to control for the endogeneity problem. This is related to the fact that if a positive relationship is found between foreign investing activity growth and firm's productivity growth this could be because the most productive firms are also those that become multinationals and not the result of increased forcign activity. 
Two studies so far have adopted a similar approach to investigate intra-firm RTT using data from the Italian manufacturing sector (Barba Navaretti and Castellani 2003) and from the Spanish and French manufacturing sectors (Barba Navaretti et al. 2002). Barba Navaretti and Castellani (2003) construct an appropriate counterfactual sample of firms by matching each firm that established its first foreign subsidiary during the period under analysis with a similar firm that had not invested abroad during that period. The productivity performance, proxied by a number of different variables (TFP growth, turnover growth and employment growth). of these two groups of firms was then compared. The authors found that, after controlling for other variables that can affect firms' productivity, investing abroad increases TFP and turnover growth, but not employment growth. However these findings suffer from two shortcomings: first, they may be country specific and, sccond, host country characteristics are not taken into consideration.

The study by Barba Navaretti et al. (2002) tries to overcome some of these limitations by using a sample of firms from different countries (France. Spain and Italy) and distinguishing. for the Italian sample, between investments in developed and developing host countries. The cconometric approach used in this study consists of extracting a random sample of firms with no foreign investments to match those active abroad and then regressing TFP growth on a dummy variable capturing the firm's international profile. The results show that outward FDI from Italy to developing countries have a positive and significant impact on productivity growth, while outward flows to developed countries have no significant effect. This result may be explained by the fact that, as discussed in the previous section, increases in productivity may derive from reductions in costs arising from vertical outward FDI, which tend to be directed to developing countries. This is confirmed by the sectoral analysis that shows a positive effect of outward FDI only on sectors characterised by economies of scale and not on high-tech sectors. These findings highlight the fact that this approach does not measure technology feedback effects directly. The analysis for the other countries reveals that the impact of foreign investment in developed countries on TFP growth is positive for France, but negative for Spain. The sectoral analysis for France reveals that this impact is stronger in high-tech sectors while in Spain there is a positive effect only in traditional sectors. The sectoral specification sheds some light on the importance of considering the relative tcchnological position of the home country in analysing the learning potential of outward FDI. 
Table 3.1 Overview of empirical studies on the impact of intra-firm R'T on firms' productivity

\begin{tabular}{|c|c|c|c|c|}
\hline Authors & Sample & Period & Main Findings & Method \\
\hline $\begin{array}{l}\text { Reddaway e't } \\
\text { al. (1968) }\end{array}$ & $\begin{array}{l}68 \mathrm{UK} \\
\mathrm{MNES}\end{array}$ & 1964 & $\begin{array}{l}\text { Evidence of intra-firm } \\
\text { RTT especially from US } \\
\text { subsidiaries and for MNIEs } \\
\text { in chemicals and food. } \\
\text { drink \& tobaces }\end{array}$ & $\begin{array}{l}\text { Survey data and } \\
\text { comparison of profits from } \\
\text { RTT with profits lacking this } \\
\text { source of knowledge }\end{array}$ \\
\hline $\begin{array}{l}\text { Mansfield } \\
\text { and Romco } \\
\text { (1984) }\end{array}$ & $\begin{array}{l}29 \text { US } \\
\text { MNES } \\
\text { and } \\
15 \text { US } \\
\text { MNES }\end{array}$ & $\begin{array}{l}1965-70 \\
1960-76\end{array}$ & $\begin{array}{l}\text { Almost half of foreign } \\
\text { R\&D expenditure resulted } \\
\text { in technologies transferred } \\
\text { back to the home country. } \\
\text { Overseas } \\
\text { R\&D has an even greater } \\
\text { positive impact on MNE } \\
\text { THP growth than R\&D at } \\
\text { home }\end{array}$ & $\begin{array}{l}\text { Survey data } \\
\text { and } \\
\text { estimation of a production } \\
\text { function with forcign } R \& D \\
\text { expenditure }\end{array}$ \\
\hline liors (1997) & $\begin{array}{l}112 \\
\text { Siwedish } \\
\text { MNEs }\end{array}$ & $1965-90$ & $\begin{array}{l}\text { Overseas R\&D does not } \\
\text { affect home plants" output } \\
\text { growth }\end{array}$ & $\begin{array}{l}\text { Estimation of a production } \\
\text { function with foreign } R \& D \\
\text { expenditures }\end{array}$ \\
\hline $\begin{array}{l}\text { Barba } \\
\text { Nawalretti et } \\
\text { al. }(2002)\end{array}$ & $\begin{array}{l}\text { Sample of } \\
7.625 \\
\text { French. } \\
\text { Spanish and } \\
\text { Italian firms }\end{array}$ & $1993-97$ & $\begin{array}{l}\text { The benefits of outward } \\
\text { FDl appear in Italian firms } \\
\text { in sectors characterised by } \\
\text { economies of seale, in } \\
\text { French firms in high-tech } \\
\text { sectors, and in Spanish } \\
\text { firms in traditional sectors }\end{array}$ & $\begin{array}{l}\text { Comparison of "newly } \\
\text { fomed MNEs productivity } \\
\text { performance with the } \\
\text { productivity growth of a } \\
\text { sample of domestic fims. }\end{array}$ \\
\hline $\begin{array}{l}\text { Barba } \\
\text { Navareti and } \\
\text { Castellani } \\
(2003)\end{array}$ & $\begin{array}{l}212 \text { ltalian } \\
\text { firms }\end{array}$ & $1993-98$ & $\begin{array}{l}\text { Investing abroad increases } \\
\text { TFP and annover growth }\end{array}$ & \\
\hline
\end{tabular}

\subsubsection{Estimating the impact on the firm knowledge base}

A more direct way of testing for the presence of knowledge flows generated by foreign investment activities was proposed by Branstetter (2000) who builds on the work of Jaffe et al. (1993) and Almeida (1996). The approach adopted in this study consists of using as a proxy for knowledge flows the citations in a sample of USPTO patents granted to 187 Japanese MNEs to patents invented in the US and testing whether the citation count is correlated with the foreign investment activities of these firms in the US. While Branstetter can measure outward FDI only by establishment counts, the data allow him to distinguish foreign R\&D facilities from other types of subsidiaries, to identify acquired units, and to take account of the firm's worldwide R\&D spending. After controlling for the number of potentially citing patents, the citing firm's R\&D investment and sales, and the technological proximity of the citing firm to US inventions. Branstetter found that both total outward FDI and outward R\&D FDI are positively and significantly associated with spillovers from US inventors to Japanese MNEs. The coefficient estimates suggest that setting up an additional R\&D facility in the US leads to a $2.3 \%$ increase in citations to US invented patents. These 
results support the hypothesis of intra-firm RTT and also that there are knowledge flows associated not only with R\&D investment abroad, but also with overall outward investing activities.

\subsubsection{Knowledge transfer within the MNE}

The international business literature has only recently started to investigate the intra-firm RTT process, mostly because the attention of this body of literature has so far been concentrated on the more traditional knowledge flows from headquarters to subsidiaries. The analysis of intrafirm RTT falls within the broader issue of technology transfer inside the multinational organisation. It is often argued that transfer of knowledge within units belonging to the same organisation is easier to achieve than is the transfer of knowledge between organisations (Grant 1996, Kogut and Zander 1992) and that the main competitive advantage of multinationals lies in the possibility of transferring and integrating knowledge generated by subsidiaries located in different countries. However, several authors have pointed out that knowledge transfer even within organisations is far from being an automatic process. There are barriers connected to the characteristics of the knowledge to be transferred, to the position of the sender unit in the internal and external network, to the relationship between the sender and the receiver units, to the prior-knowledge of the receiver units and also to the motivational disposition of both the sender and the receiver (see Kogut and Zander, 1993, Szulanski, 1996, and Gupta and Govindarajan, 2000).

Although early MNE theories perceived knowledge as a public good (Buckley and Casson 1976), it is now well accepted that there are codified and tacit forms of knowledge and that, while codified knowledge is revealed by its communication, and therefore is easily transferred, tacit knowledge is revealed through its application, implying that its diffusion is slow, costly and uncertain. ${ }^{25}$ As shown by Teece (1976), there are high costs involved in the international transfer of tacit knowledge that amount to between $2 \%$ and $59 \%$ of the total costs of the project. These costs are often associated with the efforts of codifying the knowledge to be transferred and then teaching the receiver unit (Kogut and Zander 1993). However 'firms invest in ways to reduce the tacitness of technology by encoding its use and replications in rules and documentation' (Kogut and Zander 1993, p.367). Recent research by Almeida et al. (2002) shows in fact that MNEs can be a more efficient vehicle than other

\footnotetext{
"Cowan et al. $(2000)$ further distinguishes between coditiable tacit knowledge and uncodifiable. In the first case, the need for knowledge transfer can be attained at a very low cost. becatuse there already exists code that can be used for its transmission. In the second case the cost of transfer might be very high because a code has to be created.
} 
market mediated transactions for transferring knowledge across borders. Firms advantage over markets in the international transfer of knowledge relies on the existence of operational routines and of a common organisational culture, through shared values, languages and codes (Kogut and Zander 1992). Although there are great benefits from transferring knowledge suecessfully within the organisation, there are also some risks involved. Making knowledge easy to transfer internally is a double-edged sword because the characteristics that facilitate knowledge diffusion within the organisation are also likely to favour imitation by competitors (Kogut and Zander 1992).

In achieving internal knowledge diffusion MNEs are faced with a delicate trade-off between subsidiary autonomy and internal organisational cohesion (Blanc and Sierra 1999. Zanfei 2000). While the MNE must grant a certain degree of autonomy to foreign subsidiaries to allow them to become embedded in the local context and to be able to innovate by building on local knowledge sources, it must also ensure a certain degree of integration, cooperation and communication with the headquarters and the rest of the organisation so that the knowledge leveraged locally can be transferred and exploited by the rest of the company. As Frost (1998) suggests 'effective knowledge diffusion actually requires 'dual embeddedness' on the part of the subsidiary, i.c. embeddedness in both external and internal networks' (p. 326). This issue is particularly important when comparing the roles of acquired affiliates and greenfield subsidiaries in the reverse technology transfer process. While acquired affiliates will be relatively more embedded in the local community and therefore will have greater potential to assimilate local knowledge, they will be less integrated within the organisation's internal network, which will mean they will contribute less to the technology base of the MNE. In addition greater autonomy may introduce motivational barriers in the subsidiary to technology transfer within the organisation. As Cyert (1995) points out, there is the possibility that affiliates might be reluctant to transfer knowledge to other units of the MNE because they lose an 'information monopoly' within the company and their status as a 'centre of competence' in a specific area. Alongside the source units motivations is the motivational disposition of the receiver units, which might be exemplified by the 'not-invented-here' syndrome, i.e. the resistance of managers to accept idcas that have been invented elsewhere in the company (Katz and Allen 1982).

A further obstacle to internal knowledge diffusion is inter-unit technological distance. This problem is particularly relevant for those companies that have adopted a differentiated network of R\&D. whereby subsidiaries have a set of unique capabilities reflecting the host 
country"s technological specialisation. The flow of knowledge requires that sender and the receiver have a common set of prior knowledge. The increased level of technological specialisation and diversification in the R\&D organisational network may reduce the amount of shared knowledge hindering the process of knowledge transfer. In other words, technological specialisation may introduce inter-umit differences in 'absorptive capacity', i.c. in the ability to recognise the value of new information, assimilate it and apply it to commercial ends' (Cohen and Levinthal 1990 p. 128). As demonstrated by Szulanski (1996) and by Gupta and Govindarajan (2000), absorptive capacity in the receiving unit is a necessary condition for the successful transfer of knowledge.

Another barrier to internal knowledge transfer is geographical distance between different units. The empirical evidence on localised knowledge spillovers shows that geography plays an important role in affecting the volume and quality of communication. Early studies by Alien $(1970,1977)$ showed that physical proximity affects the likelihood of communication among R\&D staff within technical functions and between technical functions and other functions in a firm. De Meyer (1991) stated: One of the most important productivity problems in R\&D is stimulating communication among researchers ... it becomes more difficult when laboratories are located far from each other' (p. 49). Although these problems have been mitigated by developments in ICT, which have facilitated the management and coordination of international research networks, geographical distance is still a barricr to the transfer of knowledge especially if it is tacit in nature (Howells 1995). Distant R\&D units find it difficult to communicate because the exchange of their knowledge takes place mainly through personal contacts (De Meyer 1993). 
Table 3.2 Overview of the empirical contributions on the determinants of intra-firm R'I'I

\begin{tabular}{|c|c|c|c|c|c|c|c|c|}
\hline \multicolumn{9}{|c|}{ Survey studies } \\
\hline Authors & Sample & Period & \multicolumn{5}{|c|}{ Determinants } & Main Findings \\
\hline & & & $\mathrm{K}$ & Emb & $\begin{array}{l}\text { Entry } \\
\text { mode }\end{array}$ & TID & GD & \\
\hline $\begin{array}{l}\text { Hakanson } \\
\text { and Nobel } \\
(2000)\end{array}$ & $\begin{array}{l}17 \\
\text { Swedish } \\
\text { MNEs }\end{array}$ & & $\sqrt{ }$ & & & & & $\begin{array}{l}\text { Both knowledge } \\
\text { contestability and } \\
\text { observability hinder intra- } \\
\text { lirm RTT }\end{array}$ \\
\hline $\begin{array}{l}\text { Hakanson } \\
\text { and Nobel } \\
(2001)\end{array}$ & $\begin{array}{l}17 \\
\text { Swedish } \\
\text { MNIEs }\end{array}$ & & & $\sqrt{ }$ & & & & $\begin{array}{l}\text { External Emb. has a } \\
\text { negative impact on intra- } \\
\text { firm RTT while internal } \\
\text { Emb. and subsidiaries' } \\
\text { innovativeness has a } \\
\text { positive effect }\end{array}$ \\
\hline $\begin{array}{l}\text { Gupta and } \\
\text { Govindarajan } \\
(2000)\end{array}$ & $\begin{array}{l}75 \text { US, } \\
\text { EU and } \\
\text { Japanese } \\
\text { MNEs }\end{array}$ & 1991 & & & $\sqrt{ }$ & $\sqrt{ }$ & & $\begin{array}{l}\text { Entry mode does not } \\
\text { affect intra-firm RTT, but } \\
\text { subsidiary size and wider } \\
\text { technological gap have a } \\
\text { positive impact }\end{array}$ \\
\hline \multicolumn{9}{|c|}{ Patent citation analyses } \\
\hline Frost (1998) & $\begin{array}{l}\text { Forcign } \\
\text { affiliates } \\
\text { in the US }\end{array}$ & $1980-90$ & & $\sqrt{ }$ & $\sqrt{ }$ & & & $\begin{array}{l}\text { Intra-firm RTT is higher } \\
\text { the more embedded the } \\
\text { subsidiaries are in the } \\
\text { host country and the more } \\
\text { imovative they are. } \\
\text { Acquired subsidiaries are } \\
\text { less likely to transfer } \\
\text { knowledge back to the } \\
\text { parent company compare } \\
\text { to greenfield units }\end{array}$ \\
\hline $\begin{array}{l}\text { Zhou and } \\
\text { Frost (2003) }\end{array}$ & $\begin{array}{l}104 \\
\text { pharma. } \\
\text { and auto. } \\
\text { MNEs }\end{array}$ & $1975-95$ & & & $v^{\prime}$ & $\sqrt{ }$ & $\sqrt{ }$ & $\begin{array}{l}\text { TD is not significant. GD } \\
\text { is significant across } \\
\text { sectors and in the } \\
\text { automotive sector. Intra- } \\
\text { firm RTT is less likely if } \\
\text { the unit has been acquired } \\
\text { and is more likely if the } \\
\text { subsidiary and the } \\
\text { headquarters have been } \\
\text { cooperating in R\&D } \\
\text { projects }\end{array}$ \\
\hline
\end{tabular}

$\mathrm{K}=$ knowledge characteristics; Emb $=$ internal and external network embeddedness: Entry mode $=$ greenfield wacquisition: $T D=$ technological distance: $G D=$ geographical distance.

Finally, as Gupta and Govindarajan (2000) point out, the relative level of development of the sender unit country compared to the receiver unit country will also affect the internal diffusion process because it will determine the value of the knowledge being transferred. A subsidiary will perceive the knowledge from a unit that is located in a country more advanced than itself to be of more value than knowledge from a unit in a relatively less developed 
country. This argument is consistent with the 'catching-up' hypothesis discussed in the previous chapter, according to which the rate of technology transfer is detemined by the size of the technological gap between two countries.

\subsubsection{Estimating the impact of knowledge characteristies and a subsidiary's embeddedness in the internal and external network}

The empirical contributions within the international business litcature on intra-firm RTT mainly deal with issues related to the impact of knowledge characteristics and the trade-off between internal and external embeddedness, and ignore the role of absorptive capacity, since it is assumed that the headquarters will have the absorptive capacity to assimilate knowledge from foreign subsidiaries. The two approaches used for testing the impact of knowledge characteristics and a subsidiary's embeddedness are survey-based data and patent citation analysis (see Table 3.2 for a summary of the main findings). The advantage of using patent citation analysis is that it enables to a systematic and longitudinal study to be conducted: its disadvantage is that it may underestimate the real volume of knowledge flows between subsidiaries and headquarters. As already pointed out, patent citations capture only the exchange of eodified knowledge while. especially in the context of internal knowledge flows, many different mechanisms are used to diffuse knowledge, which are not recorded in patent documents.

The study by Hakanson and Nobel (2000) analyses the impact of three knowledge dimensions on the incidence of technology transfers from forcign subsidiaries: 'articulability', 'observability', and 'contestability'. In the taxonomy proposed by Winter (1987), articulability refers to the degree to which knowledge can be easily codified and therefore transferred. Observability relates to "the extent of disclosure of underlying knowledge that is necessitated by the use of knowledge' (Winter 1987, p. 172). In other words observability is the extent to which knowledge can be understood from observing the manufacturing plant and the employee at work for example (Zander 1991). Finally contestability refers to the fact that knowledge is very much embedded in the organisation (Nelson and Winter 1982) and in the social context in which it is created and developed. In this study it is hypothesized that the higher the level of knowledge context specificity and observability the lower is the probability that it will be transferred back to the headquarters. Hakanson and Nobel do not assume a priori a sign for the correlation between articulability and reverse technology transfer. The data for this study were gathered through a survey questionnaire sent to R\&D managers of foreign subsidiaries of 17 Swedish MNEs. The results show that foreign subsidiaries 
contribute extensively to the technological upgrading of the parent company. Almost half of the respondents indicaled that they had been engaged at least once in the previous five years in transferring locally developed know-how back to Sweden. This is in line with the results of Mansficld and Romeo (1984) for US MNEs, but in contrast to Fors's (1997) findings for Swedish MNEs. The empirical evidence confirms the predicted negative relationship between knowledge contestability and observability on the one hand, and the probability of a foreign R\&D unit transferring technology to the parent company on the other. However no significant impact was found for knowledge articulability. Therefore although certain knowledge characteristics may hinder imitation by competitors, they also make it difficult and costly to transfer knowledge within the organisation.

The trade-off between internal and external embeddedness has been analysed in a number of studies (Frost 1998, Gupta and Govindarajan 2000, Håkanson and Nobel 2001, Yamin 1999) using different empirical methods. Hakanson and Nobel (2001), on the basis of the data gathered for their 2000 study, cxamined the impact of both host country and corporate embeddedness. They found that host country embeddedness, proxied by an index measuring the frequency of contacts with local counterparts (universities, research institutes, customers, suppliers), had a negative impact on the occurrence of RTT. Although these results are based on a very small number of observations, they show that the higher the degree of a subsidiary's external embeddedness, the stronger is the context specificity of the knowledge resulting from these socially embedded relationships and the less relevant the knowledge is for the rest of the organisation. However host country embeddedness is positively correlated with subsidiary innovativeness. Corporate embeddedness. measured by the intensity of contacts with other R\&D units together with subsidiaries' innovativeness, positively affects the incidence of intra-firm RTT. In analysing the difference between greenfield and acquired subsidiaries Hakanson and Nobel find that the former are more integrated in the organisational network while acquired units are more strongly embedded in the local context.

Other factors determining the incidence of intra-firm RTT are examined by Gupta and Govindarajan (2000) using data from a survey on 374 subsidiaries of 75 MNEs with headquarters in US, EU and Japan. This study shows that knowledge outflows from subsidiaries to headquarters are positively related to the intensity of the communication links between affiliates and the parent company. In addition Gupta and Govindarajan find that formal and informal feedback of know-how to the parent company is positively correlated with the size of the affiliate and the technology gap between the host and the home country. 
However the mode of establishment (greenfield $v$ acquisition) does not secm to have any impact on intra-firm RTT. In this study the outflow of knowledge from foreign subsidiaries is examined alongside other internal knowledge flows, i.e. from headquarters to subsidiaries and from subsidiaries to subsidiaries. This allows them to quantify the relative volume of RTT with respect to the more traditional parent-subsidiary transfers. Not surprisingly knowledge flows from the centre to the periphery are significantly greater than either reverse or lateral (subsidiary-subsidiary) flows.

The importance of knowledge flows from centre to periphery compared to flows in the opposite direction is also recorded by Frost (1998) in his patent citation analysis on a sample of USPTO patents granted to foreign affiliates in the US. ${ }^{26}$ In this study the author uses the methodology proposed by Jaffe et al. (1993) to tests whether headquarters have a higher tendency than purely domestic firms ${ }^{27}$ to cite patents originating from a US state where the MNE has an innovative subsidiary. The results show that headquarters exploit knowledge developed in the geographical proximities of their affiliates more than other home-country firms, and that foreign affiliates act as a conduit for technological diffusion of localised knowledge. Frost also examines the factors affecting the extent of this process: the subsidiary's external embeddedness, ${ }^{28}$ the degree of integration with the rest of the organisation - proxied by the subsidiary's mode of establishment, the age of the subsidiary, and the subsidiary's innovativeness. He estimates a logit model where the dependent variable is one if the citation in the headquarters patent originates in the same US state as the subsidiary patent. This variable therefore does not measure directly the citations between parent company patents and subsidiaries' patents since the purpose of Frost's study was to test whether foreign subsidiaries are likely to increase the headquarters' knowledge of host country developed technology. This binary variable is regressed against some control variables and the variables capturing the determinants of intra-firm RTT. The estimates support the hypothesis that RTT is greater when the degree of host country embeddedness is

\footnotetext{
2t In a study based on patent citation analysis for a large sample of MNEs from six countries (Canada. France. Germany. Japan. US. UK) Singh (2004b) finds that during the period $1986-95$ for all countries knowledge flows in both directions - from foreign subsidiaries to their home base and viceversa - are of comparable magnitude. However at the country level, the author found some degree of heterogeneity: in Japanese and French MNIs the volume of flows from the home country to the foreign subsidiaries is higher than the flows in the opposite direction. while the reverse is true for US and Canadian MNEs.

$2-$ Donestic firms in this study are those firms that have never been granted a patent from a US location.

2* This variable is proxied by the subsidiary's technological sourcing behaviour. i.e. it is a dummy variable that takes value of one if the subsidiary patent cites host state patents more than would be expected given the geographical distribution of R\&D activities. Frost assumes that if a subsidiary is building on local technology sources then it is also locally embeddeded.
} 
higher and lower when the subsidiary is an acquired unit. confirming the hypothesis that to achieve intra-firm RTT both internal and extemal embeddedness is required and that acquired units are less tightly linked to the corporate network. The results also show that both age and technological intensity of the subsidiary have a positive impact on the realisation of these fecdback effects.

Zhou and Frost (2003) further develop the patent citation analysis framework proposed by Frost (1998) and apply it to the pharmaceutical and automotive sectors to explore in turn the importance of R\&D co-practice (i.e. technical activity undertaken jointly by more than one organisational unit such as cross-borders projects), entry mode, and inter-unit technological and geographic distance, in determining the incidence of reverse knowledge flows. Building on the concept of social capital (Nahapiet and Ghoshal 1998. Tsai and Ghoshal 1998) and on the social dimension of knowledge spillovers, discussed in the previous chapter. Zhou and Frost postulate that $R \& D$ co-practice facilitates the development of personal relationships between inventors as a result of their working together in close proximity and therefore increases the likelihood of inter-unit knowledge exchange via the inventors' social network of relationships. The variable used to capture $R \& D$ co-practice is the number of joint patents, i.e. patents applied for by inventors belonging to the home base and foreign units of the MNE, while intra-firm RTT is measured by a dichotomy variable that is equal to one if the headquarters' patent cites a subsidiary's patent. At a descriptive level the number of these types of citations appears to have increased substantially in both sectors over the period 197595, with an upsurge in the mid-1980s, especially in the pharmaceutical sector, confirming both the upward trend of these types of internal knowledge flows and their recent nature. To test for the determinants of intra-firm RTT the authors estimate a logit model where the explanatory variables are $R \& D$ co-practice, the geographical distance between the headquarters and the cited subsidiary, the subsidiary's entry mode and the technological distance between the citing and cited unit based on the quality (proxied by citations counts) of their patent portfolios. The estimates show that $R \& D$ co-practice has a positive and significant impact on the occurrence of intra-firm RTT, which confirms the importance of social ties in the diffusion of knowledge not only between firms, but also within units of the same organisation. Across sectors, geographical distance appears to reduce the incidence of reverse knowledge flows, but this holds true only in the automotive sector, which may be related to differences in the nature of the knowledge and the underlying technological innovation process in these sectors. Knowledge produced in the automotive sector is of a more applied 
nature and therefore it is also relatively more context-specific, which makes knowledge transfer diffieult to achieve between distant agents or units. Contrary to what one might expect. technological distance does not seem to affect intra-firm RTT, while the coefficient estimate of the entry mode variable confirms previous findings: across sectors, acquired subsidiaries are much less likely than greenfield subsidiaries to be cited by headquarters patents.

On the basis of both sets of contributions, within the FDI and the international business literature it emerges that intra-firm RTT is mainly a function of the type of technological activities carried out in foreign subsidiaries, the technological characteristics of the knowledge to be transferred, their degree of host country cmbeddedness and integration in the multinational organisation. Knowledge flows from foreign units to the parent company will be more likely if forcign affiliates are undertaking asset-augmenting type activities that generate knowledge valuable to the rest of the organisation which is less context specific. Foreign subsidiaries with this mandate tend to be relatively larger and more R\&D intensive than asset-exploiting units, which explains why affiliate size and R\&D intensity affect intrafirm RTT positively. Also asset-augmenting units are located in the most advanced regions and technological areas, which is in line with the result found in Gupta and Govindarajan (2000) concerning the positive impact of a wider technology gap on the incidence of reverse knowledge flows. To be able to absorb localised sources of knowledge, foreign subsidiaries need to be embedded in the host country innovation system, but at the same time they also need to be cmbedded in the organisational network, which explains why, according to most of the empirical studies, acquired units are less likely to contribute to the internal transfer of knowledge. Another consistent result across these studies is that, although the more traditional knowledge flows, from the centre to the periphery, continue to be dominant, intra-firm RTT is an increasing phenomenon, which is in line with the findings in the R\&D internationalisation literature showing an upsurge in asset-augmenting R\&D facilitics (see for example Kuemmerle 1999). Finally, although it does not clearly emerge from the empirical evidence these feedback effects are more likely to occur in those high-tech fields where assetaugmenting $R \& D$ activities are concentrated.

\subsection{PUBLIC EFFECTS OF OUTWARD FDI: INTER-FIRM RTT}

Having described the potential private benefits accruing to MNEs from their productive and innovative activities abroad, I now analyse their public effects. which from a social perspective and also from a macroeconomic perspective are the most relevant and desirable 
outputs from these investment activities. Externalities from outward FDI will occur when the MNE does not completely internalise all the gains derived from the investment, in other words when other home country firms benefit from these activities (Globerman 1994). These potential externalities are mainly associated with the three mechanisms that have been proposed in the literature through which outward FDI can increase firms' productivity. ${ }^{29}$ First, iertical outward FDI can lead to a positive productivity spillover if the structural shift to high value-added activities allows home country firms to move down their learning curve and become more competitive in high-tech industries (Blömstrom and Kokko 1998). Second, the expansion abroad of domestic MNEs may also improve the productivity of home-country MNEs' suppliers through cenomies of scale deriving from horizontal outward FDI, if MNEs do not force domestic suppliers to lower their prices. To the extent that these activities are characterised by cconomies of scale, the increase in foreign sales may also stimulate an increase in R\&D expenditure by the parent company providing in turn a source of potential spillover effects for other home country firms (Blömstrom and Kokko 1998, Globerman 1994). Thirdly and more directly, positive externalities may derive from inter-firm RTT, i.e. from R\&D activities performed abroad aimed at tapping into foreign centres of excellence and creating new technological assets that build on localised sources of knowledge. The physical presence in foreign markets facilitates faster and/or improved understanding of the new technologies being applied in those markets, since foreign affiliates have the opportunity to assimilate the tacit knowledge involved in the use of these imnovations (Globerman 1994). Indeed Caves (1974b) observes that:

'technology is transferred through channels other than the multinational corporation: the free international movement of non-proprietary knowledge: embodiment in internationally traded goods (especially capital goods): international transactions in consulting services; and the international licensing of technology. The multinational firm need not serve as an important conduit in every industry. or as a uniquely important conduit in any (p. 185).

Therefore the role of MNE affiliates in the transfer of knowledge from foreign markets back to the home country is going to be more important in those emerging technological fields characterised by tacit knowledge (a point emphasised by Veugelers and Cassiman 2004). Indeed tacit knowledge is one of the most important factors explaining the localised nature of

\footnotetext{
2) Blömstrom and Kokko (1998) identify a further potential source of spillovers from outward FDI: market access spillovers. These spillovers are likely to emerge from vertical outward FDI and will benetit home country exporters providing them with knowledge about the host country marke conditions and with access to host country marketing and distribution networks.
} 
R\&D spillovers and it determines to what extent foreign affiliates, being close to the sources of host country innovations, can act as a vehicle for technology transfer to other home country firms. It is important to stress that this type of reverse knowledge flow only originates in asset-secking R\&D facilitics.

There are various channels through which knowledge accumulated abroad may leak across the MNE's boundaries to other home country firms and institutions. The most obvious are those identified in the inward FDI-related spillovers literature, namely labour mobility, demonstration effects, and backward and forward linkages, but there are others such as strategic alliances, licensing, informal know-how sharing, and communications at conferences and fairs. For instance a MNE, as a result of its R\&D invesiment abroad, may promote the adoption of a new production process or a new technology in its home country suppliers. Spillovers may occur as a result of a scientist or a manager with prior work experience in a foreign affiliate moving to another home country firm. Similarly, home country firms may get to know about and most importantly learn how to apply foreign developed technologies through strategic alliances or other forms of co-operations with the MNE. As the evidence on localised knowledge spillovers and the empirical literature on inward FDI have shown, most of these spillover channels work best if the agents involved in the knowledge exchange are geographically and socially proximate, in other words if they are locally embedded. ${ }^{30}$ Mutual trust, long standing relationships and constant interaction are extremely important for the process of knowledge diffusion inside a local network. As acknowledged by Saxenian (1994), knowledge diffuses over physical distances primarily through formal connections to wellsituated partners. This is an important point that is developed in the next section.

Before describing in more detail the determinants of this transfer process it is worth pointing out some of negative externality effects deriving from relocating production and R\&D activities outside the home country. One consequence of vertical outward FDI could be a reduction in knowledge intensive activities if advanced production stages are located in countries with good supply of high-skilled labour or with a better knowledge infrastructure. the so called 'hollowing out' effect (ETAN 1998). Another potential adverse effect from the relocation of $R \& D$ activities abroad might be the successful imitation by foreign competitors of technologies and home country developed innovations. The studies of Almeida (1996) and

\footnotetext{
st The existing literature on the geographical localisation of spillovers - presented in the previous chapter - uses geographical proximity as the main variable explaining technology diffusion I would argue that when firms are the main channels for technology transfer the concept of embeddedness. which is not only spatially defined. is more appropriate.
} 
of Singh (2004b) confirm the existence of this phenomenon, but they also seem to point towards the dominance of knowledge flows from host country firms to foreign subsidiaries. As a result of these potential leakage effects arising from the presence of home country affiliates in foreign markets. MNEs may suffer a decrease in sales in both the foreign and home markets, which may also provoke a decrease in demand for the products of other home country firms. Furthermore the home country as a whole may lose control over a key technology and with its position in the intemational market. Most of the public policy concems about outward FDI and in particular outward R\&D FDI have focused on these two negative effects. distegarding the potential social benefits that may derive from these investment activities.

\subsubsection{Conditions for the occurrence of inter-firm RTT: local embeddedness of MNEs}

Some of the conditions necessary for inter-firm RTT to occur have already emerged from the discussion of the intra-firm process and also from the inward FDI-related spillovers literature. On the one hand since these knowledge flows are channelled through the parent company, it hals to be assumed that knowledge diffuses first within the multinational organisation. On the other hand the process under analysis, with certain qualifications, is the reverse of that examined in the inward FDI literature; therefore similar determinants will also condition the feedback effects from outward FDI. These conditions are:

- forcign R\&D activitics have to be asset-augmenting in nature

- existence of a technology gap between home country and host location

- absorptive capacity in the home-country firms

- high degree of MNEs' home-country embeddedness.

Of these, it is the MNE's cmbeddedness that requires further examination, because it is the most important factor in explaining how knowledge spills over to other home country firms and also because it has become the subject of a debate spanning different disciplines (economic geography, international political cconomy, and international business). As pointed out in the previous chapter, the level of spillovers is a function of the degree of embeddedness, i.e. the strength of trust-based relationships among different actors in the network, and both their occurrence and the development of embedded relationships are facilitated by local proximity. While the concept of local embeddedness can easily be applied to small and medium-sized firms operating in close proximity in industrial clusters, it 
becomes difficult to apply the same concept to multinational companies." To what extent are these companies with their cross-border operations embeded in a specific location and to what extent do the local ceonomic social. political, economic and cultural network influence their behaviour and strategies?

The debate alluded to above. addresses this issue. One side of this debate brings back to the forum a claim put forward in the 1960) by Kindleberger (1969): the international corporation has no country to which it owes more loyalty than any other, nor any country where it fecls completely at home ... The nation-state is just about through as an economic unit ... The world is too small. It is too casy to get about' (p.58).

Proponents of this assertion argue that because of their increasing cross-borders activities MNEs are becoming 'stateless" corporations (Ohmac 1990. Reich 1990) and that their nationality is becoming irrelevant to both the corporation and the state. The other side argues that multinational companies are still very much rooted in their home country, they do have a home base to which they are most closely tied and that they should be considered as "national companies with international operations" (Hu 1992). The home base model presented in the previous chapter (section 2.4.1) does indeed build on the idea that MNEs derive their competitive advantage from their home country because this is where they are more strongly embedded. As Sölvell and Zander (1995) note:

'In the home base, the global firm can be characterised as an insider. where it is linked to other firms in both formal and informal networks... These linkages with geographically and culturally close actors are seen as of a certain quality and intensity, differem from linkages that cut acress national borders. They provide the channels for rapid dissemination of information and knowledge, and provide a basis for cooperation leading to continuous stream of small and large improvements. For example. key facilitators of information flows would include personal relationship due to schooling and military service, mobility of employees between competing firms. norms of behaviour supporting continuity and long-term relationships. or quasi-familiar ties between firms' (p. 20, emphasis added).

Forcign sources of knowledge, acquired through asset-augmenting activities, can complement mational sources, but as is apparent from the above quotation. MNEs will find it very difficult to achicve the same degree of embeddedness in host countries as they have in their home countries. As MNEs internationalise their activities they become embedded in the host country's productive and innovative system, but it is a difficult process. Developing and maintaining strong linkages with external networks of local counterparts is expensive and

\footnotetext{
"Dickens (" al. (1994) argue that when the concept of local embeddedness is applied to MNEs. 'local' should be interpreted as referring to 'national' and not to a very small geographic area.
} 
time consuming. Such linkages are both formal and informal, and will probably take years - if not decades - to create and sustain. Frequently, the most significant issues are 'know-who'. Contacts with govermment funding institutions, suppliers, university professors, private research teams and informal networks of like-minded researchers take considerable effort to creatc, and once developed, have a low marginal cost of maintaining. Even where the host location is potentially superior to the home location - and where previous experience exists in terms of other value adding activities - the high costs of becoming familiar with, and embedded into a new location may be prohibitive. As emphasised by Sally (1994):

\begin{abstract}
'it is in the home base that MNEs are most deeply embedded, where they have their headquarters operations and cores of value-adding activity, and where upstream activities in research, development, design, and engineering tend to be concentrated. It is there that MNEs are most strongly linked in historically conditioned relationships with external actors such as local regional and national governments, banks, trade unions, industry associations, suppliers and customers. Once MNEs expand their production networks abroad, they put down roots in foreign markets and begin to build up a series of similar linkages with external actors in those host markets. But it is in the home maket that MNEs have their origin and history before crossing national boundaries' (emphasis added p. 172).
\end{abstract}

This argument is supported by the evidence gathered in a recent study by Castellani and Zanfei (2003a) using data from the Italian Community Innovation Survey, which shows that domestic multinationals have a higher propensity to cooperate with other domestic firms, suppliers and universities, than other foreign investors. The strong embeddedness of multinational companies in their home country is also reflected in the fact that their international operations and strategies are shaped by their home country's socio-cultural and institutional legacy is underlined by Pauly and Reich (1997, see also OTAN 1994). In these studies the authors find evidence of persistently divergent patterns among MNEs of different nationalities in the way that firms structure their long-term finance and corporate governance, in their pattern of R\&D investment, and in their trading strategies. These results are consistent with the national innovation system (NIS) approach (Lundvall 1992), which asserts that firms' innovative activities depend on a complex social system with their national specificities. The lack of convergence in sectoral patterns of technological and trade specialisation and stability over time (Guerrieri 1999, Pavitt and Patel 1994, Verspagen 1993) reinforces the assumption that there is a 'national character' (Morgan 2004) shaping the technological activities of countries and firms and that these institutional frameworks evolve very slowly. The home country's NIS also has a strong influence on the technological activities of MNEs, as shown by the lack of convergence in their innovation activities reported by Pavitt and Patel (1999). Despite the increasing internationalisation of R\&D 
activities, the overall technological performance of large firms (in terms of levels and in growth rates) is strongly correlated with that of their home countries (Criscuolo and Patel 2003). National differences are significant and the specificity of the home base continues to be erucial for the technological activities of MNEs (Narula 2002). This is also due to the fact that, although decreasing, most innovative activities of MNEs are concentrated in the home country. This 'inertia' in the intemationalisation of R\&D is determined in part by the fact that firms are strongly embedded in their home country system of innovation (Gertler et al. 2000 . Narula 2002). As shown by Narula (2002) in the case of Norway, interaction within a NIS is a self-reinforcing mechanism leading to technological lock-in especially in large domestic players in traditional and mature sectors. These firms are strongly embedded in the Norwegian system of innovation that has been shaped to accommodate their need creating a systemic interdependence between the different actors.

However an important point raised by Dickens et al. (1994) in relation to MNEs' local cmbeddedness is that one should take into consideration the type of MNE operations and the type of functions that are performed in a given location to be able to assess the MNE's degree of embeddedness. In particular they suggest that the "the degree of local embeddedness should be assessed by 'function' rather than at the overall 'corporate level' (p. 36), which implies that within the same company there may be functions which are more or less rooted in the local enviromment. This qualification is crucial for understanding the impact of the adoption of complex and geographically dispersed organisational structures on the external cmbeddedness of MNEs. As more strategic functions and responsibilities are given to foreign subsidiaries, their autonomy and their role inside the corporate network is enhanced alongside it their level of local embeddedness. Therefore, although foreign subsidiaries will find it difficult to become embedded in the host country, there is a stronger incentive than in the past to try and establish tight relationships with external actors.

\subsubsection{Empirical evidence}

There are only four studies that have analysed inter-firm RTT. With the exception of Globerman, Kokko and Sjöholm (2000), these studies use the empirical framework that was initially proposed to test for the existence of international $R \& D$ spillovers, i.e. $R \& D$ externalities originating from one country and benefiting other countries, through trade (Coc and Helpman 1995. Coe et al. 1997. Gittleman and Wolff 1995, Mohen 1995, see Verspagen 1994). This approach consists of estimating a production function that contains a measurc of foreign R\&D in addition to the usual input factors. The foreign R\&D variable is the weighted 
sum of the domestic R\&D capital stocks of the countries that are the source of the spillovers, where the weights are the measures of the transmission channels under analysis: trade or/and inward FDI or/and outward FDI.

Trade and. in particular. imports of intermediate goods which embody foreign produced technological knowledge, can improve the importing country's productivity. Productivity can also increase through trade if more varietics of intermediate and capital goods or completely new technologies are made available. In addition some productivity spillovers may occur as a result of interactions with foreign producers and customers. Inward FDI can also work as a vehicle for international technology transfer through the mechanisms listed in the previous chapter. Finally, outward FDI has been considered within this empirical literature as another potential channel for cross-border technology transfer. As already pointed out, outward FDI works as a channel for international R\&D spillovers if the main motive of these investment activities is to seek to acquire new technological assets from industrial clusters with leading technologies. Therefore while inward FDI carries R\&D spillovers from the home to the host country, the flow of knowledge associated with outward FDI is in the opposite direction.

The other approach for testing for inter-firm RTT proposed by Globerman. Kokko and Sjöholm (2000) consists of using patent citations to trace international knowledge flows. Building on a previous study by Sjöholm (1996) where patent citations are used for analysing the impact of trade-mediated international R\&D spillovers.

\subsubsection{Evidence using the international $R \& D$ spillovers framework}

Before reviewing the results of the studies that have analysed FDI as a carricr of international R\&D spillovers, I want to point to some of the inherent problems with respect to the methodology used in these contributions. The first is related to the weighting factors used for the construction of the foreign R\&D capital stock. In the literature generally two alternative weighting schemes are used that were initially proposed for measuring trade-related spillovers. Cohen and Helpman (1995) $(\mathrm{CH})$ uses as weights the contribution of each sender country's imports over the receiver country's total imports. This implies that a country will receive more R\&D spillovers if it imports more from countries with high R\&D capital stocks. ${ }^{32}$ In the formulation proposed by Lichtenberg and Van Pottelsberghe de la Potterie

$\because$ Coe and Helpman's (1995) formulation of the foreign R\&D capital stock is: $S_{u}=\sum_{i=n} \frac{M_{u}}{M_{u}} R_{n}$, where, $M_{n}$ is the flow of imports of goods and services of country $i$ from country $j, M_{n}=\sum_{n=1} M_{n}$ is the total imports of 
(1998) (LP), the weighting factor is equal to the share of the sender country's GDP that is exported to the receiver country. This assumes that a country will receive more R\&D spillovers if it imports more from a country with high R\&D intensity. ${ }^{33}$ Lichtenberg and Van Pottelsberghe de la Potterie (1998) point out that the weighting scheme used by $\mathrm{CH}$ for traderelated spillovers may introduce some aggregation bias', i.e. it is not invariant to the degree of disaggregation of the datit used. Another problem is connected to the non-stationarity of the time-series variables used in the TFP regression. If the variables are nonstationary, estimating the regression with the variables in levels may give rise to spurious regressions if the error term from the regression is not stationary or, in other words, if the variables are not cointegrated. Estimating the equation in first differences instead may be informative about the short-run but not the long-run relationships (see the discussion in Coe and Helpman, pp. 867870). While testing for non-stationarity in time series regressions is relatively simple, methods for addressing this problem in panel datasets have been made available only recently and were implemented in the study by Van Pottelsberghe de la Potterie and Lichtenberg (2001), but not in carlier analyses. In addition, as pointed out by Mohen (2001), this empirical framework may be affected by problems of collinearity between the different R\&D stock variables.

Finally Verspagen (1997) observes that the panel estimation method used in these studies, the so-called within or fixed-effect method, which consists of an OLS estimate using data from which the country mean over time has been subtracted, does not allow one to estimate coefficients of variables, which are constant over time but different across countries. These differences across countries are included in an intercept-dummy for each country. As a result the possible dynamic heterogeneity of knowledge spillovers across countries is left out of the analysis. However the literature on inward-FDI related spillovers, reviewed in the previous chapter, both from a theoretical and an empirical perspective, emphasises the importance of host country specific factors in determining the spillover potential and rcalisation from MNEs activities. Equally the efficiency of outward FDI as a carrier of technology across borders will depend on a number of home country characteristics. In particular the two most important factors are, first. the ability of each country to absorb foreign R\&D spillovers and. second, the technological gap between the sender and the receiver country, in other words the technological congruence or proximity between them (also argued by Verspagen 1997).

country $i$ from all the other trade patterns in the sample, and $R$, is the R\&D stock of country $j$.

${ }^{3}$ Lichtenberg and Van Pottelsberghe de la Potterie (1998) measure the foreign R\&D stock as: $S_{u}=\sum_{i n} \frac{M_{*}}{Y_{n}} R_{u}$. where $Y_{n}$ is the GDP of country $i$. 
Although most of these studies were carried out using data from developed countries and with data aggregated at the country level Nadiri and Kim point out (1996) that 'R\&D spillovers are likely to be country-specific even for the highly industrialised $G 7$ countries: A study by Luintel and Khan (20)3) proposes a different econometric method based on the estimation of a multivariate VAR which provides country-specific parameter estimates. Although the authors do not consider FDI channels in their analysis of international R\&D spillovers, their results show that there is a significant amount of heterogeneity across countries, which implies that the panel estimates conceal important cross-country differences. With these caveats in mind, I begin by reviewing the studies that have analysed the contribution of inward FDI followed by those that have considered the role of outward FDI in the international transfer of technology.

Using the $\mathrm{CH}$ weighting scheme, Hejazi and Safarian (1999) test for both import-related and inward FDI-related R\&D spillovers using a panel of six OECD countries. The authors find that inward FDI affects domestic productivity: the estimated coefficient on the FDI-weighted foreign R\&D stock is positive and significant and it is also higher than the trade-weighted foreign R\&D coefficient. In addition the introduction of inward FDI reduces the impact of trade. However these estimates should be interpreted with caution since Hejazi and Safarian obtain mixed results on cointegration and therefore their results for growth rates may reflect deviations from long-run relationships. Braconier and Sjöholm (1998) investigate at a more disaggregated level the effect of both inward FDI and trade using data on nine manufacturing industries in six large OECD countries. The results of this study, based on the LP weighting scheme, indicate that industries that have received a large share of FDI from R\&D intensive countries have witnessed relatively high productivity growth. Contrary to previous studies, no significant effects on productivity growth are found for R\&D embodied in imports of intermediate products. These estimates do not seem to be affected by the same problems as Hejazi and Safarian's (1999) since the non-stationarity of the error term of the regression is consistently rejected, i.c. the variables are cointegrated.

These positive findings on international spillovers transmitted through inward FDI contrast with the results obtained by other studies where all threc international R\&D transmission channels are analysed simultaneously. The study by Xu and Wang (2000) examines the role of trade, inward FDI and outward FDI as diffusion channels for a sample of industrialised countries using both the $\mathrm{CH}$ and LP weighting schemes, but not accounting completely for the non-stationarity of the variables. The estimates of the regressions based on the $\mathrm{CH}$ weights 
show that, after controlling for the technology gap and the human capital of the receiver country, R\&D spillovers through trade and outward FDI have a positive impact on TFP growth, while inward FDI-related spillovers do not affect domestic productivity performance. However, when using LP weighting factors, FDI channels do not appear to be significant for international technology diffusion. Although $X_{u}$ and Wang acknowledge the importance of taking into account both the technological distance between the sender and the receiver country, proxied by the receiver's TFP level relative to that of the US, and the absorptive capacity, their econometric estimates, based on the fixed-effect method, do not completely capture cross-country heterogeneity in these two variables.

These findings are in contrast with the results obtained by Van Pottelsberghe de la Potterie and Lichtenberg $(2001)^{34}$ for a longer time period and a panel of 13 OECD countries that do not completely overlap with the ones in Xu and Wang's sample. In this study the possible cointegration among the different variables was tested using econometric techniques proposed for panel data, and the weighting scheme applied was the one proposed by the authors in an earlier paper (Lichtenberg and Van Pottelsberghe de la Potterie 1996). Their estimates suggest that outward FDI and trade are two significant channels through which technology is diffused across countries, while inward FDI, contrary to Hejazi and Safarian's (1999) and Braconier and Sjöholm's (1998) findings, does not seem to have a positive impact on host country productivity growth. The estimated bilateral elasticity of output with respect to foreign R\&D indicates, for example, that a one per cent increase in the US R\&D capital stock raises Japanese output by $0.0272 \%$ through trade-related spillovers and by $0.0274 \%$ through outward-FDI related spillovers. According to these figures Japan and the UK are the countries that benefit most from the feedback effects from outward FDI, while technology sourced through outward FDI contributes only marginally to the productivity growth of the US, Portugal, ltaly and Denmark. In line with the findings of the R\&D internationalisation literature, these estimates also show that the US is an important generator of R\&D spillovers but a weak receiver, i.c. the amount of asset secking FDI into the US is greater than the outward FDI by US MNEs. For larger European countries, with the exception of the UK, the authors found the opposite to be the case: they benefit more from their outward foreign investment activities than the rest of the world benefits from its outward FDI directed towards them. Across countries, the contribution of outward FDI to home country productivity growth appears to have been stronger during the 1980 s, which is consistent with the increasing

\footnotetext{
"See also Lichtenberg and van Pottelsberghe de la Potteric (1996) for an earlier version of this paper.
} 
tendency for foreign R\&D activities to have a technology sourcing motive. Summarising these results Van Pottelsberghe de la Potterie and Lichtenberg state that inward FDI, on average, takes on the characteristics of a "Trojan horse'; they are intended more to take advantage of the technology base of the host countries than to diffuse the technological adrantage originating in the home country'.

Table 3.3 Econometric studies testing for FDI channels in the international technology transfer process

\begin{tabular}{|c|c|c|c|c|c|c|}
\hline \multicolumn{7}{|c|}{ International R\&D spillovers framework } \\
\hline \multirow[t]{2}{*}{ Authors } & \multirow[t]{2}{*}{ Sample } & \multicolumn{3}{|c|}{ Channels } & \multirow[t]{2}{*}{ Main Findings } & \multirow[t]{2}{*}{ Empirical issues } \\
\hline & & IFDI & OFDI & Trade & & \\
\hline $\begin{array}{l}\text { Hejazi and } \\
\text { Safarian } \\
(1999)\end{array}$ & $\begin{array}{l}\text { 6OECD } \\
\text { countries } \\
1971-90\end{array}$ & + & & + & $\begin{array}{l}\text { IFDI is more } \\
\text { important than } \\
\text { trade in transferring } \\
\text { technology across } \\
\text { borders }\end{array}$ & $\begin{array}{l}\text { CH weighting scheme. } \\
\text { potential problems arising } \\
\text { from mixed results on } \\
\text { cointegration tests. } \\
\text { Very high correlation } \\
\text { between trade weighted } \\
\text { and IFDI weighted } \\
\text { foreign R\&D stock }\end{array}$ \\
\hline $\begin{array}{l}\text { Braconicr } \\
\text { and Sjöholm } \\
(1998)\end{array}$ & $\begin{array}{l}9 \text { sectors } \\
6 \text { OEDC } \\
\text { countries } \\
1979-91\end{array}$ & + & & () & $\begin{array}{l}\text { Trade appears not } \\
\text { be a vehicle for } \\
\text { international R\&D } \\
\text { spillovers, while } \\
\text { IFDl does }\end{array}$ & $\begin{array}{l}\text { LP weighting scheme. } \\
\text { Variables are } \\
\text { cointegrated. } \\
\text { No correlation matrix }\end{array}$ \\
\hline $\begin{array}{l}X u \text { and } \\
\text { Wang }(2000)\end{array}$ & $\begin{array}{l}13 \\
\text { OECD } \\
\text { countries } \\
1983-90\end{array}$ & () & $(+)$ & + & $\begin{array}{l}\text { OFDI and trade are } \\
\text { spillover channels } \\
\text { only if } \mathrm{CH} \\
\text { weighting scheme } \\
\text { is used. If the LP } \\
\text { scheme is used } \\
\text { neither IFDI nor } \\
\text { OFDI are } \\
\text { significant }\end{array}$ & $\begin{array}{l}\text { LP and } \mathrm{CH} \text { weighting } \\
\text { scheme: potential } \\
\text { problems arising from } \\
\text { mixed results on } \\
\text { cointegration tests. } \\
\text { Very high correlation }\end{array}$ \\
\hline $\begin{array}{l}\text { Pottelsberghe } \\
\text { and } \\
\text { Lichtenberg } \\
(2001)\end{array}$ & $\begin{array}{l}13 \\
\text { OECD } \\
\text { countries } \\
1971-90\end{array}$ & 0 & + & + & $\begin{array}{l}\text { Foreign R\&D can } \\
\text { affect domestic } \\
\text { TFP growth } \\
\text { through trade and } \\
\text { OFDI, but not } \\
\text { through IFDI }\end{array}$ & $\begin{array}{l}\text { LP weighting scheme. } \\
\text { Variables are } \\
\text { cointegrated. } \\
\text { No correlation matrix }\end{array}$ \\
\hline $\begin{array}{l}\text { Braconicr et } \\
\text { al. }(2002)\end{array}$ & $\begin{array}{l}\text { Swedish } \\
\text { MNEs } \\
1978-94\end{array}$ & 0 & $(+)$ & & $\begin{array}{l}\text { Evidence of intra- } \\
\text { firm RTT. At the } \\
\text { industry level } \\
\text { neither IFDI nor } \\
\text { OFDI are } \\
\text { significant }\end{array}$ & $\begin{array}{l}\text { LP weighting scheme. } \\
\text { Very high correlation. } \\
\text { Data on foreign MNEs. } \\
\text { activities instead of } \\
\text { financial FDI flows or } \\
\text { stocks }\end{array}$ \\
\hline
\end{tabular}




\begin{tabular}{|c|c|c|c|c|c|c|}
\hline \multicolumn{7}{|c|}{ Patent citations analysis } \\
\hline Authors & Sample & \multicolumn{3}{|c|}{ Channels" } & Main Findings & Empirical issues \\
\hline & & IFDI & OFDI & Trade & & \\
\hline $\begin{array}{l}\text { (iloberman el } \\
\text { al. }(2000)\end{array}$ & $\begin{array}{l}220 \\
\text { Swedish } \\
\text { patents } \\
1986\end{array}$ & 0 & - & . & $\begin{array}{l}\text { Trade-related } \\
\text { spillovers more } \\
\text { important for } \\
\text { SMEs. } \\
\text { Both MNEs and } \\
\text { SMFs benefit from } \\
\text { OFDI: strong } \\
\text { correlation between } \\
\text { foreign citations } \\
\text { and OFDI. but not } \\
\text { IFDI }\end{array}$ & $\begin{array}{l}\text { Country-specific results: } \\
\text { no control for firm- } \\
\text { related or technological } \\
\text { or sectoral-related factors }\end{array}$ \\
\hline
\end{tabular}

"F' indicates a positive impact of foreign R\&D spillovers on productivity growth: ' 0 " indicates an insignificant impact, the parentheses indicate that the results are fragile, or unstable: IFDI = inward FDI: OFDI $=$ outward FDI.

Although the study by Van Pottelsberghe de la Potteric and Lichtenberg addresses some of the econometric issues outlined above, it suffers from two major shortcomings: first it does not account for cross-country differences in the ability to absorb R\&D spillovers and in technological proximity; second it does not identify the FDI motives. Feedback effects from outward FDI are associated with asset-augmenting activities, while, as pointed out by some of the empirical studies reviewed in Chapter 2. inward FDI-related spillovers are more likely to occur when foreign subsidiaries are undertaking asset-exploiting activities. The evidence gathered by the R\&D internationalisation literature shows that there are sector-specific factors that may affect the direction of the technology transferred through FDI and which cannot be taken into consideration at the country level of aggregation. One way to account for foreign subsidiaries' technological behaviour is to use different types of data. FDI data based on financial flows include transactions which do not give rise to real activities and do not include those foreign activities that do not involve net flows of capital: therefore they are a poor proxy of multinationals' foreign operations.

The firm and industry level study by Braconier et al. (2002) tries to overcome some of these shortcomings using data on Swedish foreign affiliates' activities between 1978 and 1994. Using the LP weighting scheme, the authors examine the role of inward and outward FDI as potential channels for international R\&D spillovers. The dataset allows the authors to distinguish between different kinds of activity undertaken by foreign affiliates and to build a different weighting scheme of forcign R\&D stocks using information on forcign subsidiaries' 
employment and R\&D activities. ${ }^{35}$ The econometric analysis at the firm-level consists of regressing the log of MNE's labour productivity as a whole, proxicd by valued added per employec, on the MNE's total R\&D spending, its capital intensity, the Swedish R\&D stock in the industry where the MNE is active. the unweighted foreign R\&D stock (which captures other sources of intemational R\&D spillovers), the foreign R\&D stock weighted by outward FDI and the same stocks weighted by inward FDI. Regardless of the estimation technique used, the authors fail to find any evidence of spillovers transmitted through inward FDI: Swedish MNEs' labour productivity is affected neither by inward FDI-related R\&D spillovers nor by the level of inward-FDI penetration in Sweden, measured by the level of employment in foreign owned-firms. The authors found instead some positive effect of outward FDIchannelied R\&D spillovers, but only when the weighting scheme used was based on foreign affiliates R\&D activities. This supports the idea that the type of activity carried out by foreign subsidiaries matters significantly for the incidence of spillovers. Similar results are obtained when instead of overall MNE labour productivity, only the home part of the MNE is considered. Estimates from the industry-level regression do not support the hypothesis that FDI (inward or outward) works as a transmission channel for international R\&D spillovers. As Braconicr et al. argue, the results of this study can not be generalised to other developed countries, due to the specificity of the Swedish manufacturing sector (a few highly internationalised large firms carrying out most of the private sector R\&D). Although not clearly stated by the authors, the firm-level analysis tests for intra-firm RTT while the industry-level regression examines inter-firm RTT.

In summary, the results of these studies presented in Table 3.3 generally converge towards the recognition that outward FDI works as a channel for international technology transfer. However the impact of the different transmission channels is rather mixed, due to the number of channels that are simultaneously considered, the different weighting schemes used, and the ways in which the non-stationarity of the variables is dealt with.

\subsubsection{Testing for inter-firm RTT using patent citations}

Another way of incorporating important determinants of international technology diffusion is to use patent citations as a proxy for knowledge flows. This approach was proposed by

\footnotetext{
35 R\&D spillovers from outward FDI are cqual to the Swedish MNE's share of activity, measured by either number of employees or R\&D spending in a particular industry multiplied by the host country"s R\&D stock in the same industry. Similarly R\&D spillovers from inward FDI are equal to the share of Swedish employment in foreign affiliates in a sector over the total employment in that sector in the affiliates country of origin. multiplied by the R\&D stock in that country and sector.
} 
Globerman ef al. $(2000)$ who analyse 220 patents applied for by Swedish MNEs and small and medium sized enterprises (SMEs). The empirical framework consists of regressing the number of citations to patents originating in a foreign country against a number of control variables - bilateral trade, inward FDI (proxied by the employment in foreign affiliates from that country operating in Sweden), and outward FDl (measured by the number of employees in Swedish affiliates in that country). The authors control for the technology gap between Sweden and each foreign country (proxied by a variable measuring the similarity in production structure between the two countries), the knowledge stock available in that country, and the geographical distance between the two countries. Using a conditional logit estimation framework Globerman et al. found both for the sample of MNE and SME patents. that higher outward FDI is associated with more patent citations to the partner countries. These results support the existence of inter-firm RTT, i.c. 'that knowledge is systematically diffused from the headquarters of Swedish MNEs to smaller non-multinational firms" (Globerman et al. 2000, p. 33). A negative correlation was found between citation counts and inward FDI for both samples of firms, which implies that the activity of forcign affiliates in Sweden does not contribute to the domestic knowledge base. According to Globerman et al. this result may be explained by the large share of inward FDI from Nordic countries which are characterised by relatively low domestic patent stocks. Finally the trade channel seems to be more important as a carrier of knowledge for SMEs than for MNEs, which is consistent with the idea that MNEs can access knowledge through their network of foreign affiliates and they do not need to rely on additional information that trade contacts may provide.

\subsection{Conclusions}

This chapter has presented a synthesis of the various empirical and theoretical contributions on the public and private effects of outward FDI, focusing in particular on those studies dealing with its technological impact on the home part of the multinational and on other home country firms. Regardless of the potential policy relevance intra-firm RTT, there is still limited understanding of this phenomenon.

On reviewing the empirical studies on intra-firm RTT it emerges that, despite the theoretical relevance and practitioners' interest in the parent company's ability to integrate competencies developed abroad, little research has been conducted on this topic. The existing studies within the FDI literature on intra-firm RTT have either analysed this phenomenon indirectly by examining the contributions of FDI activitics to parent company productivity (sec Barba Navaretti et al. 2001. Barba Navaretti and Castellani 2003) or have failed to distinguish 
between different types of R\&D activities performed abroad (Mansfield and Romeo 1984 , Fors 1997. Branstetter 200(0). Furthermore, in all these contributions the technology transfer process remains a black box. This is also a limitation of most of the studies within the international business literature (the exception being Zhou and Frost 2003). Although these empirical investigations have helped to identify and assess the importance of different factors affecting the internal transfer of knowledge from foreign subsidiaties to the headquarters, more research is needed to understand what the different channels are through which knowledge produced abroad is absorbed and deployed by the rest of the company. In Chapter 6 of this thesis I try to fill this gap by conducting a case study analysis that investigates the role of researchers" mobility in the intra-firm RTT process.

A number of studies, discussed in the previous chapter, have identified labour mobility as an important channel for inter-firm technology transfer, not only between proximate but also between distant firms (Saxenian and Jinn-Yuh 200)!). However these empirical contributions have been concerned with the role of labour mobility as a means for transferring knowledge across firms and little is known about the use of this mechanism for diffusing knowledge within different divisions of the same firm. This issue is particularly important in those multinational companies that have R\&D units in distant locations and indeed this technology transfer channel was suggested in the Redlaway report as a means to achieve intra-firm RTT ('A process of moving staff between different countries will sometimes go some way towards passing round the fruits of this experience', Reddaway et al. 1968. p. 308).

This survey of the literature has identified the lack of direct empirical investigation (an exception being the study by Globerman et al. 2000) into fecdback effects from R\&D activities located abroad to other home country firms. The studies on international R\&D spillovers are unable to isolate the benefits of inter-firm RTT from any other potential gains accruing to home country firms from investment activities abroad that are not directly linked to technology flows. This is mainly due to the use of financial data on FDI flows, which are a poor proxy for the magnitude of economic activities of foreign subsidiaries and a very weak indicator of their technological activities. Some single country studies. such as the one by Braconier et al. (2000) on Sweden, have used better measures of the economic activities of MNEs abroad (employment for example), but results from these studies are country-specific and difficult to generalise, and they suffer from the limitations affecting the empirical framework used to test for international R\&D spillovers (i.c. high correlation among the explanatory variable and non-stationarity). 
Because of the numerous drawbacks of this approach, in Chapter 7 of this thesis the process of inter-firm RTT is examined by tracking knowledge flows using patent citation analysis, as proposed by Ciloberman et al. (2000). This method allows one to test directly for the contribution of outward FDI to the diffusion of new technologies from abroad to the home country and does not suffer from the same econometric problems as the studies on international R\&D spillovers. Drawing also on the work on the geographical localisation of spillovers (Jaffe et al. 1993) and on the patent citation analyses within the intemational business literature (Frost 1998, Branstetter 2000), I analyse whether multinational companies act as a channel for inter-firm RTT. As argued in this chapter, reverse knowledge flows from asset-augmenting R\&D units that produce knowledge more basic in nature, less context specific, and without having a particular development purpose would be expected. Such knowledge may be tacit and would be acquired more efficiently and accurately through direct and close interaction with local knowledge pools. The extent of inter-firm RTT depends on a number of factors. First, because the headquarters acts as a conduit for technology flows, one must assume that knowledge diffuses first within the MNE. Second, the successful diffusion of knowledge requires absorptive capacity in the receiver units (home country firms). Third. and most importantly, technological knowledge should flow voluntarily or involuntarily outside the firm's boundaries. The MNE's embeddedness in its home country is the main factor facilitating this. 


\section{CHAPTER 4}

\section{SOME METHODOLOGICAL ISSUES: A \\ COMPARISON OF USPTO AND EPO PATENTS AND PATENT CITATIONS}

\subsection{INTRODUCTION}

The purpose of this chapter is to provide a detailed overview of the method and the data sources used in Chapters 5 and 7, which exploit data on patents and patent citations from the US patent office (USPTO) and the European Patent Office (EPO). In this chapter I focus on the methodological issues related to the use of this type of data for addressing the research questions investigated in this thesis. I concentrate particularly on the differences between the two patent systems in relation to patent indicators. This is a very important aspect especially where patents are used to assess the innovative activities of multinational companies and the knowledge flows originating from them, given the cross-border nature of their activities.

Most of the studies reviewed in Chapter 2 (an exception being Le Bas and Sierra 2002) used patents granted by the USPTO to measure the extent of R\&D internationalisation of both nonUS MNEs and US MNEs. However as acknowledged by some of the authors of these studies (see for example Patel and Vega 1999) this data source might underestimate the patenting activities of firms operating outside the US and overestimate the patenting activities of USbased companies. This problem, known as the 'home advantage' effect (European Commission 1997) is associated with the fact that firms have different propensities to patent in each national market according to the expected market share for their innovation. Most obviously, firms tend to protect their inventions in their domestic market. As a result, national patent offices receive a large number of domestic patent applications (i.e. patent applications from residents in their own country) and therefore they are biased towards domestic inventive activities. If a 'home advantage' effect is also present within the EPO system, the extent of this problem might be mitigated by the fact that, as argued by Archibugi (1992), the EPO can be considered a truly international patent system since a single application can be potentially extended to all member countrics. In this chapter I will try to assess the extent of this bias in both patent systems by comparing a set of indicators of R\&D internationalisation constructed from USPTO and EPO patent data. 
Another related issue that 1 address in this chapter is the patenting behaviour of MNEs. In particular I test for whether they systematically protect their inventions in both the EPO and the USPTO, given the extent of their cross-border activities and the amount of financial resources they have. This analysis will help to evaluate the "home advantage' effect and with it the bias affecting internationalisation indicators based on patent data. These tests will be performed using a unique database of USPTO and EPO patents owned by 131 high-tech European. US, and Japanese MNEs for the period 1989-2000, and their patent families. i.e. patents that have been applied in various countries to protect the same invention.

I start by reviewing the major advantages and disadvantages of using patent statistics to capture firms' innovative activitics, concentrating on the 'home advantage' effect. I then discuss in section 4.3 the main differences between the two patent systems, and in section 4.4 1 report and discuss the results of the comparative analysis of EPO and USPTO internationalisation indicators. Section 4.5 presents the estimates of the empirical model that tries to assess MNEs' patenting strategy behaviour. The last section summarises and concludes this chapter.

\subsection{Patents AS TECHNOLOGICAL INDICATORS}

A patent grants the inventor for a limited period the exclusive right over the commercial exploitation of his/her invention; thus patent statistics are by definition related to innovation. As argued by Griliches (1990) patents can be used as either an output or an input indicator of imnovative efforts. When patent statistics are used as an output measure they are an indicator of the success of the underlying inventive activity, while when they are used as an input measure they are an indicator of the efforts that have been put into the creation of a new product or process and, as such, patents are related to R\&D expenditure statistics. In this study I use patent data as an input indicator. i.e. as a proxy for the inventive activities of multinational companies, in line with the previous empirical literature on $R \& D$ internationalisation (see the work of Cantwell 1989, and Pavitt and Patel 1991).

There are a number of studies that review the advantages and disadvantages of patent data for comparing the innovative performance of countries and companies (Archibugi 1992. see for example Basberg 1987. Griliches 1990, Pavitt 1988). Here I comment only briefly on the main limitations. First not all inventions are patentable due to explicit legal exclusion, and not all inventions are patented since firms may decide to protect their innovations by alternative means such as secrecy. This problem manifests itself most clearly in the sectoral variability in 
the propensity to patent. Second, patents. by definition, will only capture codified knowledge that is embodied in new products or processes, leaving aside tacit aspects of knowledge. This characteristic of patents will affect the geographical analysis of both patents and patent citations. Codified knowledge is supposed to be more easily and rapidly transferred across spatial boundaries than tacit form of knowledge. This implies. as pointed out by Frost (1998), that studies based on patent data will tend to be biased against finding significant localisation effects. Third, firms have different propensities to patent in each national market, according to the expected market share for their innovation. This will affect comparative studies that try to evaluate differences in firms' innovative performance across countries, such as when the R\&D internationalisation strategies of multinational firms are examined. Related to this issue. there is also the problem that patent legislation varies across countries, which affects the cost, length and effectiveness of the protection granted and in turn also affects the keenness of inventors to apply for patent protection (Archibugi 1992). ${ }^{36}$ The next section analyses these two issues in depth.

\subsubsection{The home advantage effect}

There are many reasons why firms decide to apply for patent protection. The main one is to protect an existing or potential market for their invention. As a result, firms will show different propensities to apply for patent protection in each country depending on their expectations about the commercial exploitation in that particular market. In general, firms will tend to protect their inventions in the home country of the inventor leading to the so-called 'home advantage' effect (EC 1997): national patent offices receive a disproportionate large number of domestic patent applications (i.e. patent applications from residents) and this can give a misleading indication of domestic invention activities. This introduces problems if these patent data are used in international comparisons of innovative activities, be it at the country or at the firm levels. In performing these comparisons it should be remembered that the average value of patents differs substantially across countries due to differences in patent legislation, as shown by the great variety among countries in the ratio between patent applications to patents granted (Soetc and Wyatt 1983).

A common method applied to correct for these problems is to base bilateral international comparisons on patenting activity in a third country. Patents registered in a common foreign

\footnotetext{
sh The other major disadvantage of using patents is that they do not reflect the great variability in the quality and commercial value of inventions. However, this limitation will not directly affect this study since it does not use patents as an ReD output measure.
} 
country will have undergone an equal screening process and therefore can be usefully compared. Moreover. since an external patent application is more expensive, the use of foreign patents operates as a filter against low-value inventions. In comparison to purely domestic patents, patents extended abroad are more valuable. "However some eriticisms have been levelled at this method (see Pavitt 1988 for a review). The main one is connected with the fact that firms' and therefore countries' propensities to patent in any particular third country will vary in line with their trading and investment relations. Despite this limitation, Soete and Wyatt (1983) show that there is high correlation between the extent of foreign patenting and a country's level of industrial R\&D expenditure and between the sectoral distribution of domestic and foreign patents. Overall Soete and Wyatt (1983) conclude that foreign patenting is a 'relatively unbiased' science and technology indicator.

Most studies at the country level - and indeed also at the firm level - have used patents registered with the USPTO, because of the availability of these data and their long time series. However the use of this dataset may introduce some bias in intemational comparisons of patenting activities. First, it might not capture the innovative activity of non-US firms that takes place outside the US. A counter-argument (advanced by Cantwell and Hodson 1991) is that non-US firms have an interest in protecting their most significant innovations in the USPTO because the US is the largest market for technologically advanced products. On these grounds, studies of the internationalisation of R\&D activities have for long used USPTO data (see the work conducted by Cantwell at Reading University and the studies by Patel and Pavitt at SPRU) and only more recently has EPO data been used (Le Bas and Sierra 2002). Second, USPTO data may present a distorted pieture of the relative technological position of US firms, as a result of the 'home advantage' effect. Therefore one should be cautious about in drawing conclusions about the US or about US firms when using this database. As Patel and Vega (1999) point out in their study on the internationalisation of R\&D activities: "using US patent data for US companies and for US subsidiaries of non-US companies means that there will be an over-estimation of the role of domestic R\&D for the former and foreign $R \& D$ for the latter' (p.148).

Archibugi and Pianta (1992) have shown the extent of this bias in their analysis of countries' specialisation profiles. They conclude that: 'domestic patenting is an unreliable indicator of a country's specialisation, as it is distorted by a large number of inventions of lesser

\footnotetext{
"Putnam (1996) shows that the number of jurisdictions in which patemt protection is sought is correlated with the value of the invention.
} 
significanee, which are not extended abroad, and are aimed only at protecting the domestic market from foreign competition' (p. 84). In particular these authors find that, though 'the US patent system has often been employed for international comparisons, our results suggest that US specialisation measured on patents granted in the US is not an adequate description of the country's international strengths" (p. 89).

As mentioned above Archibugi (1992) maintains that the EPO is the only patent office that can be considered truly international since a single application can be potentially extended to all 19 member countries. However this claim and the 'home advantage' effect at the firm level has not been systematically investigated, in recent years. A survey by Bertin and Wyatt (1988) on the patenting strategies of 93 MNEs carried out in 1983-84 shows that the home country is the most important country of origin from which they submit patent applications' ${ }^{3}$ The US scores very high in the ranking of countries where these MNEs file their patents. ${ }^{39}$ with the exception of the ranking given by French MNEs where it comes last. Another study by Schmoch and Schnöring (1994), further discussed in Grupp and Schmoch (1999), on 23 MNEs in telecommunications manufacturing investigates in more detail the foreign patenting strategies of these firms using patent statistics for the period 1987-89. What emerges from this analysis is that the home country remains the most important jurisdiction in which firms seck protection for their inventions, and that many of these inventions are not protected in other countries. Some European MNEs (Sicmens, GEC, Italtel. Nokia, Bosch) tend to file a larger number of patents in other European countries than they do in the US, despite the fact that this is the single largest market. Others such as Thompson, Philips and Ericsson put a special focus on the US market and therefore register a large number of inventions with the USPTO, a strategy followed by most Japanese MNEs. These two studies by Bertin and Wyatt and by Schmoch and Schnöring suggest therefore that even MNEs show a greater tendency to protect their invention within their home market and that non-US MNEs show different propensities to file a patent with the USPTO. This decision is related to their market strategies and, as observed by Schmoch and Schnöring (1994), is strongly correlated with the international trade patterns in telecommunications equipment.

\footnotetext{
"In this study the country of origin of a patent is the country from which a firm submits the patent application. Usually this is the country where the R\&D has been carried out. but. as explained by Bertin and Wyatt (1988). for administrative ratsons it might be the firm:s home country.

$\therefore$ The US appears scoond in the ranking of English and German MNEs. and third in the raking of Swiss and Swedish MNl:s.
} 
However given that these studies were carried out during the 1980s, is questionable whether these results still reflect the patenting strategy of multinational companies in a period characterised by increasing $R \& D$ internationalisation. It is particularly important to determine the "home advantage" effect in firm-level studies because it is very difficult to overeome this problem. In theory one could replace patent indicators with other S\&T indicators, such as R\&D expenditure, for the home country or for domestic firms, but while this is feasible in country level studies, ${ }^{+1}$ it is almost impossible to apply it to the firm level, because financial accounts repont only consolidated R\&D expenditures with no distinction between different locations of activity. ${ }^{+1}$

Another way to eliminate the 'home advantage' effect is to group the total amount of a country's or a firm's patents into patent families. A patent family consists of all the patent doctments that have been published in various countries to protect the same inventions. Once the patents related to a single invention have been consolidated, the patent family can be used as a unit of analysis, climinating the multiple counting of inventions across countries. Faust and Schedl (1982) propose using the priority application of each family, i.e. the first patent application filed for an invention, as the unit of analysis. This procedure can be applied both to country and to firm level studies, but data on patent families are not casily available. ${ }^{42}$ In trying to assess the extent of the 'home advantage' effect and thus the validity of using USPTO and EPO data to examine the R\&D intemationalisation strategy of MNEs the patent families of 131 high-tech European, US, and Japanese MNEs in the Fortune 500 are analysed in section 4.4 (for names of the companies sce Table A4-1 in the appendix).

\subsection{MAIN DIFFERENCES BETWEEN THE USPTO AND EPO SYSTEMS}

Before describing the dataset used in this chapter it is important to list some of the differences between the US and European patent systems. The most significant concerns the criteria on which a patent award is based. While in the US the rule is that the applicant should be the first to iment, in the EPO the rule is that the patent is awarded to the first to file. Thus in the

\footnotetext{
40 This solution was proposed by Soete $(1981)$ in his study of the technological determinants of international competitiveness.

${ }^{4}$ Certain companies report R\&D expenditure in different geographical regions (c.g. Europe. North America. Asia) but across companies there is a lot of variation in the way these regions are defined. In addition even within companies these data are not available systematically in each financial report and geographical regions might change from year to year.

t? To my knowledge there are three databases with this coverage: Derwent World Patent Index (WPAT). INPADOC provided by the International Patent Documentation Centre and the FAMI internal database at the EPO (see Michel and Bettels. 2001).
} 
United States, in case of litigation. the applicant has to show that he was the inventor of the patented invention, while in Europe the applicant needs only to prove that he applied for patent protection before the litigant. As a result of this different approach in establishing the inventor, until $2001^{+3}$ patents were published by the USPTO only once they had been granted. so that the identity of the inventor and the details of the innovation were secret until then. In the EPO system patents are published 18 months after the filing date or after the priority date (i.e. the date a patent application is filed in any country that is party to the Paris Convention) at the latest. Therefore empirical studies using USPTO data are based on patents granted and usually their granting year, while those using EPO data are based on patent applications to capture most of the innovation activity in a firm or in a country, and priority year to be as close as possible to the date of the invention.

Furthermore, while in the USPTO system a patent application is in the name of the individual inventor(s) (see article 1.41 of the USPTO patent rules), in the EPO the patent applicant tends to be a company employing the inventor rather than the inventor him/herself (see rule 17 of the implementing regulation of the European Patent Convention). As a result, in the USPTO the application will contain the residence of each named inventor (rule 1.51), whereas in the EPO there are specific rules for the applicant's address -- namely that it must be where his/her residence or principal place of business is located (rule 26) - but not for the inventor's address unless he/she applied for the patent. As a result of these different legal requirements, the inventor's address in the EPO may sometimes coincide with his work address or with the address of the business unit that dealt with the patent application. Thus the inventor's address in EPO applications may not always correspond to the locus of the invention.

Another difference exists between the two patent offices with respect to the procedures adopted during the examination process. While in the USPTO an application is examined automatically, in the EPO an application is considered as a request for a search to establish the state of the art in relation to the invention, and only subsequently, at the applicant's request. will the application be examined. The aim of these EPO search reports, called patentability search reports, is to provide information on the technical content which is relevant with respect to the patentability of the invention ... and ... which permits restriction of the claims to precisely what was not known at the time of filing the patent application' (Michel and Bettles 2001, p. 187). To fulfil this goal patentability reports contain citations to patents and

\footnotetext{
4: Under the procedure put in place in November 2000. US applications are published after 18 months from the carliest claimed priority date.
} 
non-patent documents that have either been suggested by the inventor or added by the patent examiner, as well as the so-called 'categories of citation', which indicate the relevance of the citations and who added it. i.c. the examiner or the applicant. Patent citations in the EPO originate from these search reports and from the final examination process that is carricd ou if the applieant decides to continue with the examination procedure. As will be shown in the next chapter, this procedure logether with the different requirements concerning the description of the state of the art has an impact on the number of patent citations in the two patent systems.

\subsection{R\&D INTERNATIONALISATION INDICATORS: USPTO VS. EPO DATABASES}

This chapter uses two datasets containing patents filed by 131 high-tech European. US and Japanese MNEs listed in the Fortune 500): the SPRU Large Firm Database (see Criscuolo and Patel 2003 for a detailed description) based on USPTO patent data, and a similar database developed by Schoenmaker and Verspagen (see Verspagen and Schoenmakers 2004) on the basis of EPO patent applications obtained from the European Patent Office (Bulletin CD). In both datasets patents have been consolidated at the level of the firm using the Dun and Bradstreet Linkages database 'Who Owns Whom' (1999) which contains group ownership structures as they were in 1998. This database includes only full. i.c., one hundred per cent, subsidiaries. In both datasets the ownership and affiliate structure of a firm is taken at a fixed point in time (1998) and patents are assigned to each multinational firm assuming no changes in the structure over time. Obviously, this is a sub-optimal procedure. A better procedure would be to use annual data from the Dun and Bradstreet Linkages database, and to consolidate patents at the level of the firm using a different ownership structure for every year under investigation. However, as pointed out by Verspagen and Schoenmaker (2004). most multinational companies apply for the bulk of their patents under the multinational company name. In this area the changes are less pressing, i.e., mergers generally occur at a lower level. Although one cannot rule out mistakes as a result of this procedure, it seems reasonable to assume that their number is relatively small. A mistake would result if a firm patented during the period under consideration through a certain subsidiary, but sold off this subsidiary before 1998 (the point of reference for the ownership structure). Given the tendency to patent through company headquarters, one would expect such occurrences to minimal.

For each company 1 have information about their patent applications to the EPO during the period 1989-2000 and for each patent I have data on the address of the inventor, the technological class and the priority date. Similarly, the SPRU Large Firm dataset gives 
information on the name of the inventor and his/her address, the technological class, and the year of application to the USPTO. Table 4.1 reports the distribution of US and EPO patents by firms' nationality and by their principal produce group. defined as the technology area in which the firm's production is concentrated. In aggregatc. US firms account for $36 \%$ of the total, European firms for $38 \%$, and lapanese for 26\%. Among European firms Germany has the highest number of firms (15). followed by France (9) and the UK (9). The total number of US patents granted between 1989 and 2000 is almost three times greater than the number of patents granted by the EPO.

Table 4.1 Distribution of the 131 firms in the sample and their USPTO and EPO patents between 1989-2000 by nationality and principal product group

\begin{tabular}{|c|c|c|c|c|c|c|c|}
\hline Sector & $\begin{array}{l}\text { Number } \\
\text { of firms }\end{array}$ & $\begin{array}{c}\text { US } \\
\text { MNES }\end{array}$ & $\begin{array}{c}\text { EU } \\
\text { MNEs }\end{array}$ & $\begin{array}{c}\text { JP } \\
\text { MNES }\end{array}$ & $\begin{array}{c}\text { EPO } \\
\text { applications }\end{array}$ & $\begin{array}{c}\text { EPO } \\
\text { patents } \\
\text { granted }\end{array}$ & $\begin{array}{l}\text { USPTO } \\
\text { patents } \\
\text { granted }\end{array}$ \\
\hline Aerospace \& Defence & 9 & 7 & 2 & & 7.439 & 3.736 & 14.996 \\
\hline Chemicals & 13 & 2 & 9 & 2 & 35.365 & 18.484 & 36.762 \\
\hline Electrical \& Electronics & 14 & 3 & 6 & 5 & 57.734 & 24.568 & 62.890 \\
\hline IT Related & 10 & 6 & & 4 & 30.099 & 11.469 & 80.26 .3 \\
\hline Machinery & 8 & 3 & 3 & 2 & 6.594 & 3.264 & 8.022 \\
\hline Metals & 11 & 1 & 4 & 6 & 5.157 & 2.751 & 6.402 \\
\hline Mining \& Petroleum & 15 & 7 & 6 & 2 & 10.654 & 5.723 & 16.464 \\
\hline Motor Vehicles \& Parts & 21 & 4 & 8 & 9 & 27.767 & 14,020 & 40.445 \\
\hline Pharmacenticals & 12 & 7 & 5 & & 19.241 & 7,088 & 24.592 \\
\hline Photography & 6 & 3 & & 3 & 23,619 & 11.414 & 45.093 \\
\hline Telecommunications & 12 & 4 & 7 & 1 & 23.879 & 7.148 & 28.933 \\
\hline Overall & 131 & 47 & 50 & 34 & 247,548 & 109.655 & 364.862 \\
\hline
\end{tabular}

Using these two datasets I calculated some internationalisation indicators to show the extent of the home advantage effect of the US and the European patent systems. In deriving these indicators I used priority application years for EPO patents and application years for USPTO patents. I used a fractional count method to count EPO patents. This takes account of patents with multiple applicants: if a patent has $m$ applicants, of which $m_{m}$, are from firm $B$ or one of its subsidiaries, and $n$ inventors, of which $n_{a}$ are from country $A$, then the number of patents originating from country $\mathrm{A}$ and assigned to firm $\mathrm{B}$ is equal to $1 /\left(n_{a} m_{b}\right)$. For US patents I followed the standard counting method, that is, taking the country of residence of the first inventor to attribute the patent to a particular location. I applied different counting methods to EPO and USPTO patents because, while in the USPTO the order of the inventors is a reflection of their contribution to the development of the patented invention, in the EPO the order of the inventors does not follow this rule. Columns (1) to (6) in Table 4.2 report - 
organised by the nationality and the principal product group of the parent company - the share of patents applied for to the EPO and invented in the home country of the multinational in the total number of patents and the corresponding share computed using USPTO patents granted. Thus column (1) in Table 4.2 shows that $88 \%$ of EPO patents applied for by European MNEs in acrospace \& defence were invented in the home country of the multinational, whereas according to USPTO patents this share is almost 93\%. The remaining columns (7-10) show the share of patents owned by EU and Japanese MNEs invented in the US, i.c. attributable to their US subsidiaries, and the share of EU-invented patents calculated using both EPO and USPTO patents (columns $11-16) .^{\text {th }}$ The figures for EPO patents have been derived using patent applications while these based on USPTO have been calculated using patents granted. The results for EPO patents granted are not significantly different and therefore have not been reported.

As discussed in section 4.2.1, one would expect to find a 'home advantage' effect in both the USPTO and EPO figures, i.c. the USPTO figures will show greater patenting activity by US MNEs in the US and by US affiliates of foreign companies with respect to the figures based on EPO data, and vice-versa for EPO statistics. However the bias in the EPO may be less pronounced because this patent office is not a national patent office like the USPTO. At the same time it is claimed that large non-US firms will patent most of their inventions in the USPTO because the US is the largest technological market: therefore USPTO patents should capture the global R\&D activities of these firms and not just those in the US.

\footnotetext{
4h This means for instance that the sum of the shares in columns (1). (7) and (11) is not equal to 100 because 1 do not consider those patents invented outside the MNEs' home country, the US, and other EU countries.
} 


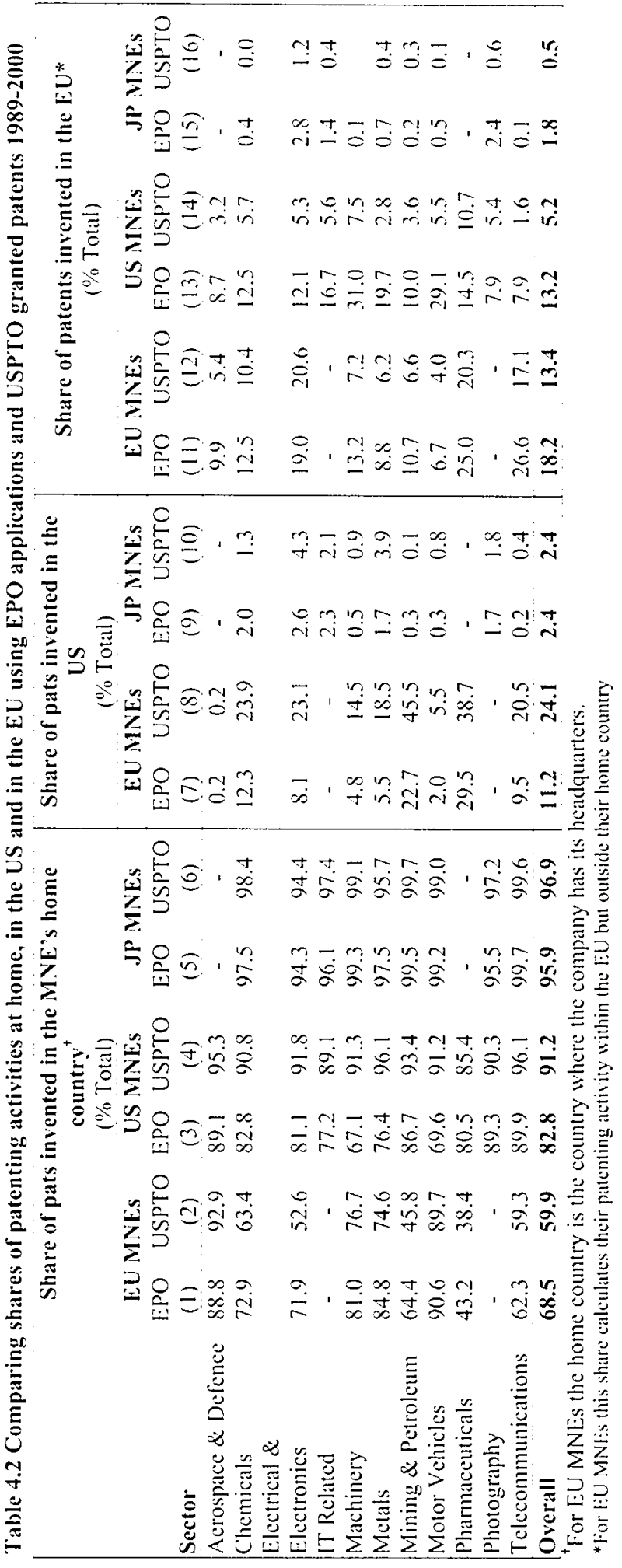


Table 4.2 shows that both patent systems appear to overestimate the home country patenting activity of their national firms. According to USPTO data the share of US-invented patents granted to US MNEs is equal to $91.2 \%$ while the same share amounts to $82.8 \%$ on the basis of EPO applications. The home country share of EU MNE patents is $68.5 \%$ based on EPO applications and drops to $59.9 \%$ using USPTO data. This bias is particularly significant for European MNEs in mining \& petroleum and electrical \& electronics where there is a difference of respectively 18.6 and 19.3 pereentage points difference in home country shares based on EPO data and shares based on USPTO data. The analysis of these shares at the firm level reveals that these results are driven by some outliers: Shell and BP in the mining \& petroleum industries, and Philips and Marconi in the electrical \& electronics industry. 45 Similarly, the large difference between EPO and USPTO figures for US MNEs' home country share in both machinery and motor vehicles \& parts can be explained by the patenting behaviour of a few lirms: Johnson Controls (49.2\% EPO, $92.1 \%$ USPTO) and TRW $(53.5 \%$ EPO, $80.9 \%$ USPTO).

Table 4.2 also reports the patenting activitics of US subsidiaries of European and Japanese MNEs. The 'home advantage' effect in this case is very significant: across all sectors, with the exeption of the aerospace \& defence, the share of USPTO patents attributable to US affiliates is significantly larger than the share derived on the basis of EPO applications. As expected, major differences within EU MNEs are found in mining \& petroleum and electrical \& electronics. These sectoral patterns are determined by the behaviour of the firms that drive the results for the home country share (BP, Shell, Marconi, and Philips) ${ }^{4 / 6}$ and by other outliers (Electrolux and ABB in electrical \& electronics, Thyssen and IRI in metals, Henkel and Hoechst in chemicals). Similarly the share of patents applied for by EU affiliates of US MNES to the EPO is $13.2 \%$, while the share of patents granted to them by the USTPO is only $5.2 \%$ (see columns 13 and 14 in Table 4.2 ). ${ }^{47}$ The biggest difference is observed for firms operating in motor vehicles \& parts (in particular TRW and Ford) and in machinery (Johnson controls).

\footnotetext{
45 According to E:PO data. 53.5\% of Shell's patent applications are for inventions made in either the UK or the Netherlands. while this share calculated using USPTO patents is equal to $30.3 \%$. For BP the EPO and USPTO home country shares are $41.4 \%$ and $19.9 \%$ respectively. The home country share for Philips varies from $77.2 \%$ using EPO data to $42.8 \%$ using USPTO patents: for Marconi these figures are $64 \%$ and $41.8 \%$.

to The findings for Philips are in line with those presented in Schmoch and Schnöring (1994).

4- Europe refers to the 15 countries belonging to the European Union (prior to May 2004) plus lecland. Liechtenstein. Norway and Switzerland.
} 
Across sectors the share of home country patents and of patents invented in the US filed by Japanese MNEs appear to be consistent across the two databases. This implies that both USPTO and EPO data can be used to capture the patenting activities of the home part of Japanese MNEs and of their US subsidiaries. However the same cannot be said for the patenting performance of lapanese subsidiaries in the EU: the share computed on the basis of USPTO patents is more than three times smaller than that derived using EPO data.

Despite these differences, the relative level of internationalisation across countries appears consistent in the two datasets: European companies are the most engaged in undertaking R\&D activities outside their home countries, whereas US and Japanese companies show a much weaker propensity to perform R\&D activitics abroad. At the sectoral level there are some inconsistencies, mainly in relation to R\&D activities of US MNEs' subsidiaries located in Europe. According to EPO figures, US motor vehicles \& parts and machinery MNEs are among the most engaged in R\&D in Europe, whereas according to USPTO figures US pharmaceuticals MNEs have the highest shares of technological activity in this region.

Some of the firm-level results can be explained in part by recent international M\&A, the effect of which is not completely captured by these databases. As firms are consolidated for one year only, 1998, the analysis of their patent portfolios reflects the R\&D activities of the firm as constituted in that year and do not take into account changes resulting from purchascs or sales of subsidiaries before or after that time. For example, BP acquired two large American companics before 1998: Standard Oil Company and Amoco. The patenting activities of these two firms account for $95.5 \%$ of BP's USPTO patents invented in the US, introducing an upwards bias in BP's share in the US and a corresponding downward bias in its home country share. Similarly, the acquisition of American companies by Hoechst (Celanese Corporation in 1987 and Marion Merrell Down in 1995 which together account for $71 \%$ of Hocchst's USPTO patents originating from US locations), and by ABB (Combustion Engineering in 1990. which accounts for 58\% of ABB's USPTO patents invented in the US) are another reason for the discrepancy between EPO and USPTO figures for these companies.

However in other instances the discrepancy between EPO and USPTO figures reflects different patent strategies of particular companies which, as reported by Schmoch and Schnöring (1994) and by Bertin and Wyatt (1986), are connected not only to their decisions concerning market penetration, export. licensing and technological alliances, but also to 
technological conditions. For example the results for Shell can be explained by two factors. ${ }^{4}$ First, the US subsidiaries of Shell have historically being organised as almost separate companies with very independent R\&D strategies and significant autonomous R\&D investment. This explains Shell's high US share of USPTO patents. Second, most of the results of R\&D activities carried out in the US. especially in drilling, are not applicable to Europe where most of Shell's oil extraction takes place off-shore. This explains why these patents have not been extended to EPO protection.

To summarise, both the USPTO and EPO data show evidence of a home country bias especially in relation to the patenting activity of foreign affiliates: if one uses EPO patent data to analyse the internationalisation strategies of MNEs, the R\&D activities of EU MNEs originating from US locations will be underestimated, while using USPTO patents will underestimate the innovative efforts carried out in European affiliates of US MNEs. A possible explanation for this finding is that a considerable amount of R\&D activity carried out by foreign subsidiaries aims to adapt products to local market conditions and therefore what has been invented by these units cannot be exploited in other contexts and need not be protected in other jurisdictions. This implies that the choice of dataset will therefore be determined by the specific geographical focus and research questions under analysis. These results point also towards a more careful examination of mergers and acquisition strategies of the firms in the sample, as in the case of BP patent portfolio.

\subsubsection{EPO and USPTO patent families}

In order to understand the patenting behaviour of the MNEs in the sample and to shed some light on these findings 1 extracted from the on-line patent database "cspracenet' (http://ep.espacenet.com/) all the patent family members for each EPO and USPTO patent. A patent family is the group of the patents granted in several countries protecting the same invention as defined by the priority patent application. In practice several methods can be used to establish a relationship between a patent and its priority patent and thus there can be different definitions of a patent family. This is because depending on the patent office or on the applicant's strategy, a single priority patent can lead to several patents in the same patent office and a single patent can be based on several priority applications. ${ }^{+4}$ The definitions used

\footnotetext{
4" I would like to thank Virginia Acha for suggesting this interpretation.

49 In the OECD Triadic patent families in 1997 on average a USPTO (EPO) patent had 1.5 (1.8) priority documents per patent and 1.2 (1.1) patents with the same priority (Dernis 2003). In the EPO dataset under analysis a patent has on average 1.1 priority documents.
} 
in practice are illustrated in Table 4.3. The definition adopted by the OECD for the Triadic patent families database (see Demis 2003 ) considers all the patents (PI-P4) as belonging to a single family because of their direct and indirect links with the same priority patent $(\operatorname{Pr} l)$. This definition aims at consolidating all interrelated priorities patents.

Table 4.3 Patent family definitions: an example

\begin{tabular}{llll}
\hline Patent & Priority Patent & \\
P1 & Prt & & \\
P2 & Prt & $P r 2$ & \\
P3 & & $P r 2$ & $\mathrm{Pr} 3$ \\
$P 4$ & & & $P r 3$ \\
\hline
\end{tabular}

However a family can include only the documents sharing at least one priority patent application in common. In this case. patents P1 and P2 belong to a family created by the priority patent Prl, patents P2 and P3 are part of another family stemming from the priority document Pr2. and P3 and P4 form another family originating from the priority Pr3. This is the definition used by the esp(ci,cenet database and it is the one adopted in this analysis. Therefore starting from the list of EPO patent applications and USPTO patents granted 1 retrieved the other patent documents with the same priority patent. For example starting with EPO patent EP902817 I obtained the family members: AU3030697. DE19648716. JP2000511958T, NO985525. US6059989, and WO9747703. All these patents have the same priority number, which, in this case, is the German patent and, according to the data provided by the esp (acenet dataset, the EPO patent has five other family members in the IPO (Japanese Patent Office), the USPTO, the WIPO (World Intellectual Property Organisation), the Austrian and the Norwegian patent offices. The applicant of this EPO granted patent also chose to protect this invention in other members states (AT, CH, DE, DK. FI, GB. IT, LI, SE) and in theory this patent would give rise to more family members. one in each of these national patent offices that have been designated for protection. ${ }^{50}$ In practice, with the exception of Germany, Austria and Spain, national patent offices of the EPO member countries do not attribute new national numbers to EPO patents. As a result not all EPO granted patents give rise to a new patent in each of the countries designated in the application.

\footnotetext{
"Because the EPO is a regional patent body it examines applications from 19 European countries and whenever the EPO application has been granted it has the effect of and is subject to the same conditions as a national patent granted by the states designated in the EPO application. After an FPO patent is granted the applicant is reguired to complete a series of formalities in order to have the EPO patent enter into force in each designated country. But not all member countries follow this gencral rule. For more details on LPO patents entering the national phase sec www.european-patent-office.org/inpadoc/faq/ls_cov.htm.
} 
To overcome this problem, I artificially inflated the patent family size by considering each designated state in EPO granted patents as an additional family member.

Putnam (1996) and a number of other authors (see for example Harhoff et al. 2003, Lanjouw and Schankerman 1999) used patent families. and in particular their size, i.e. the number of countries in which patents are filed, as a proxy for the value of a patent. Secking patent protection in multiple countries is expensive and therefore one can assume that the greater the more countries in which an invention is protected, the greater is the firm's perceived and expected economic value of that invention. In this study I used this information to provide an insight into MNE patenting strategy. I was particularly interested in assessing to what extent firms apply for protection in the country where the R\&D activity was undertaken and how often they extend the patent protection to both the EPO and the USPTO. It is assumed that non-US MNEs will apply to the USPTO for protection their inventions regardless of where they were invented. However, the findings in the previous section have already provided some evidence that is not always the case. A thorough investigation of this issue would require data from European national patent offices and information on USPTO patent applications, rather than patents granted. As I had no access to these data the analysis was performed on the basis of EPO patent applications and USPTO patents granted. Thus I only include those national applications that have been extended to the EPO and/or to the USPTO and those USPTO applications that have been successful. Although these limitations introduce some bias into the analysis, my rescarch question aims to assess the bias affecting studies on R\&D internationalisation that are carried out mainly using these types of data.

I first describe the patent families of EPO patent applications and USPTO patents granted over the period 1989-2000. Descriptive statistics for these samples of patents are presented in Table 4.4. The difference in the average patent family size between the EPO and the USPTO samples is noticeable. EPO families have on average six family members, whereas USPTO families have just three, but the average size is six if they are owned by EU MNEs. The higher average size of EPO families reflects the fact that the EPO is a regional patent body. Finally, the standard deviations are rather large, especially for the patent families of EU MNEs, indicating that there is indeed a large variety across firms in terms of family size. 
Table 4.4 size of patent families $1989-2000$

\begin{tabular}{lcccc|cccc} 
& \multicolumn{3}{c}{ USPTO patents granted } & \multicolumn{3}{c}{ EPO applications } \\
\cline { 2 - 9 } Descriptive & \multicolumn{3}{c}{ EU } & US & JP & \multicolumn{4}{c}{ EU } & US & JP \\
statistics & Overall & MNEs & MNEs & MNEs & Overall & MNEs & MNEs & MNEs \\
\hline Mean & 3.07 & 6.06 & 2.07 & 2.28 & 5.97 & 7.14 & 5.88 & 4.09 \\
Median & 1.00 & 4.00 & 0.00 & 2.00 & 4.00 & 5.00 & 4.00 & 3.00 \\
Standard & & & & & & & & \\
Deviation & 4.85 & 6.70 & 4.14 & 2.82 & 5.77 & 6.55 & 5.66 & 3.58 \\
\hline
\end{tabular}

Table 4.5 provides a more detailed picture of the families of USPTO patents granted to the sampled multinationals grouped according to their principal product group. Table A4-2 in the appendix reports these shares with the patents regrouped into 32 technological fields according to the classification in Hall el al. (2001). Columns (1) to (4) show the shares of those USPTO patents, without equivalents in other patent offices, granted to the entire sample of firms, EU MNEs. US MNEs, and Japanese MNEs respectively. Thus taking the sample of EU MNEs in acrospace \& defence, Table 4.5 shows that $12.9 \%$ of all USPTO patents granted to these firms do not have other patent family members. Columns (5)-(8) report the perentage of USPTO patents granted to the same groups of firms with family members in at least the three major patent offices (USPTO, EPO and JPO). Taking again the sample of EU MNEs in acrospace \& defence, $33.3 \%$ of all USPTO patents granted to these firms have also been filed both in the EPO and in the JPO. However, by construction, this does not rule out the possibility that these USPTO patents have family members in other national patent offices. Columns (9)-(10) report the share of USPTO patents granted respectively to all the MNEs under analysis and to Japanese MNEs with a family member in at least the EPO. 


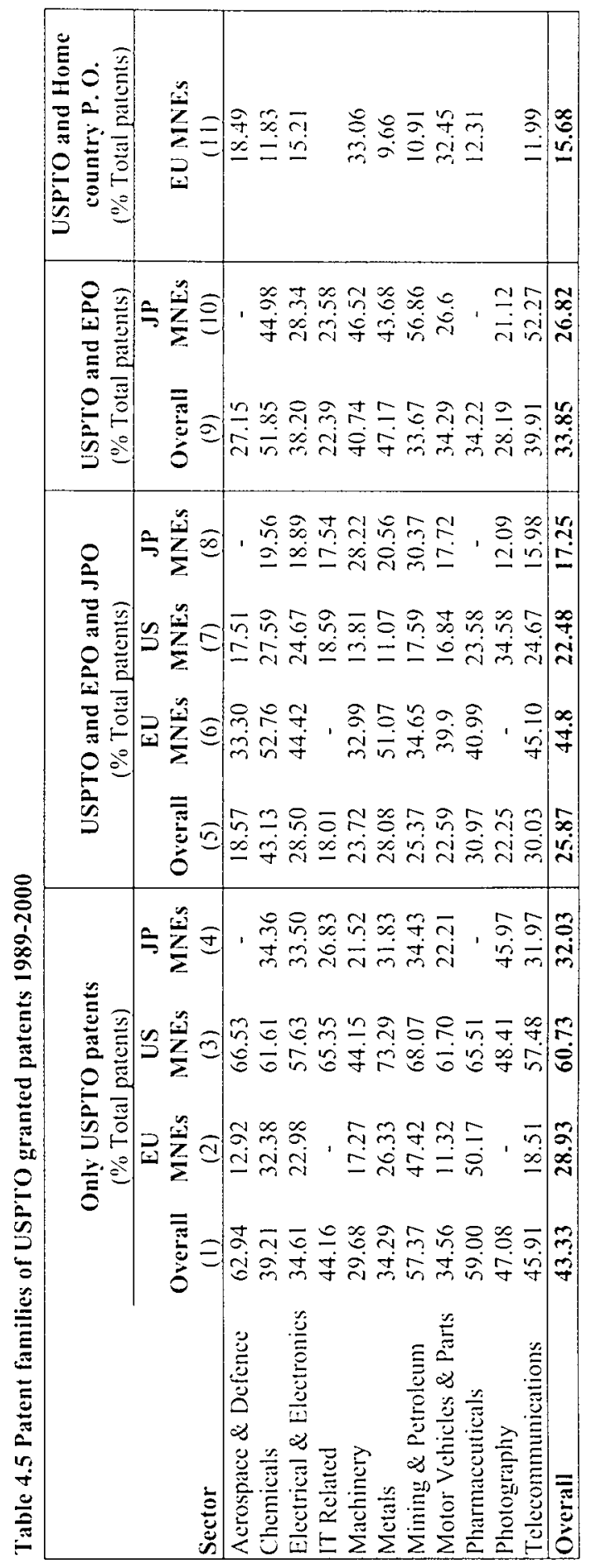


Thus. 44.9\% of USPTO patents granted to Japanese chemical MNEs have also been filed in the EPO, but they may have been filed in other mational patent offices as well. The last column in Table 4.5 contains the percentage of those EU MNE USPTO patents invented outside their home country that have equivalents in at least their national patent office, either because this country has been chosen among the designation states of an EPO application or because the multinational has separately filed an application to this patent office. Note that the shares reported in Table 4.5 need not sum to $100 \%$ for each group of firms, since the various families shown are not mutually exclusive.

A distinctive feature of Table 4.5 is the very high proportion (almost $44 \%$ ) of USPTO patents without equivalents in other patent offices. This share is particularly high for those patents granted to US MNEs $(60 \%)$, which reflects the fact that US MNEs are less engaged in R\&D activities outside the US and also that the USPTO is their national patent office. For EU and Japanese MNE patents this share is equal to approximately $30 \%$, indicating that most of these USPTO patents have a family member in another national office. However it is interesting to note that half of the USPTO patents granted to European pharmaceutical companies have not been filed in other patent offices. This may be due to the fact that patents in biotechnology are considered patentable in the USPTO, but not in other countries (Hingley and Park 2003) and is corroborated by the high share of patents without equivalents in biotechnology and drugs (sec Table A4-2 in the appendix). The high share for EU MNEs in petroleum \& mining may be explained both by the acquisition by BP of Amoco and Standard Oil and by the fact that most of Shell's US-invented patents may not be exploited in Europe because of the different exploration techniques in the two regions. This is in line with the high share of EU-owned USPTO patents in the technology class 'carth workings \& wells' without equivalents (see Table A4-2 in the appendix).

Columns (5)-(8) report the percentage of USPTO patents with family members in all three patent offices (USPTO, EPO and JPO). This is the OECD definition of a Triadic patent family, though using a different method for regrouping patents into families. Overall, only one quarter of all USPTO patents have a family member in both the EPO and the JPO, although this share reaches $43 \%$ for chemical companies. These figures are driven by the patenting behaviour of EU MNEs. which show a higher tendency to file patents in all three patent offices than do their US and Japanese counterparts. This suggests that when EU MNES decide to extend their USPTO patents abroad they apply to both the EPO and the JPO. In contrast. Japanese MNEs do not appear to follow the same strategy. The low share for 
Japanese MNlis may indicate that their US innovations cannot be exploited or exported back to Japan. But they can be exploited in Europe to a certain extent, als shown by the figures in column (10). Across all sectors, more than one quarter of Japanese MNE USPTO patents have a family member in the EPO, but this share is equal to more than $50 \%$ for companies in telecommunications, and mining $\&$ petroleum.

Table 4.6 shows the corresponding shares for the patent families of EPO applications ${ }^{5}$ and Table $A 4-3$ in the appendix reports these shares calculated for each of the 30 technological sub-fields (sec Table A4-8 in the appendix for a description of these ficlds in terms of IPC codes) constructed using the international patent classification developed by the Observatoire des Sciences et des Techniques (OST) and the Fraunhofer Institute (FhG-ISI) (sec OST 2002 appendix A5a-1 p. 346). Some interesting results emerge. First, across all sectors these shares tend to be higher than those calculated on the basis of USPTO patents. This could be indicative of the more 'international' character of the EPO with respect to the USPTO. Second, EU MNEs display the lowest share of Triadic patent families, consistent with the fact that the EPO is like a national patent office for EU MNEs. Third, although higher than the corresponding USPTO figures, only $20 \%$ of EPO applications made by EU MNEs and invented outside their home country are also filed in their national patent offices. Although these findings cannot be compared directly with the results of Bertin and Wyatt (1988) and Schmoch and Schnöring (1994) since I do not have access to national patent office data, this share seems quite low. It is difficult to know to whether this is because the innovative efforts of foreign subsidiaries cannot be exploited back in the home country of the multinational or whether the EPO data are not able to capture this patenting behaviour because technologies developed abroad are only protected in the patent office of the country where the invention was made and in the MNE's home country patent office.

\footnotetext{
"I have not reported the shares of EPO patents without equivalents in other patent offices becaltse they are very small. since most patents are first filed with a national patent office and then transferred to the EPO.
} 


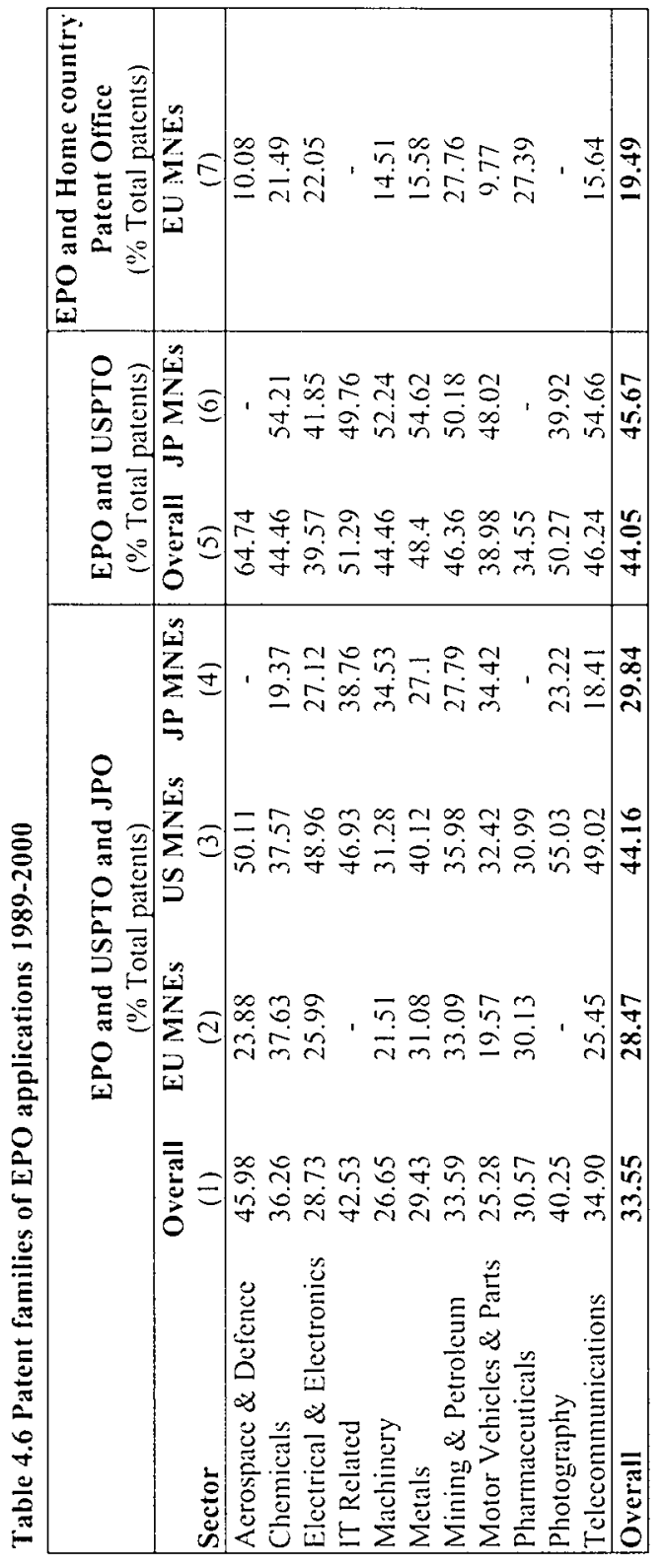




\subsubsection{Equivalents of EPO and USPTO patents}

Having described the patent families of both datasets. I now assess to what extent EU and US MNEs file a patent to both the EPO and the USPTO to protect the results of their foreign R\&D activities. The propensity to filc patents in both patent offices is affected, among other factors, by their degree of R\&D internationalisation and this will in part explain the differences between the internationalisation shares based on EPO and USPTO data presented in Table 4.2. One way to investigate this issue is to analyse EPO/USPTO equivalent patents, i.c. patents registered in both patent offices protecting the same invention.

To carry out this analysis it is necessary for the sets of EPO and USPTO equivalent patents to include exactly the same patents. Although in theory one should identify the same set of equivalent patents regardless of the starting set, in reality there are a number of problems that makes the process of identification difficult. A first complication derives from the fact that a patent in the EPO dataset might have more than one applicant while, in the USPTO database used in this study, a patent is assigned only to one organisation. This implies that if, for instance, an EPO/USPTO equivalent patent is applied for jointly by Siemens and the University of Berlin it will appear in the USPTO as being assigned either to Siemens or to the University of Berlin or as not assigned. ${ }^{52}$ As a result this patent will be part of my initial set of Siemens EPO patents, but it may not be included in the portfolio of Siemens USPTO patents. ${ }^{53}$ A second problem is the fact that the assignee in the USPTO may be different from the applicant name on the equivalent EPO patent and also the company to which the USPTO patent has been assigned might not be a subsidiary of any MNE in the sample. A similar situation may arise in relation to the applicant name on EPO patents. If the cases where a patent has more than one applicant are excluded, this problem occurs in $60 \%$ of the cases of unmatched equivalents. One possible explanation for this is that patents filed in the EPO by one particular company have been subsequently reassigned by the inventor in the USPTO to another company not part of the multinational that made the application to the EPO. This may also arise from the different patent application procedures of the two patent offices. As mentioned carlier, for the USPTO the inventor is the patent applicant, while for the EPO it is normally the company cmploying the inventor that applies for patent protection. Despite these

\footnotetext{
\$2 According to llall et al. (2001) unassigned patents are those for which the inventors have not yet granted the rights to the invention to a legal entity. such as a corporation ... These patents were thus still owned by the original inventors at the time of patenting. and they may or may have not transferred their patent rights at a later time' (p.12).

5 In 15\% of cases equivalent patents could not be matched because the EPO patent had more than one applicant. while in $18 \%$ of catses the reason was that patents were not assigned to any organisation.
} 
problems. 91.7\% of equivalent patents belonging to the wo initial sets were successfully matched. The total number of I:PO/USPTO equivalent patents owned by US and EU MNEs is equal to 38.977 and 39,047 respectively.

1 used these datal to calculate the share of EPO/USPTO equivalent patents invented in a particular location in the total number of EPO (USPTO) patents originating from that location. This showed, for example, what proportion of EPO (USPTO) patents invented in the US is filed in both patent offices. Before presenting the results. two issues need to be explained.

The first relates to the inventor's address. So far in the analysis I have used different methods to attribute EPO and USPTO patents to a particular country (fractional counting for the EPO. first inventor address for the USPTO); however this may introduce some bias in the calculation of these shares if EPO/USPTO equivalents tend to be invented by inventors with residence in different countries than patents without equivalents in the other patent office. In addition. because of the different regulations in the two patent systems concerning the inventor's address, even for the EPO/USPTO equivalent patents inventors addresses may differ, which again may distort comparison of the shares constructed with the EPO set with those based on the USPTO sample. I checked the extent of these two potential problems by retrieving from the NBER dataset of USPTO patents (Hall et al. 2001) the addresses of all the inventors available for patents granted only up to 1999. Inventors' addresses for EPO/USPTO equivalents coincided in almost all cases the number of unmatched addresses goes from $0 \%$ to $3.85 \%$ of the total number of equivalents). The only exception was Philips: for $20 \%$ of its equivalent patents the EPO and the USPTO inventor's address does not match. In most instances, the inventor's address in the EPO patent was the address of Philips' R\&D laboratory in Eindhoven. ${ }^{54}$ I therefore decided to eliminate this company from the analysis. I then computed the shares, using a fractional counting method for the set of USPTO patents also (see Table A4-4 and A4-5 in the appendix). ${ }^{55}$ Since there were no major differences in the corresponding shares, this section presents the results based on the fractional count for EPO patents and on first inventor's address for USPTO patents. ${ }^{50}$

\footnotetext{
st This may explain the difference beween Philips" EPO and USPTO-based internationalisation indicators. discussed at the beginning of this section.

$\$$ In comparing the figures in Tables 4.7 and 4.8 with those in Tables $A 4-4$ and $A 4-5$. it should be remembered that the data used for the latter refer to a shorter time period (1989-99).

st In the entire EPO dataset only $12.7 \%$ of applications made by EU MNES and $10 \%$ of applications made by US
} 
The other issue to be resolved is connected to the fact that only USPTO patents that have been granted are included while I have information on all EPO applications. Because of different standards in relation to novelty in the regulations of the two patent offices, and differences in legislation, it is possible that there is a significant number of applications that were filed in both the EPO and USPTO but were successful only in the USPTO, or vice-versa. For the sample of EPO applications made by EU and US MNEs filed with and granted by the USPTO, only $64 \%$ and $49 \%$ respectively were also granted by the EPO. This may affect the interpretation of the shares since the difference between the proportion calculated on the basis of EPO applications and that based on USPTO patents might merely reflect the different success rates in the two patent offices. Therefore I dropped from the sample those EPO patents that were not approved. However the figures calculated on the basis of EPO applications still provide information about the patenting behaviour of these MNEs; thus, they are reported in the appendix (Tables A4-6 and A4-7).

Table 4.7 shows the distribution by both sector and location of invention of the share of EPO/USPTO equivalent patents in the total number of EPO patents granted to EU MNEs and their counterparts in the USPTO. EPO patents with USPTO equivalents represent almost half of all EU MNE EPO patents, but only just over one third of all the USPTO patents granted to these firms. This implies that less than two thirds of the EU MNEs' patenting activities reflected in the USPTO are not measured by the EPO, whereas almost half of the patenting activities of these firms captured by the EPO are not reported in the USPTO. It appears therefore that these two datasets offer a different picture of the innovative activities of these firms, a picture that overlaps only partially.

MNLs have inventors from different countries. For the sample of EPO applications with USPTO equivalents the share of patents with inventors from several countries is slightly lower: $11.7 \%$ for EU MNE and $7.4 \%$ for US MNE patents. This may indicate that EPO/USPTO equivalents are not more likely than patents without equivalents in the other patent office to have inventors from different countries and therefore may explain why. at the sectoral level. there are no significant differences between the shares derived using the two counting methods. 


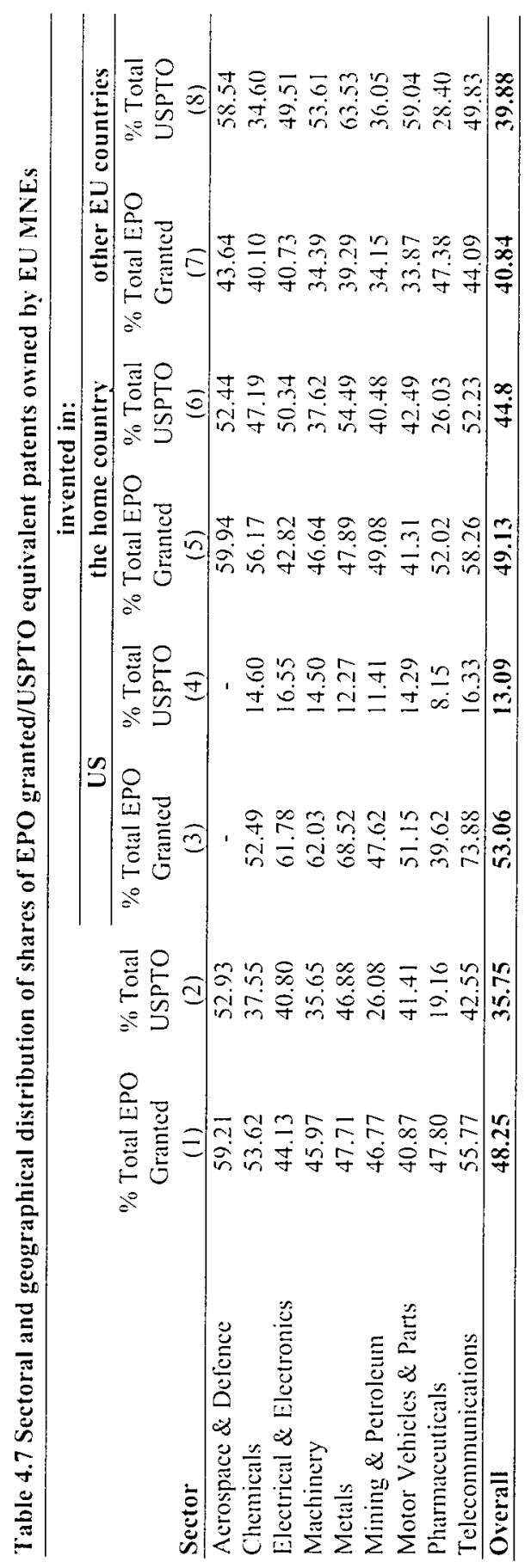


The other columns in Table 4.7 illustrate how this problem may affect the internationalisation indicators presented in Table 4.2. The third and fourth columns of Table 4.7 show the percentage share of US-invented EPO patents with USPTO equivalents in respectively the total number of US-invented EPO patents and USPTO patents. Thus if both shares were equal to 100 it would imply that all the US-performed R\&D activities of EU MNEs were captured to the same extent by the EPO and the USPTO. If instead the EPO share was very large while the USPTO share was very small, it would mean that the EPO dataset was measuring only a small proportion of the patenting activity of US affiliates, assuming that USPTO data better reflect their innovative performance. This possible outcome is illustrated in Figure 4.1 where the shaded area representing the number of EPO/USPTO equivalent patents overlaps almost completely with the set of EPO granted patents invented in the US and only partially with the set of USPTO patents originating from the same location.

\section{Figure 4.1 An illustration of the EPO/USPTO shares of equivalent patents}

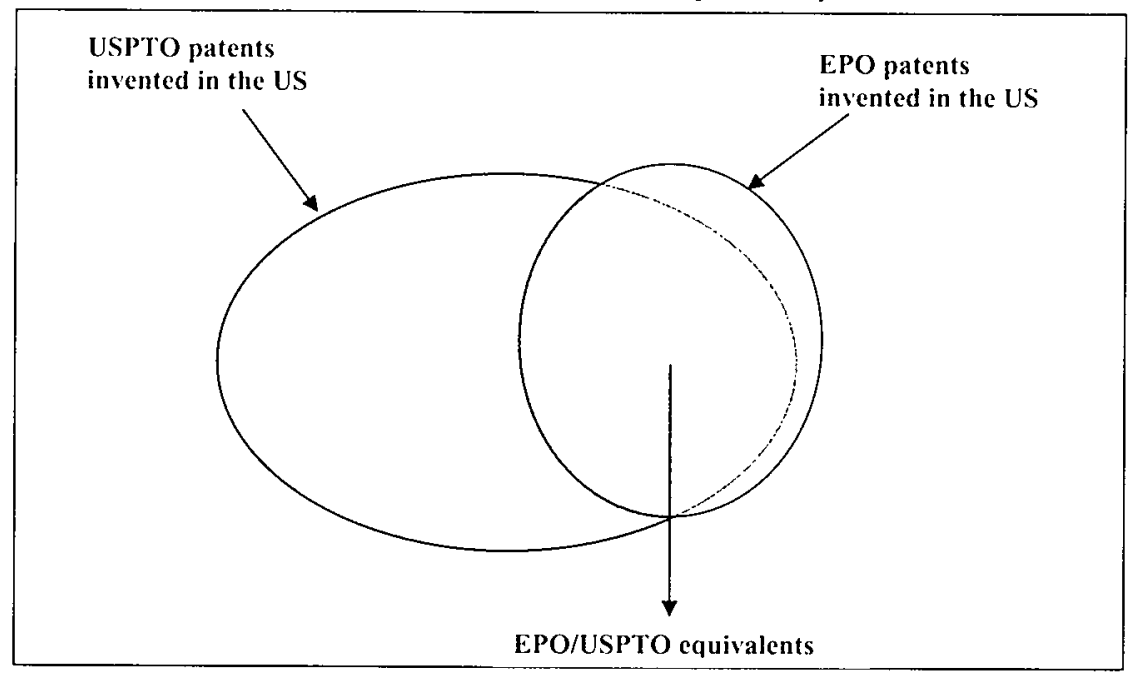

The actual figures show that the case for EPO applications is less extreme (see Table A4-6 in the appendix) but not for EPO granted patents. The number of US-invented EPO/USPTO cquivalents represents $53 \%$ of all EU MNE EPO patents and only $13 \%$ of their USPTO patents invented in this country. However there is some variation across sectors. In metals, telecommunications, machinery, and electronics the problem is particularly severe: the number of EPO/USPTO equivalents represents $62 \%$ to $74 \%$ of EPO patents but the same EPO/USPTO equivalents account for only $12 \%$ to $16 \%$ of USPTO patents. 
Columns 5 and 6 report the shares of EPO/USPTO equivalents invented in the home country of the MNEs. In this case the number of EPO/USPTO patents accounts for almost half of all the EPO patents granted to EU MNEs and 45\% all their USPTO patents that originate from these countries. Thus, USPTO data will only measure part of the patenting activities of EU MNES' R\&D facilities in their home countries and especially in the case of pharmaceuticals where the low share may be due to the previously mentioned differences between the practices of the two patent offices conceming the patentability of inventions in biotechnology. The figure computed using EPO applications is much higher (see Table A4-6 in the appendix). This may also explain the low share of USPTO patents granted to European affiliates in chemicals and pharmaceuticals (see columns 7 and 8 ) represented by EPO/USPTO equivalents. Overall the figures in columns 7 and 8 are similar to those for home country patenting activities, but there is a substantial amount of variation across sectors. The number of EPO/USPTO equivalents in sectors like motor vehicles \& parts, and metals represents $59 \%$ to $63 \%$ of USPTO patents invented within the EU but only $33 \%$ to $39 \%$ of EPO patents from the same locations. This might be due to the asset-exploiting nature of these foreign R\&D activities, whose results are potentially less applicable to other contexts.

Table 4.8 presents the shares for the sample of patents owned by US MNEs (see Table A4-7 in the appendix for the proportions based on EPO applications). EPO/USPTO equivalent patents correspond to only $14 \%$ of all USPTO patents granted to US MNEs, while they amount to $63 \%$ of all EPO patents granted to these firms. The respective figures calculated on the basis of EPO applications show a greater, though still quite small, overlap (25\% and $50 \%$ ). Thus the EPO data, whether applications or patents granted, only capture a very small proportion of the innovative activities of these firms. This problem, if anything, becomes more severe if one tries to measure the activity of these firms within their home country: EPO/USPTO equivalents represent $13 \%$ of the total number of US-invented USPTO patents and $66 \%$ of EPO patents invented there (see columns 5 and 6 ). This seems to indicate that US MNEs do not extend their US-invented USPTO patents to the EPO. US machinery, motor vehicles \& parts, electrical \& electronics, and telecommunications MNEs appear to have adopted this strategy more intensively than firms in other sectors. 


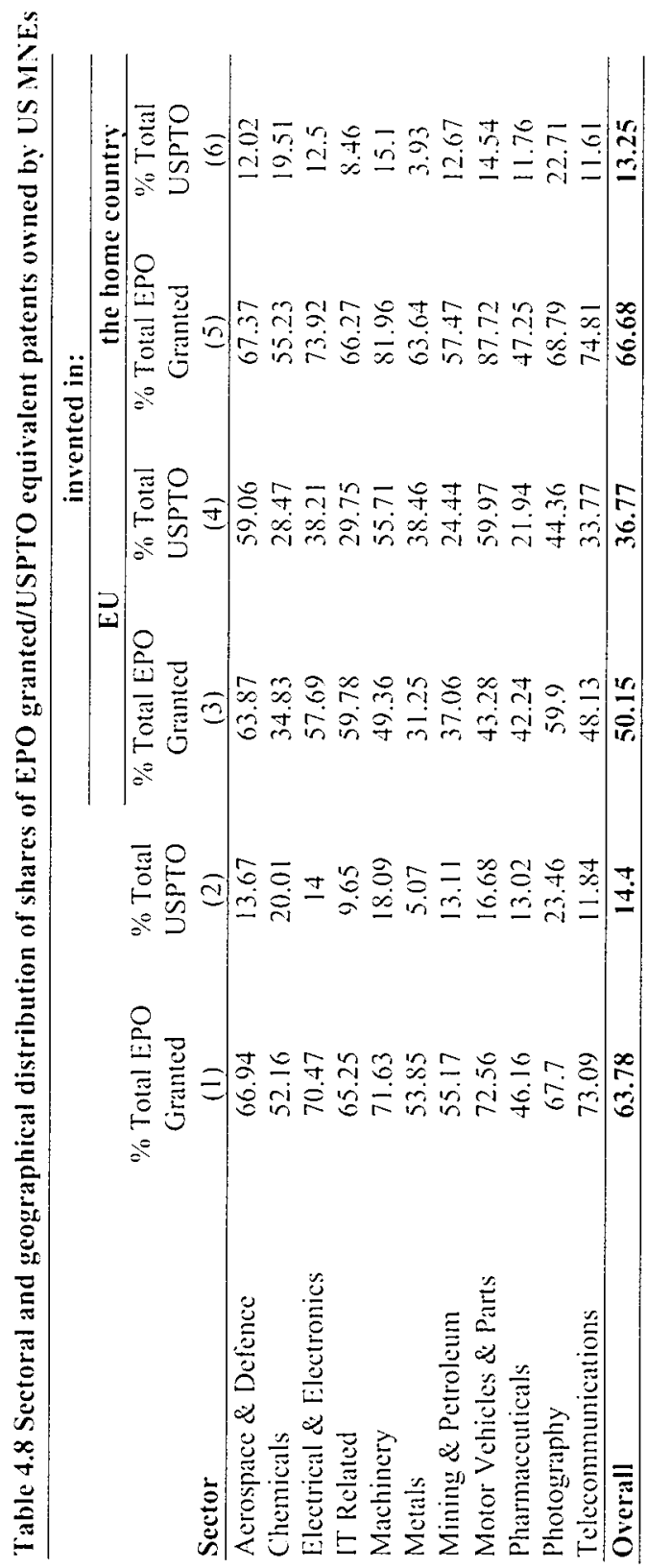


According to the figures in columns 3 and 4 of Table 4.8 , EU-invented EPO/USPTO equivalents represent hall of all EPO patents originating from this region and just over one third of USPTO patents. Thus there is a greater degree of overlap between these two datasets than is the case for patents originating from the home country. US aerospace \& defence, machinery, and photography MNEs appear to file a significant number of EU-invented patents in both the EPO and the USPTO (see the corresponding figures in Table A4-7 in the appendix). whereas companies in IT-related industries and pharmaceuticals seem to follow the opposite strategy, based on shares of EPO patents granted. The shares calculated on the basis of EPO applications show a different trend (see Table A4-7); this might be explained by the different standards applied in the EPO and the USPTO for biotechnology and software inventions.

There are three main conclusions that can be derived from the figures presented in Tables 4.7 and 4.8. First, the EPO and the USPTO capture different technological activities with a degree of overlap that changes with the geographical origin of the patents. For instance almost $45 \%$ of US-invented patents owned by EU MNEs are filed with, and granted only by the EPO (60\% of applications). A priori, one would expect that most EPO patents invented in the US would have had an equivalent in the USPTO and vice versa for EU-invented patents. It could be that the EU MNEs who filed US-invented patents with the EPO made unsuccessful applications to the USPTO.

Second, if one assumes that the USPTO measures the innovative activity performed in the US better, then the EPO captures a very small proportion of both the home-country R\&D activities of US MNEs and the innovative efforts of US affiliates of EU MNEs. In other words, US-invented patents tend to be patented in, and granted by, the USPTO and only in $13 \%$ of the cases are these patents also applied for and granted by the EPO $(25 \%$ is the share for EPO applications). This is in line with the home-country bias found in Table 4.2 for both US subsidiaries of EU MNEs and the home country patenting activities of US MNEs. In contrast, the bias for EU-invented patents is less severe: $40 \%$ and $50 \%$ of EPO patents granted respectively to US and EU MNEs originating from within the EU are also filed with and granted by the USPTO. This seems to confirm in part that the EPO is a more international patent office with less home-country bias.

Third, on the basis of the figures presented both in this section and in the previous one, the claim that large non-US firms will tend to file for patents with the USPTO even when the 
innovative activity did not take place in the US can be rejected. Filing for a patent in more than one patent office is an expensive procedure and, therefore, even for large firms with significant financial resources, external patent protection will be sought only when the expected commercial value and exploitation of the invention justify it. ${ }^{57}$ There may be other reasons explaining the patenting behaviour of these firms that are more related to the different standards for patentability in the two systems. Some of these factors are identified by Hingley and Park (2003) in their analysis of the country of origin of priority patents that form Triadic patent families. They found that the number of USPTO priority patents consistently decreased during the 1980 s and they offer three possible explanations.

First, because the USPTO has lowered the standards of novelty and non-obviousness, USPTO patents cannot be filed with other patent offices because they are not valuable enough. Second, the increase in the cost of patenting in the USPTO might have discouraged applicants from secking patent protection elsewhere. Third, the existence of different patentability standards across patent offices might have lead US applicants to seck protection for inventions related to technologies such as software and biotechnology at home, but not in other countries, where such inventions are not considered patentabic.

\subsubsection{Empirical model}

The figures presented so far are indicative of a correlation between the location of invention and the likelihood of filing a patent with both the EPO and the USPTO. This is tested in a multivariate regression framework that allows control for firm and technology-specific fixed effects. In theory, firms have three options: they can patent in the USPTO only, in the EPO only, or in both patent offices. In reality they can apply for patent protection with more than two patent offices at a time, but this investigation is only looking at the EPO and the USPTO. Therefore the dependent variable I use should take 3 values ( 0 if a firm decides to patent only with the EPO, 1 if it protects its invention only in the USPTO and 2 if it applies for a patent in both offices) and a multinomial model should be used in this case. I attempted to estimate this model, but the assumption of independence from irrelevant alternatives (IIA) was rejected, ${ }^{58}$

\footnotetext{
5 The cost of an average European patent (English Language, 10 claims. 8 countries. 10 year duration) in 2003 was $€ 31.100$. This includes an estimate of professional representation before the EPO $(\in 6.120)$. the official patent office fees that are a relatively small part of the costs (in this case $€ 4,270$ ): translation into the languages of eight contracting states $(€ 11.800)$ and renewal fees for a patent maintained for 10 years $(€ 8.910)(\mathrm{Nash}$ 2003). For a USPTO patent the fees for filing and issue of a patent are $\$ 2.030$ and renewal fees for up to 11 years are $\$ 2.090$ (see USPTO rule 1.16). The legal fees are around $\$ 4.000$ according to the USPTO web site (http:/Www.uspto.gov/go/kids/kidprimer.html). but they can be as much as $\$ 8.000$ according to some law firms.

st The multinomial logit model requires that the odds ratio for any pair of choices is assumed independent of any third alternative, i.e. elimination of one of the choices should not change the ratios of the probabilities of the
} 
which implies that the multinomial model would give consistent but inefficient estimates. I therefore estimated a probit model where the dependent variable takes the value of 1 if a patent in one patent system has an equivalent in the other system and zero otherwise. This model assumes that the occurrence of an invention that itself is patented in both patent offices depends on an unobservable index (EPO_USPTO) that is a function of a vector $\left(X_{i}\right)$ of explanatory variables observed for each patent $i$. The higher the value of EPO_USPTO the higher is the chance that the invention has been protected in both offices.

$$
\text { EPO_USPTO }=\beta^{\prime} \mathrm{X}_{i}+\varepsilon_{i t}
$$

where $\beta$ is a $(k \times 1)$ vector of parameters and $X_{i}$ is a $(k \times 1)$ vector of explanatory variables. In what follows I report marginal effects estimates that have been calculated at the means of the explanatory variables. For dummy variables, marginal effects were calculated at the discrete change in the expected value of the dependent variable as the dummy variable changed from 0 to 1 .

The explanatory variables used in the probit model try to control for the economic and technological value of the patent. The economic and technological value of the innovation is captured by the number of citations received by each patent within each system and within a time lag of 4 years $(C R)$. Thus I counted the number of citations an EPO (USPTO) patent receives from subsequent EPO (USPTO) patents filed within 4 years of the filing date of the cited patent. Patent citations have been shown to be correlated with the value of innovations (Trajtenberg 1990) and the total number of citations received by patents has been used in other studies as an indicator of their relative importance (Lanjouw and Schankerman 1999 , Trajtenberg et al. 1997). Another variable that can be used to control for the value of a patent is the size of its patent family. Putnam (1996) and other authors have shown that there is a high positive correlation between the value of a patent and its family size. However introducing the total number of equivalent patents in the probit model might cause some problems of simultaneity; therefore for the sample of EPO patents I constructed a variable equalling the number of countries designated for protection among EPO member countries (dest_states). Following Guellec and Pottelsberghe (2002), I tried to control for high value patents using different groupings of countries and built a dummy variable $(G 3+1)$ which takes the value of one if Germany, France, the United Kingdom and another country are designated

remaining choices. Choices that are close, in the sense of being highly correlated. tend to violate the IIA assumption. I tested the validity of this assumption using both the Hausman and Macladden (1984) test and the Small and Hsiao (1985) procedure. 
for protection. Guellec and Pottelsberghe in their 2002 study also show that the procedure followed in filing a patent with the EPO has an impact on the success rate of EPO applications and therefore on the technological value of the patent. In particular they found that EPO applications transferred through the Patent Co-operation Treaty (PCT) route are more successful than direct applications. I tried to capture this with a dummy variable $(P C T)$ equalling one if the EPO or the USPTO patent has been applied for through the PCT route, and zero otherwise." In addition, since with the PCT procedure the applicant can achieve patent protection in up to 100 member countries, one can also assume that the applicant will tend to follow this route when it intends to protect the invention in both the EPO and the USPTO. I considered the total number of applicants $\left(10 t_{-} a p p l\right)$ of an EPO patent and the total number of inventors ( $t o t_{\text {_ }} \mathrm{im}$ ) of a USPTO patent as a proxy for the size of the R\&D project giving rise to the patented invention. The assumption I made is that the higher the number of applicants or inventors involved in the innovative effort, the higher the technical quality of the patent. Although the main variables of interest are the ones capturing the location of the invention, I would expect the likelihood of an EPO patent having a USPTO equivalent, and vice versa, increases with the value of the patent, because extending patent protection abroad involves higher costs for the applicant company.

To test whether the location of the invention has an impact on the probability of a firm secking protection in both patent offices I created different dummy variables describing the geographical location of the team of inventors listed in the patent file. If at least one inventor was resident in a European country, inv_EU is equal to one and zero otherwisc. Similarly $i n v_{-} U S$ is a dummy variable equal to one if at least one inventor has an US address. I also controlled for the degree of international research collaboration by introducing a dummy variable that takes the value of one if there is more than one inventor (multi_reg_im) with addresses in different regions (EU or US).

From the figures reported in Tables 4.7 and 4.8 a positive impact on the likelihood of an EPO patent having a USPTO equivalent if it was invented in the US (and vice versa) would be expect, i.c. the estimated coefficient on inv_US ( $i m_{-} E U$ ) should be positive. In contrast EUinvented EPO patents should show a lower probability of being extended for protection in the

\footnotetext{
51) The authors distinguish between patents that were transferred to the EPO through the PCT procedure during the first stage, called Chapter I, and those that were transferred during the second stage. called Chapter II. In my dataset all EPO applications through the PCT route were transferred after Chapter I, i.e. the international filing date coincides with the filing date of the EPO application (sec Guellec and Pottelsberghe 2002 for a more extensive explanation of the PCT procedure).
} 
USPTO (and vice versa), i.e. the estimated coefficient on invEE (im_US) should be negative. But a priori I did not know whether these effects would be stronger if the applicant is an EU or a US multinational, or whether they differ across sectors or technology fields. The shares presented in the tables pointed towards some sectoral heterogeneity that could be tested more accurately in a regression framework. To assess the presence of different patenting behaviour in the EU and the US by EU and US MNEs, I constructed four multiplicative dummy variables ( $E U$ in $E U: E U$ inv_US: US_ $i n v_{-} E U ; U S \_i n V_{-} U S$ ) derived by interacting the two location variables ( $i n v_{-} E U$ and $i n v_{-} U S$ ) with two other dummies (EU and US) capturing the home region of the applicant.

For EU MNEs I also distinguished between patents originating from the home country of the multinational and those developed by European subsidiaries. This is captured by two dummy variables: home_ctry, which takes the value of one if there is at least one inventor from the home country of the applicant, and other $E U$ which is equal to one if there is at least one inventor in the patent file with residence in one European country outside the home country. Although the figures reported in Table 4.7 do not suggest it, it is interesting to see whether there is some difference between patents originating from the home country of EU MNEs and patents invented in European subsidiaries of these companies. Given that the main core and strategic R\&D activities are carried out in the home base of the multinational, inventions developed at home might be less context-specific and more general in nature; thus they may be more likely to be extended for protection in an external patent office. I therefore expected the likelihood of an EPO patent having a USPTO equivalent to be positively correlated with the home_ctry variable, but negatively correlated with the otherEU variable.

Finally 1 included in the probit model a large number of dummy variables to control for additional sources of variation. For the sample of EPO patents, I introduce 11 technology class dummies that were constructed on the basis of the classification provided by OST and ISI: electronics components \& semiconductors; telecommunications \& audiovisual; instruments; chemicals \& drugs; biotechnology \& agricultural products; metal working \& materials; industrial chemicals \& oil refining; machinery \& engineering; transportation; industrial processes; and household consumption (see Table A4-8 in the appendix). For the sample of USPTO patents, I included six technology field dummies based on the classification contained in the NBER patent database: chemicals; computers \& communications; drugs \& medical; electrical \& electronics; mechanicals; and others. I also introduced year dummies (corresponding to the priority year for EPO applications and to the 
application year for USPTO patents), and firm dummies. These technology and firm-specific dummies should control for factors, other than the value of the patent and the location of invention, to explain the patenting strategy of these firms. I do not claim to be able to completely explain the patenting behaviour of these firms: this would require a more qualitative type of analysis, such as the survey carried by Bertin and Wyatt (1988). I am interested here in the sign and the significance of the marginal effect of the dummies capturing the location of invention.

I estimated the probit model first using the sample of EPO patents for the period 1989-2000 and then using the sample of USPTO patents for the period 1990-99, for which I have information on the total number of inventors. Table 4.9 reports the summary statistics of the variables used in the regressions according to the nationality of the applicant $(v$ is the dependent variable). A large share of EPO patents were applied for through the PCT: on average $30 \%$ of US MNE patents and $36 \%$ of EU MNE patents. In contrast, the share of USPTO patents applied for through the PCT procedure is much smaller: less than $10 \%$ on average for US MNEs and 19\% for EU MNEs. The number of citations received by EPO patents from other EPO patents ranges from 0 to 60, while forward citations within the sample of USPTO patents show a maximum of 131 citations per patent at an average of more than 3 citations per US-owned patent and just under 2 per EU-owned patent. This large disparity in the number of citations received in the two systems will be examined in more detail in the next chapter. The share of USPTO patents with EPO-equivalent patents granted is equal to $51 \%$ for the sample of US MNEs' patents and $68 \%$ for the sample of EU MNEs patents (see variable EPO granted $)$. 
Table 4.9 Descriptive statisties

\begin{tabular}{|c|c|c|c|c|c|c|c|c|c|c|c|}
\hline \multicolumn{6}{|c|}{ Sample of EPO patents } & \multicolumn{6}{|c|}{ Sample of USPTO patents } \\
\hline \multicolumn{6}{|c|}{ US MNES } & \multicolumn{6}{|c|}{ US MNES } \\
\hline Variable & Obs. & Mean & $\begin{array}{l}\text { Std } \\
\text { Der }\end{array}$ & Min & $\operatorname{Max}$ & Variable & Obs. & Mean & $\begin{array}{l}\text { Std } \\
\text { Dev }\end{array}$ & Min & $\operatorname{Max}$ \\
\hline$\gamma$ & 76904 & 0.511 & 0.500 & () & 1 & $\mathrm{v}$ & 122595 & 0.256 & 0.436 & 0 & 1 \\
\hline Gramted & 76904 & (0.391 & 0.488 & 0 & 1 & $E P O$ gramted & 31497 & 0.512 & 0.499 & 0 & 1 \\
\hline tot_appl & 76904 & 1.040 & 0.256 & 1 & 5 & tot im & 122595 & 2.464 & 1.631 & 1 & 32 \\
\hline des_states & 76904 & 9.187 & 6.530 & (0) & 20) & & & & & & \\
\hline $63+1$ & 76904 & 0.932 & 0.251 & () & 1 & & & & & & \\
\hline$P C T$ & 76904 & 0.305 & 0.461 & 0 & 1 & $P C T$ & 122595 & 0.098 & 0.297 & 0 & 1 \\
\hline$C R$ & 76904 & 0.611 & 1.427 & 0 & 60 & $C R$ & 122595 & 3.333 & 5.498 & 0 & 131 \\
\hline multi reg_im & 76904 & 0.043 & 0.204 & () & 1 & mulli_reg_im & 122595 & 0.033 & 0.179 & 0 & 1 \\
\hline$i n \cdot \overline{E U}$ & 76904 & 0.155 & 0.362 & () & 1 & in $\overline{E U}$ & 122595 & 0.064 & 0.245 & 0 & 1 \\
\hline$i m \cdot U S$ & 76904 & 0.840 & 0.367 & 0 & 1 & $i m:-U S$ & 122595 & 0.924 & 0.264 & 0 & 1 \\
\hline \multicolumn{6}{|c|}{ EUMNES } & \multicolumn{6}{|c|}{ EUMNES } \\
\hline Vari & Obs. & Mean & $\begin{array}{l}\text { Std } \\
\text { Dev }\end{array}$ & Min & Max & Vari & Obs. & Mean & $\begin{array}{l}\text { Std } \\
\text { Dev }\end{array}$ & Min & $\operatorname{Max}$ \\
\hline$Y$ & 112390 & 0.346 & 0.476 & 0 & 1 & $v$ & 66983 & 0.495 & 0.500 & 0 & 1 \\
\hline Gromled & 112390 & 0.458 & 0.498 & 0 & 1 & EPO granted & 33131 & 0.684 & 0.465 & 0 & 1 \\
\hline$t o t \_a p p l$ & 112390 & 1.042 & 0.213 & 1 & 6 & tot_inv & 66983 & 2.647 & 1.712 & 1 & 22 \\
\hline des states & 112390 & 10.557 & 6.037 & 0 & 20 & & & & & & \\
\hline$G 3+1$ & 112390 & 0.890 & 0.312 & 0 & 1 & & & & & & \\
\hline$P C T$ & 112390 & 0.360 & 0.480 & 0 & 1 & $P C T$ & 66983 & 0 . & 0.392 & 0 & 1 \\
\hline$C R$ & 112390 & 0.513 & 1.262 & 0 & 38 & $C R$ & 66983 & 1.855 & 3.409 & 0 & 93 \\
\hline multi_reg_im & 112390 & 0.032 & 0.176 & 0 & 1 & multi_reg im & 66983 & 0.038 & 0.192 & 0 & 1 \\
\hline$i n w_{-} \overline{E U}$ & 112390 & 0.891 & 0.311 & 0 & 1 & inv $\bar{E} U$ & 66983 & 0.751 & 0.433 & 0 & 1 \\
\hline$i m-U S$ & 112390 & 0.120 & 0.324 & 0 & l & inv US & 66983 & 0.256 & 0.437 & 0 & 1 \\
\hline home ctry & 112390 & 0.736 & 0.441 & 0 & l & home cory & 66983 & 0.625 & 0.484 & 0 & 1 \\
\hline Other $E U$ & 112390 & 0.187 & 0.390 & 0 & 1 & other $\bar{E} U$ & 66983 & 0.157 & 0.364 & 0 & 1 \\
\hline
\end{tabular}

The results from the multivariate probit specifications for the sampic of EPO patents are summarised in Table 4.10. The first three columns show the estimates based on EPO patents both applied for and granted - while the remaining columns report the marginal effects obtained using only the sample of granted patents. The models in columns 1 and 4 use as a proxy for the value of the patent the number of countries designated in the EPO application, while in the other specifications this control variable is captured by the set of the designated countries $(G 3+1)$. 
Table 4.10 Empirical estimates from the probit model for the sample of EPO patents

\begin{tabular}{|c|c|c|c|c|c|c|c|c|}
\hline & (1) & (2) & (3) & (4) & (5) & (6) & (7) & (8) \\
\hline & \multicolumn{3}{|c|}{ Patent applications } & \multicolumn{5}{|c|}{ Patents granted only } \\
\hline & \multicolumn{3}{|c|}{ 1989-2000 } & \multicolumn{3}{|c|}{$1989-2000$} & $1989-92$ & $1996-98$ \\
\hline grctmed & & & $\begin{array}{c}0.141 \\
(52.50)\end{array}$ & & & & & \\
\hline des_states & $\begin{array}{c}0.036 \\
(5.97) \cdots \\
-0.001 \\
(5.05) \cdots\end{array}$ & $\begin{array}{c}0.035 \\
(5.84) \cdots\end{array}$ & $\begin{array}{c}0.033 \\
(5.49)^{\cdots}\end{array}$ & $\begin{array}{c}0.026 \\
(3.00) \cdots \\
-0.004 \\
(7.38)^{\prime} \cdots\end{array}$ & $\begin{array}{c}0.025 \\
(2.90)\end{array}$ & $\begin{array}{c}0.027 \\
(2.86)^{\ldots}\end{array}$ & $\begin{array}{l}-0.001 \\
(0.07)\end{array}$ & $\begin{array}{r}0.008 \\
(0.28)\end{array}$ \\
\hline$G 3+1$ & & $\begin{array}{c}0.032 \\
(7.63) \cdots\end{array}$ & $\begin{array}{c}0.031 \\
(7.31)\end{array}$ & & $\begin{array}{c}0.037 \\
(5.94)\end{array}$ & $\begin{array}{c}0.038 \\
(5.68)^{\cdots}\end{array}$ & $\begin{array}{c}0.037 \\
(3.46)^{\cdots}\end{array}$ & $\begin{array}{l}-0.005 \\
(0.32)\end{array}$ \\
\hline$P C T$ & $\begin{array}{c}-0.059 \\
(19.85)^{\cdots}\end{array}$ & $\begin{array}{c}-0.058 \\
(19.51)^{*}\end{array}$ & $\begin{array}{c}-0.074 \\
(24.69)^{\cdots}\end{array}$ & $\begin{array}{l}-0.039 \\
(8.45) \cdots\end{array}$ & $\begin{array}{l}-0.04 \\
(8.75)^{\cdots}\end{array}$ & $\begin{array}{l}-0.021 \\
(3.95)^{\cdots}\end{array}$ & $\begin{array}{c}0.031 \\
(3.39)^{\cdots}\end{array}$ & $\begin{array}{c}-0.225 \\
(17.28)^{\cdots}\end{array}$ \\
\hline$C R$ & $\begin{array}{l}-0.008 \\
(8.33)^{\cdots}\end{array}$ & $\begin{array}{l}-0.008 \\
(8.76)^{\cdots}\end{array}$ & $\begin{array}{c}-0.01 \\
(10.82)^{\cdots}\end{array}$ & $\left(\begin{array}{c}-0.014 \\
(1 ! .04)\end{array}\right.$ & $\begin{array}{c}-0.015 \\
(11.67)^{\circ}\end{array}$ & $\begin{array}{l}-0.01 \\
(0.81)^{\cdots}\end{array}$ & $\begin{array}{l}-0.01 \\
(4.71)^{\cdots}\end{array}$ & $\begin{array}{l}-0.006 \\
(0.89)\end{array}$ \\
\hline mulli_reg_im & $\begin{array}{l}-0.029 \\
(3.58)^{\cdots}\end{array}$ & $\begin{array}{l}-0.029 \\
(3.55) \cdots\end{array}$ & $\begin{array}{l}-0.023 \\
(2.76) \cdots\end{array}$ & $\begin{array}{l}-0.025 \\
(1.79)^{\circ}\end{array}$ & $\begin{array}{l}-0.024 \\
(1.76)^{\circ}\end{array}$ & $\begin{array}{l}-0.022 \\
(1.30)\end{array}$ & $\begin{array}{l}-0.022 \\
(0.78)\end{array}$ & $\begin{array}{l}-0.056 \\
(1.41)\end{array}$ \\
\hline$E U_{-} i m_{-} E U$ & $\begin{array}{l}-0.055 \\
(5.29)^{\cdots}\end{array}$ & $\begin{array}{l}-0.054 \\
(5.22)^{\cdots}\end{array}$ & $\begin{array}{l}-0.064 \\
(6.19) \cdots\end{array}$ & $\begin{array}{l}-0.04 \\
(2.37) . *\end{array}$ & $\begin{array}{l}-0.041 \\
(2.40)^{\circ}\end{array}$ & $\begin{array}{l}-0.094 \\
(4.47)^{\circ}\end{array}$ & $\begin{array}{l}-0.055 \\
(1.48)\end{array}$ & $\begin{array}{l}-0.253 \\
(4.99) \cdots\end{array}$ \\
\hline$U S_{-} i m_{-} E U$ & $\begin{array}{l}-0.076 \\
(8.55)^{\cdots}\end{array}$ & $\begin{array}{l}-0.076 \\
(8.60) \cdots\end{array}$ & $\begin{array}{c}-0.089 \\
(10.03)^{\cdots}\end{array}$ & $\begin{array}{l}-0.103 \\
(0.87) \cdots\end{array}$ & $\begin{array}{l}-0.107 \\
(7.12) \cdots\end{array}$ & $\begin{array}{l}-0.119 \\
(6.80)^{\cdots}\end{array}$ & $\begin{array}{l}-0.115 \\
(4.10)^{\ldots}\end{array}$ & $\begin{array}{l}-0.16 \\
(3.97)^{\ldots}\end{array}$ \\
\hline$E U_{-} i n V_{-} U S$ & $\begin{array}{c}0.093 \\
(8.71)^{\cdots}\end{array}$ & $\begin{array}{c}0.092 \\
(8.63)^{\cdots}\end{array}$ & $\begin{array}{c}0.096 \\
(8.92) \cdots\end{array}$ & $\begin{array}{c}0.043 \\
(2.57)^{*}\end{array}$ & $\begin{array}{c}0.042 \\
(2.49)^{*}\end{array}$ & $\begin{array}{c}0.063 \\
(3.00)\end{array}$ & $\begin{array}{c}0.01 \\
(0.26)\end{array}$ & $\begin{array}{c}0.184 \\
(3.51)^{\cdots}\end{array}$ \\
\hline US_inv US & $\begin{array}{c}0.108 \\
(12.17)^{\cdots \cdots}\end{array}$ & $\begin{array}{c}0.106 \\
(12.03)^{*}\end{array}$ & $\begin{array}{c}0.109 \\
(12.29)^{\cdots}\end{array}$ & $\begin{array}{c}0.075 \\
(5.25)^{\cdots}\end{array}$ & $\begin{array}{c}0.073 \\
(5.07)^{\cdots}\end{array}$ & $\begin{array}{c}0.083 \\
(5.01)^{\cdots}\end{array}$ & $\begin{array}{c}0.029 \\
(1.11)\end{array}$ & $\begin{array}{c}0.227 \\
(4.98)^{\cdots}\end{array}$ \\
\hline $\begin{array}{l}\text { Observations } \\
\text { Log-likelihood }\end{array}$ & $\begin{array}{r}189294 \\
-106984 \\
\end{array}$ & $\begin{array}{r}189294 \\
-106968 \\
\end{array}$ & $\begin{array}{r}189294 \\
-105588 \\
\end{array}$ & $\begin{array}{c}81602 \\
-51686.6 \\
\end{array}$ & $\begin{array}{r}81602 \\
-51696.5 \\
\end{array}$ & $\begin{array}{c}64800 \\
-40469.9 \\
\end{array}$ & $\begin{array}{c}25119 \\
-15810.9 \\
\end{array}$ & $\begin{array}{r}10315 \\
-5178.55\end{array}$ \\
\hline$E U_{-} m m_{-} E U=U$ & $S_{-} i m{ }_{-} E U$ & 4.10 & & & 10.70 & 0.91 & 1.85 & 1.39 \\
\hline Prob $>\chi^{2}$ & & 0.04 & & & 0.00 & 0.34 & 0.17 & 0.24 \\
\hline$E U_{-} i m, U S=$ & $i_{-} v_{-} U S$ & 1.63 & & & 2.35 & 0.64 & 0.21 & 0.58 \\
\hline Prob $>x^{2}$ & & 0.20 & & & 0.13 & 0.42 & 0.65 & 0.45 \\
\hline
\end{tabular}

All estimates include unreported firm, year and technological field dummies. Patents in the field of chemicals and pharmaceuticals have been dropped from the sample of patents used to derive the results in columns 6.7. and 8 . Robust t-statistics in brackets. significant at $10 \%$; ${ }^{\circ}$ significant at $5 \%$ : significant at $1 \%$.

By comparing the results in column 1 (2) with the ones in column 4 (5) it can be scen that the cstimates based on EPO applications are not very different from the ones obtained using only the sample of granted patents. However the fact that in column 3 the marginal effect of the dummy variable capturing the success of the EPO application (gremted) is positive and highly significant leaves open the possibility that the patent families of successful patents are different from the unsuccessful ones. I therefore discuss the findings based on patents granted only. 
The estimated coefficients on the variables capturing geographical origin and ownership of the patents are significant and have the expected sign: an EPO patent invented in the EU has a negative impact on the likelihood of it being extended to the USPTO. while the opposite is true for one invented in the US. However the analysis of the estimates at the sectoral (presented in Table 4.11) and technological levels (reported in Table 4.12) highlights some heterogeneity in the patenting behaviour of these firms and also some outliers. Estimates in column T4 of Table 4.12 show that an EU-invented patent in the field of chemicals \& pharmaceuticals granted to EU MNEs appears to be positively and significantly correlated with the probability of its having an USPTO equivalent (estimated coefficient on EU im EU $>0)$. This also applies to patents owned by EU pharmaceutical companies (sce Table 4.11 ). The estimated coefficient on $E U_{-} i n v_{-} E U$ is also positive, although not significant, for the sample of patents owned by MNEs in metals, mining \& petroleum, motor vehicles \& parts, and for patents in fields of metalwork \& materials, transportation, and houschold consumption.

Thus the estimates at the technological and sectoral levels suggest that the overall results may be driven by patents in chemicals \& pharmaceuticals, or by the patenting behaviour of MNEs in pharmaceuticals. I therefore re-estimated the probit model eliminating patents in the chemicals \& pharmaceuticals fields. The results of this regression are reported in column 6 of Table 4.10. The estimates do not change much, but the results of the tests of equality of the coefficients on the dummies variables capturing the geographical origin and ownership of the patents produce different outcomes. US MNEs show a higher negative propensity than the EU MNEs to extend EU-invented EPO patents to the USPTO when tested for the equality of the coefficients on $E U_{-} i n v_{-} E U$ and $U S_{-} i w_{-} E U$ reported in column 5 of Table 4.10. However this result might be driven by the sample of patents in chemicals \& pharmaceuticals for which the equality of the coefficients is also rejected (sec Table 4.12 column T4). Indeed if in column 6 of Table 4.10 patents in this technological field are excluded from the analysis, EU and US MNEs show the same propensity to extend both EU and US-invented EPO patents to the USPTO. This result appears to be consistent across the two sub-periods, 1989-92 and 1996-98 (see columns 7 and 8 , respectively), but does not apply to all sectors and technology ficlds. 


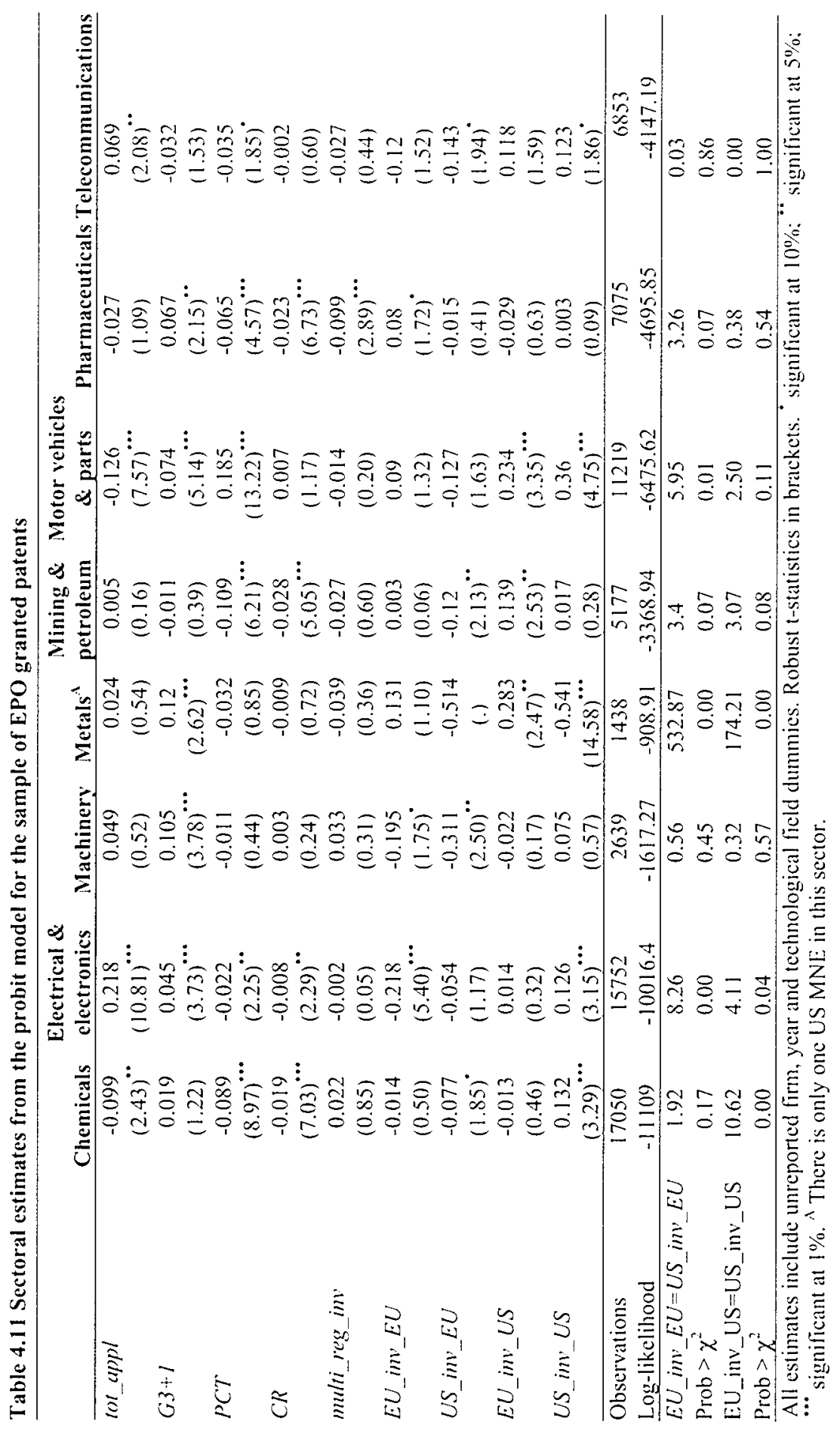




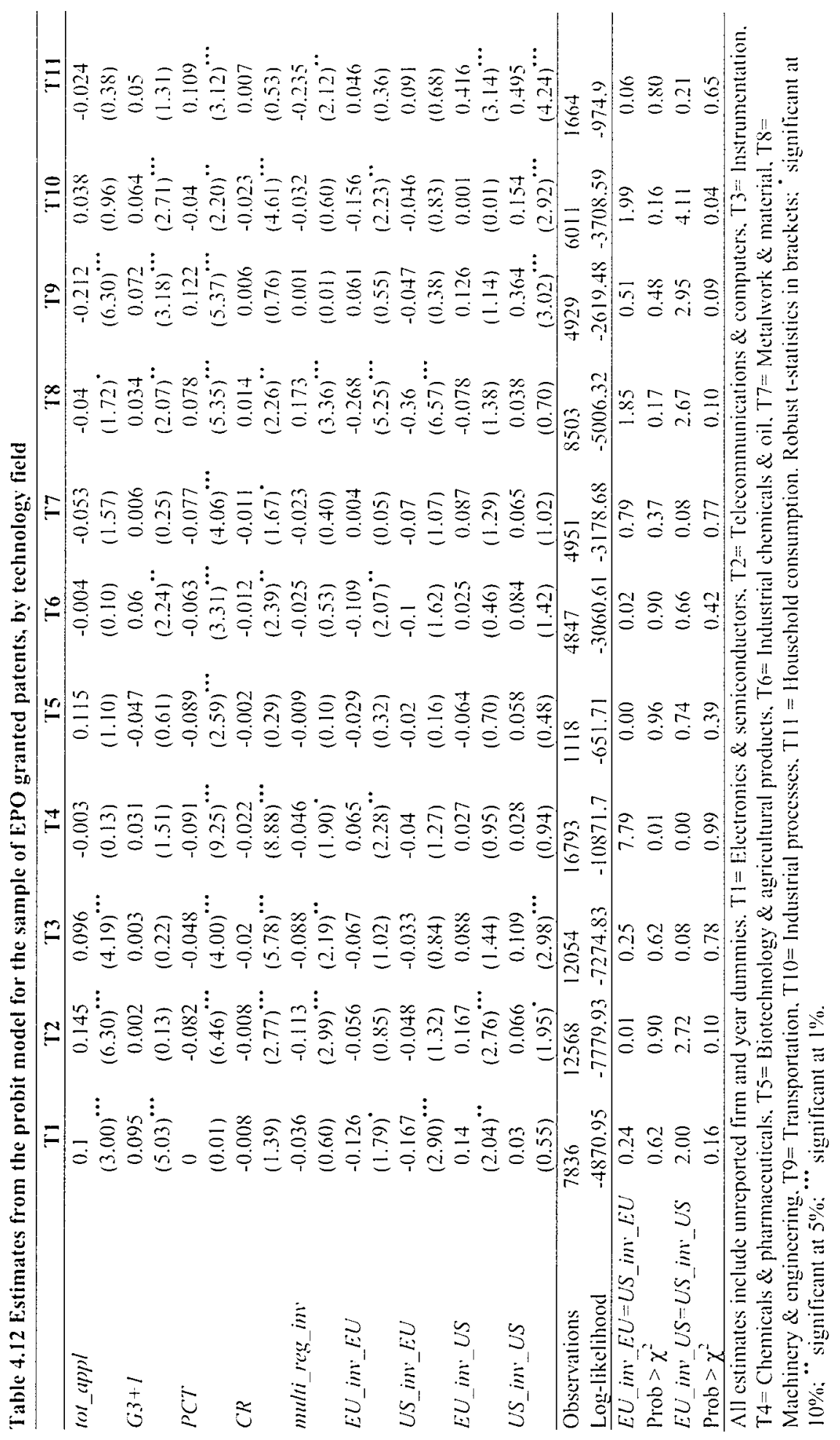


The results of the test reponted in Table 4.11 show that for the chemicals, electrical \& clectronics, metals, and mining \& petroleum sectors equality of the coefficients on the variables $E U_{-} i m_{-}$US and $U S_{L_{-}} i m w_{-}$US can be rejected. ${ }^{(t)}$ With the exception of firms in mining \& petroleum, there is a higher propensity for US-owned EPO patents invented in the US to be filed in the USPTO than their EU-owned counterparts. The test for equality of the coefficients $E U_{-} i m v_{-} E U$ and $U S_{-} i w_{-} E U$ can be rejected for the sample of patents in metals, motor vehicles \& parts, mining \& petroleum, pharmaceuticals, and electrical \& electronics. For all these sectors, with the exception of electrical \& electronics, the alternative hypothesis

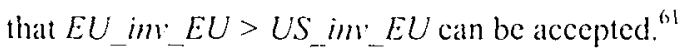

Tables 4.13 and 4.14 report the results for the sample of EU MNEs' EPO granted patents by sector and technology field to assess whether home country patents differ from patents for inventions made in other EU countries. In general whether an invention originates in an EU subsidiary or in the home country of the MNE has a negative impact on the likelihood of observing an EPO patent with a USPTO equivalent. Thus the a priori expectation that the likelihood of the EPO patent having a USPTO cquivalent is positively correlated with the home ctry variables is not confirmed. This is in line with the shares reported in Table 4.7, but is in contrast with what might be expected on the basis of the type of R\&D activities that tend to be performed in the MNE's home country. But there are some exceptions. The probability that patents for home country inventions in chemicals and mining \& petroleum MNEs are also filed in the USTPO is positive and significant as it is for patents for inventions in the field of chemical \& pharmaceuticals (estimated coefficient on home_c $t y>0$ ). These findings suggest that the estimates for this technology field on the EU inv EU dummy are mainly due to the sample of patents invented in the MNE's home country.

Although in most technological classes and sectors the coefficient on the home_ctry dummy is negative, there is a statistically significant difference between the impact of patents originating from the home country and from subsidiaries in other EU countries: EPO patents for inventions made in the MNE's home country are more likely to be filed for protection in the USPTO than patents for inventions made in other EU countries (see the results of the tests for the equality of coefficients on home_ctry and otherEU in Table 4.13 and 4.14).

\footnotetext{
Results for the metals sector should be read with caution since there is only one US MNE in this sector.

(1) The exclusion of patents granted to Philips from the electrical \& electronics sector does not change the results.
} 
In relation to the estimates of the control variables, with the exception of the variable proxying the size of the R\&D project $\left(t o t_{-}(t p p l)\right.$ and the dummy variable capturing patents designating Germany, France, the UK and at least one other country $(G 3+I)$, the coefficients on the other variables, although significant, are not positive. Contrary to what was expected, EPO patents applied for through the PCT procedure are less likely to be extended for protection in the USPTO; patents granted to firms in motor vehicles \& parts and in the fields of machincry \& enginecring, transportation, and houschold consumption are the exceptions. It is also worth noting that the sign of this coefficient changes across the two time periods, indicating some changes in the patenting strategies of the firms under analysis. Somewhat surprisingly, the number of citations received from subsequent EPO patents is not positively correlated with the presence of a USPTO patent in the family. Research co-operation between inventors from the EU and the US does not appear to lead to an equivalent patent in the other patent office, with the exception of patents in machinery \& engincering. This is consistent with the findings from comparing the inventor's address in EPO/USPTO equivalent patents with that in EPO patents without USPTO equivalent (see footnote 56). Finally, the higher the number of member countries designated for protection the lower is the likelihood that the EPO patent will have a USPTO equivalent, which is in line with the results obtained by Guellec and Pottelsberghe (2002).

In summary, the results obtained using the sample of EPO granted patents confirm that geographical origin and ownership is correlated with the probability of there being a USPTO equivalent among the family members: US-invented patents are also filed in the USPTO, while EU-invented patents are not, regardless of whether they originate from the MNE's home country or from another EU subsidiary. This holds true for both EU and US MNEs, although there is some degree of heterogeneity across sectors and technology ficlds. In particular patents owned by EU MNEs in pharmaceuticals and patents in chemicals \& pharmaceuticals appear to be extended for protection in the USPTO as are patents granted to chemicals and mining \& petroleum originating from the EU MNE's home country. 


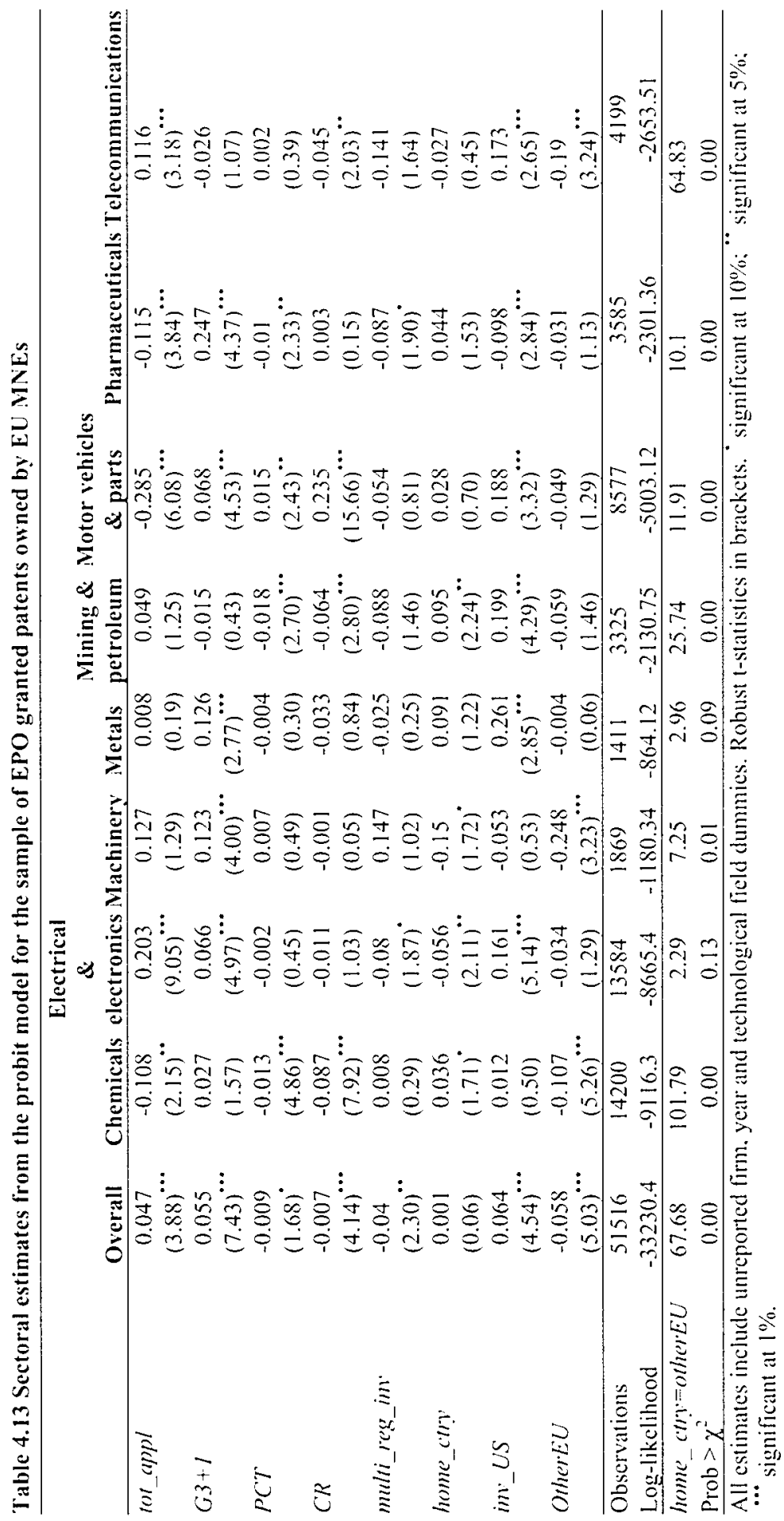




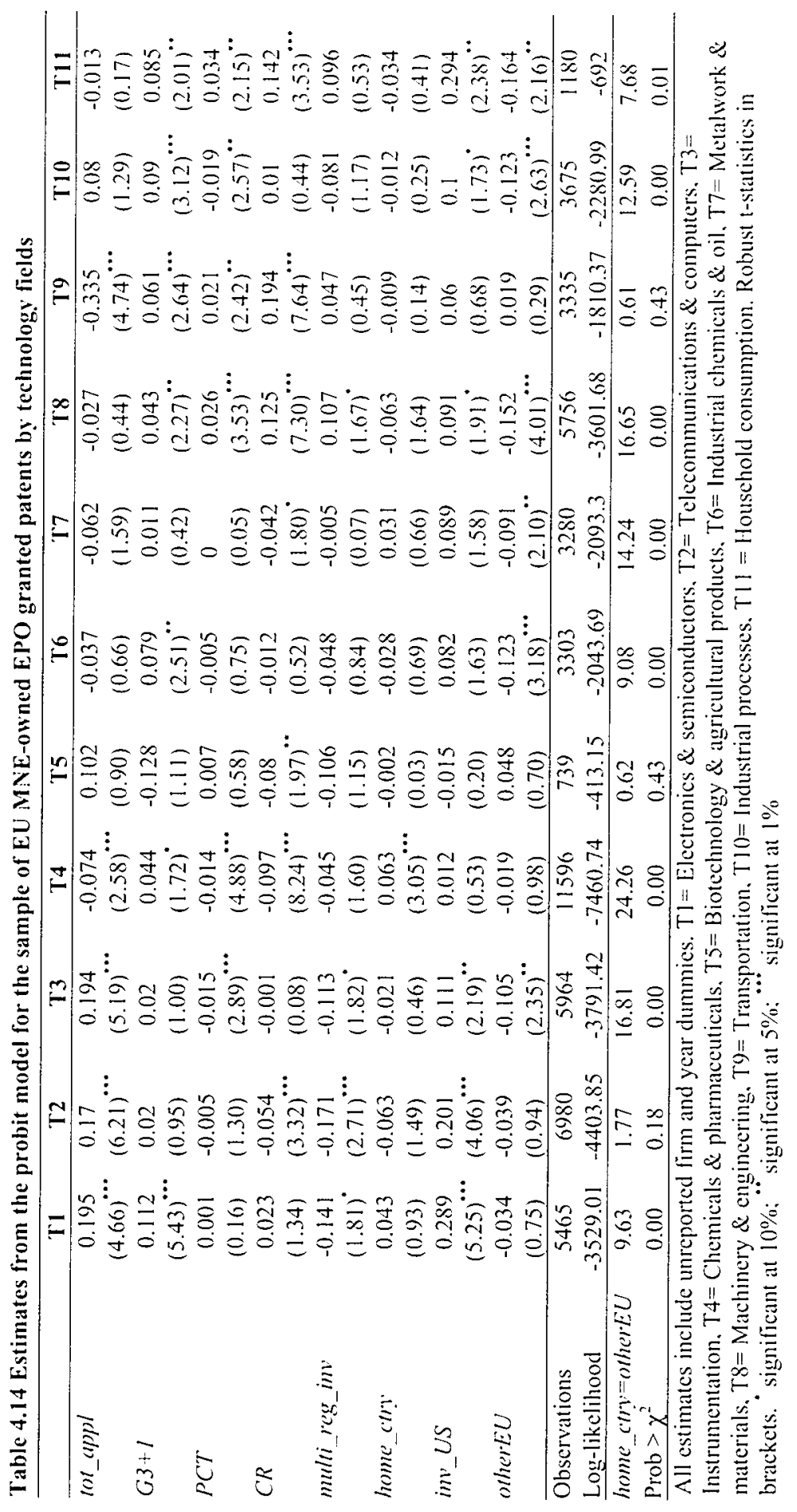


Table 4.15 Empirical estimates from the probit model for the sample of USPTO patents

\begin{tabular}{|c|c|c|c|c|c|}
\hline & \multirow{2}{*}{\multicolumn{2}{|c|}{$\begin{array}{l}\text { (1) } \\
\text { EPO equivalents applied for } \\
\text { and granted } \\
\end{array}$}} & \multirow{2}{*}{\multicolumn{3}{|c|}{$\begin{array}{l}\text { (3) } \\
\text { EPO equivalents granted }\end{array}$}} \\
\hline & & & & & \\
\hline & \multicolumn{2}{|c|}{$1990-99$} & $1990-99$ & $1990-91$ & $1997-98$ \\
\hline \multirow[t]{2}{*}{ tot im } & 0.001 & 0.002 & 0.002 & 0.002 & 0.002 \\
\hline & $(0.83)$ & $(2.18)^{\circ}$ & $(2.56)^{*}$ & (1.01) & $(2.37)^{\circ}$ \\
\hline \multirow[t]{2}{*}{$P C T$} & 0.49 & & & & \\
\hline & $(118.09)^{* * *}$ & & & & \\
\hline \multirow[t]{2}{*}{$C R$} & 0.004 & 0.004 & 0.004 & 0.006 & 0 \\
\hline & $(15.75)^{* * *}$ & $(17.93)^{\cdots}$ & $(18.42)^{\cdots}$ & $(10.64)^{\cdots}$ & $(0.25)$ \\
\hline \multirow[t]{2}{*}{ multi_reg inv } & -0.044 & -0.045 & -0.043 & -0.061 & -0.048 \\
\hline & $(5.63)^{* * *}$ & $(5.95)^{\cdots}$ & $(6.22)^{\cdots}$ & $(3.20)^{\cdots}$ & $(5.44)^{\cdots}$ \\
\hline \multirow[t]{2}{*}{$E U_{-} i m v_{-} E U$} & 0.178 & 0.185 & 0.176 & 0.215 & 0.188 \\
\hline & $(16.84)^{* * *}$ & $(18.33)^{\cdots}$ & $(17.71)^{\cdots}$ & $(8.72)^{\cdots}$ & $(11.43)^{\cdots}$ \\
\hline \multirow[t]{2}{*}{$U S_{-} i m \cdot E U$} & 0.199 & 0.204 & 0.210 & 0.189 & 0.195 \\
\hline & $(22.26)^{* * *}$ & $(23.57)^{\cdots}$ & $(23.68)^{\cdots \cdot}$ & $(8.78)^{\cdots}$ & $(12.69)^{\cdots \cdot}$ \\
\hline \multirow[t]{2}{*}{$E U_{-} m_{-} L S$} & -() .1 & -0.096 & -0.095 & -0.118 & -0.052 \\
\hline & $(10.47)^{* * *}$ & $(10.38)^{\cdots}$ & $(12.36)^{\cdots}$ & $(5.50)^{\cdots}$ & $(4.95)^{\cdots}$ \\
\hline \multirow[t]{2}{*}{$U S_{-} i m_{-} U S$} & -0.072 & -0.08 & -0.082 & -0.099 & -0.083 \\
\hline & $(9.75)^{* * *}$ & $(11.14)^{\cdots}$ & $(12.47)^{\cdots}$ & $(5.74)^{\cdots}$ & $(8.23)^{\cdots}$ \\
\hline Obscrvations & 189578 & 189578 & 163754 & $366 i 4$ & 38268 \\
\hline Log-likelihood & -98497.05 & -107315 & -73533.9 & -554.8 & -12596.3 \\
\hline$\overline{E U}$ inv_EU $=$ US_inv_EU & & 1.04 & 1.86 & 1.30 & 0.76 \\
\hline Prob $>\chi^{\overline{2}}$ & & 0,31 & 0.17 & 0.25 & 0.38 \\
\hline$E U i m U S=U S i m U S$ & & 4.30 & 10.16 & 1.54 & 0.93 \\
\hline Prob $>\chi^{2}$ & & 0.04 & 0.00 & 0.21 & 0.34 \\
\hline
\end{tabular}

All estimates include unreported firm. year and technological field dummics. Robust t-statistics in brackets. "significant at $10 \%$ : " significant at $5 \%$ : ${ }^{\cdots}$ significant at $1 \%$

I now turn to analysing the results based on the sample of USPTO patents. Columns 1 and 2 of Table 4.15 present the estimates based on the sample of USPTO patents that have EPO equivalents, including those EPO patents not granted. In column 1 in the regression a dummy variable is introduced to capture the fact that a USTPO patent may be filed through the PCT procedure. As expected, USPTO patents filed through this procedure have a significant and positive likelihood of being extended for protection in the EPO too. However the very high value of the robust t-statistics may be indicative of a simultaneity problem, i.e. the $P C T$ dummy and the dependent variable (the likelihood of a USPTO having an EPO equivalent) tend to have the same value - this is true in $71 \%$ of cases. I therefore dropped this variable from the analysis even though it has little effect on the probit estimates. Column 3 reports the results obtained when those EPO equivalent patents that have not been granted are excluded. Again there are no significant changes in the marginal effects and in their standard crrors. However, as argued in the previous scction, it is more appropriate to use the sample of EPO- 
granted patents to reduce the impact of different sucess rates in the two patent offices. The estimated coefficients (displayed in column 3) on the dummy variables characterising the patents" geographical origin and ownership are as expected. EU-invented USPTO patents granted to both EU and US MNEs are more likely to have an EPO equivalent, while the opposite is true for US-invented patents. This is consistent across time (sec columns 4 and 5), across sectors and across technology fields (see estimates in Table 4.16 and Table 4.17, respectively). ${ }^{2}$ The only exception is US-invented patents granted to both EU and US MNES in the motor vehicles \& parts sector (see Table 4.16). Firms in this sector appear to extend to the EPO not only those patents originating from within the EU but also those for inventions made in the US, which suggests that the results of their R\&D efforts in the US can be also exploited in Europe.

Column 3 of Table 4.15 reports the results of the tests for equality of the coefficients on the dummy variables capturing the ownership and geographical origin of the patents. These tests indicate that EU and US MNEs display the same tendency to extend their EU-invented USPTO patents to the EPO, whereas US firms are more likely to file US-invented patents in the EPO than their EU counterparts. However this rule does not seem to apply to a subsample of patents whose applications were made between 1990 and 91 or to a sub-sample from a more recent period (1997-98). Estimates reported in Tables 4.16 and 4.17 also show a significant degree of heterogeneity across sectors and technology classes. EU MNEs in chemicals, mining \& petroleum, and pharmaccuticals show a higher propensity than US MNEs to file their EU-invented USPTO patents in both patent offices. ${ }^{63}$ This applies also to patents in the related fields of chemicals, and drugs \& medical. In contrast, EU-invented patents granted to EU MNEs in motor vehicles \& parts are less likely to be extended to the EPO than their US counterparts. In relation to the estimates on the control variables, it is worth noting that the estimated coefficient on the mumber of forward citations is positive and significant, contrary to what was found in the probit model based on the sample of EPO patents.

\footnotetext{
6.2 For the sample of EPO patents. I ran the probit model for the sample of EU-owned USPTO patents to assess whether home country patents differ from patents invented in other EU locations. Although not reported, the estimates for these two dummy variables were consistently positive across both sector and technology.

6. The results for the sample of electrical \& electronics multinationals appear to be affected by the patenting behaviour of Philips. When the patents granted to this firm are excluded the $p$-value of the test for equality of the coefficients on $E U_{-} i m_{-} E U$ and $U S_{-} m_{-} E U$ changes to 0.45 , i.c. the possibility that EU and US MNEs display similar patenting behaviour for EU-imented patents cannot be rejected.
} 


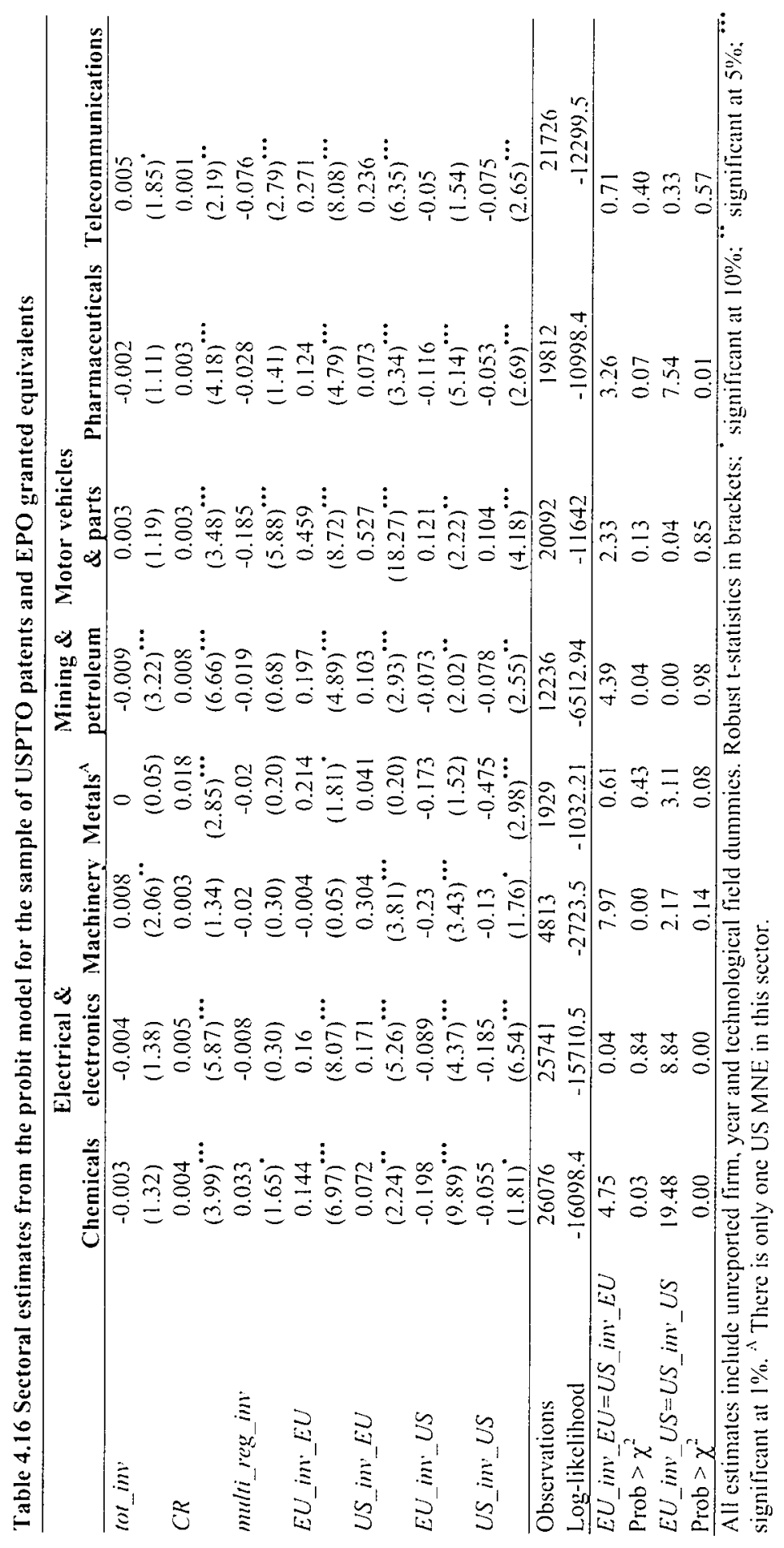




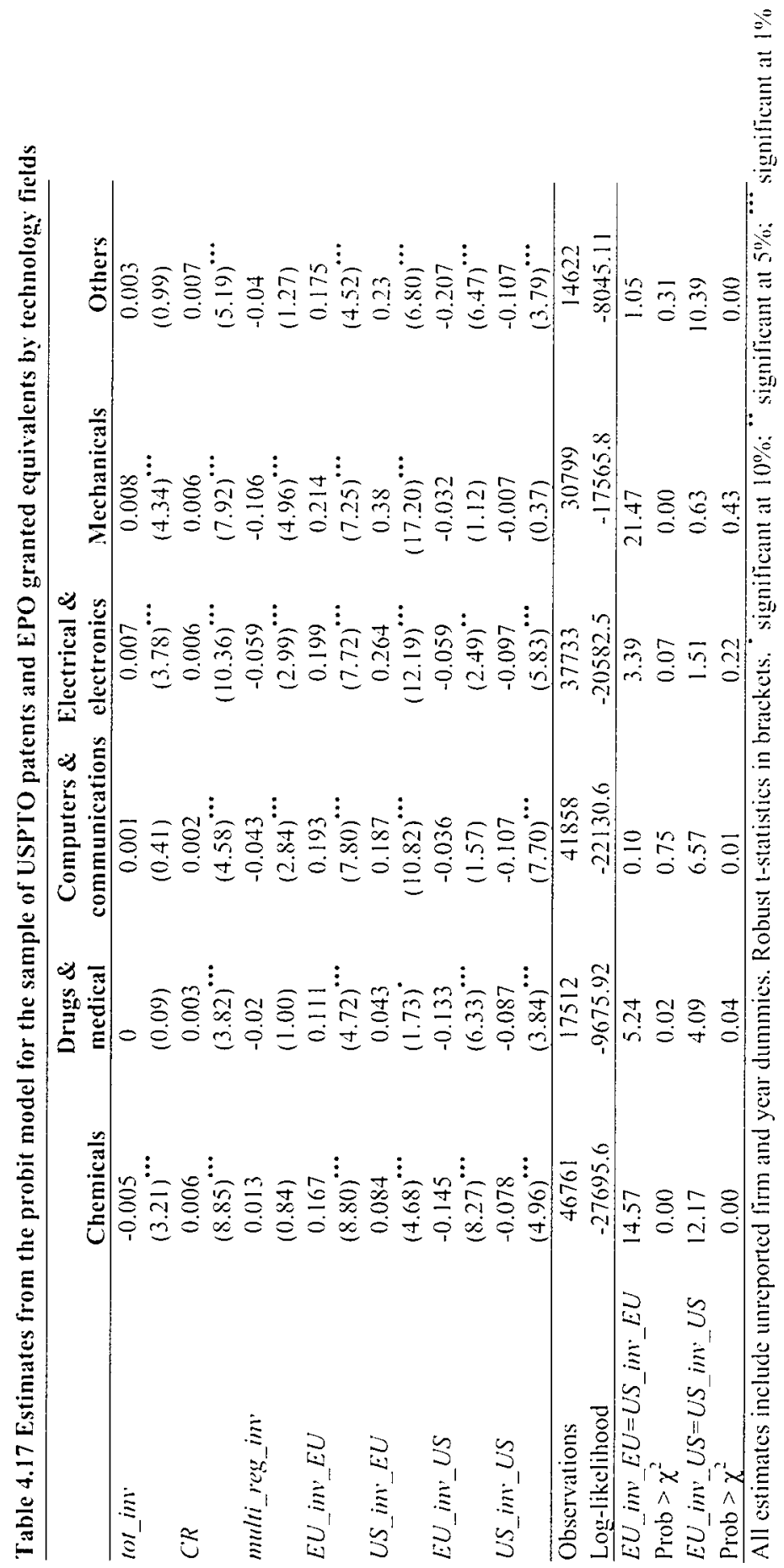


Therefore, to summarise, across all sectors EU and US MNEs appear to adopt a similar patenting strategy: they are less likely to extend patents for inventions made in one region (EU or US) to the other region's patent office (EPO or USPTO). This implies that the home country bias is the same for US and EU MNEs. However there is some sectoral specificity that emerges from both the EPO and USPTO estimates of the probit model. In particular EPO patents granted to EU MNEs active in the technology field of chemicals \& pharmaceuticals for inventions made in the EU appear also to be filed with the USPTO. Similarly US-invented USPTO patents granted to both EU and US MNEs in motor vehicles \& parts seem to be filed in both regional patent offices. This suggests that the results of the innovative efforts in this sector that are carried out in one region can be exploited in the other region. EU and US MNEs operating in pharmaceuticals, chemicals, and mining \& petroleum show different propensities to file their patents in both patent offices: EU MNEs seem to be more likely than US MNES to extend their EU-invented USPTO patents to the EPO.

\subsection{Conclusions}

This chapter aimed to address a well known problem associated with patent indicators: the 'home advantage' effect (i.e. domestic applicants, proportionate to their innovative activities, tend to file more patents in their home country than do foreign applicants). As a result, in making international comparisons of innovative activities - be it at the level of the country or of the firm - one cannot rely on any particular patent office's data because the analysis can be biased towards domestic inventive activities. This problem particularly affects empirical analyses, such as are described in Chapters 5 and 7 of this thesis, that aim to measure the internationalisation process of multinational companies using patent indicators.

Most patent-based studies on R\&D internationalisation use USPTO data under the assumption that non-US firms have an interest in protecting their most significant innovations in this patent office because the US is the largest market for technologically advanced products. Therefore it was generally believed that although the USPTO data may not completely capture the innovative activity of non-US firms that takes place outside the US, this bias would not affect the analysis of the patenting activities of large multinational companies. More recently, EPO data have been used to measure the R\&D internationalisation process (see Le Bas and Sierra 2002) and claims have been made that the EPO is the only truly international patent office which implies that, in contrast to national patent offices, the EPO is not biased towards a particular nation, i.c. it does not exhibit a 'home advantage' effect (Archibugi 1992). However neither this claim for the EPO nor the 'home advantage effect' at 
the firm level for USPTO data has been systematically investigated, in recent years. This chapter attempts to assess the extent of the 'home advantage' effect in both datasets and thus the validity of using USPTO and EPO data to analyse the internationalisation of R\&D activities, examining the patenting strategy of 131 high-tech European, US, and Japanese MNEs. In particular it analyses their patent families and their propensity to protect their inventions in both patent offices.

The empirical analysis begins by comparing internationalisation indicators computed using the sample of EPO and USPTO patents owned by the firms in the sample. It was found that, contrary to what had been assumed so far, there is evidence of a home country bias in both datasets that affects especially the measurement of foreign subsidiaries' patenting activity. In other words, the EPO data underestimate the R\&D activities of EU MNEs in the US, while USPTO data underestimate the innovative efforts of European affiliates of US MNEs. It is argued that these findings can be explained by the fact that foreign R\&D activities mainly aim to adapt products to the local market and thus their innovations cannot be exploited in other contexts, i.e. they do not need to be protected in other patent offices. However, in spite of this bias, both the EPO and the USPTO data provide a similar picture of the relative level of R\&D internationalisation across countrics.

These findings were explored further by analysing the patent families of both sets of EPO and USPTO patents. Three important points emerge from this analysis. First, contrary to what might be expected, most US-invented EPO patents are not also filed with the USPTO and similarly for EU-invented USPTO patents. As a result the EPO and the USPTO capture different technological activitics of the MNEs under analysis with a degree of overlap that changes with the geographical origin of the patents. For example, almost $45 \%$ of US-invented patents owned by EU MNEs are filed with, and granted, only by the EPO. Second, USinvented patents tend to be patented in, and granted by, the USPTO and only in $13 \%$ of the cases are they also patented and granted by the EPO. This implies that, if the USPTO describes more closely the innovative efforts carried out within the US, the EPO captures only a very small proportion of the results of R\&D activities performed in the US. However the bias for EU-invented patents is less severe: around half of EU-invented EPO patents are also filed with and granted by the USPTO. This seems to confirm in part the claim that EPO is a more international patent office with less home-country bias. Third, the claim that large nonUS firms will tend to file their patents in the USPTO even when the innovative activity did not take place in the US can be rejected. Filing a patent in more than one patent office is an 
expensive procedure and therefore, even for large firms with significant financial resources, external patent protection will be sought only when the expected commercial value and exploitation of the invention justify it.

In order to shed some light on the determinants of the decision to apply for patent protection in both patent offices a probit model was estimated. In this model the probability that an EPO (USPTO) granted patent will have a family member within the USPTO (EPO) depends on the location of the invention, the patent's technological characteristics, the number of applicants (total number of inventors), the technological value of the patent - measured by the number of citations received - and the procedure used to file the patent. Across all sectors both EU and US MNEs appear to adopt a similar patenting strategy: they are less likely to extend patents invented in one region (EU or US) to the other regional patent office (EPO or USPTO). This implies that the home country bias is the same for patents owned by US and EU MNES. However some sectoral specificity emerged from both the EPO and USPTO estimates of the probit model. In particular EU-invented EPO patents granted to EU MNEs active in the field of chemicals \& pharmaceuticals appear to be also filed in the USPTO. Similarly, US-invented USPTO patents granted to both EU and US MNEs in motor vehicles \& parts seem to be filed in both regional patent offices. This suggests that for these sectors the results of the innovative efforts carried out in one region can be somewhat exploited in the other region.

Overall, the findings of this chapter would seem to suggest that even large firms with multinational operations and extensive financial resources are very selective in their decision to apply for protection in more than one patent office. As has been shown, this 'rational' patenting strategy leads to a significant home country bias in the USPTO data. Thus in drawing inferences from patent and patent citations analyses it should be remembered that results could be biased towards domestic patenting activities. This is important when interpreting the findings presented in Chapters 5 and 7.

At the same time the evidence presented in this study also points towards a more careful interpretation of patent family size as an indicator of the economic value and technological impact of inventions, as initially suggested by Putnam (1996). Although further research needs to be done on this issue, from the results obtained in this study it appears that the propensity to file a patent in more than one patent office is correlated with factors such as the different patentability standards across patent offices that are not related to the potential economic and technological value of an invention. These results are in line with the findings 
of a study by Lanjouw and Schankerman (2004) who have found that patent family size compared to other indicators (forward citations, backward citations, and claims) is much less important in explaining the variance of a patent's quality. In a carlier study (Lanjouw and Schankerman 1999) it emerged that there is a threshold effect of patent family size which indicates that it is the decision to file a patent in another patent office rather than in how many patent offices that reveals the value of a patent. Similar findings were obtained by Guellec and Pottelsberghe (2002), although in this study the value of a patent is proxied by its probability of being granted. and the patent family size is equal to the number of designated states in an EPO application. This evidence supports the conjecture that the size of a patent family does not reflect only its value and therefore the link between these two variables is not so clear cut. 


\section{APPENDIX}

Table A4-1 List of MNEs in the sample

\begin{tabular}{|c|c|c|c|}
\hline Aerospace \& defence & HQ & Mining \& petroleum & $11 \mathrm{Q}$ \\
\hline Aerospatiale Mattras & US & Ashland Oil Inc. & US \\
\hline Allied-Signal Inc. & US & Atlantic Richnield Co. & US \\
\hline Bowing $C^{\circ} O$ & EU & British Petroleum (o. Ple (BP) & EU \\
\hline British Acrospace Plc & US & Chewron Corp. & US \\
\hline l_ockheed Martin Corp. & US & IEN.I Ente Nazionale ldrocarburi & EU \\
\hline Northrop (irumman Corp. & US & 1:1f-Aquitaine & E:U \\
\hline Raytheon Co. & $\mathrm{BU}$ & Fxxon Corp. & US \\
\hline Textron Inc. & US & Idemitsu Kosan Co. Lid. & $\mathrm{JP}$ \\
\hline United Technologies (orp. & US & Nippon Oil Co. Lud. & $\mathrm{JP}$ \\
\hline \multicolumn{2}{|l|}{ Chemicals } & Occidental Petroleum Corp. & US \\
\hline Akzo Nobel N.V. & $\mathrm{EU}$ & Petrolina $S \wedge$ & EU \\
\hline Asahi Chemical Industry $(\mathrm{co}$. Ltd. & $J p$ & Phillips Petroleum Co. & US \\
\hline Bast $\mathrm{AG}$ & $\mathrm{BU}$ & Shell & $\mathrm{EU}$ \\
\hline Bayer $A C i$ & $\mathrm{BU}$ & Texaco Inc. & US \\
\hline Dow Chemical co. & US & Total & $\mathrm{EU}$ \\
\hline Du Pont & US & \multicolumn{2}{|l|}{\begin{tabular}{|l} 
Motor vehicles \& parts \\
\end{tabular}} \\
\hline Henkel & $\mathrm{I}: \mathrm{U}$ & $B M W \wedge G$ & $\mathrm{EU}$ \\
\hline Ilocehs $\wedge \mathrm{G}$ & $\mathrm{EU}$ & Chrysler Corp. & US \\
\hline Imperial Chemical lndustries Ple (ICI) & $\mathrm{EU}$ & Daimler-Benz AC & IUU \\
\hline MG Technologies $A G$ & EU & Denso Corp. & $J P$ \\
\hline Mitsui Chemicals Inc. & $J P$ & Fiat S.p.a. & $\mathrm{EU}$ \\
\hline Montedison Spa & $\mathrm{EU}$ & Ford Motor Co. & US \\
\hline Norsk Hydro A/S & $\mathrm{EU}$ & Fuji Heavy industries $C^{\circ}$. Lid. & $J P^{2}$ \\
\hline \multicolumn{2}{|l|}{ Electrical \& electronics } & (jencral Motors Corp. & US \\
\hline Asea Brown Boveri Lad. $(A B B)$ & :U & Ilonda Motor Co. Lid. & $\mathrm{JP}$ \\
\hline Commissariat a l'energie atomique & EU & Isuzu Motors Lid. & $J P$ \\
\hline Electrolux $A b$ & $\mathrm{EU}$ & MANAG & $\mathrm{E}: \mathrm{U}$ \\
\hline Emerson Electric Co. & US & Marda Motor Corp. & $\mathrm{JP}$ \\
\hline Gencral Electric $C^{\circ} \mathrm{O}$ & US & Mitsubishi Motor Corp. & $\mathrm{JP}$ \\
\hline General Ilectric (o. Ple & E:U & Nissan Motor Co. Ltd. & JP \\
\hline Hitachi Lid. & $\mathrm{JP}$ & Peugeol SA & EU \\
\hline Matsushita Electric Works. Lid & $J P$ & Robert Bosch Gimbh & $\mathrm{I}: \mathrm{U}$ \\
\hline Philips Electronics N.V. & $\mathrm{EU}$ & Suzuki Motor Corp. & IP \\
\hline Rockwell Automation & US & Toyota Motor Corp. & $\mathrm{jP}$ \\
\hline Sinyo Electric Co. Ltd. & $\mathrm{JP}$ & TRW Inc. & US \\
\hline Sharp Corp. & $\mathrm{JP}$ & Volkswagen $A G$ & EU \\
\hline Siemens $A G$ & $\mathrm{BU}$ & Volvo $A B$ & EU \\
\hline Sony Corp. & $\mathrm{JP}$ & \multicolumn{2}{|l|}{ Pharmaceuticals } \\
\hline \multicolumn{2}{|l|}{ IT related } & Abbott Laboratorics & US \\
\hline Compay Computer Corp. & US & American Home Products Corp. & US \\
\hline Dell Computer Corp. & US & Bristol-Myers Squibb Co. & US \\
\hline Fujitsu Lid. & $J P$ & Glaxo Wellcome Ine. & $\mathrm{EU}$ \\
\hline Hewlett-Packard Co. & US & Johnson \& Johnson & US \\
\hline $\mathrm{IBM}$ & US & Merck \& Co. Inc. & US \\
\hline Intel Corp. & US & Monsanto Co. Inc & US \\
\hline Mitsubishi Electric Corp. & JP & Novartis & EU \\
\hline NEC Corp. & $\mathrm{JP}$ & Pfizer Inc. & US \\
\hline Texas Instruments Inc. & US & Rhone-Poulene Sa & I:U \\
\hline \multirow[t]{2}{*}{ Toshiba Corp. } & JP & Roche Holding $\triangle G$ & EU \\
\hline & & Smithkline Beecham Plc & $\mathrm{l}: \mathrm{U}$ \\
\hline
\end{tabular}




\begin{tabular}{|c|c|c|c|}
\hline Machinery & HQ & Photography \& photocopying & HQ \\
\hline BTR Plc & $\overline{\mathrm{I} U}$ & Canon lnc. & $J P$ \\
\hline Caterpillar lnc. & $1: 0$ & Eastman Kodak $\mathrm{Co}$. & US \\
\hline Decre \& Co. & US & Fuji Photo Film Co. Ltd. & $J P$ \\
\hline Fried. Krupp AG & US & Minnesota Mining and Manufacturing $C_{0}$. & US \\
\hline Johnson Controls Inc. & EU & Ricoh Co. Lid. & $J P$ \\
\hline Komatsu Lid. & US & Xerox Corp. & US \\
\hline Mamesmann $\mathrm{AO}$ & JP & Telecommunications & \\
\hline Mitsubishi lleavy Industrics Lid. & EU & Alcatel & EU \\
\hline Mctals & $J P$ & AT\& $\mathrm{T}$ Corp. & US \\
\hline Aluminum Co. of America & US & British Telecommunications Plc & EU \\
\hline Degussa $A \mathrm{G}$ & US & Ericsson & EU \\
\hline IRI & EU & France Telecom & EU \\
\hline Kawasaki Steel Corp. & $\mathrm{EU}$ & GTE Corp. & US \\
\hline Kobe Steel Lid. & JP & Koninklijke KPNN.V. & EU \\
\hline Mitsubishi Materials Corp. & JP & Lucent Technologies inc. & us \\
\hline Nippon Steel Corp. & $\mathrm{JP}$ & Motorola Inc. & US \\
\hline Nkk Corp. & JP & Nippon Telegraph \& Telephone Corp. & IP \\
\hline Sumitomo Metal Industries Co. Ltd. & JP & Nokia Corp. & EU \\
\hline Thyssen $A C i$ & $\mathrm{JP}$ & SIP & EU \\
\hline Usinor-Sacilor Sa & $\mathrm{EU}$ & & \\
\hline
\end{tabular}




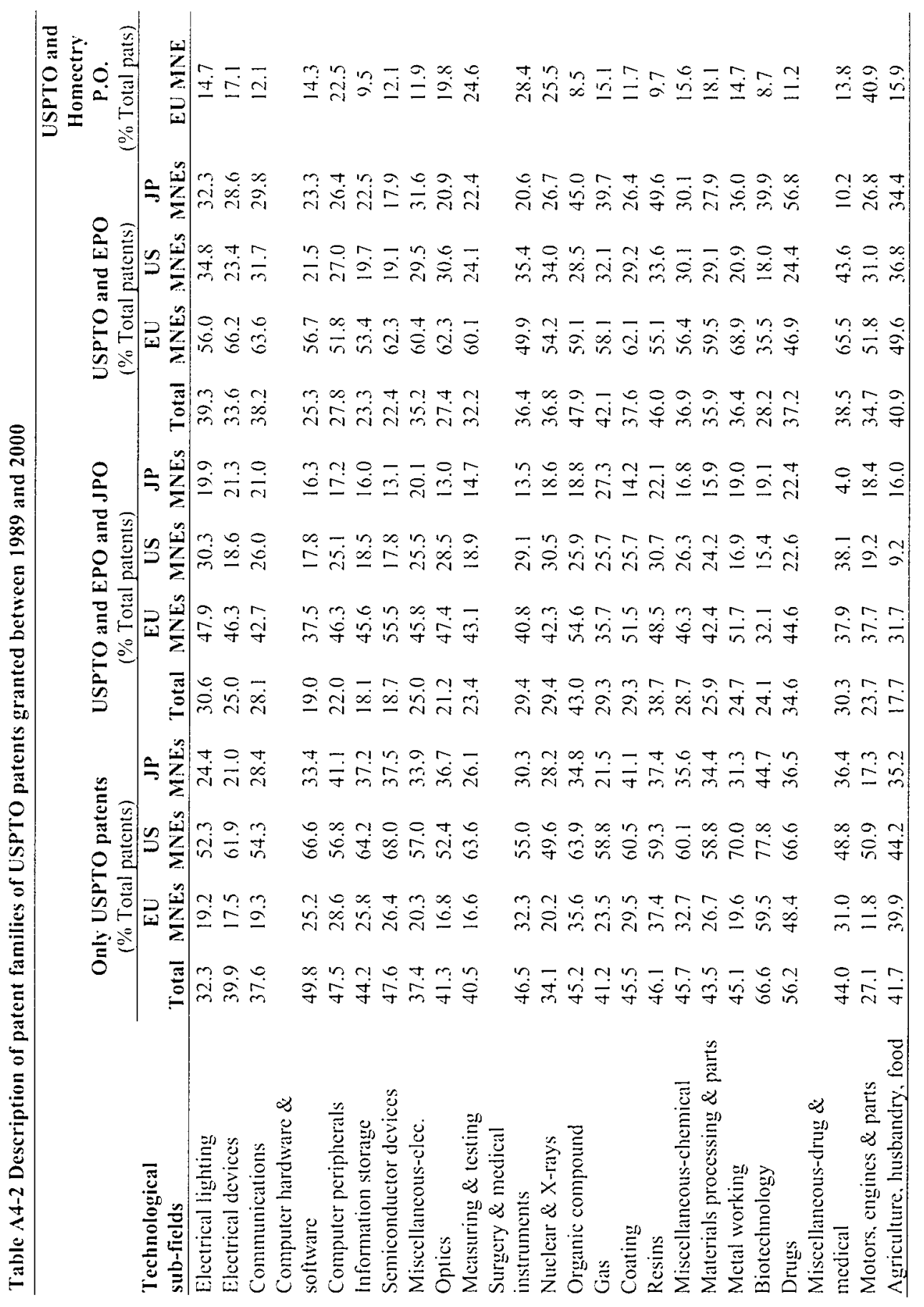




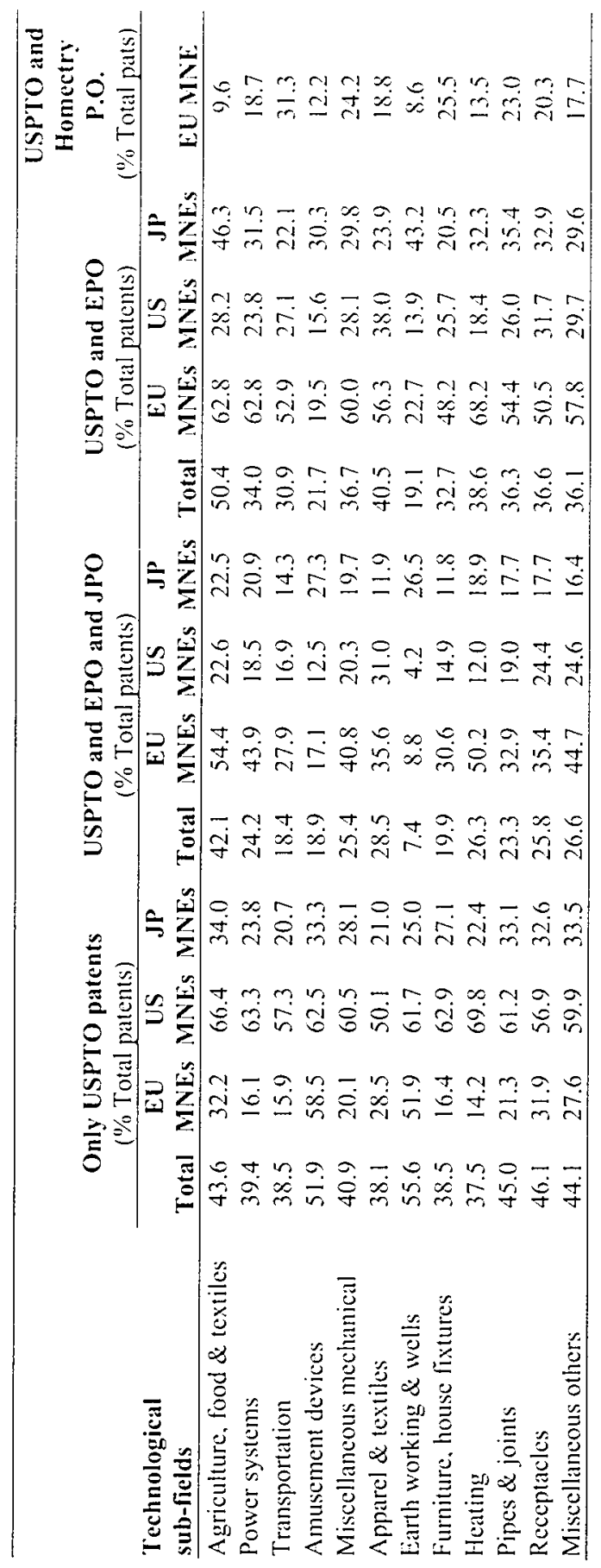




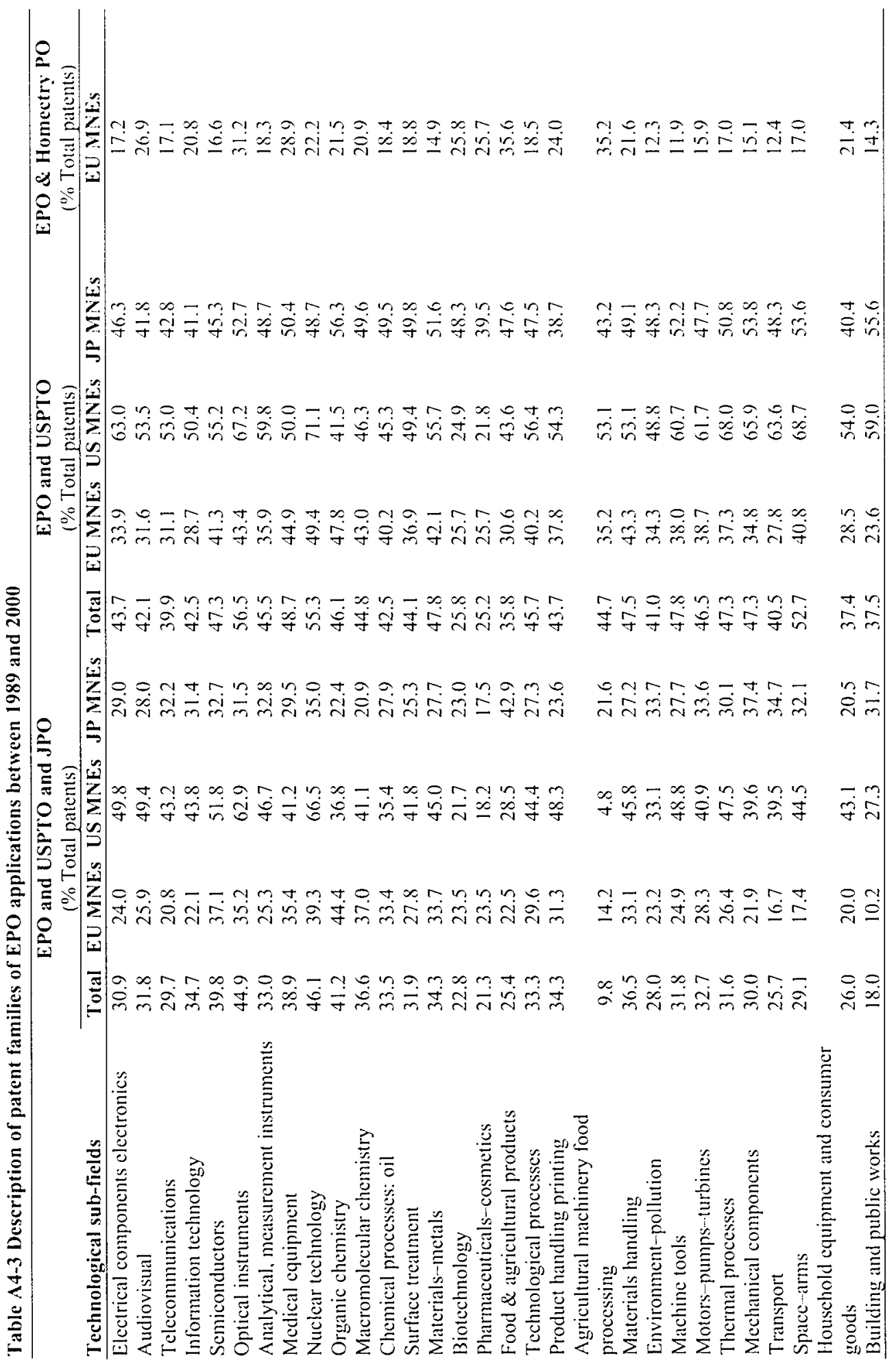




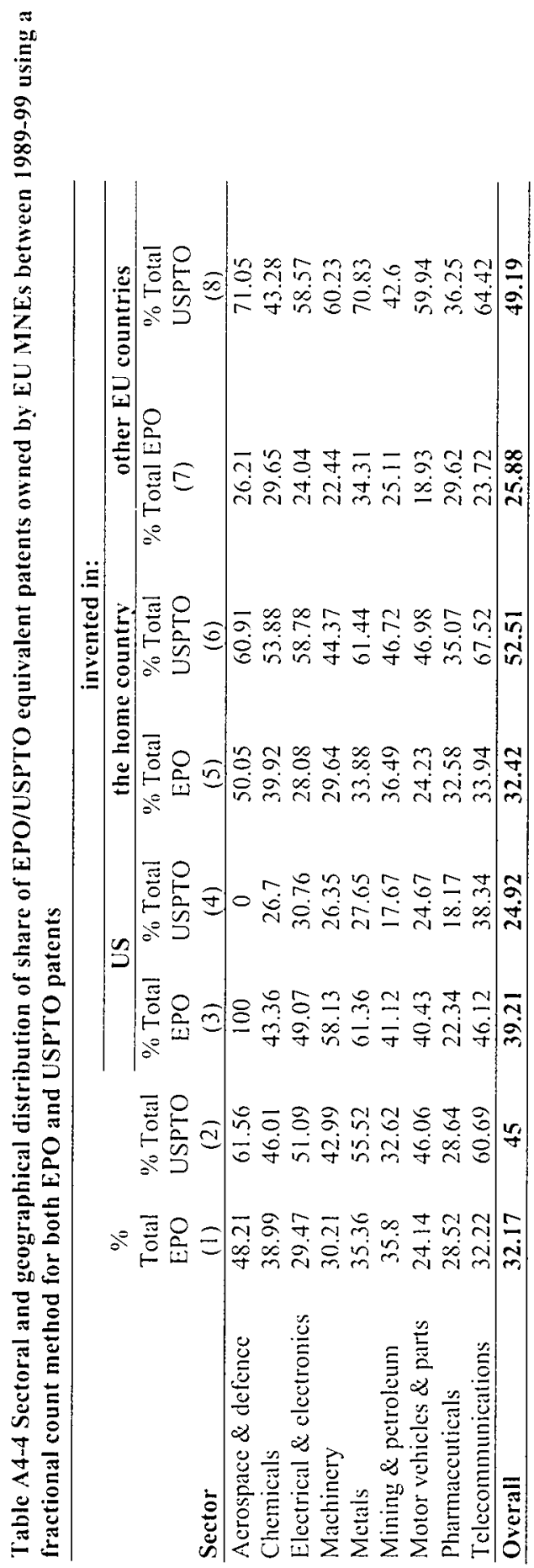




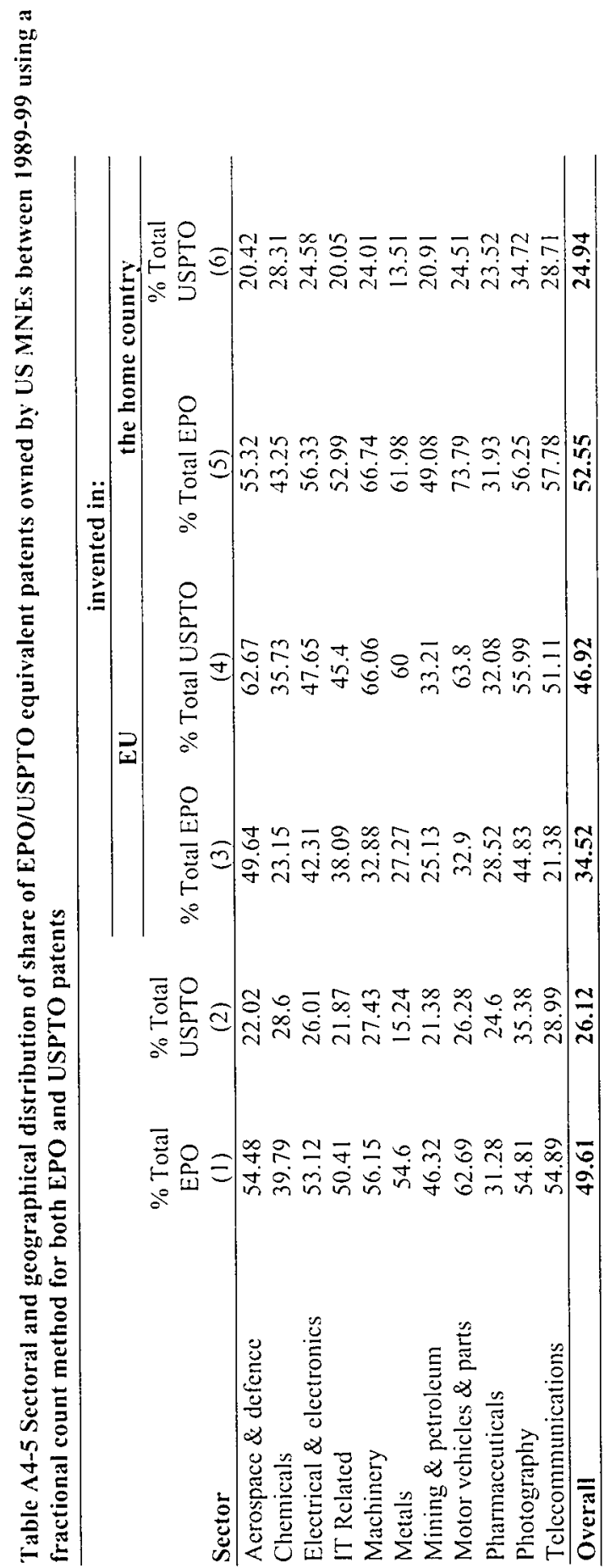




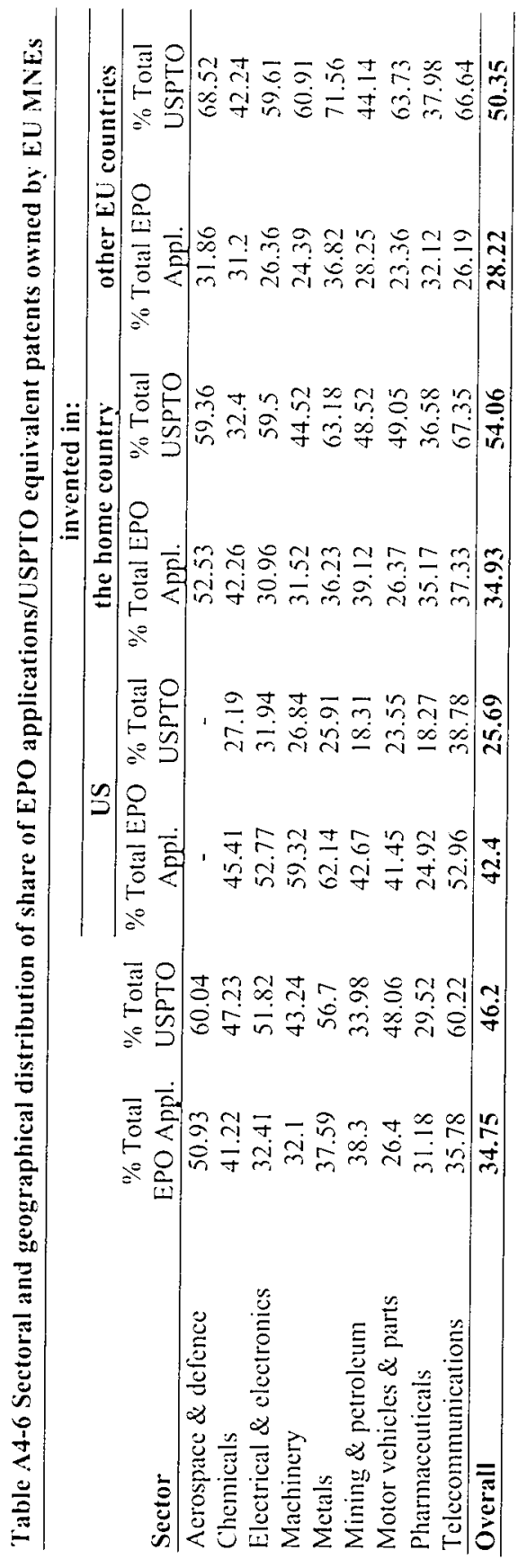


Table A4-7 Sectoral and geographical distribution of share of EPO applications/USPTO equivalent patents owned by US MINES

\begin{tabular}{lcccccc}
\hline & & & \multicolumn{4}{c}{ invented in: } \\
\cline { 4 - 7 } & \% Total & & \multicolumn{3}{c}{ EU } & \multicolumn{3}{c}{ the home country } \\
\cline { 4 - 7 } & EPO & \% Total & EPotal & & \% Total \\
Sector & Appl. & USPTO & Appl. & USPTO & Appl. & USPTO \\
\hline Acrospace \& defence & 56.73 & 22.51 & 49.91 & 62.75 & 57.67 & 21.04 \\
Chemicals & 40.62 & 28.21 & 24.43 & 36.79 & 43.94 & 27.69 \\
Electrical \& electronics & 54.38 & 26.44 & 44.75 & 50.62 & 56.61 & 24.87 \\
IT Related & 51.34 & 20.17 & 38.74 & 44.83 & 54.07 & 18.37 \\
Machinery & 56.23 & 26.83 & 32.68 & 63.67 & 67.19 & 23.63 \\
Metals & 53.89 & 14.66 & 27.27 & 52.94 & 60.8 & 13.05 \\
Mining \& petroleum & 48.08 & 21.95 & 28.29 & 34.82 & 50.59 & 21.35 \\
Motor vehicles \& parts & 62.36 & 26.01 & 34.29 & 64.89 & 72.3 & 24.3 \\
Pharmaceuticals & 32.96 & 24.3 & 32.11 & 33.99 & 33.31 & 22.93 \\
Photography \& photo. & 56.21 & 35.43 & 46.67 & 55.8 & 57.56 & 34.83 \\
Telecommunications & 55.56 & 27.81 & 22.04 & 52.81 & 58.69 & 27.55 \\
\hline Overall & $\mathbf{5 0 . 8 8}$ & $\mathbf{2 5 . 5 4}$ & $\mathbf{3 6 . 0 1}$ & $\mathbf{4 7 . 9 7}$ & $\mathbf{5 3 . 7 3}$ & $\mathbf{2 4 . 3 3}$ \\
\hline
\end{tabular}


Table 14-8 Classification of EPO patents in technological fields and sub-fields

\begin{tabular}{|c|c|c|}
\hline Technological fields & Technological sub-fields & IPC codes \\
\hline \multirow[b]{2}{*}{$\begin{array}{l}\text { Biotechnology \& } \\
\text { agricultural products }\end{array}$} & Biotechnology & CO7G, C12M, CI2N,C12P, CI2Q, CI2S \\
\hline & $\begin{array}{l}\text { Food \& agricultural } \\
\text { products }\end{array}$ & $\begin{array}{l}\text { A01H, A2HD, A23B, A23C, A23D, A23F, A23G, A23J. } \\
\text { A23K, A231. C12C, C12F, C12G, C12H, C } 12 \mathrm{~J}, \mathrm{Cl} 13 \mathrm{D}, \\
\mathrm{C} 13 \mathrm{~F}, \mathrm{C} 13 \mathrm{~J}, \mathrm{C} 13 \mathrm{~K}\end{array}$ \\
\hline \multirow{3}{*}{ Chemicals \& drugs } & Organic chemistry & COOC, CO7D), C07F, C07H, C07J, CO7K \\
\hline & Macromolecular chemistry & 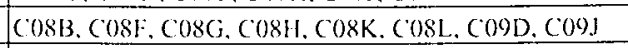 \\
\hline & $\begin{array}{l}\text { Pharmaceuticals \& } \\
\text { cosmetics }\end{array}$ & $A G 1 \mathrm{~K} . \mathrm{A} 61 \mathrm{P}$ \\
\hline \multirow[t]{2}{*}{$\begin{array}{l}\text { Household } \\
\text { consumption }\end{array}$} & $\begin{array}{l}\text { Household equipment \& } \\
\text { consumer goods }\end{array}$ & 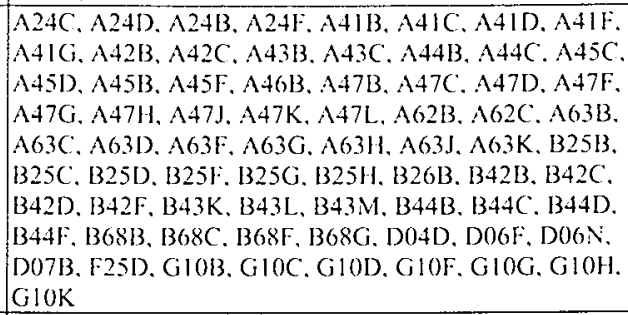 \\
\hline & Building \& public work & $\begin{array}{l}\text { E0IB, E0IC, E01H, E0ID, E01F, E02B, E02C, E02D, } \\
\text { E02F, E03B. E03C, E03F, E03D, E04D, E04F, E04G, } \\
\text { E04H, E04B, E04C, E05B, E05C, E05D, E05F, E05G. } \\
\text { E06B, E06C, E06D, E2IB, E2IC, E2ID, E2IF }\end{array}$ \\
\hline \multirow[t]{2}{*}{$\begin{array}{l}\text { Electronics } \\
\text { components \& } \\
\text { semiconductors }\end{array}$} & $\begin{array}{l}\text { Electrical components } \\
\text { electronics }\end{array}$ & 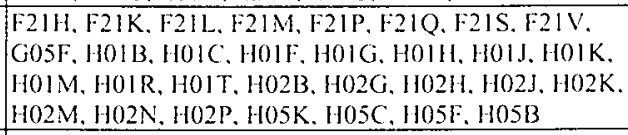 \\
\hline & Semiconductors & HOIL. B81C \\
\hline \multirow[b]{2}{*}{$\begin{array}{l}\text { Industrial chemicals } \\
\& \text { oil refining }\end{array}$} & Surface treatment & $\begin{array}{l}\text { B05C, B05D, B32B, C23C, C23D, C23F, C23G, C25B, } \\
\text { C25C, C25D, C25F, C } 30 B\end{array}$ \\
\hline & Chemical processes: oil & 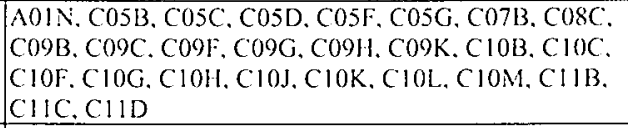 \\
\hline \multirow{3}{*}{ Industrial processes } & Technological processes & $\begin{array}{l}\text { BOIB. B01D. B01F. B01J, B01L. B02C. B03B. B03C, } \\
\text { B03D. B04B. B04C, B05B, B06B. B07B, B07C. B08B. } \\
\text { F25J. F2613 }\end{array}$ \\
\hline & Product handling printing & $\begin{array}{l}\text { B25J, B4IB, B4IC, B4ID, B41F, B41C, B4IJ, B4IK, } \\
\text { B4IL, B4IM, B4IN, B65B, B65C, B65D. B65F, B65H, } \\
\text { B65G, B66B, B66C, B66D. B66F, B66G, B67B, B67C, } \\
\text { B67D }\end{array}$ \\
\hline & Environment pollution & $\begin{array}{l}\text { A62D, B09B, B09C, C02B, C02C, CO2F, F01N, F23G, } \\
\text { F23J }\end{array}$ \\
\hline \multirow{4}{*}{ Instrumentation } & Optical instruments & $\begin{array}{l}\text { G02B, G02C, G02F, G03B, G03C, G03D, G03F, G03G, } \\
\text { G03H, H01S }\end{array}$ \\
\hline & $\begin{array}{l}\text { Analytical, measurement } \\
\text { instruments }\end{array}$ & 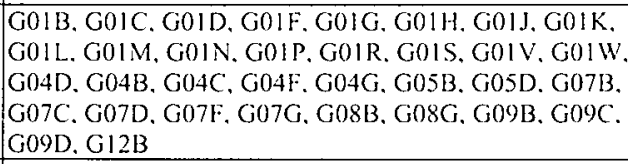 \\
\hline & Medical equipment & $\begin{array}{l}\text { A6IB, A61C, A6ID, A6IF, A61G, A61H, A61L, A6IJ. } \\
\text { A61M, A61N }\end{array}$ \\
\hline & Nuclear technology & $\begin{array}{l}\text { G01T. G2IB. G21C.G2ID, G2IX. G2IF, G2IG. G2IH. } \\
\text { G21K. G21J.H05H. H05G }\end{array}$ \\
\hline
\end{tabular}




\begin{tabular}{|c|c|c|}
\hline Technological fields & Technological sub-fields & IPC codes \\
\hline \multirow{6}{*}{$\begin{array}{l}\text { Machinery \& } \\
\text { engineering }\end{array}$} & Motors pumps \& turbines & 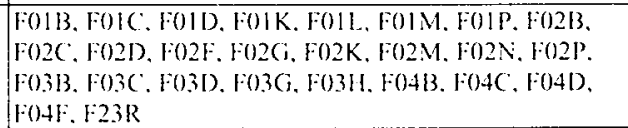 \\
\hline & Mechanical components & $\begin{array}{l}\text { F1513, F15C, F15D, F16C, F16D, FIGF, F16G. F161L, } \\
\text { F16J, F16K, F16N, F16T, F16B, F16L, F16M, F16P. } \\
\text { F16S, F17B, F17C, F17D, G05G }\end{array}$ \\
\hline & Machine tools & 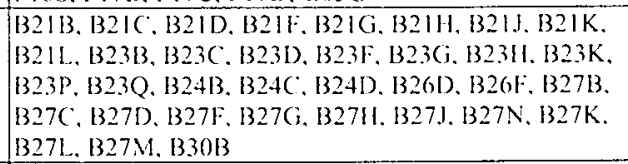 \\
\hline & Thermal processes & 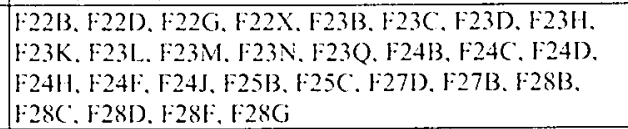 \\
\hline & Space Arms & 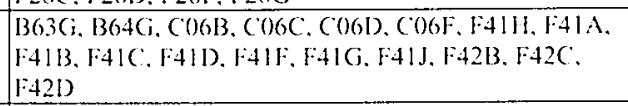 \\
\hline & $\begin{array}{l}\text { Agricultural machinery \& } \\
\text { food processing }\end{array}$ & $\begin{array}{l}\text { A01B, A01C, A01D, A01F, A0IG, A01J,A01K, A01L, } \\
\text { A01M. A21B, A21C, A22B, A22C, A23N, A23P. B02B, } \\
\text { C12L. C13C, C13G, C13H }\end{array}$ \\
\hline \multirow[b]{2}{*}{$\begin{array}{l}\text { Metalwork \& } \\
\text { materials }\end{array}$} & Materials metals & 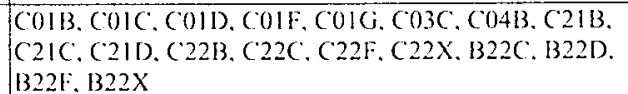 \\
\hline & Material handling & 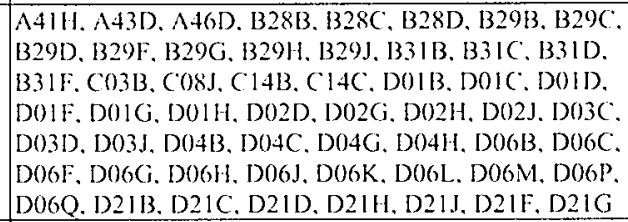 \\
\hline \multirow{3}{*}{$\begin{array}{l}\text { Telecommunications } \\
\& \text { audiovisual }\end{array}$} & Telecommunications & 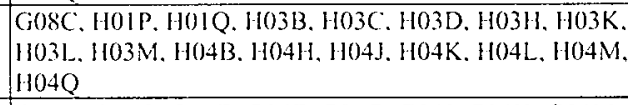 \\
\hline & Information technology & $\begin{array}{l}\text { G06D. G06C. G06E. G06F. G06G. G06J. G06K. G06M. } \\
\text { G06N.G06T.G11C. GioL }\end{array}$ \\
\hline & Audio visual & $\begin{array}{l}\text { G09G, G09F, G11B, G09G, H03F, H03G, H03J, H04N, } \\
\text { HO4R, H04S }\end{array}$ \\
\hline Transportation & Transport & 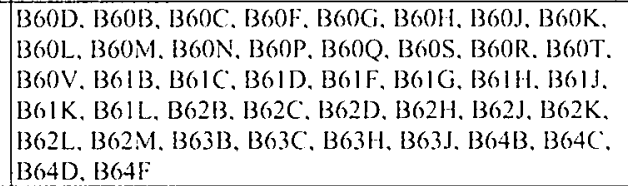 \\
\hline
\end{tabular}




\section{CHAPTER 5}

\section{ASSET-EXPLOITING AND ASSET-AUGMENTING R\&D ACTIVITIES OF EUROPEAN AND AMERICAN MNES}

\subsection{INTRODUCTION}

This chapter presents an analysis of the technology-sourcing behaviour of forcign subsidiaries operating in high-tech sectors. The purpose of the chapter is to assess the relative proportions of those R\&D activities conducted abroad that are asset-augmenting and asset-exploiting in order to identify the sectors where RTT is more likely to occur. The results presented in this chapter represent the background for Chapters 6 and 7 where I examine both inter-firm and inma-firm RTT.

From the literature review in Chapter 2 it emerged that much of the existing empirical work on asset-exploiting and augmenting activities of MNEs concentrates on foreign-owned R\&D in the US. In this chapter I empirically test the extent of the asset-exploiting and augmenting component of the R\&D activities of both European MNEs in the US, and US MNEs in Europe by analysing the citation patterns of patents for inventions made by foreign R\&D facilitics. As assumed in other studies reviewed in Chapter 2 (see Almeida 1996. Frost 1998, 2001, Jaffe et al. 1993), I consider patent citations as a proxy for knowledge flows between firms, but instead of using citations contained in patents granted by the USPTO, I use citations listed in EPO applications. I therefore describe the different legal requirements and procedures of the two patent systems in relation to both the obligations placed on the applicant about the disclosure of 'prior art' relevant to the patentability of the invention, and also the different practices of patent examiners in this activity. By analysing the USPTO and EPO citations reported in the sample of equivalent patents used in the previous chapter, $I$ can show what the implications of these different legal requirements are regarding both the number and geographical distribution of patents eited in the two systems.

\footnotetext{
Parts of this chapter draw on (riscuolo et al. (2004).
} 
This chapter aims also to contribute to the theoretical literature on R\&D internationalisation proposing a 'macro view' of asset exploiting R\&D activities. I argue that when MNEs engage in asset-cxploiting $R \& D$ abroad, they often seck to utilise a variety of resources associated with the innovation system of the home country and not just the parent company's MNEspecific technological competences, as has been assumed by the international business literature. This qualification is very important especially when the primary objective is to assess the economy-wide effects of internationalisation of $R \& D$, rather than to determine its impact on the MNE itself. I also argue that most firms tend to undertake both asset exploiting and augmenting activities simultaneously.

This chapter is structured as follows. The next section discusses the nature of assetaugmenting R\&D activitics and presents the 'macro' view of asset-exploiting R\&D. Section 5.3 summarises the advantages and disadvantages of using patent citations as a proxy for knowledge flows. The main differences between the EPO and the USPTO as regards the patent citation process are also described. Section 5.4 describes the procedure used to build the database and the trends that emerge in terms of the patenting and patent citation activities of these firms. Section 5.5 presents the results of a comparative analysis of citations contained in patents protecting the same invention both in the EPO and in the USPTO. Finally, section 5.6 describes the method used to test the research questions addressed in this chapter and the results of the analysis. Section 5.7 concludes and outlines the next steps in the thesis.

\subsection{MNES' ASSET-EXPLOITING AND ASSET-AUGMENTING R\&D ACTIVITIES: A 'MACRO' PERSPECTIVE}

Studies of the internationalisation of R\&D have drawn on the theories that underpin the location of international production to explain the location of firms' $R \& D$ activities. R\&D can be said to internationalise for broadly the same motives as traditional elements of the value chain, although not at the same rate nor to the same extent. Two primary types of R\&D activity have been identifice within this approach, asset-exploiting and asset-augmenting. ${ }^{6.4}$

Asset-exploiting R\&D occurs when firms seek to promote the use of their technological assets in conjunction with, or in response to, specific conditions in a foreign location. This has also been referred to as home-base exploiting (HBE) activity ${ }^{65}$ (Kuemmerle 1996). Location

\footnotetext{
in This dichotomy represents two extrencs and is an oversimplification of reality. As Patel and Vega (1990) and Le Bas and Sierra (2002) show, there is a varicty of intermediate types.

"Although the HBE-HBA terminology dominates in the literature. as I point out in Chapter 2. this classification scheme is only consistent with a very traditional view of the MNE as centred in a dominam home-base: it cannot take
} 
conditions may require some modification being made to products or processes in order for them to be more appropriate to local conditions, or in some cases, to create peripheral products. In such activities, the technological advantages of the firm primarily reflect those of the home country. Since a large percentage of the foreign R\&D activities of firms tends to be production-supportive (i.e. asset-exploiting), such demand-side considerations are significant. The level of foreign R\&D in any given host location, however, is also dependent on the kinds of value-adding activity undertaken there. In general, the more embedded the foreign subsidiary, and the greater the intensity of its value-adding activity, the greater the amount of R\&D activity.

The second broad classification is that of strategic asset-augmenting activity (Dunning and Narula 1995) or home-base augmenting (HBA) activity (Kuemmerle 1996). In making these kinds of investments, firms aim to improve their existing assets or to acquire (and internalise), or create completely new, technological assets through foreign R\&D facilities. The assumption in such cases is that the foreign location provides access to location-specific advantages that are not as readily available in the home base. In many cases the advantages sought are associated with the presence of other firms. The investing firm may seck to acquire access to the technology of other firms, either through spillovers (in which case the firm seeks bencfits that derive from economies of agglomeration), by direct acquisition (through merger and acquisition, M\&A), through R\&D alliances, or by arms-length acquisition.

There are several reasons why such asset-augmenting $R \& D$ activities are hard to achicve from the home basc. As suggested by Von Hippel (1994), when the knowledge relevant for innovative activities is located in a certain geographical area and is very 'sticky', the R\&D activity should take place at that site, so as to minimise costs. As discussed more extensively in Chapter 2, one of the reasons for such sticky knowledge is the tacit nature of knowledge often stands out. In addition, the tacit nature of knowledge associated with production and innovation activity implies that physical or geographical proximity is important for its transmission (Blanc and Sierra 1999). Although the marginal cost of transmitting codified knowledge from one location to another does not depend on distance, the marginal cost of transmitting tacit knowledge increases with distance.

account of the increasing importance of foreign subsidiaries to the technological upgrading of the overall organisation. In fact, by emphasising the role of the home base, the HBE-HBA jargon cannot easily be made consistent with the possibility that firms evolve towards network structures, hence reducing the importance of a single home and cxpanding the number of countries where the firm ends up being based (Narula and Zanfei 2004). I will therefore use the more accurate asset-exploiting and asset-augmenting terminology instead.

von Hippel (1994) defines stickiness as the incremental expenditure required to transfer that unit of knowledge. 
While the theoretical exposition of asset-augmenting and asset-exploiting R\&D has taken a broad, macro perspective. empirical work has followed two distinct approaches. The first approach focuses on the nature of asset-exploiting R\&D as an intra-firm process. That is, foreign-located R\&D secks to adapt and use technologies associated with the parent company. These studies, reviewed in Chapter 2, are generally based either on surveys (Florida 1997. Kuemmerle 1999, Serapio and Dalton 1999) or more recently on patents (Le Bas and Sierra 2002. Patel and Vega 1999) and patent citations analysis (Almeida 1996, and Frost 1998. 2001). This 'narrow' view of asset-exploiting R\&D can be contrasted with a 'macro' vicw that sees asset-exploitation as being implicitly associated with the technological resources of the entire home location (see c.g. Dunning and Narula 1995).

This distinction is very important. especially when the primary objective is to determine the cconomy-wide effects of internationalisation of R\&D, rather than to determine the MNEspecific efficiencies (as the 'narrow' approach has largely done). At the macro-level, the discussion on asset exploiting is augmenting activities bears important similarities to the debate on the local nature of technological spillovers in the economics literature (Jaffe and Trajtenberg 1996, 1999, e.g. Jaffe et al. 1993, Maurseth and Verspagen 2002). The issue here is whether or not knowledge spillovers between firms, or from (semi-) public knowledge institutes to firms, depend on geographical distance. The studies cited above find that, both in the US and Europe, such a relationship indeed exists. Thus, knowledge spillovers tend to be more intense between parties that are located close geographically. Various explanations have been offered for this finding, such as the tacit nature of knowledge (as discussed above), but also the existence of spillovers due to a common pool of resources in a region (e.g. skilled labour, education institutes or specific scientific equipment).

The 'narrow' and 'macro' views of asset-augmenting R\&D activities are similar and consistent in acknowledging the significance of localised knowledge. If knowledge spillovers are indeed localised, one may expect that local knowledge bases would tend to differ with regard to focus and quality. The only efficient way for a firm to tap into a local knowledge base would then be to be physically present, which indeed is what defines an assetaugmenting activity. This similarity suggests that techniques could be used that are proposed in the literature for tracing localised spillovers in order to search for interactions between the local knowledge base and foreign-owned R\&D activity, and hence to distinguish augmenting from exploiting R\&D activities (cf. Almeida 1996, and Frost 200l). This is what is attempted in the empirical section of this chapter. 
However, the two views are different in how they examine asset-exploiting activity. An MNE's knowledge base is not simply a function of its activities in the home location, but of its home location's innovation system. There are complex interdependencies between economic actors in any given location, and because the MNE's parent is often highly embedded in its home location, these linkages determine its knowledge base and the efficiency with which it can enhance its technological assets. Economic actors include both non-firm organisations as well as suppliers, who are often inextricably linked to the MNE and its innovation activity. Thus I would maintain that when a firm engages in asset-exploiting R\&D activity abroad, it secks to exploit not just its own technological assets, but those associated with its home country innovation environment.

Likewise, on a more macro-level, when firms engage in R\&D in a foreign location to avail themselves of complementary assets that are location specific, they are aiming to internalise several aspects of the system of innovation of the host location. However, developing and maintaining strong linkages with external networks of local counterparts is expensive and time consuming, and is tempered by a high degrec of integration with the innovation system in the home location. Even when the host location is potentially superior to the home location - and where previous experience exists in terms of other value-adding activities - the high costs of becoming familiar with, and becoming integrated into a new location may be prohibitive (sec Zanfei 2000 for a discussion).

However, the high costs associated with integrating into the host location's system of innovation - in contrast to the low marginal cost of maintaining its embeddedness in its home location's innovation system - creates an 'inertia' that makes firms reluctant to expand internationally (Narula 2002). These costs must be tempered by supply-side considerations: the development of complex technologies benefits from diversity and heterogeneity in the knowledge base, which may come from competitors, from interaction with customers and from other complementary technologies. A single national innovation system is often unable to offer the full range of interrelated technological assets required for this diversification strategy (Narula 2002). In other words, complex opposing forces underlic the kinds of R\&D activities a firm undertakes, and where they are located. It is rare for firms to undertake either types of R\&D overseas to the exclusion of the other (Zander 1999).

It is axiomatic that asset-augmenting activities will be located where opportunities for internalising spillovers are highest. This implies seeking proximity to 'technology leaders' 
and, given that firms tend to concentrate their more strategic R\&D activities in their home location, this high level of competence is often reflected in the associated system of innovation. Thus, asset-augmenting activitics may be associated with locations that exhibit a technological or comparative advantage. relative to other locations, and particularly relative to the home location of the MNE secking these assets (Dumning and Narula 1995, Patel and Vega 1999. Le Bas and Sicra, 2002).

It is worth noting that technology leaders are not always synonymous with industry leaders. It is important to realise that firms - particularly in technology-intensive sectors - increasingly need to have multiple competences (Granstrand 1998. see Granstrand et al. 1997). Even when products are based on a single technology, the processes used to manufacture them often utilise several technologies. However, taking a macro approach requires us to bear in mind that, because products may depend on multiple technologies, one firm may be marginally ahead in one particular technology and its competitor in another. However at the macro-level, both may have equally 'powerful' innovation systems. And, even within any given technology (and in particular within technology intensive sectors), leadership can change rather rapidly. This is another reason that firms may simultancously engage in assetaugmenting and exploiting activities.

Large firms tend to engage in both asset-augmenting and asset-exploiting activities, because any given subsidiary has a need for a variety of technologies, and any given host location may possess a relative technological advantage in one area, but be disadvantaged in another. MNEs tend also to engage in production activities (whether in the same or another physical facility) in the host location, and this prompts a certain level of asset-exploiting R\&D. Thus, an MNE in a given location may not only be secking to internalise spillovers from unrelated firms, but may also be engaging in intra-firm knowledge transfers within the same multinational group, and indeed may simultancously engage in asset exploiting and augmenting activity.

Some caveats should be noted. Mercly establishing R\&D activities abroad for the purposes of internalising spillovers does not necessarily guarantee that firms will be successful in so doing. There are many factors that determine the MNE's efficiency in internalising spillovers. There are complex - and sometimes contrary - forces that influence their ability to do so both at micro and macro levels. First, there are firm- and technology-specific forces. In particular, the need to seek the diversity of knowledge, technology and capability to remain 
internationally competitive and second, there are demand issues such as information and proximity to markets.

Another micro-level determinant is the difficulty of managing cross-border R\&D activities. It is not sufficient for the foreign affiliate to internalise spillovers if it cannot then make them available to the rest of the $M N E$ - there needs to be internal proximity between overseas $R \& D$ and the rest of the MNE (Blane and Sierra, 1999). Dispersion of R\&D activities across the globe requires extensive coordination both between units and between units and headquarters to collect and disseminate information efficiently. This acts as a centripetal force on R\&D, and accounts for a tendency of firms to locate their R\&D (or at least the most strategically significant elements of it) close to headquarters. Such growing, complex linkages, both of networks internal to the firm, and those between external networks and internal networks, require coordination if they are to provide optimal benefits (sec Zanfei 2000 for a discussion). Networks are not only difficult to manage, but also require considerable resources (both managerial and financial).

This leads to the following rescarch question: To what extent do foreign affiliates in technology-intensive sectors display asset-augmenting R\&D activities relative to assetexploiting activities, i.e. to what extent do they draw upon local sources of knowledge rather than home country knowledge?

Following Almeida (1996) and Frost (2001). I addressed this issue employing patent citation analysis, using data on both European foreign affiliates operating in the US and US foreign affiliates active in Europe. The dataset I used allows me to analyse the technological sourcing behaviour of foreign affiliates operating in two geographical regions with different technological advantages and characteristics. In addition, from a methodological point of view, the current citation analysis study differs from previous ones in the source of its patent data. While Almeida and Frost used USPTO data, I used data on patents filed with the EPO and their citations to EPO and USPTO patents. The next section discusses the characteristics of the dataset, and the advantages and disadvantages of using EPO rather than USPTO data.

\subsection{PATENT CITATIONS: A PROXY FOR KNOWLEDGE FLOWS}

As discussed at length in the previous chapter, although patents suffer from certain limitations, they are a rich source of information, covering a long time period, about where innovative activity has taken place, the names and addresses of inventors and the firms to 
which the patents rights have been assigned. and the technological field of the invention. At the level of individual multinational firms, patent statistics are available for a longer time period than R\&D statistics and provide more detailed information on the geographical spread of innovative activities. In particular they contain references to prior patents and scientific literature. The legal purpose of the patent references is to indicate which parts of the knowledge described are claimed in the patent and which parts other patents have claimed carlicr. Although similar to references in journal articles, patent citations are different in tivo respects. First, while academic citations are mainly the prerogative of the author, citations in patents are the results of a highly mediated process which involves the inventor, the patent attorney and the patent examiner (Mcyer 2000). Second, articles in joumals may be cited for a variety of reasons, not all of them reflecting recognition of work done previously or a transfer of knowledge. Authors may cite articles for strategic reasons, for cxample, because the authors of the cited article are potential reviewers. However inventors have an incentive not to cite patents unnecessarily, as it may reduce the claim of novelty of the invention and therefore the scope of the monopoly rights granted by the patent. So, in principle, when a patent cites another patent, this indicates that the knowledge embodied in the cited patent has been in some way useful for developing the new knowledge described in the citing patent and that the citing patent has no claim over that particular knowledge. This is the line of reasoning offered in Jaffe et al. (1993), and Jaffe and Trajtenberg (1996 and 1998) for USPTO patents.

Patent citations represent a 'paper trail' of knowledge flows between the citing and the cited inventor, although as pointed out by Jaffe and Trajtenberg (2002) 'one that is incomplete and mixed with a fair amount of noise' (p. 12). Patent citations are an incomplete measure of knowledge flows because they only capture those flows that result in a novel and patentable technology and therefore they cannot be used to make inferences about knowledge transfers that do not result in a patent, such as tacit forms of knowledge, learning via imitation or reverse enginecring. Patents are the ultimate example of codified knowledge. because they require an exact description of technological findings according to legally defined methods. However as I pointed out in Chapter 2, the fact that patent citation studies have found evidence of localised knowledge spillovers suggests that tacit knowledge plays a significant role in the interpretation, use and assimilation of codified knowledge; in other words codified and tacit knowledge flows are closely linked and complementary (Mowery et al. 1996). According to the 'knowledge conversion' model of Nonaka and Takeuchi (1995) there is a strong interaction between codified and tacit knowledge during the creation of new 
technological assets. Tacit knowledge can be converted into some forms of codified knowledge that can then be incorporated in patent documents. Indeed, this ability to codify and 'articulate' knowledge represents one source of firms' sustainable competitive advantage (Hedlund 1994, Teece and Pisano 1994). As argued by Kogut and Zander (1993) firms invest in ways to reduce the tacitness of technology by encoding its use and replications in rules and documentation`(p. 6.37).

It should also be emphasised that knowledge flows are a much broader concept than simply what is captured by patent citations. In terms of the distinction introduced by Griliches (1992) and presented in (hapter 2. patent citations focus on a specific form of pure knowledge spillovers. Rent spillovers, which reflect the fact that intemediate input prices do not completely emboly the product innovations or the quality improvements resulting from R\&D activities, are completely ignored. However, as correctly pointed out by Breschi and Lissoni $(2001)$, in theory patent citations try to measure pure knowledge spillovers, empirically it is hard to exclude those knowledge flows (giving rise to patent citations) which are mediated by markets or market mechanisms. Even within the category of pure knowledge spillovers. patent citations (to the extent that they are related to spillovers) are only a part of the story. For example, in order for patents to be cited, both the spillover-receiving and spillovergencrating firm must be actively engaged in R\&D and apply for patent protection. Therefore knowledge flows can occur without generating citations. But equally there may also be citations that do not represent an actual knowledge source utilised by the inventor in the development of the invention. This source of noise is due to the fact that, though suggested by the inventor together with his attorney, the final decision on which patents to cite lies ultimately with the patent examiner. This implies that the inclusion of a given citation does not necessarily indicate that the inventor has knowledge of the technology underlying the cited patent. However, as noted by Griliches (1990), the fact that most citations are added by examiners is a measure of their objectivity, since they are supposed to be experts in the relevant technological field and therefore their intervention in the citation process may correct for the inventor's bias towards under-reporting prior art by adding concealed or missed references.

Jaffe et al. (1998) point out three other sources of noise. The first derives from the intervention of the patent attorney who may decide to cite a patent not considered prior art by the inventor. The attorney may be trying to avoid the risk of future legal battles (strictly legal citation). The second is connected with the possibility that inventors might have learnt about 
the cited invention only after the development of their own invention (after-fact citation). In this case citations cannot be interpreted as sources of knowledge contributing to the development of the citing patent, but they still represent realised knowledge flows between the citing and cited inventor. The third source of noise is associated with the citation of patents which, while not directly drawn upon by the inventor in the inventing process, are nonetheless seen as basic to this process (teaching citation).

These issues are analysed in more detail by Jaffe ef al. (2002) in which a sample of inventors is asked about the extent and the mode of their communication with the inventors they cite and about the extent to which a patent citation is indicative of this communication. The authors found evidence that a significant fraction of the links indicated by patent citations reflect some kind of spillover. Almost $40 \%$ of the inventors indicated that they learnt about the cited invention either before or during the development of their invention. But in one-third of cases they did not know about the cited patent, which could be due to the intervention of the patent attorney or patent examiner in the citation process. Overall the authors found that citations are affected by a fair amount of noise, since about half of them lacked any relevance to knowledge flows. Despite all these limitations, they concluded that patent citations "can be used as proxies for knowledge spillover intensity for example between categories of organisations or between regions'.

Duguet and MacGarvie (2003) provide new evidence on the legitimacy of patent citations as a measure of knowledge flows. Matching a sample of French firms' responses to the Community Innovation Survey with a count of citations made and received by their patents, the authors were able to explore the relationship between patent citations and firms' technology sourcing behaviour. They found that citations are significantly correlated with the way firms acquire and disseminate new technologies. In particular their results indicate that backward citations, i.e. citations made to other patents by the surveyed firms, were positively and significantly correlated with learning through R\&D collaboration, licensing foreign technology, $M \& A$, and equipment purchases. These results also showed that citations to patents originating from countries more economically integrated with France tended to be correlated with more dircet means of knowledge acquisition, such as R\&D collaboration and licensing. Citations to patents originating from other countries were found to be associated with technology acquisition through arms-length transactions, such as equipment purchases. Thus, the evidence gathered in these two studies goes some way towards justifying the use of patent citations as a reasonable proxy for knowledge flows. 


\subsubsection{Differences between EPO and USPTO patent citations data}

Although in previous studies on the technological sourcing behaviour of foreign subsidiaries (sec Almeida 1996, and Frost 1998. 2001) citations in USPTO patents are used, here I use citations contained in EPO applications as a measure of knowledge flows. As discussed in the previous chapter, there are some differences between the two patent systems regarding the examination process and the criteria followed in awarding a patent. There are also some different requirements concerning the description of the state of the art. While in the USPTO the inventor and his/her attorney are obliged to provide a list of those references describing the state of the art which are considered relevant to the patentability of the invention - the so called 'duty of candour' - the EPO has no similar requirement (Akers 2000, Meyer 2000. Michel and Bettles 2001). As a result, in the EPO, examiners rather than inventors or applicants, add the large majority of patent citations, implying that inventors may not always be aware of the cited patents. However Akers (2000) argues that there is always an incentive for the inventor to add to the EPO application all prior art documents to avoid future patent opposition. In the USPTO inventors add the majority of the citations because they have to comply with the legal requirement to disclose prior art known or believed to be relevant.

As pointed out by Michel and Bettels (2001) applicants to the USPTO 'rather than running the risk of filing an incomplete list of references, they tend to quote each and every reference even if it is only remotely related to what is to be patented. Since most US examiners apparently do not bother to limit the applicants' initial citations to those references which are really relevant in respect to patentability, this initial list tends to appear in unmodified form on the front page of most US patents' (p. 197, emphasis added). Although the study by Narin et al. (1988) based on a sample of patents granted in 1975-83 indicates that only between $36 \%$ and $50 \%$ of all references in the full text appear on the front page of the patent, Michel and Bettels (2001) found that US patents contain about three times as many patent references as European patents. This general finding will be assessed in section 5.5 using a sample of equivalent patent applications made by the MNEs under analysis to the EPO and granted by the USPTO to protect the same invention.

Therefore, EPO citations may be less noisy than USPTO citations given that they are strictly related to the description of prior-art relevant to the patentability of the invention (Michel and Bettles 2001). Thus a citation link in the European case can be seen as an indicator of technological relevance. However, most of the citations in EPO patents are added by the examiner and thus they are only an indirect indication of knowledge actually used by the 
inventor. But citations in the European system may nonetheless indicate a potential spillover. Although this potential may not have been realised in all cases, it is reasonable to assume that since patents are public knowledge, professional R\&D laboratories would be reasonably well informed about existing patents in their field. Therefore I would argue that European patent citations are a useful indicator of knowledge flows.

\subsection{THE DATASET}

My primary data sources are the EPO database on patent applications (Bulletin CD) and patent citations to other patents within the EPO and to other non-EPO patents (REFI database) over the period 1977-2000. All patent applications. whether they have been granted, rejected (or withdrawn), or are still under review have been used. The results presented in Chapter 4 show that both the EPO and the USPTO suffer from a 'home advantage' effect, i.e. they appear to be biased towards domestic patents. As a result the use of EPO data introduces a bias into the statistical analysis of the pattern of technological activitics of MNEs. In particular EPO data will underestimate the R\&D activities of US MNES and EU MNEs taking place in the US. This implies that my analysis will be biased against finding a high level of R\&D activity by EU MNEs in the US. The sample of European and US MNEs under analysis is the same as was used in Chapter 4 although regrouped in nine sectors as described in Table 5.1 (for a list of the companies in the sample see Table A4-1 in the appendix of Chapter 4).

1 included only patent applications made by the MNEs under analysis and excluded citation pairs if one of the patents did not belong to a firm in my sample. Patent applications from firms not included in the MNE groups being studied were excluded from the analysis. Thus I have not captured the innovative activities of other agents in the home and host national innovation systems. such as private and public research institutes, small and medium-sized firms, and other large firms I therefore cannot measure to what extent MNEs are drawing from these sources of knowledge. While this limits the description of the technological sourcing behaviour of foreign subsidiaries, I do take account of the innovative activities of large players in the local innovation system. From a methodological point of view, analysis of a closed set of firms allows me to control for the sets of both potentially citing and cited patents, as will become clear in the next section. 
Table 5.1 Sectoral distribution of MINEs in the database

\begin{tabular}{lcc}
\hline Sector & EU MNEs & US MNEs \\
\hline Aerospace \& defence & 2 & 7 \\
Chemicals & 9 & 2 \\
Electrical and electronics & 6 & 3 \\
Industrial machinery \& transportation & & \\
Machinery & 3 & 3 \\
Motor rehicles \& pats & 4 & 8 \\
Metals & 4 & 1 \\
Mining \& petroleum & 6 & 7 \\
Pharmaceuticals & 5 & 7 \\
Photography & 0 & 3 \\
Telecommunications & & \\
Telecommunications & 4 & 7 \\
IT Related & 0 & 6 \\
\hline Overall & $\mathbf{4 7}$ & $\mathbf{5 0}$ \\
\hline
\end{tabular}

Table 5.2 shows the number of patents applied for by EU (US) affiliates in the US (EU) in two sub-periods 1985-87 and 1995-97 and their share in the total number of EPO applications made by EU MNEs (US MNEs). ${ }^{6.7}$ Some interesting findings emerge from the data. First, across most sectors and for both European and American affiliates there has been a general upward trend in the number of applications, as well as the percentage of patent applications made by the firms in the sample, attributable to research in a foreign location. The largest increase is for EU MNEs in pharmaceuticals and telecommunications. The US has attracted significant R\&D investments by European pharmaceutical companies in the last decade: $36 \%$ of all patents can be attributed to their US subsidiaries. This figure is even more striking if one takes into account that the EPO data underestimate the innovative efforts outside the EU, as shown in the previous chapter. US MNEs in industrial machinery \& transportation are also becoming increasingly engaged in R\&D in Europe: almost $35 \%$ of their patenting activity originates from this region. Second, EU and US MNEs in aerospace \& defence, and metals show a much weaker propensity to perform R\&D abroad. Indeed, there are too few observations (citations and/or patents) to report the results of the statistical analysis of their citations. Third, there is substantial difference in the total numbers of US affiliates' patents and European affiliates' patents, which must be taken account of in the patent citation analysis.

\footnotetext{
n: In the case of multiple inventors. I use a fractional counting method. i.e., if there are $p$ inventors in the EU and $q$ inventors in the US, the EU is attributed $p(p+q)$ of the patent, and the US $q /(p+q)$.
} 
Table 5.2 EPO applications by affiliates, 1985-87 and 1995-97

\begin{tabular}{|c|c|c|c|c|c|c|c|c|}
\hline \multirow[b]{2}{*}{ Sector } & \multicolumn{4}{|c|}{ EU MNE affiliates in the US } & \multicolumn{4}{|c|}{ US MIN affiliates in the $\mathrm{EU}$} \\
\hline & $\begin{array}{c}1985- \\
87 \\
\end{array}$ & $\begin{array}{l}\text { as } \% \text { of } \\
\text { all } \mathrm{EU} \\
\mathrm{MNL} \\
\text { pats }\end{array}$ & $1995-97$ & $\begin{array}{l}\text { as \% of } \\
\text { all EU } \\
\text { MNE } \\
\text { pats }\end{array}$ & $1985-87$ & $\begin{array}{l}\text { as } \% \text { of } \\
\text { all US } \\
\text { MNE } \\
\text { pats }\end{array}$ & $1995-97$ & $\begin{array}{l}\text { as } \% \text { of all } \\
\text { US MNE } \\
\text { pats }\end{array}$ \\
\hline Acrospace \& defence & 2.6 & 0.9 & 1.5 & 0.5 & 187.1 & 10.7 & 120.1 & 6.9 \\
\hline Chemicals & 985.3 & 12.5 & 9() 7.1 & 12.2 & 152.7 & 10.0 & 206.8 & 14.0 \\
\hline $\begin{array}{l}\text { lilectrical \& } \\
\text { electronics } \\
\text { lndustrial mach. \& }\end{array}$ & 288.2 & 4.2 & 889.0 & 9.1 & 206.2 & 14.4 & 247.1 & 19.8 \\
\hline transp. & 146.2 & 3.9 & 159.9 & 2.5 & 270.1 & 25.8 & 760.5 & 34.8 \\
\hline Metals & 90.2 & 16.6 & 43.8 & 5.9 & 6.5 & 14.3 & 9.9 & 21.3 \\
\hline Mining \& petroleum & 476.2 & 23.9 & 325.5 & 20.5 & 97.0 & 8.2 & 129.3 & 12.2 \\
\hline Phamacenticals & 636.3 & 23.0 & 1014.7 & 36.3 & 327.4 & 16.7 & 442.3 & 14.6 \\
\hline Photography & & & & & 131.6 & 7.8 & 344.3 & 10.1 \\
\hline Telecommunications & 33.8 & 3.2 & 624.5 & 13.7 & 340.2 & 9.6 & 726.1 & 11.8 \\
\hline
\end{tabular}

Since the statistical analysis was conducted at both sectoral and technological levels, it is interesting to examine the technological profile of foreign subsidiaries' patents and identify to what extent the product groups of their parent companies correlate with their technological specialisation. Because R\&D internationalisation strategies are partly driven by the technological specialisation of the host location, it may be the case that foreign subsidiaries' knowledge bases are much more diversified than the product range of their parent companies.

Table 5.3 shows the distribution of foreign subsidiary patenting across sectors and across 30 technological sub-ficlds over the period (1977-2000). The grouping of IPC patent classes into technical sub-fields was based on the concordance developed by OST and ISI used in the previous chapter (see Table A4-8 in the appendix of Chapter 4). Table 5.3 lists the top three fields for foreign subsidiary patenting activity for each sector in rank order by the number of patents in that field and their shares in total of subsidiaries' patents.

Another point that is worthy of attention is to what extent the technological dimension of the innovative activities of foreign subsidiaries captured by the EPO data overlaps with that measured by USPTO data. In the previous chapter it was shown that only a small proportion of patents granted to foreign subsidiaries are filed in both patent offices: I would therefore expect that the technological specialisation of the firms in the sample based on EPO data will differ from the specialization found using USPTO data. If this is the case, the result of the patent citation analysis will differ depending on whether EPO and USPTO data are used. To assess the scale of this problem, Table A5-I in the appendix presents shares calculated using the sample of patents granted to these foreign subsidiaries by the USPTO, classified into 32 technological fields and based on the concordance contained in Hall et al. (2001). 
As expected a strong correlation was found between subsidiaries' technological and product specialisation. For instance firms in telecommunications, and industrial machinery \& transportation are mainly active in their related fields of telecommunications and transportation. However there are some exceptions. Note. for example, the high share of patents in macromolecular chemistry in the portfolios of EU subsidiaries of US MNEs operating in the electrical \& electronics sector, which may be the result of the relative technological advantage of Europe in this area. Another interesting result is the high share of biotechnology patents applied for by the US subsidiarics of EU MNEs, which confirms the findings of previous studies on R\&D internationalisation by these firms in the US (see for example Senker 1998).

Finally, although the technological classification of EPO patents based on IPC codes does not perfectly correspond with the classification of USPTO patents based on USPC (US patent classes), a comparison of the figures in Table 5.3 and Table A5-1 in the appendix gives an indication of the different innovative activities captured by the two datasets. In particular according to USPTO data, both EU and US MNEs' subsidiaries in electrical \& electronics appear to be focused on the area of nuclear technology while EPO figures suggest technological specialisation in other domains (electronies and macromolecular chemistry). Similarly, according to USPTO data, European subsidiaries of US MNEs in photography seem to concentrate their innovative efforts in chemicals whereas according to EPO figures they appear to be involved in optical technologies. This implies that patent citation analysis based on EPO data may give rise to different results from an analysis using USPTO data given that firms tend to protect different types of innovation activity in each patent office. However it is difficult to assess how this will affect the analysis of foreign subsidiaries' technology sourcing behaviour.

\subsection{TESTING FOR hOME COUNTRY BIAS IN EPO AND USPTO CITATIONS}

Before presenting the results of the patent citation analysis I will try to assess the implications of using citations in EPO applications rather than those listed in USPTO patents. In Chapter 4 , cvidence of a 'home advantage' effect was found for both patent systems, which, as already pointed out, will affect the result of this study. However whether this home country bias is also present in the citation patterns of EPO and USPTO patents was unknown. To test for the presence of a 'home advantage' effect in EPO and USPTO citations I used the citations contained in the sample of equivalent patents examined in the previous chapter. For USPTO patents I had information only on citations made to and received from other USPTO patents. 
For each EPO patent. I had information on the number of citations made both to other EPO patents and to patents filed in other patent offices. The following analysis includes all the citations contained in the EPO and USPTO patents and not just the citations to patents owned by the MNEs in the sample (as I will do in the statistical analysis presented in the next section).

The dataset of EPO-USPTO equivalents contains 78,024 patents. There are 580,863 backward citations within the USPTO system, 111.557 within the EPO system and 108.567 citations made by EPO patents to patents filed in other national patent offices. From these figures it is clear that USPTO backward citations are five times more frequent than citations within the EPO system, although only two and half times more frequent than the combined total of EPO and non-EPO citations. More than half the citations made to non-EPO patents are to USPTO patents $(58 \%)$. German patents received $18 \%$ of citations made by EPO applications, UK patents $9 \%$ and French patents $8 \%$. As expected, of the EPO applications citing USPTO patents more than two-thirds $(67 \%)$ were for inventions made in the US. Similarly, a large proportion of the USPTO patents cited were for inventions made in the US (70\%) and only $11 \%$ were granted to inventors resident in Europe. Therefore USPTO patent citations in EPO applications mainly capture knowledge flows within the US. 


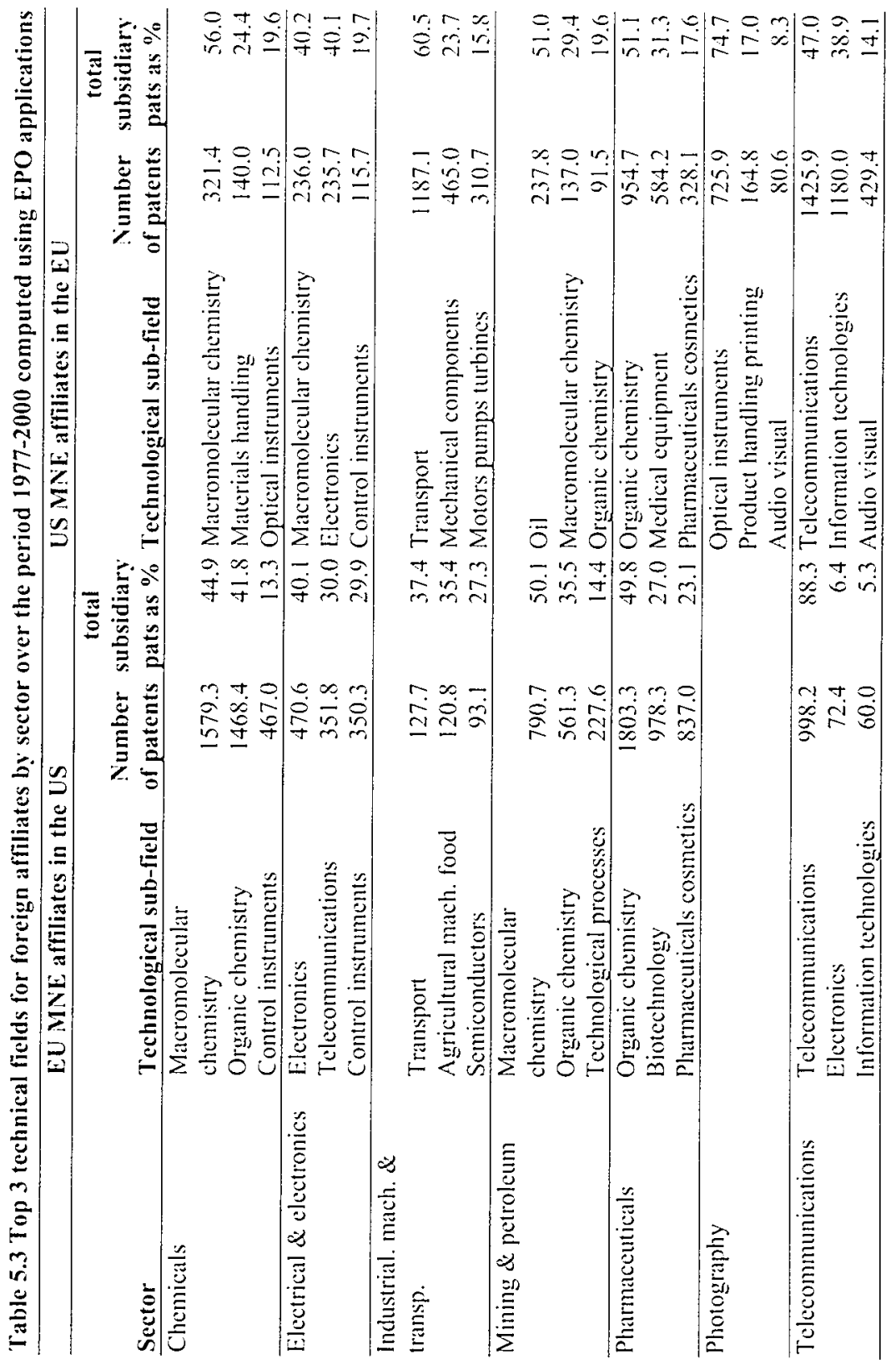


1 also assessed how many of the USPTO patents cited in EPO applications were also cited by their USPTO equivalents. Only $8 \%$ of the USPTO patents cited in EPO patents were also cited by their USPTO equivalents. Of the remaining $92 \%$, the vast majority were only cited by the sample of USPTO equivalents. It should be noted that there is a significant difference in the number of intra-firm citations in this sample of overlapping and non-overlapping USPTO cited patents. Of the USPTO patents cited only by the sample of USPTO equivalents. $20 \%$ were intra-firm citations, while in the sample of overlapping USPTO citations only $2 \%$ were intra-firm citations. If it is assumed that intra-firm citations tend to be added by the inventor or the patent attorney, these results would indicate that the EPO cxaminer, and not the inventor, included these USPTO patents in EPO applications.

Table 5.4 shows the differences across the two patent systems in terms of the average number of backward citations. On average USPTO patents cite patents, almost six times more than the average number of citations made in the EPO equivalent patents to other EPO patents (1.3). The difference between the two systems becomes even more pronounced if the number of backward citations by patents in the $90^{\text {th }}$ percentile and the value of the standard deviation are examined. The results are similar if intra-firm citations are excluded. The exclusion of intrafirm citations from the sample of within-USPTO citations substantially reduces the average number of backward citations while the mean calculated using within-EPO citations remains almost unchanged. This might be indicative of a smaller number of applicants' citations. However the discrepancy in the number of backward citations is reduced if account is laken of the citations made by EPO patents to patents filed in other patent offices. The average number of backward citations made by EPO and non-EPO patents is 2.79 per patent, reaching a value of 5 for patents in the $90^{\text {th }}$ percentile. These results show a much greater discrepancy between the two systems as regards the number of backward citations than was reported by Michel and Bettles (2001). Another trend emerging from this data is that while the mean of backward citations made by EPO patents is fairly constant over time. the pattern for the average number of within-USPTO citations shows an increasing trend. ${ }^{68}$

\footnotetext{
ax For the sub-sample of USPTO (EPO) citing patent applications made between 1989 and 1994 the average number of backward citations is equal to 7.09 (1.27) with patents in the $90^{\text {th }}$ percentile making 14 (3). For the set of citing patent applications made between 1995 and 1999 the mean number of backward citations is 7.95 (1.31) and for the $90^{\text {th }}$ percentile $16(3)$.
} 
Table 5.4 Descriptive statistics of backward citations of EPO/USPTO equivalent patents

\begin{tabular}{|c|c|c|c|}
\hline & \multicolumn{2}{|c|}{$\begin{array}{c}\text { Number of } \\
\text { backward citations }\end{array}$} & $\begin{array}{l}\text { Number of backward } \\
\text { citations to EPO and } \\
\text { non-EPO patents }\end{array}$ \\
\hline USPTO & \multicolumn{2}{|c|}{$\begin{array}{c}\text { excl. } \\
\text { intra-firm } \\
\text { citations }\end{array}$} & \\
\hline Mean & 7.44 & 6.29 & \\
\hline Standard deviation & 7.85 & 6.94 & \\
\hline 9()$^{\text {th }}$ percentile & 15 & 13 & \\
\hline \multicolumn{4}{|l|}{ EPO applications } \\
\hline Mean & 1.30 & 1.31 & 2.79 \\
\hline Standard deviation & 1.41 & 1.41 & 2.40 \\
\hline $90^{\text {th }}$ percentile & 3 & 3 & 5 \\
\hline \multicolumn{4}{|l|}{ EPO granted } \\
\hline Mean & $1 . \overline{33}$ & 1.34 & 2.79 \\
\hline Standard deviation & 1.39 & 1.39 & 2.32 \\
\hline $90^{\text {th }}$ percentile & 3 & 3 & 5 \\
\hline
\end{tabular}

There is clearly a substantial difference between the two databases in terms of citations. It is difficult to know to what extent these differences reflect different citation practices on the parts of the applicants and/or the different roles of the patent examiners. It may be that applicants file patents protecting the same invention with different descriptions of the state of the art depending which patent office they are applying to. As mentioned carlicr. in the USPTO the inventor has to comply with the legal requirement to disclose prior art known or believed to be relevant, whereas the EPO imposes no such obligation. In both the USPTO and in the EPO patent examiners decide which patents to cite. However, according to Michel and Bettles (2001), USPTO examiners tend to accept most of the citations suggested by the inventor and report them on the front page, whereas, in the EPO, patent examiners cite in the search report references that are really relevant to patentability. Both these factors may contribute to this large discrepancy in the number of citations appearing on the front pages or in the scarch reports of the patent documents.

\subsubsection{Geographical distribution of backward citations}

Another important issue is the geographical origin of these citations. I counted EPO citations using a fractional count method. For example, if a patent $A$ with two inventors, one from the US and one from the EU, cites patent B with one inventor from the EU, I counted 3 citations (EU-EU; EU-US: EU-EU) and attributed two-thirds of the citation to the EU-EU combination and one-third to the EU-US combination. ${ }^{69}$ I used this method to count citations made to

\footnotetext{
1." Counting the backward citations becomes more complicated when there is more than one applicant firm for the citing patent. In this case 1 applied a fractional count method. Taking the same example as in the text if patent $A$ is coapplied for by an EU firm and a US firm. 1 counted 6 citations (number of applicants $x$ number of citing inventors $x$
} 
USPTO patents by EPO applications using the information of all the inventors' addresses from the NBER dataset. Citations within the USPTO system are attributed only to one particular location based on the address of the first inventors in the citing and cited patents. This is standard procedure used in patent citation analysis based on USPTO data (see for example Jaffe et al. 1993).

Before commenting on the results of the geographic analysis, it must be emphasised that it is citations made by patents protecting the same technology that is being compared; therefore it is assumed that an EPO patent and its USPTO equivalent build on similar sources of innovation originating from specific locations. For instance an EPO/USPTO cquivalent patent in the field of semiconductors will most likely cite patents for inventions made in Silicon Valley because this is where most of the cutting-edge research in this area is performed. Therefore there would be no need to control for the geographical distribution of potentially cited patents if the EPO and the USPTO equally reflected the geographical distribution of R\&D activities. However, based on the findings in the previous chapter, there is evidence of a home country bias in both the USPTO and the EPO data leading to US (EU) inventions patents being underrepresented in the EPO (USPTO). As a result, there is a strong probability that many of the semiconductor patents invented in Silicon Valley will only be filed with the USPTO; thus the EPO and citations within the EPO system may not capture to the same extent as the USPTO this source of innovation. But if I include in the analysis citations by EPO patents to USPTO patents, I may correct for this possible bias. I therefore calculated these shares not only on the basis of citations within the USPTO and the EPO system, but also based on the sample of citations in EPO applications of both EPO and USPTO patents (EPO and USPTO).

number of cited inventors) and attributed a weight of one-sixth to each possible regional combination. In this case. two-sixth of the citations are attributed to EU MNE patents originating in EU locations citing US patents. $2 / 6$ to US MNE patents originating in EU locations citing US patents, one-sixth to EU MNE patents originating in US locations citing EU patents, and one-sixth to US MNE patents originated in US locations citing EU patents. 
Table 5.5 Geographical distribution of the citations made by EPO/USP'TO equivalents to patents filed in each patent office

\begin{tabular}{|c|c|c|c|c|c|c|c|c|c|}
\hline \multirow{3}{*}{$\begin{array}{l}\text { Citing } \\
\text { pats } \\
\text { invented } \\
\text { in: }\end{array}$} & \multicolumn{3}{|c|}{$\begin{array}{c}\text { Cited pats invented in the } \\
\text { EU } \\
(\%)\end{array}$} & \multicolumn{3}{|c|}{$\begin{array}{c}\text { Cited pats invented in the } \\
\text { US } \\
(\%)\end{array}$} & \multicolumn{3}{|c|}{$\begin{array}{c}\text { Cited pats invented in the } \\
\text { ROW } \\
(\%)\end{array}$} \\
\hline & & EPO and & & & $E P O$ and & & & EPO and & \\
\hline & $\begin{array}{l}\text { EPO } \\
\text { (1) }\end{array}$ & $\begin{array}{c}\text { USPTO } \\
(2)\end{array}$ & $\begin{array}{c}\text { USPTO } \\
\text { (3) }\end{array}$ & $\begin{array}{c}\text { EPO } \\
(4)\end{array}$ & $\begin{array}{c}\text { USPTO } \\
(5)\end{array}$ & $\begin{array}{l}\text { USPTO } \\
\text { (6) }\end{array}$ & $\begin{array}{l}\text { IEPO } \\
\text { (7) }\end{array}$ & $\begin{array}{c}\text { USPTO } \\
\text { (8) }\end{array}$ & $\begin{array}{c}\text { USPTO } \\
\text { (9) }\end{array}$ \\
\hline $\mathrm{EU}$ & 63.96 & 45.66 & 23.62 & 20.93 & 35.73 & 53.83 & 15.11 & 18.61 & 22.55 \\
\hline ROW' & 28.53 & 20.24 & 16.10 & 33.95 & 44.87 & 53 & 37 & 34 & 30.31 \\
\hline US & 26.43 & 17.03 & 15.77 & 52.73 & 63.90 & 62.13 & 20.84 & 19.07 & 22.11 \\
\hline
\end{tabular}

Table 5.5 shows the geographical distribution of the patents cited by each patent office according to the origin of the citing patent. It reports the number of citations made to patents from one region made by patents invented in a particular region over the total number of citations made by patents invented in this region. Therefore the percentage shares in columns 1, 4 and 7 sums to 100. The figures in Table 5.5 show are clear evidence that there is a home country bias in citation patterns: $64 \%$ of backward citations computed within the EPO system by patents invented in the EU are to EU-invented patents, while the same proportion amounts to only $23 \%$ on the basis of citations within the USPTO system. For citations made by EUinvented patents to US-invented patents the proportion calculated using within-USPTO citations is more than twice as large as that based on within-EPO citations. For US-invented citing patents the difference between these two shares is less pronounced (compare column 4 with column 6). According to within-EPO citations just over half of citations in this set of patents are to US invented patents (sec last row of column 4), while the share based on within-USPTO citations is just over $62 \%$. As expected, the shares computed using the sample of citations made by EPO applications to both EPO and USPTO patents attenuates the differences between the two patent systems since these citations are mostly for inventions made in the US.

This bias must be taken into account of when using backward citations to examine the geographical dimension of knowledge flows that cross the area protected by a particular patent office. The use of a dataset containing citations within a particular patent system and citations to patents filed in other patent systems would seem to be one way to correct for this bias. However, as the exercise of matching together the sample of EPO and USPTO equivalent patents has shows (see section 4.4 .2 in Chapter 4) working with patent data from different patent offices is complex because of the different rules used for assigning patent 
rights. This introduces serious problems for the consolidation of patents at the level of the firm. Consolidation at this level is necessary to study not only in the geographical dimension of knowledge spillovers but also their organisational dimension.

The evidence presented in this section shows that it is not only the number of citations that differs between the two systems but also their geographical origin. More specifically, citations in the EPO are biased towards EU-invented patents while the opposite holds for withinUSPTO citations. As a result, a patent citation analysis based on within-EPO citations only would be biased against finding evidence of foreign subsidiaries citing US-invented patents. One way to correct for this bias is to consider not only within-EPO citations but also citations made by EPO applications to USPTO patents which the approach adopted in the next section.

\subsection{Statistical TeSting}

In order to investigate to what extent foreign subsidiaries draw upon local sources of knowledge rather than home country knowledge, I applied a number of statistical tests to the patent citation data. I identified the location of the invention by looking at the inventor"s address. Only addresses in the European Union ${ }^{70}$ (EU) or the United States (US) were used in the analysis, and, in the empirical data, the word 'foreign' means 'in the other region'. The region of ownership (i.e., EU or US) is identified by the location of the headquarters of the multinational group (sec Table A4-1 in the appendix of Chapter 4). Thus for each patent the region of the owner-company, and the region of the invention is known. I assume that patents invented abroad reflect the R\&D activities of foreign affiliates.

Comparing citations between these groups of patents was complex because three factors must be taken into consideration which may disturb a 'fair' comparison. First, it is necessary to control for the number of potentially citing patents. For example, if more patents are applied for by US firms located in Europe than by European firms located in the US, the raw number of citations by US owned patents in Europe would be large even if the number of citations per patent of this type was relatively low. As shown previously, the number of European and US multinationals in each sector is quite different, and therefore controlling for the patenting activity carried out in each location is important.

\footnotetext{
"As in the previous chapter. Europe refers to the 15 countries belonging to the Furopean Union (prior to May 20(0)4) plus lceland, Liechtenstein. Norway, and Switzerland.
} 
Second, it is necessary to correct for factors that affect changes in citation intensities over time. The most obvious is the truncation or 'cohort' effect, which implies that older patents receive more citations than younger patents because there has been a greater opportunity for them to be cited. Finally, there is a potential bias connected to the increasing number of applications to the EPO. This yields higher citation rates for younger patents, simply because most of the citations occur within a relatively short period after the application date of the patent.

To correct for the first potential bias I divided the citation count by both the number of potentially citing patents and the number of potentially cited patents. To remove the bias introduced by the other two factors, I followed Hall et al. (2001) and divided by the average number of citations received by patents applied in the same year.

The citation rate in year $t$ between the cited firms $(j)$ and the citing firms $(i)$ operating in sector $n$ is calculated using the following formula:

$C R_{i j, t, n}=\frac{N C_{i i, t, n} 1000}{N P_{t, T, n} N P_{i, t}}$

where $N C_{i j, t, n}$ represents the total number of citations made by firm i's patents to firm $j$ 's patent applications made in year $t$, where firm $i$ operates in sector $n ; N P_{j, t}$ denotes the number of potentially cited patents, which is equal to the number of firm $j$ 's patents in year $t ; N P_{i, T t, n}$ is the number of potentially citing patents, which is equal to the number of patents of firm $i$ between time $t$ and last period of observation $(T=2000) ; N C_{T O T T O T}$, represents the number of citations made by the total number of patents in the sample to patents applied at time $t: N P_{T o r}$ .$t$ is the total number of patents of all firms in the sample in year $t$.

The denominator in equation (1) divides the number of citations received by all patents applied for in year $t$ over the number of applications in that year. It thus represents the average citation rate of patent applications in year $t$ by all firms in the sample operating in all sectors under analysis (including aerospace \& defence and metals). Through this procedure I remove from the citation count the variability arising from the yearly fixed effect. The numerator of equation (1) measures the actual citation rate between two companies, for example European subsidiaries in the US $(i)$ and US MNEs $(j)$, taking into account the patenting behaviour of the 
two firms. It should be noted that not only intra-sector citations but also inter-sector citations, c.g. citations made by chemical companies to electronic companies, were considered.

According to the theory outlined above, asset-augmenting foreign-based R\&D is mainly aimed at exploiting the knowledge base of the host region. Therefore, one would expect a knowledge flow from business units in the host location to the foreign subsidiaries located there. Hence citations by foreign affiliates to firms in the host region should be more extensive than citations to firms in the home region. Conversely, in asset-exploiting R\&D activity, the knowledge generated in the home region is implemented in the host region, and this should be reflected by more citations to patents from the home region. Note that this interpretation corresponds to the 'macro' definition of asset-exploiting activities. The 'micro view' of asset-exploiting activitics is that R\&D sites located abroad have a bias towards citing patents originating from their parent-company only, and not from other firms in the homebase region (sec for example Almeida 1996, and Frost 1998, 2001). The 'macro' view of asset-exploiting activities, which takes into account the notion of innovation systems, looks instead at the total knowledge base of the home-base region, and this is why no distinction is made between citations by foreign affiliates to the parent company and to other home country firms in my analysis of asset-cxploiting R\&D activities. Asset-augmenting activitics of European affiliates in the US are indicated by a high rate of citations made by EU subsidiaries patents to US-owned patents for US inventions (and vice versa), while a high rate of citations made by these firms to EU-owned patents invented in the EU (including intra-firm citations) indicates asset-exploiting activities.

Table 5.6 Geographical origin of patents cited by US affiliates of EU MNEs (1977-2000)

\begin{tabular}{|c|c|c|c|c|c|c|c|c|}
\hline \multirow[b]{2}{*}{ Sector } & \multicolumn{4}{|c|}{ Within-EPO citations } & \multicolumn{4}{|c|}{ EPO \& USP'TO citations } \\
\hline & $\begin{array}{l}\text { Home } \\
\text { region } \\
\text { patents }\end{array}$ & $\begin{array}{l}\% \text { of } \\
\text { Total } \\
\end{array}$ & $\begin{array}{c}\text { Host } \\
\text { region } \\
\text { patents } \\
2\end{array}$ & $\begin{array}{l}\% \text { of } \\
\text { Total }\end{array}$ & $\begin{array}{l}\text { Home } \\
\text { region } \\
\text { patents }\end{array}$ & $\begin{array}{l}\% \text { of } \\
\text { Total }\end{array}$ & $\begin{array}{c}\text { Host } \\
\text { region } \\
\text { patents } \\
\text { I }\end{array}$ & $\begin{array}{l}\% \text { of } \\
\text { Total }\end{array}$ \\
\hline Chemicals & 1982.4 & 39.3 & 779.8 & 15.5 & 2377.1 & 34.9 & 1410.6 & 20.7 \\
\hline Electronics & 596.2 & 36.5 & 643.2 & 39.4 & 702.5 & 28.7 & 1136.8 & 46.5 \\
\hline Industrial mach. \& transp. & 119.1 & 37.7 & 66.1 & 20.9 & 144.4 & 27.7 & 190.8 & 36.5 \\
\hline Mining \& petroleum & 522.5 & 29.6 & 350.2 & 19.8 & 600.9 & 24.5 & 623.3 & 25.4 \\
\hline Phamaceuticals & 1212.4 & 28.9 & 612.0 & 14.6 & 1383.3 & 26.4 & 1020.5 & 19.5 \\
\hline Telecommunications & 464.9 & 49.6 & 299.3 & 31.9 & 544.3 & 41.4 & 553.1 & 42.0 \\
\hline
\end{tabular}


I next report some descriptive statistics of the citation count and citation rates. Tables 5.6 and 5.7 show the number of citations made by patents applied for, respectively, by EU subsidiaries in the US and US subsidiaries in Europe, to both home region and host region patents and their shares in the total number of citations made to other patents in the dataset. using both within-EPO citations and citations by EPO applications to EPO and USPTO patents."

Table 5.7 Geographical origin of patents cited by EU affiliates of US MNEs (1977-2000)

\begin{tabular}{|c|c|c|c|c|c|c|c|c|}
\hline \multirow[b]{2}{*}{ Sector } & \multicolumn{4}{|c|}{$\begin{array}{l}\text { Within-EPO citations } \\
\text { Citations made to: }\end{array}$} & \multicolumn{4}{|c|}{$\begin{array}{c}\text { EPO \& USPTO citations } \\
\text { Citations made to: }\end{array}$} \\
\hline & $\begin{array}{l}\text { Home } \\
\text { region } \\
\text { patents }\end{array}$ & $\begin{array}{l}1 \% \text { of } \\
\text { Total }\end{array}$ & $\begin{array}{l}\text { Host } \\
\text { region } \\
\text { patents }\end{array}$ & $\begin{array}{l}\% / \% \text { of } \\
\text { Total }\end{array}$ & $\begin{array}{l}\text { Home } \\
\text { region } \\
\text { patents }\end{array}$ & $\begin{array}{l}\% \text { of } \\
\text { Total }\end{array}$ & $\begin{array}{l}\text { Host } \\
\text { region } \\
\text { patents }\end{array}$ & $\begin{array}{l}\% \text { of } \\
\text { Total }\end{array}$ \\
\hline Chemicals & 371.2 & 37.2 & 395.2 & 39.6 & 572.0 & 43.5 & 456.5 & 34.8 \\
\hline Electronics & 285.7 & 33.0 & 288.2 & 33.3 & 465.4 & 41.6 & 319.4 & 28.5 \\
\hline Industrial mach. \& transp. & 238.9 & 23.4 & 362.2 & 35.5 & 452.0 & 34.1 & 413.5 & 31.2 \\
\hline Mining \& petroleum & 396.3 & 38.0 & 262.0 & 25.1 & 596.9 & 45.7 & 280.5 & 21.5 \\
\hline Pharmaccuticals & 736.7 & 23.2 & 726.0 & 22.8 & 927.5 & 25.8 & 794.8 & 22.1 \\
\hline Photography & 476.4 & 39.4 & 273.2 & 22.6 & 717.7 & 45.6 & 325.5 & 20.7 \\
\hline Telecommunications & 1274.8 & 45.7 & 852.2 & 30.5 & 2033.9 & 54.5 & 944.2 & 25.3 \\
\hline
\end{tabular}

According to the within-EPO citation figures in Table 5.6, in all sectors except electronics, EU MNE subsidiaries appear to draw more heavily on their home region knowledge sources than their host region sources. This is also the case for European subsidiaries of US MNEs (sec Table 5.7). although in chemicals and in industrial machinery \& transportation the proportion of eitations to host region patents is higher than the proportion to home region patents. However, when I included in the calculation citations made by EPO applications not only to EPO patents but also to USPTO patents, both the role of the host region (i.e. US) knowledge sources for EU MNE subsidiaries and the role of home region sources for US MNE subsidiaries increased. ${ }^{72}$ This is particularly evident for MNEs in electronics. telecommunications and industrial machinery \& transportation. These findings are in line with the results presented in the previous section for a subset of EPO patents with USPTO

\footnotetext{
${ }^{71}$ Citations were computed using a fractional count method as explained in section 5.5 .

" Citations to USPTO patents granted to the MNEs in the sample represent $23 \%$ of the total number of EPO and USPTO citations made in EPO applications. Two-thirds of USPTO patents cited were for inventions made in the US and $55 \%$ of $1: P O$ applications referring to these patents originate from within the US.
} 
cquivalents, and provide support for the suggestion to use the sample of EPO and USPTO citations to correct for the home country bias in within-EPO citations. ${ }^{73}$

Table 5.8 Deseriptive statistics of citation rates

\begin{tabular}{|c|c|c|c|c|c|}
\hline Sector & MNE & R\&D activity & Median & Std Dev & $\operatorname{Max}$ \\
\hline \multirow[t]{4}{*}{ Chemicals } & $\mathrm{EU}$ & Fxploiting & .0047 & .0062 & .0319 \\
\hline & & Augmenting & .0050 & .0196 & .1003 \\
\hline & US & Exploiting & .0088 & $.0(19)$ & .0171 \\
\hline & & Augmenting & .0041 & .0026 & .0108 \\
\hline \multirow[t]{4}{*}{ Electronics } & $\mathrm{EU}$ & Txploiting & .002 & .0024 & .011 \\
\hline & & Augmenting & .0040 & .0054 & .0242 \\
\hline & US & Exploiting & .0073 & .0173 & .0897 \\
\hline & & Augmenting & .0023 & .0015 & .0054 \\
\hline \multirow{4}{*}{$\begin{array}{l}\text { Industrial machinery } \\
\text { \& transportation }\end{array}$} & EU & Exploiting & .0015 & .0073 & .0368 \\
\hline & & Augmenting & .0025 & .0033 & .0153 \\
\hline & US & Exploiting & .0026 & .0076 & .0322 \\
\hline & & Augmenting & .0013 & .0138 & .0683 \\
\hline \multirow{4}{*}{ Mining \& petroleun } & $\mathrm{EU}$ & Exploiting & .0028 & .0030 & .0144 \\
\hline & & Augmenting & .0053 & .0107 & .0539 \\
\hline & US & Exploiting & .0171 & .0261 & .1044 \\
\hline & & Augmenting & .0035 & .0039 & .0132 \\
\hline \multirow[t]{4}{*}{ Pharmaccuticals } & EU & Exploiting & .0032 & .0138 & .0696 \\
\hline & & Augmenting & .0044 & .0051 & .0251 \\
\hline & US & Exploiting & .0069 & .017 & .0845 \\
\hline & & Augmenting & .0032 & .0035 & .0155 \\
\hline \multirow[t]{2}{*}{ Photography } & US & Exploiting & .0074 & .0145 & .0606 \\
\hline & & Augmenting & .0020 & .0021 & .0092 \\
\hline \multirow[t]{4}{*}{ Telecommunications } & EU & Exploiting & .0016 & .0044 & .0137 \\
\hline & & Augmenting & .0045 & .0042 & .0143 \\
\hline & US & Exploiting & .0075 & .0141 & .0522 \\
\hline & & Augmenting & .0016 & .0073 & .0292 \\
\hline \multirow[t]{4}{*}{ Overall } & $E U$ & Exploiting & .0029 & .0073 & .0696 \\
\hline & & Augmenting & .0045 & .0099 & .1003 \\
\hline & US & Exploiting & .0076 & .0166 & .1044 \\
\hline & & Augmenting & .0025 & .0063 & .0683 \\
\hline
\end{tabular}

Although interesting, little can be inferred from the figures presented in these tables because of the need to control for a number of other variables. Therefore for each set of foreign subsidiarics I calculated the relevant citation rates using the sets of EPO and USPTO citations and reported descriptive statistics in Table 5.8 (sec Table A5-2 in the appendix for descriptive statistics on the citation rates across technology fields).

The aim of this chapter being to assess the extent of asset-augmenting and asset-exploiting activities of European and American subsidiaries located in the two regions I carried out a

\footnotetext{
However 1 only computed the number of potentially citing patents and cited patents on the basis of EPO applications.
} 
series of Mann-Whitney tests for two independent samples amed at testing whether or not the various citation rates differed using data from the whole period $1977-2000{ }^{74}$ I ran these tests at sectoral and technology levels aggregating patents into 10 categories according to the classification provided in Table A4-8 in the appendix. ${ }^{75}$ However. on the basis of the results in Table 5.31 did not expect to observe major differenees between the two sets of tests given the high correlation between the subsidiaries' technologies and product specialisation. The results of the analysis at the technology level are reported in full in the appendix and referred to in the text when necessary.

The first set of tests analyses the citation behaviour of US (European) subsidiaries in Europe (the US) in order to establish in which sectors asset-augmenting effects dominate the assetexploiting ones. I describe the statistical procedure for the case of European stubsidiaries in the US. The null hypothesis is that European-owned R\&D facilities in the US carry out the same amount of asset-augmenting and exploiting activities, i.e. that there is no bias towards citing patents from European firms or towards citing patent from US firms. The Mann-Whitney test measures whether these two citation rates differ significantly. I also performed a two-tailed Mann-Whitney to test the null hypothesis of equal medians between the two populations of citations made by EU subsidiaries' patents to EU-owned patents for inventions in the EU and citations made by EU subsidiaries patents to US-owned patents for inventions in the US. Table 5.9 also reports the results of a right one-tailed test to see whether the difference between the two populations' medians was positive. This indicates whether the assetexploiting part of European owned R\&D activities in the US dominates the asset-augmenting component.

The test results indicate that the null hypothesis cannot be rejected in any sector except electronics and mining \& petroleum. European affiliates seem to be embedded in the technological base in the host country to the same extent as they are embedded in that of home region. In other words no strong tendency was found for R\&D activities in these cases to be either asset-exploiting or asset-augmenting. ${ }^{76}$ In electronics, and mining \& petroleum, European affiliates show a statistically significant bias towards citing the host region's

\footnotetext{
"I use the Mann-Whitney lest rather than the parametric t-test because the sample distribution of citation rates is not normally distributed.

Results for houschold consumption are not reported because of the small number of observations.

The same results were obtained using the sample of within-EPO citations for MNEs in slectronics. mining \& petroleum. and telecommunications. While for chemicals, phamaceuticals, and industrial machinery \& transportation the asset-exploiting component appears to dominate. this might be due to the fact that this dataset underestimates the technological sourcing behaviour of EU MNE subsidiaries in the US.
} 
knowledge base, which is indicative of a strong asset-augmenting component. Indeed this characterises the overall tendency of European R\&D activities in the US. ${ }^{77}$ These results are confirmed by the analysis at the technology level (see Table A5-3 in the appendix), the only noticable difference being the predominance of asset-exploiting types of activitics in transport-related technologies.

Table 5.9 Testing the relative propensity to engage in asset-exploiting and asset-augmenting activities by EU MNEs

\begin{tabular}{lcccc}
\hline \multicolumn{5}{c}{ Ho: Asset-exploiting = Asset-augmenting } \\
\hline Sector & $\mathbf{U}$ & $\begin{array}{c}\text { 2-tail p-value } \\
\text { Prob (diff }=\mathbf{0})\end{array}$ & $\begin{array}{c}\text { right } \text { Prob (diff }>\mathbf{0} \text { ) } \\
\text { Probalue }\end{array}$ & Inference \\
\hline Chemicals & -0.443 & .657 & .463 & Exploiting = Augmenting \\
Electronics & -3.692 & .000 & .189 & Exploiting < Augmenting \\
Industrial mach. \& transp. & -1.342 & .179 & .387 & Exploiting = Augmenting \\
Mining \& petroleum & -3.259 & .001 & .226 & Exploiting < Augmenting \\
Pharmaceuticals & -1.114 & .265 & .406 & Exploiting = Augmenting \\
Telecommunications & -0.748 & .454 & .437 & Exploiting = Augmenting \\
\hline Overall & $-\mathbf{3 . 6 5 4}$ & $\mathbf{. 0 0 0}$ & $\mathbf{3 8 8}$ & Exploiting < Augmenting
\end{tabular}

I performed similar tests for the citation behaviour of US subsidiaries' patents. These results are reported in Table 5.10. I found that in all sectors the null hypothesis could be rejected. More, specifically 1 found that on average US R\&D facilitics located in Europe draw upon home country more than host country sources. ${ }^{78}$ The evidence at the technology level confirms these findings with the exception of transport-related technologies for which the asset-augmenting and asset-cxploiting components are equally strong (sce Table A5-4 in the appendix).

\footnotetext{
"As pointed out in Chapter 4. BP had recently acquired two large American competitors (Standard Oi] Company and Amoco). This could bias the result of the test for mining \& petroleum towards finding a dominant asset-alugmenting component of foreign R\&D activities. However the result obtained for this sector are robust to the exclusion of this company.

${ }^{7 *}$ These results are robust to the exclusion of USPTO citations from the dataset.
} 
Table 5.10 Testing the relative propensity to engage in asset-exploiting and asset-augmenting activities by US MNES

\begin{tabular}{lcccc}
\hline \multicolumn{5}{c}{ Ho: Asset-exploiting = Asset-augmenting } \\
\hline Sector & $\mathrm{U}$ & $\begin{array}{c}\text { 2-tail p-value } \\
\text { Prob (diff }=0)\end{array}$ & $\begin{array}{c}\text { right 1-tail p-value } \\
\text { Prob (diff }>0)\end{array}$ & Inference \\
\hline Chemicals & 3.849 & .000 & .824 & Exploiting > Augmenting \\
Electronics & 4.726 & .000 & .898 & Exploiting > Augmenting \\
Industrial mach. \& transp. & 1.742 & .081 & .647 & Exploiting > Augmenting \\
Mining \& petrolcum & 4.848 & .000 & .908 & Exploiting > Augmenting \\
Pharmaccuticals & 2.949 & .003 & .748 & Exploiting > Augmenting \\
Photography & 4.908 & .000 & .913 & Exploiting > Augmenting \\
Telecommunications & 3.557 & .000 & .799 & Exploiting > Augmenting \\
\hline Overall & 7.978 & .000 & .723 & Exploiting > Augmenting \\
\hline
\end{tabular}

To summarise. these results indicate that asset-exploiting activities are important especially for foreign R\&D investment of US MNEs in Europe. However, the evidence also indicates that asset-augmenting activities are an important aspect of European R\&D investment in the US. In four of the six cases related to the R\&D activities of US subsidiaries of EU MNEs, asset augmenting and asset-exploiting activities were in balance. That is to say, citation rates to home country and intra-fim patents were the same as the citation rates to host country patents. The significance of asset-augmenting activities of European MNEs in the US is in line with the studies reviewed in Chapter 2, which is remarkable given that, in using EPO patent data, the present analysis is biased against measuring the innovative activities of firms outside the EU.

The second set of statistics tests the extent to which firms from the two locations differ with respect to the importance of foreign is domestic sources of knowledge, i.e. whether US or European firms are more asset-augmenting or asset-exploiting intensive'. I again applied the two-sample Mann-Whitney test for equality of medians. First. I compared the asset-exploiting component of European R\&D investment in the US with that of their US counterparts. I tested both the hypothesis that European and US subsidiaries exhibit the same propensity to cite home region firms (where the home region differs per group of firms, of course) and the hypothesis that the asset-exploiting component of European R\&D investment in the US is stronger than the American counterpart. 
Table 5.11 Testing the relative extent of asset-exploitation activities by EU MNEs and US MNEs

\begin{tabular}{|c|c|c|c|c|}
\hline \multicolumn{5}{|c|}{ Ho: EU MVEs asset-exploiting = US MVEs asset-exploiting } \\
\hline Sector & U & $\begin{array}{l}\text { 2-tail p-value } \\
\text { Prob (diff }=0 \text { ) }\end{array}$ & $\begin{array}{l}\text { ight 1-tail p-value } \\
\text { Prob (diff }>0 \text { ) }\end{array}$ & $\begin{array}{c}\text { Inference on } \\
\text { Asset-Exploiting Activities }\end{array}$ \\
\hline Chemicals & -2.692 & .007 & .273 & EU MNES < US MNEs \\
\hline Hectronics & -7.249 & .000 & .142 & EU MNES < US MNES \\
\hline Industrial mach. \& transp. & -1.279 & .201 & .392 & EU MNES = US MNES \\
\hline Mining \& petroleum & -4.847 & .000 & .092 & EU MNES < US MNES \\
\hline Pharmaceuticals & -2.413 & .015 & .297 & EU MNES < US MNES \\
\hline Telecommunications & -3.407 & .000 & .210 & EUMNES < US MNES \\
\hline Overall & -6.530 & .000 & .309 & EU MNEs < US MNES \\
\hline
\end{tabular}

The results are presented in Table 5.11. For all sectors except industrial machinery \& transportation, the null hypothesis can be rejected: US R\&D activities in the EU rely more heavily on their home knowledge competences than their European counterparts. This may be interpreted as a greater tendency towards asset-exploiting activities in the case of US firms. For firms in industrial machinery \& transportation I found that US affiliates build on the home region knowledge base as much as European affiliates. ${ }^{79}$ This is confirmed by the results of the analysis at the technological level which show that in the field of machinery \& enginecring EU-owned patents invented in the US tend to cite patents originating in the home region to the same extent as US-owned patents invented in the EU (see Table A5-5 in the appendix).

Table 5.12 reports the test results obtained when I compared the asset-augmenting nature of R\&D activities undertaken in the US by European MNEs with their US counterparts. The null hypothesis in this case is that both groups of affiliates show an equal tendency to cite host country patents. I observed that in aggregate and for four out of six sectors, R\&D facilities of European MNEs operating in the US tend to draw upon host country technological resources more than their American counterparts. In industrial machincry \& transportation, and telecommunications I could not reject the null hypothesis, i.c. European subsidiaries in the US secm to exploit and build on the host country knowledge base as much as US subsidiaries in the EU do. ${ }^{\text {so }}$ This evidence is consistent with that obtained from the analysis of the

\footnotetext{
"If I use only within-F:PO citations I obtain similar results to those in Table 5.11. The exceptions are MNl:s operating in the chemical (where EU MNls draw as much as their American counterparts from home region soures) and pharmaceutical sectors (where IUU MNIS appear to build more intensively than US MNI:s on their home technology basc).

"With the exception of telecommunications and electronies, the results are different if only citations made to other I:PO patents are considered. In general the asset-augmenting component of $1 \mathrm{U}$ MNEs appears to be less signiticant: European subsidiaries in chemicals and industrial machinery seem to be less involved in lechnology sourcing behaviour in the US than their American counterparts: in mining \& petroleum and pharmaceuticals both
} 
technological dimension of foreign subsidiaries sourcing behaviour: the citation patterns in transportation point towards an equal asset-augmenting character of EU-owned and USowned foreign R\&D activities (see Table A5-6 in the appendix). Similarly the strong assetaugmenting component of US subsidiarics of EU MNEs in chemicals and pharmaceuticals can be explained by the prevalence of this type of $R \& D$ activity in the area of biotechnology. As I discuss in the following chapter and as shown by other studies, European firms in these sectors are actively engaged in tapping into the US knowledge base in this technological field. This result is quite striking however given that small biotechnology firms are not included in the sample.

Table 5.12 Testing the relative extent of asset-augmenting activities by EU MNEs and US MNEs

\begin{tabular}{lcccc}
\hline \multicolumn{5}{c}{ Ho: EU MNEs asset-augmenting $=$ US MNEs asset-augmenting } \\
\hline Sector & \multicolumn{5}{c}{$\begin{array}{c}\text { 2-tail p-value } \\
\text { Prob }(\text { diff }=\mathbf{0})\end{array}$} & $\begin{array}{c}\text { right } \\
\text { Prob (diff }>\mathbf{0})\end{array}$ & $\begin{array}{c}\text { Inference on } \\
\text { Asset-Augmenting Activities }\end{array}$ \\
\hline Chemicals & 1.825 & .068 & .654 & EU MNEs > US MNEs \\
Electronics & 4.004 & .000 & .837 & EU MNEs > US MNEs \\
Industrial mach. \& transp. & 1.589 & .112 & .634 & EU MNEs = US MNEs \\
Mining \& petroleum & 1.712 & .086 & .644 & EU MNEs > US MNEs \\
Pharmaceuticals & 1.629 & .103 & .637 & EU MNEs > US MNEs \\
Telecommunications & 0.723 & .469 & .561 & EU MNEs = US MNEs \\
\hline Overall & $\mathbf{5 . 2 9 0}$ & $\mathbf{. 0 0 0}$ & .655 & EU MNEs > US MNEs \\
\hline
\end{tabular}

\subsection{CONCLuSIONS}

The internationalisation of $R \& D$ has been driven by a myriad of factors, the most prevalent of which are the need to respond to different demand and market conditions across locations, and the need for MNEs to respond effectively to these by adapting their existing product and process technologies through foreign-located asset-exploiting R\&D. This chapter has tested a 'macro' approach, arguing that when MNEs engage in asset-exploiting R\&D abroad, they often seek to utilise a variety of resources associated with the innovation systems of the home country, and not just the parent company specific technological competences. In addition to proximity to markets and production units, firms also venture abroad to seek new sources of knowledge, which are associated with the innovation system of the host region. I also argued that few firms engage exclusively in asset-augmenting or asset-exploiting activities in a foreign location because technology leadership changes over time, and because products and processes require multiple technological competences.

EU and US foreign affiliates show an equal tendency to exploit the host region technology base. 
This chapter also addressed some important methodological issues concerning the use of patent citations analysis. It has been shown that there are substantial differences between the USPTO and EPO not only in the number but also, and more importantly, in the geographical distribution of backward citations within each system. There is clear evidence of a home advantage' effect on the citation patterns in both within-EPO and within-USPTO citations. By examining the citations in a sample of patents owned by the MNEs in the sample protecting the same invention in both the EPO and the USPTO, I found that EPO patents for inventions made in Europe tend to cite EU-invented patents more than their USPTO equivalents do (the reverse is true for US-invented patents). The inclusion of citations made by EPO applications to USPTO patents appears to mitigate this problem by correcting the bias towards EUinvented patents. Thus I have carried out the patent citation analysis including both citations among EPO patents and citations to USPTO patents.

The empirical results presented in this chapter underpin the remainder of the thesis. By using patent citation analysis to quantify the relative asset-augmenting and asset-exploiting character of forcign-based R\&D activity, I found that US affiliates in Europe still rely extensively on home-region knowledge sources, while the asset-augmenting component of R\&D investment from Europe into the US is in a few cases even stronger than the assetexploiting component. The significant asset-exploiting nature of US MNEs is evident when comparing with European R\&D investment in the US: in all sectors, apart from industrial machinery \& transportation, US MNEs operating in the EU tend to exploit their home-country technology base more than their European counterparts do. I also showed that the assetaugmenting component of European R\&D in the US in chemicals, electronics mining \& petroleum, and pharmaceuticals is stronger than that of their American counterparts.

These results seem to confirm that asset-augmenting activity is largely a phenomenon associated with European firms' activities in the US, while American subsidiaries in Europe are predominantly engaged in adapting products and processes developed in the home country to host market conditions and they are less involved in accessing specialised knowledge from the local innovation system. This trend is in line with the general impression that US firms lead in most of these high-tech sectors and Europe is not able to attract asset-augmenting R\&D investment from US MNEs. This US leadership may also explain the significant extent of technological sourcing behaviour of European MNEs in the US. However the scenario is not completely negative for Europe: US firms also engage in asset-augmenting activities to at 
least the same extent as their European counterparts in the US in industrial machinery \& transportation, and in telecommunications.

These findings have some important implications for European policy makers. First they point to the need for policy makers to address specific weaknesses in the structure of the innovation system that leads domestic firms to perform R\&D abroad and that make the domestic economy unappealing for forcign R\&D investment. In order to improve the attractiveness of Europe as a base for forcign R\&D activities a number of policy areas and objectives can be identified. These range from increasing the availability. mobility and quality of research scientists and engineers to improving the excellence and scale of the science base through policies that encourage science-industry linkages and networking of public and private research. European policy makers have the challenge of deploying national technology policy in a way that encourages the innovative activities of forcign subsidiaries but at the same time directs the benefits of these activities to the domestic firms and technology base. In other words, attracting R\&D-related investment from abroad is not enough: efforts should be addressed to ensuring that foreign firms are well embedded in the domestic economy and contribute to the domestic technology base. This could be achieved by encouraging cooperation between foreign subsidiaries and domestic firms and research institutions.

There are several important caveats. First, while my results indicate that MNEs do engage in asset-augmenting R\&D activity, my sample of firms only includes many of the world's largest MNEs. These firms are amongst the world's most successful firms, and they have considerable experience - as well as resources - to efficiently exploit cross-border knowledge flows. However, innovation systems consist of a varicty of economic actors not all of which are MNEs. This study has not considered R\&D activity by firms other than the MNEs in the sample in defining the knowledge base of a (host or domestic) region. In certain technologics such as biotechnology where smaller firms predominate in innovative activities, this might significantly change the results. Second, I have utilised a high level of industrial aggregation, and within that focused on knowledge-intensive, mostly high technology sectors. Obviously, supply and demand imperatives vary considerably by sector and sub-sector. More mature technologies evolve much more slowly than do nascent ones, and some have a less tacit component than others. In other words, the importance of physical proximity for technology transfer varies quite considerably between technologies and products. My analysis is at the sectoral-level, albeit aggregating from firm level data, thereby subsuming important differences within individual MNE's technological portfolios. 
Third. I have scen considerable - and statistically significant - differences in the behaviour of US and EU firms. However, the EU consists of a number of disparate countries, each with its own innovation system. Data on internationalisation of R\&D indicate considerable heterogeneity between countries of the EU (Archibugi and lammarino 2000). For instance, Belgian and Dutch firms demonstrate a much higher level of R\&D internationalisation than ltalian or Norwegian MNEs. This might suggest that a comparison of the EU and the US is spurious, since the aggregation of 19 countries creates such a broad generalisation as to render policy implications not really useful. I decided to follow this approach for several reasons. First, because comparison between the US and most individual European economies is difficult, given the small size of many EU countries. By taking the EU as a unit I could compare two roughly equal sized economic units. Sccond, coordination of industrial policy between EU countries and EU-wide initiatives coordinated by Brussels are increasing.

The results presented in this chapter, while important in their own right, point to the need for further investigation into the potential impact of the increasing asset-augmenting component of European R\&D investment in the US, both at the level of the firm and at the level of the MNE's home country. Chapter 6 explores how European MNEs organise their R\&D activities across borders and how they achieve knowledge transfer and integration (intra-firm RTT). Chapter 7 seeks to assess whether other firms located in the home country benefit from the internationalisation of R\&D activities by European chemical and pharmaceutical companies (inter-firm RTT). 


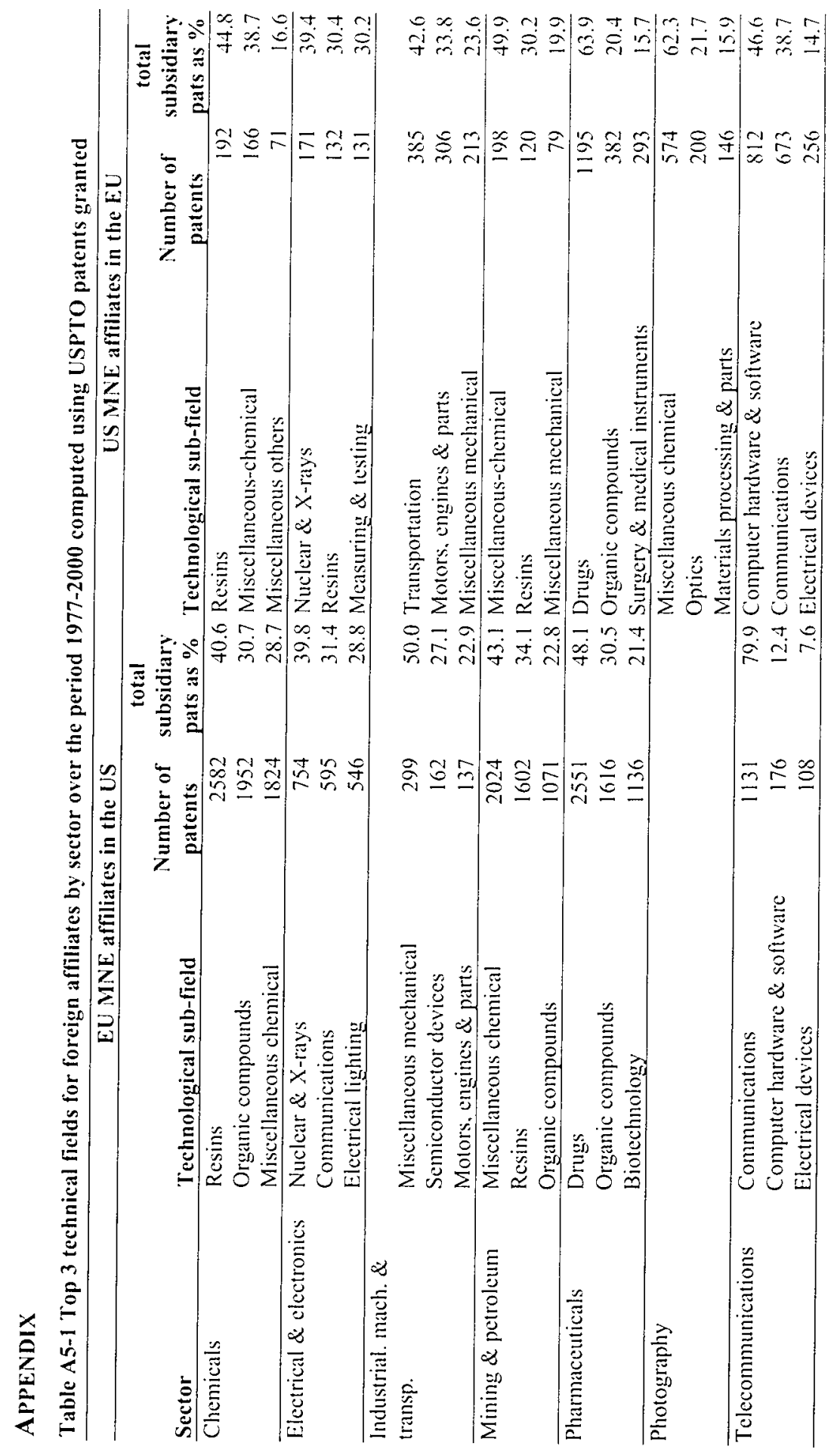


Table A5-2 Descriptive statistics for the citation rates computed on the basis of patents regrouped in technological fields

\begin{tabular}{|c|c|c|c|c|c|}
\hline \multirow{2}{*}{$\begin{array}{l}\text { Technological field } \\
\text { Biotechnology \& agricultural products }\end{array}$} & \multicolumn{4}{|c|}{ MNE R\&D activity Median Std Dev } & \multirow{2}{*}{$\frac{\operatorname{Max}}{.0182}$} \\
\hline & EU & Exploiting & .0015 & .0046 & \\
\hline & & Augmenting & .0025 & .0050 & .0251 \\
\hline & US & Exploiting & .0035 & .0051 & .0160 \\
\hline & & Augmenting & .0004 & .0019 & .0058 \\
\hline \multirow[t]{4}{*}{ Chemicals \& drugs } & EU & Exploiting & .0049 & .0112 & .0582 \\
\hline & & Augmenting & .0048 & .0078 & .0346 \\
\hline & US & Exploiting & .0090 & .0090 & .0324 \\
\hline & & Augmenting & .0039 & .0045 & .0212 \\
\hline \multirow[t]{4}{*}{ Electronics components \& semiconductors } & EU & Exploiting & .0019 & .0036 & .0169 \\
\hline & & Augmenting & .0063 & .0062 & .0314 \\
\hline & US & Exploiting & .0061 & .0156 & .0798 \\
\hline & & Augmenting & .0017 & .003 & .0154 \\
\hline \multirow[t]{4}{*}{ Industrial chemicals \& oil } & $\mathrm{EU}$ & Exploiting & .005 & .0172 & .0885 \\
\hline & & Augmenting & .0049 & .1012 & .5013 \\
\hline & US & Exploiting & .0128 & .0289 & .1511 \\
\hline & & Augmenting & .0045 & .0034 & .0113 \\
\hline \multirow[t]{4}{*}{ Industrial processes } & $\mathrm{EU}$ & Exploiting & .0029 & .0051 & .0206 \\
\hline & & Augmenting & .0034 & .0074 & .0385 \\
\hline & US & Exploiting & .0065 & .0268 & .1090 \\
\hline & & Augmenting & .0014 & .0043 & .0216 \\
\hline \multirow[t]{4}{*}{ Instrumentation } & $\mathrm{EU}$ & Exploiting & .0025 & .0017 & .0071 \\
\hline & & Augmenting & .0055 & .0023 & .0086 \\
\hline & US & Exploiting & .0067 & .0131 & .0501 \\
\hline & & Augmenting & .0020 & .0013 & .0058 \\
\hline \multirow{4}{*}{ Machinery \& enginecring } & $\mathrm{EU}$ & Exploiting & .0024 & .0065 & .0284 \\
\hline & & Augmenting & .0043 & .0049 & .0199 \\
\hline & US & Exploiting & .0028 & .0128 & .0572 \\
\hline & & Augmenting & .0010 & .0017 & .0064 \\
\hline \multirow[t]{4}{*}{ Metals works \& materials } & $\overline{E U}$ & Exploiting & .0033 & .0035 & .0172 \\
\hline & & Augmenting & .0041 & .0070 & .0322 \\
\hline & US & Exploiting & .0077 & .0098 & .0398 \\
\hline & & Augmenting & .0032 & .0023 & .0085 \\
\hline \multirow[t]{4}{*}{ Telecommunications \& audiovisual } & $\overline{\mathrm{EU}}$ & Exploiting & .0011 & .0039 & .0109 \\
\hline & & Augmenting & .0042 & .0043 & .0154 \\
\hline & US & Exploiting & .0067 & .0103 & .0444 \\
\hline & & Augmenting & .0014 & .0091 & .0339 \\
\hline \multirow[t]{4}{*}{ Transportation } & EU & Exploiting & .0013 & .0028 & .0081 \\
\hline & & Augmenting & .0026 & .0065 & .0224 \\
\hline & US & Exploiting & .0018 & .0057 & .0261 \\
\hline & & Augmenting & .0013 & .0179 & .0888 \\
\hline
\end{tabular}

Note: these citation rates have been computed applying equation (1) in section 5 .6 but substituting to firm $i$ and $j$. lechnological ficld $i$ and $j$. 
Table A5-3 Testing the relative propensity to engage in asset-exploiting and asset-augmenting activities by EU MNES

\begin{tabular}{|c|c|c|c|c|}
\hline \multicolumn{5}{|c|}{ Ho: Asset-exploiting $=$ Asset-augmenting } \\
\hline Technological lield & $\mathrm{U}$ & $\begin{array}{l}\text { 2-tail p-value } \\
\text { Prob }(\text { diff }=0)\end{array}$ & $\begin{array}{l}\text { right 1-tail p-value } \\
\text { Prob (diff }>0 \text { ) }\end{array}$ & Inference \\
\hline $\begin{array}{l}\text { Biotechnology \& } \\
\text { agricultural products }\end{array}$ & -1.228 & .219 & .397 & $\begin{array}{l}\text { Exploiting =- } \\
\text { Augmenting }\end{array}$ \\
\hline Chemicals \& drugs & -0.309 & .757 & .474 & Exploiting $=$ \\
\hline $\begin{array}{l}\text { Electronics components \& } \\
\text { semiconductors }\end{array}$ & -3.857 & .000 & .175 & $\begin{array}{l}\text { Exploiting < } \\
\text { Augmenting }\end{array}$ \\
\hline Industrial chemicals \& oil & -0.103 & .917 & .491 & Exploiting $=$ \\
\hline Industrial processes & -0.495 & .620 & .458 & Exploiting $=$ \\
\hline Instrumentation & -3.403 & .000 & .214 & Exploiting $<$ \\
\hline Machinery \& enginecring & -1.836 & .060 & .345 & Exploiting $=$ \\
\hline Metals works \& materials & -1.155 & .248 & .403 & Exploiting = \\
\hline $\begin{array}{l}\text { Telecommunications \& } \\
\text { audiovisual }\end{array}$ & -0.275 & .783 & .477 & $\begin{array}{l}\text { Exploiting = } \\
\text { Augmenting }\end{array}$ \\
\hline Transportation & -1.604 & .108 & .363 & Exploiting $>$ \\
\hline
\end{tabular}

Table A5-4 Testing the relative propensity to engage in asset-exploiting and asset-augmenting activities by US MNES

Ho: Asset-exploiting = Asset-augmenting

\begin{tabular}{|c|c|c|c|c|}
\hline Technological field & $\mathrm{U}$ & $\begin{array}{l}\text { 2-tail p-value } \\
\text { Prob (diff }=0 \text { ) }\end{array}$ & $\begin{array}{l}\text { right 1-tail } p \text {-value } \\
\text { Prob (diff }>0 \text { ) }\end{array}$ & Inference \\
\hline $\begin{array}{l}\text { Biotechnology \& } \\
\text { agricultural products }\end{array}$ & 2.267 & .023 & .688 & $\begin{array}{l}\text { Exploiting > } \\
\text { Augmenting }\end{array}$ \\
\hline Chemicals \& drugs & 3.383 & .000 & .785 & Exploiting $>$ \\
\hline $\begin{array}{l}\text { Electronics components \& } \\
\text { semiconductors }\end{array}$ & 4.363 & .000 & .870 & $\begin{array}{l}\text { Exploiting > } \\
\text { Augmenting }\end{array}$ \\
\hline Industrial chemicals \& oil & 4.229 & .000 & .856 & Exploiting $>$ \\
\hline Industrial processes & 4.310 & .000 & .863 & Exploiting > \\
\hline Instrumentation & 5.176 & .000 & .936 & Exploiting $>$ \\
\hline Machinery \& engineering & 3.774 & .000 & .818 & Exploiting \\
\hline Metal work \& matcrials & 3.563 & .000 & .799 & Exploiting $>$ \\
\hline $\begin{array}{l}\text { Tclecommunications \& } \\
\text { audiovisual }\end{array}$ & 3.186 & .001 & .768 & $\begin{array}{l}\text { Exploiting > } \\
\text { Augmenting }\end{array}$ \\
\hline Transportation & 1.196 & .231 & .601 & Exploiting $=$ \\
\hline
\end{tabular}


Table A5-5 Testing the relative extent of asset-exploitation activities by EU MNEs and US MNEs

\begin{tabular}{|c|c|c|c|c|}
\hline \multicolumn{5}{|c|}{ Ho: LU MNEs asset-exploiting = US MNES asset-exploiting } \\
\hline Technological field & $\mathbf{U}$ & $\begin{array}{l}\text { 2-tail p-value } \\
\text { Prob (diff }=0 \text { ) }\end{array}$ & $\begin{array}{l}\text { right 1-tail p-value } \\
\text { Prob (diff }>0)\end{array}$ & $\begin{array}{c}\text { Inference on } \\
\text { Asset-Exploiting } \\
\text { Activities }\end{array}$ \\
\hline $\begin{array}{l}\text { Biotechnology \& } \\
\text { agricultural products }\end{array}$ & -1.336 & .181 & .387 & EU MNES = US MNES \\
\hline Chemicals \& drugs & -3.403 & .000 & .214 & EU MNES < US MNES \\
\hline $\begin{array}{l}\text { Electronics components \& } \\
\text { semiconductors }\end{array}$ & -3.919 & .000 & .170 & EU MNES $<$ US MNES \\
\hline Industrial chemicals \& oil & -3.774 & .000 & .182 & EU MNES $<$ US MNES \\
\hline Industrial processes & -2.846 & .004 & .260 & EU MNES < US MNES \\
\hline Instrumentation & -4.599 & .000 & .113 & EU MNIS < US MNES \\
\hline Machincry \& engineering & -1.547 & .121 & .370 & EU MNES $=$ US MNES \\
\hline Mctal work \& materials & -2.869 & .004 & .259 & EU MNES < US MNES \\
\hline $\begin{array}{l}\text { Telecommunications \& } \\
\text { audiovisual }\end{array}$ & -3.652 & .000 & .193 & EU MNES < US MNES \\
\hline Transportation & -1.707 & .087 & .355 & EU MNEs < US MNEs \\
\hline
\end{tabular}

Table A5-6 Testing the relative extent of asset-augmenting activities by EU MNEs and US MNEs

Ho: EU MNEs asset-augmenting = US MNEs asset-augmenting

\begin{tabular}{|c|c|c|c|c|}
\hline Technological field & $\mathbf{U}$ & $\begin{array}{l}\text { 2-tail p-value } \\
\text { Prob (diff }=0 \text { ) }\end{array}$ & $\begin{array}{l}\text { right } 1 \text {-tail p-value } \\
\text { Prob (diff }>0)\end{array}$ & $\begin{array}{c}\text { Inference on } \\
\text { Asset-Augmenting } \\
\text { Activities } \\
\end{array}$ \\
\hline $\begin{array}{l}\text { Biotechnology \& } \\
\text { agricultural products }\end{array}$ & 2.161 & .037 & .680 & EU MNEs > US MNEs \\
\hline Chemicals \& drugs & 1.279 & .201 & .608 & EU MNES = US MNES \\
\hline $\begin{array}{l}\text { Electronics components \& } \\
\text { semiconductors }\end{array}$ & 4.228 & .000 & .856 & EU MNES > US MNES \\
\hline Industrial chemicals \& oil & 0.949 & .342 & .580 & EU MNES $=$ US MNES \\
\hline Industrial processes & 2.930 & .003 & .747 & EU MNEs > US MNEs \\
\hline Instrumentation & 4.414 & .000 & .872 & EU MNES $>$ US MNES \\
\hline Machinery \& engineering & 3.259 & .001 & .774 & EU MNEs > US MNEs \\
\hline Metal work \& materials & 1.901 & .057 & .660 & EU MNES > US MNES \\
\hline $\begin{array}{l}\text { Telecommunications \& } \\
\text { audiovisual }\end{array}$ & 1.980 & .047 & .667 & EU MNES $>$ US MNES \\
\hline Transportation & 1.002 & .316 & .585 & EU MNES $=$ US MNES \\
\hline
\end{tabular}




\section{CHAPTER 6}

\section{KNOWLEDGE TRANSFER INSIDE THE GLOBAL R\&D NETWORK: THE CASE OF EUROPEAN PHARMACEUTICAL COMPANIES}

\subsection{INTRODUCTION}

The literature reviewed in Chapters 2 and 3 and the findings in Chapter 5 suggest that in hightech sectors there has been a movement away from the traditional function of the subsidiary, i.c. adopting technology transferred by the parent company, to the creation and development of local technological competences that complement the competences of the rest of the MNE. This has changed not only the role of the subsidiaries from 'knowledge users' to "knowledge producers' and that of the headquarters from 'technology creator' to 'technology organiser' (Cantwell 2001), but has also brought to the fore the once peripheral view of the MNE as a geographically dispersed network of specialised units (Bartlett 1986. Hedlund 1986. Perlmutter 1965). This organisational model was originally proposed to capture the emergence of a structure containing many different kinds of centres where traditional headquarters functions were carried out. Håkanson (1990) and more recently Gassmann and von Zedtwitz (1999) analysed the emergence of these network structures in the R\&D organisation. In what they define as the integrated R\&D nenrork configuration. foreign subsidiaries capture and leverage technological knowledge from pockets of excellence around the world, actively contributing as much as the home part of the MNE to the creation of new technological assets.

The evolution of the R\&D organisation from a 'centralised hub' to a multi-hub 'integrated network" introduces a number of managerial challenges. First, firms have to find an equilibrium between dispersion and centralisation. R\&D centres need to be scattered around the world to acquire local competences, but at the same time, in each location. there must be a critical mass of resources to guarantec informal interaction and communication among R\&D personnel. Second. firms must ensure that the knowledge generated in different units of the network is transferred to the rest of the organisation. This requires the adoption of new mechanisms for the dissemination and integration of both explicit and tacit knowledge. 
This chapter explores these issues in six of the largest European pharmaceutical companies. These companies provide a particularly interesting context in which to investigate these questions for three principal reasons. First, as I showed in Chapters 4 and 5, European MNEs in this industry carry out an increasing proportion of their R\&D activities in the US in order to acquire specialised capabilities in biotechnology. The extreme case is Novartis, which has recently moved the centre of its worldwide research operations to Cambridge, Massachusetts, and now defines itself as a Swiss-American company. Second, the pharmaceutical industry has moved from being a trial-and-crror drug discovery process to becoming a more sciencebased deductive method of search (Arora and Gambardella 1994) which has led to new divisions of labour and new R\&D organisation both across functions (Chiesa 1996c) and across borders. Finally, this sector has recently undergone a process of consolidation that has been characterised by complex M\&A among large incumbents firms. In this context of organisational distance between R\&D units that previously belonged to competing companies and lack of interpersonal relationships among R\&D personnel, building a better understanding of how knowledge integration is achieved, is critically important.

The aim of this chapter is to analyse how these firms have achieved a balance between dispersion and centralisation in their R\&D network structure and what mechanisms they have adopted to ensure the diffusion and cross-fertilisation of technical knowledge inside this organisation. In particular I am interested in how mobility of researchers between R\&D units within a company affects the knowledge diffusion and integration process. Knowledge resides in individuals and knowledge flows not only between but also within firms, take place in social communities, i.e. in networks of relationships among organisational members. As shown by a number of the studies reviewed in Chapter 2 (for example Almeida and Kogut 1999, Rosenkopf and Almeida 2003, Stolpe 2002), inter-firm researcher mobility has been proven to facilitate the transfer of knowledge, especially tacit knowledge, through the creation and reinforcement of personal relationships. The role of mobility as a means to achieve technology transfer within an organisation has been less analysed. As pointed out by Chiesa (1996a), the human resource management literature has mainly focused on the pros and cons of using local managers or expatriates to control and manage foreign subsidiaries ( see for example Zeira 1976, Zeira and Banai 1984, Zeira and Harari 1979). In contrast little attention has been paid to the management of R\&D workers, as firms have traditionally relied on the fact that the scientific culture dominated the local culture and that interaction between foreign R\&D units and the rest of the organisation was poor or non-existent. Few studies (see for 
example Westney 1993) have discussed the importance of international assignments in MNEs as a factor fostering knowledge-sharing among geographically dispersed R\&D units. The aim of this elhapter is to fill in the gap in the literature and to shed light on the role of this intrafirm technology transfer mechanism.

Section 6.2 discusses the theoretical framework. Section 6.3 describes the different phases of the drug discovery process. Section 6.4 outlines the methodology of the study. Section 6.5 describes the main distribution of the innovation activities and R\&D organisation across geographically dispersed units. Section 6.6 reports the cmpirical findings from the case study of the mechanisms employed to ensure that technical knowledge crosses both geographical and disciplinary boundaries, and the role of researchers' mobility. The concluding section offers some discussion of the general trends in the organisation of R\&D in the pharmaceutical sector.

\subsection{THE EMERGENCE OF INTEGRATED R\&D NETWORKS STRUCTURES}

Traditionally the most strategic and 'core' innovation activities were concentrated in the central R\&D unit in the home country of the MNE. In this model, dubbed the 'ethnocentric' (Perlmutter 1965) or 'centralised hub' (Bartlett 1986), there was only one centre and MNEs relied largely on one location, i.e. the home country, as the principal and almost the only source of their competitive advantage. In this organisational setting the flow of knowledge was mainly in one direction: from the headquarters, where it was created, to the subsidiaries, where it was further developed to adapt products and processes to the local market. However during the mid-1980s a different organisational model was proposed to take account of the fact that MNEs were facing increasing pressures towards "global integration and responsiveness to local conditions' (Bartlett 1986). In this context MNEs could not rely only on exploiting internationally the technological assets built on home-country competences, but had to source knowledge from each leading market and national technology system. As a result the so-called 'geocentric' (Perlmutter 1965), 'integrated network' (Bartlett 1986) or 'heterarchy' (Hedlund 1986) organisational model was proposed to represent the emergence of a structure containing many different kinds of centres where what were traditionally headquarters functions could be carried out. As stated by Hedlund (1986). in this model at the extreme each subsidiary is at the same time a centre for and perhaps a global coordinator of activities within one field' (p. 21). 
Until recently, the extent to which MNEs were moving towards the multi-hub R\&D network structure was still being debated (Ghoshal and Westney 1993). However the literature on 'centres of excellence' (Holm and Pederson 2000, Frost et al. 2002) or 'creative subsidiaries' (Pearce 1999) and the studies by Chicsa (1996b) and Gassmann and von Zedtwitz (1999) on international R\&D organisational structures have produced new evidence confirming the emergence in certain high-tech industries of some kind of R\&D network structure which approaches the ideal heterarchical model. As shown by Gassmann and von Zedtwitz (1999) five different R\&D organisation structures co-exist ranging from the ethnocentric model to the integrated R\&D network structure (see Table 6.1 for a summary of the specific strengths and limitations of cach model).

Table 6.1 Basic features of international R\&D organisations

\begin{tabular}{|c|c|c|c|c|}
\hline $\begin{array}{l}\text { Type of R\&D } \\
\text { organisation }\end{array}$ & $\begin{array}{c}\text { Organisational } \\
\text { structure }\end{array}$ & Strengths & Weakness & Examples \\
\hline $\begin{array}{l}\text { Ethnocentric } \\
\text { centralised }\end{array}$ & Centralised R\&D & $\begin{array}{l}\text { Economies of scale } \\
\text { and specialisation }\end{array}$ & $\begin{array}{l}\text { Lack of } \\
\text { responsiveness of } \\
\text { local markets }\end{array}$ & $\begin{array}{l}\text { Volvo. } \\
\text { Toyota. } \\
\text { British Gas, } \\
\text { Microsoft }\end{array}$ \\
\hline $\begin{array}{l}\text { Geocentric } \\
\text { centralised }\end{array}$ & Contralised R\&D & $\begin{array}{l}\text { Economies of scale } \\
\text { and specialisation } \\
\text { and sensitivity to } \\
\text { local markets needs }\end{array}$ & $\begin{array}{l}\text { No systematic } \\
\text { internationalisation } \\
\text { strategy }\end{array}$ & Nissan. Hilti \\
\hline $\begin{array}{l}\text { Polycentric } \\
\text { decentralised }\end{array}$ & $\begin{array}{l}\text { Decentralised R\&D } \\
\text { with weak centre }\end{array}$ & $\begin{array}{l}\text { Strong } \\
\text { responsiveness to } \\
\text { local market } \\
\text { conditions }\end{array}$ & $\begin{array}{l}\text { Coordination and } \\
\text { integration } \\
\text { problems }\end{array}$ & $\begin{array}{l}\text { Philips. Shell. } \\
\text { Sulzer }\end{array}$ \\
\hline $\begin{array}{l}\text { R\&D hub } \\
\text { model }\end{array}$ & $\begin{array}{l}\text { Dispersed R\&D with } \\
\text { strong centre }\end{array}$ & $\begin{array}{l}\text { Exploitation of local } \\
\text { advantages }\end{array}$ & $\begin{array}{l}\text { High coordination } \\
\text { costs }\end{array}$ & $\begin{array}{l}\text { BASF, } \\
\text { Siemens, } \\
\text { Sony, NEC, } \\
\text { Sharp, } \\
\text { Mitsubishi }\end{array}$ \\
\hline $\begin{array}{l}\text { Integrated } \\
\text { network }\end{array}$ & $\begin{array}{l}\text { Highly dispersed } \\
\text { R\&D, several } \\
\text { competence centres }\end{array}$ & $\begin{array}{l}\text { Leverage of local } \\
\text { strengths to the rest } \\
\text { of the organisation. } \\
\text { Exploitation of } \\
\text { potential synergies } \\
\text { across different } \\
\text { locations and } \\
\text { projects }\end{array}$ & $\begin{array}{l}\text { High level of } \\
\text { internal } \\
\text { specialisation. } \\
\text { Management of } \\
\text { complex network } \\
\text { relationships and } \\
\text { knowledge flows }\end{array}$ & $\begin{array}{l}\text { ABB, Canon, } \\
\text { Hoechst. } \\
\text { Novartis, } \\
\text { Roche } \\
\text { Schering }\end{array}$ \\
\hline
\end{tabular}

Sonrece based on Gassmann and von Zedtwitz (1999)

In the ethnocentric centralised R\&D organisation all R\&D functions are concentrated in the home country and are very closely controlled and managed from the centre. While concentration of R\&D activities allows cost reductions through economies of scalc, economies of specialisation, and reduction in coordination costs, it ignores local market 
conditions, and the possibility of responding to local markets needs and opportunities is precluded. The geocentric centralised $R \& D$ organisation tries to overcome the lack of market sensitivity of the ethnocentric organisation by establishing stronger linkages with foreign production units through international assignments of R\&D personnel, and intense contacts with host country suppliers and customers. This configuration however does not allow for the implementation of a systematic internationalisation strategy since the bulk of the R\&D activity is kept at home. The polveentric decemralised R\&D structure is characterised by a geographically dispersed network of autonomous subsidiaries with their own assets and capabilities, which allows them to respond to local demands and opportunities. This more locally oriented structure with its more fragmented organisation may however be difficult to coordinate. R\&D duplications and inefficiencies in internal knowledge transfer and information exchange may be serious organisational impediments to the inter-unit knowledge diffusion process. In the R\&D hub model there is a central R\&D unit, often in the home country, that very closely manages and controls the decentralised R\&D activities. This structure allows the firm to access knowledge sources from different centres of excellence around the world while retaining control over the allocation of resources, though involving of high coordination costs. Finally in the integrated R\&D netrork each R\&D unit assumes a leading role in the creation of unique competences that can be leveraged by the rest of the organisation. Within this model, the creation of new technologies is not the prerogative of the centre, but rather takes place in foreign subsidiaries building on and exploiting host countries' competitive advantage. This structure allows the firm to take advantage of dispersed sources of knowledge and to exploit synergies across the different R\&D centres through cross-border innovation projects. As Bartlett (1986) states:

-.the assumption behind this configuration is that management should consider each of the worldwide units as sourees of ideas, skills, capabilities, and knowledge that can be harnessed for the benefit of the total organisation ... The company becomes a truly integrated network of distributed and interdependent resources and capabilities' (p. 381-382).

In this organisational structure certain R\&D units may be designated the company's 'centres of excellence' for a particular phase of the innovation process. These units play a very important role in upgrading the firm technological assets since they cmbody 'a set of capabilitics that has been explicitly recognised by the firm as an important source of value creation, with the intention that these capabilities be leveraged by and/or disseminated to other parts of the firm' (Frost et al. 2002, p. 1000). 
Other studies by the same authors (von Zedtwitz and Gassmann 2002) and by Chiesa (1996b) have shown that in the same company different structures can be adopted for development and research activities sometimes leading to a physical separation between these two functions. Von Zedtwitz and Gassmann (2002) argue that this is due to the different drivers underpinning the internationalisation of rescarch and development activities. The quest for technical know-how and scientific knowledge is the main factor behind the organisation of the research function, while the need to support and aceess local markets shapes the direction of internationalisation in development. Chicsa (1996b) states that both the geographical spread of external sources of knowledge as well as the degree of dispersion of internal R\&D resources determines the $R \& D$ organisational structure. The $R \& D$ structure needs to be shaped to ensure the access to, and exploitation of, relevant external sources of technological knowledge and/or market-related knowledge. The need to access technological knowledge sources will be particularly strong in those multiple technology firms (see e.g. Granstrand 1998, Granstrand et al 1997) that rely on the ability to integrate different technologies, most of which are only available outside the firm boundaries. This explains the emergence of an integrated network structure in the research activities of certain technology-intensive sectors. The need to access external sources of market-related knowledge will be greater in those industries with a presence in a larger number of markets and will give rise to geographically dispersed organisation of developmem activities. However, even within each sector, different firms will show different degrees of geographical dispersion in their R\&D activities depending on the knowledge they have available internally. In other words, the R\&D structure will also reflect the geographical distribution of the firm's internal capability. This results in part from its historical heritage and M\&A strategies, but is also a function of the divisibility of labour in R\&D. which in turn is affected by the intrinsic nature of the technological innovation process. For cxample, Chiesa (1996b) compares electronics industrics with chemicals industries. While electronics firms can divide their products into modules and subsystems that can be developed autonomously, in chemical companies the nature of the products and the production processes make it difficult to carry out different phases of the research process in geographically dispersed units. Generally, if the knowledge is complex, context specific, hard to observe, and tacit, it is difficult to implement a dispersed R\&D network structure because such knowledge is very hard to transfer (Kogut and Zander 1993. Winter 1987) and development and research processes cannot be divided among different units. 
Thus, one would expect to observe different structures in research and in development, although similar R\&D organisations tend to emerge in firms belonging to the same sector because of similar degrees of international division of labour in R\&D and similar needs to access external sources of technological or/and market-related knowledge. The greater the degree of knowledge dispersion and international division of labour, the more the organisation adopted will look like an integrated-network structure. Intra-sectoral differences can be explained by individual firms' historical evolution and acquisition strategies.

\subsubsection{Managerial challenges of the integrated $R \& D$ network}

If the main advantage of implementing a geographically dispersed R\&D network structure is the ability to tap selectively into centres of excellence, the main drawback is the high costs of coordinating and achicving knowledge diffusion and integration. As Hedlund and Ridderstråle (1995) point out:

'[the efficient operation of the network structure involves] the managerial challenge [of] moving from controlling a set of bilateral relationships between a clear strategic centre and a set of implementing subsidiaries, or a fragmented system independent national units. to utilising the creative abilities of an integrated global network' (p. 158).

Communication among different R\&D units is crucial but at the same time it is also more complex than in the 'centralised hub' structure. In the home-based model the innovation process was mainly based on a one-way intra-firm flow of technology and resources from the parent company to its foreign subsidiaries and only partly on inter-firm knowledge flows from host country firms to the foreign subsidiaries. In the integrated network model technological upgrading emerges from complex external and internal knowledge flows both horizontally (between subsidiaries) and vertically (from the centre to the periphery). Thus the firm has to move away from the management of a set of dyadic relationships between the centre and the foreign R\&D unit and adopt a more systemic coordination mechanism in order to promote intensive communication flows, both within networks internal to the firm, and between external and internal networks. Such growing linkages require complex coordination if they are to provide optimal benefits (see Zanfei 2000 for a discussion) and substantial resources (both managerial and financial). It is no surprise, therefore, that external technology development is primarily the domain of larger firms with more resources, and more experience in transnational activity (Hagedoorn and Schakenraad 1994).

If coordinating these exchanges of knowledge is complex and challenging, it is even more difficult to achieve them. As discussed in Chapter 3, these internal knowledge flows can be 
hampered, not only by geographical distance. but also by their technological, organisational and cultural distance among the different units. The adoption of a geographically distributed R\&D organisation implies the existence of a strong cultural heterogeneity that creates barriers to knowledge sharing. The lack of a common culture and greater subsidiary autonomy within the organisation can also create motivational barriers that are particularly important in determining knowledge sharing between units that have been recently acquired, as is the case in the firms interviewed in this study. Technological specialisation and international diversification can also reduce the amount of common prior-knowledge among $R \& D$ units and result in inter-unit divergence in technological capabilities (Zander 1999).

If the increasing level of internal technological specialisation can be an obstacle to the diffusion of knowledge it may also represent the main strength of the integrated $R \& D$ network structure. Enhancement of the quality of the innovation process may derive from the international cross-fertilisation of knowledge within individual technologies and/or the recombination of knowledge across related technologies (Zander 1999). As argued by Bartletl and Ghoshal (1990):

by creating flexible linkages that allow the efforts of multiple units to be combined, a company can create synergies that can significantly leverage its innovation process. Like locally leveraged innovations, the globally-linked process captures the MNC"s potential scope economies and harnesses the benefits of worldwide learning' (p.222).

Henderson and Cockbum $(1994,1996)$ have shown that in pharmaceutical firms the ability to encourage and sustain an extensive flow of information and knowledge among scientific disciplines, therapeutic specialities and organisational units is crucial for discovering new drugs. The increase in research productivity in drug discovery through the exploitation of synergies across disciplines can in part be attributed to the new, more systematic, drug discovery process. The search for new compounds is now shaped by knowledge of the fundamental physiological mechanisms and therefore knowledge acquired in one therapeutic area can lead to advances in other areas. For example the research into the structure and function of alpha and beta receptors originally directed towards the development of superior cardiovascular drugs has since spawned an important stream of research into the workings of the central nervous system' (Henderson and Cockburn 1994, p. 67).

This implies that firms need to achicve not only vertical but also horizontal knowledge transfers. In the Mansfield (1975) and Teece (1976) taxonomy: 
- vertical flows refer to the transfer of technical information and know-how within various stages of the R\&D process, for example the transfer of technical information from the drug discovery stage to the development stage of a project.

- horizontal flows refer to the transfer of technical information from one project to another project either in the same therapeutic area or in a different one (i.e. inter- or intra-disciplinary technological knowledge flows).

In other words, if MNEs want to increase their technological performance by adopting a geographically dispersed and diversified network of R\&D units, they must overcome a number of managerial challenges to ensure that the knowledge produced in the differentiated network is not only diffused internally, but is also recombined and integrated. As pointed out by Almeida et al. (2002):

\footnotetext{
'The fundamental feature of the international movement of knowledge in MNCs is not so much the diffusion of knowledge from the units that specialise in knowledge creation to those that specialise in knowledge application, but a much more complex process where units are engaged in simultaneously and interactively in both creation and application. The challenge of managing knowledge. therefore involves not only its transfer but also its development through the combination of the transferred knowledge with the recipient's existing knowledge" (p. 148).
}

One of the means of achicving knowledge integration is the creation of a common culture and convergence towards the same set of values - what Gupta and Govindarajan (2000) define as socialisation mechamisms, c.g. job rotations among subsidiaries and between subsidiaries and headquarters. Hedlund (1986) recognises the importance of human resource management in the 'heterarchical' model: 'In order for internalisation of noms to take place, a lot of rotation of personnel and international travel and postings are necessary... Advances in information technology may help the formation of the nervous system of the firm, but this will not be enough for building internal cultures' (p. 29, emphasis added).

Particularly in the R\&D context the adoption of socialisation mechanisms is crucial in facilitating technology transfer because they help to establish inter-personal relationships among researchers through which less codified forms of knowledge can be shared. As discussed in Chapter 2, R\&D spillovers not only have a geographical but also a social dimension. The studies reviewed in that chapter showed that inter-firm researcher mobility is very important in explaining knowledge spillovers, operating through the formation of social ties between researchers who have worked together in the past. These social relationships allow the sharing of information among researchers even when they are no longer part of the 
same organisation. Cross-border research projects, temporary international assignments to other R\&D units, site rotations of rescarchers, short-term visits, and exchange programmes are some of the practices used to promote the formation of social ties among R\&D personnel working in distant laboratories of the same organisation (Bartlett and Ghoshal 1990. Chiesa and Manzini 1996, De Meyer 1993. Persaud el al. 2001, Teigland et al. 2000, Westney 1993. Zhou and Frost 2003). The study by Westney (1993) on cross-Pacific R\&D investments by Japanese and US electronics firms shows that cross-border project teams and international assignments of technical people facilitate integration in R\&D projects. Zhou and Frost (2003) argue that cross-border project teams create a common understanding and help to identify 'who knows what' in other R\&D units. Similar results can be achieved through temporary secondments of R\&D personnel to other R\&D facilities. Therefore mobility of researchers accomplishes two purposes through the creation of personal ties: it enhances the international transfer of knowledge and it increases the level of interaction and communication which should both reduce inter-unit attrition and create potential technology transfer channels.

The next section summarises the major phases of the drug discovery process and the characteristics of the knowledge involved in the research and development activities. This description will help to explain what types of activities are undertaken in different units of the R\&D network.

\subsection{RESEARCH AND DEVELOPMENT IN THE PHARMACEUTICAL INDUSTRY}

The drug discovery and the development process can be divided in six stages:

\section{Target identification}

II. Lead identification

III. Lcad optimisation

IV. Pre-clinical development (toxicology, pharmacology, drug metabolism in animals. formulation and chemical development)

V. Clinical development:

Phase 1: tolerability in healthy volunteers

Phase 2: controlled efficacy in patients and studies assessing the clinical proof of concept 
Phase 3: large scale clinical trials to establish the efficacy of the drug

Phase 4: monitoring of the clinical trials to identify side effects

VI. Registration with the health authorities.

Stages 1, I1, and III comprises the drug discovery phase (R), which aims to identify new compounds: and the remainder of the process comprises the development phase $(\mathbf{D})$, when compounds are tested to assess their efficacy and tolerability. The division between $\mathbf{R}$ and $\mathbf{D}$ is not clear-cut and certain companies classify under $\mathbf{R}$ part of the clinical development up to the proof of concept. In investigating the firm-specific factors detemining the division between $\mathbf{R}$ and $\mathbf{D}$ activities is particularly important if one wants to understand why a particular R\&D organisation structure has been implemented. However this is beyond the scope of this study.

In the target identification stage studies are undertaken to understand the role of the particular mechanism in the discase under investigation, and this leads to the discovery of target receptors or enzymes involved in the disease mechanism. In the lead identification phase a large number of molecular entities are screened in order to identify those that either activate, or inhibit or bind to the target. Compounds with high affinity and selectivity for the target mechanism, good pharmaceutical and pharmacokinetic properties and pharmacological activity are then entered into the pre-clinical development stage. In this stage. toxicology studies are carried out on animals to assess the tolerance and the immediate hazards of the new compound. The preclinical phase also includes the scaling-up of active compound synthesis and formulation development.

Clinical trials are composed of four phases. In the first phase the candidate drug is tested on healthy human voluntecrs to assess the maximum tolerated dose and check for side effects. During this phase drug metabolism and bioavailability studies are carried out. If no problems are encountered, the compound then moves into Phase 2 to determine its safety when used on patients suffering from the target disease. Phase 2 also determines whether the compound works and can be demonstrated to be operating by the desired mechanism. This represents what is called proof of concept, i.e. that the compound is able to target the discase mechanism and to attenuate the disease or its symptoms. In phase 3 large-scale clinical trials are undertaken, that might involve up to a thousand patients, to verify precisely the clinical tolerance, and toxicity and efficacy of the drug. In the last phase more data are collected to 
evaluate uncommon side effects. After the clinical trials the drug is registered with the appropriate health authorities. Follow-up studies are carried out to look for new indications, new formulations and new dosage forms of the drug.

Developments in the technologies employed in the drug discovery phase have completely changed the nature of the rescarch process in the pharmaceutical industry (Arora and Gambardella 1994. Henderson and Cockburn 1994. Nightingale 2000. Reiss and Hinze 2000). Traditionally the discovery of a new compound was the result of a trial-and-error process during which thousands of compounds were sereened in order to find one with a specific biological profile, because in general the 'mechanism of action' of a compound was not clearly understood. This process required huge laboratories to conduct large-scale screening. and extensive financial, human and technological resources. Furthermore, as pointed out by Arora and Gambardella (1994), each experiment produced knowledge that was very contextspecific because they researchers were not able to associate the chemical structure and properties of the molecules with a particular disease. During the 1990s the introduction of what are known as enabling technologies, such as high-through-put screcning. combinatorial chemistry, bio-informatics, and scientific advances in biomedical sciences have completely transformed the experimental design and the drug discovery process. The discovery of a drug is now the result of a science-deductive method and researchers know which biochemical and molecular pathways they want to block or stimulate, and are aware of the basic features of the molecules that might serve this purpose. Drug research follows a systematic design shaped by knowledge of the biochemical origins of the target disease. In particular, genomics and the development of functional models for discases have provided an increasing number of potential drug targets which can now be validated more easily using bio-informatic tools. By using biological data and computational methods, bio-informatics can model biological pathways and simulate biological processes. Combinatorial chemistry has provided a new way of synthesising a large variety of different molecules that can now be screened more quickly using high through-put screening systems.

The use of new technologies has reduced both the time needed to test potential active substances, and the number of researchers required. As a result there have been important changes in the organisation and management of the R\&D function. In essence the size of the experimental unit has been reduced and the degree of knowledge specialisation has increased, as has as the number of relevant scientific disciplines. As pointed out by Henderson (1994), if pharmaceutical firms want to remain competitive they need to builds on a wide range of 
disciplines, many of which are advancing at an extraordinarily rapid rate' (p. 615). In addition the new technological paradigm in drug discovery has reduced the importance of tacit and context-specific knowledge in certain phases of this process. However the development of a drug still requires large amounts of human and financial resources and its efficiency relies on the achievement of a critical mass to carry out highly standardised large-scale activities.

\subsection{METHODOLOGY}

The exploratory nature of the questions addressed in this chapter makes a case study approach based on data collection the most appropriate research strategy. Data were collected through 24 face-to-face semi-structured interviews with R\&D managers and scientists in six of the largest European pharmaceutical companies (some descriptive statistics of the interviewed companics are reported in Table 6.2). Between two to six interviews of one and half hours were carried out in each company between June 2002 and April 2003. In each company I interviewed scientists with at least 6 months experience in one of the US R\&D facilities and R\&D managers. The intervicws were based on two separate but overlapping sets of questions for the managers and the scientists. This allowed me to corroborate the validity of the data that might otherwise be biased depending on the position of the individuals within the organisation. However since the interviews were only carried out in the headquarters of the company they may reflect only the perceptions of the central organisation.

The general method used to analyse the data gathered in the interviews is based on a procedure described by Glaser and Strauss (1967) as 'constant comparison method'. Glaser and Strauss describe this method as following four distinct stages:

1. comparing incidents applicable to each category:

2. integrating categories and their properties:

3. delimiting the theory;

4. writing the theory. 


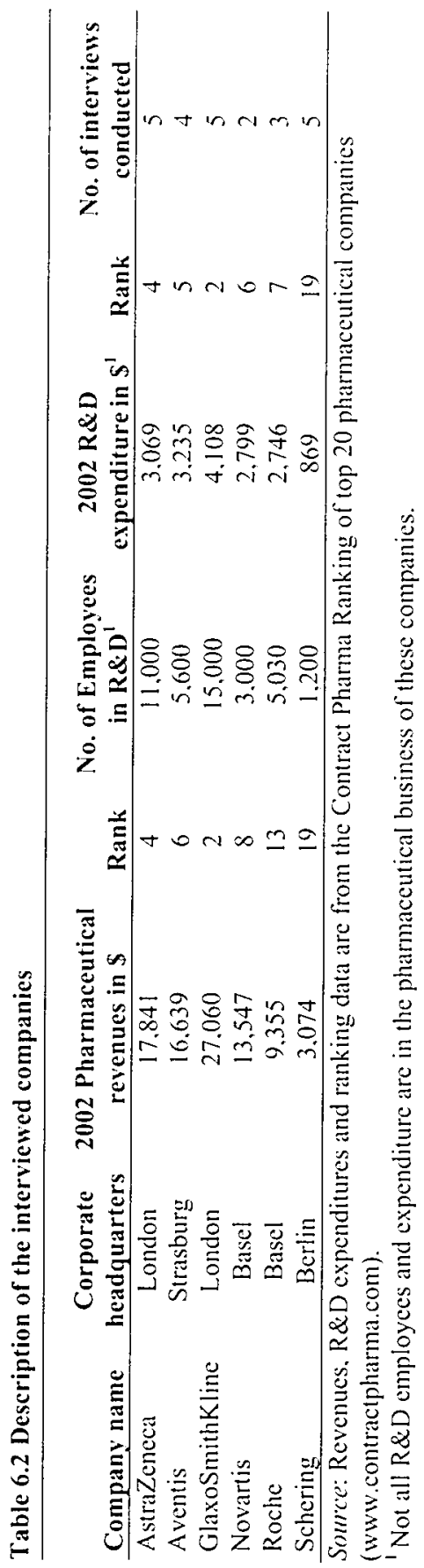


Since my analysis aims at providing a description of the R\&D organisation and technology transfer mechanisms, 1 used this method to examine the data. The first stage included 'coding' the interview material. This involved devising codes or subheadings to link the raw data fragments such as paragraphs, phrases or sentences from the interviews, to pieces of text relevant to a particular theme or key concepts. All interviews were taped and transcribed and then passages of text were grouped into patterns according to the codes they had been assigned.

Data from interviews with seientists were coded under four headings:

- Knowledge characteristics and sources involved in the research activity

- The mode and intensity of interaction with other researchers in the same and other rescarch units.

- Reasons for being seconded overseas

- Knowledge transfer us personal development.

- Knowledge exchange and accumulation during the assignment

- Nature of the knowledge being accumulated: technical $w$ organisational is 'social'.

- Knowledge sources: internal vis external (host country firms and institutions).

- Applicability of the knowledge learned abroad

Data from intervicws with the R\&D managers were coded around the following themes:

- R\&D organisation structure

- Geographical distribution of the different units and the range of technological activities undertaken by them.

\section{- Knowledge transfer mechanisms}

- Mode of interaction of a unit with other R\&D units in the firm.

- Mechanisms in place for achieving vertical and horizontal knowledge flows. 


\section{- Rationale behind the use of international assignments}

Constant comparison was used to evaluate the data to determine the similarities and differences among them and to identify the concepts and categories that they represented. Through constant comparison of the findings from within-firm and across-firm analyses, the core categories including themes. concepts. and possibly relationships between variables began to emerge. This process wats repeated until the conceptual categories were saturated, i.e. when no additional data could develop the properties of a category any further.

The qualitative approach adopted in this study was preferred to the quantitative approach used in three studies to analyse inter-firm knowledge transfer and the role of inventors' mobility across firms (Almeida and Kogut 1999. Rosenkopf and Almeida 2003, Stolpe 2002). In these three studies, reviewed in Chapter 2, patents and patent citation analysis are used to track the mobility of inventors and technical knowledge flows.

Before carrying out the case study 1 investigated a similar method to examine intra-firm inventors' mobility using information on the inventor's name and address contained in USPTO patents. Surprisingly I was able to identify only 10 inventors out of 29.588 from a sample of 24 chemical and pharmaceutical companies that 1 use in the next chapter who had both a European and a US address while working for the same company over the period 198099. ${ }^{81}$ A chemist I interviewed provided an explanation for this finding. Although he had spent six months on secondment to a US R\&D lab where he had worked on a project that had resulted in a patent application, the address on the patent was his permanent address in Europe. This was due to the fact that, when the patent was filed in the USPTO, he was back in Europe and thus the address on the patent was his current address and not the address of where the work had been carried out. This example confirms the findings in Chapter 4, i.e. that there is some noise in the information contained in patent data in relation to the inventor's address. In Chapter 4 it was noted that the EPO regulation does not impose any specific rules for the address of the inventor and this leads to some inconsistency, which however was significant only for the case of Philips. The anecdotal evidence reported in this chapter shows another source of noise in the case of USPTO data. However based on the comparison of the inventors addresses in EPO and USPTO equivalent patents presented in Chapter 4, one can assume that this noise does not significantly affect the geographical analysis of firms'

\footnotetext{
"In a recent stedy based on patent citations. Agrawal et al. (2003) found that only $6 \%$ of a sample of US patem applications were made by inventors that moved around within US states. Therefore my findings for inventors who moved from the US to Europe while still working for the same company, are not surprising.
} 
patenting activity. But it may represent a problem when patent data are used to track the temperely movement of researchers within the same company.

\subsection{THE INTEGRATED R\&D NETWORK: CENTRES OF EXCELLENCE FOR DRUG DISCOVERY}

Before turning to the findings on the different mechanisms adopted to achieve internal knowledge transfer and integration, a description of the R\&D organisations and of the main drivers that led to the specific configurations encountered is needed. Different international R\&D structures entail very different knowledge transfer efforts and different levels of integration among gcographically dispersed units.

In all the companies the main factor explaining the adoption of a geographically distributed organisational structure in rescarch activities was the need to exploit and access external sources of knowledge from leading centres. This emerged very clearly from an interview with a pharmaceutical $R \& D$ manager.

-The origin of this investment [in a research facility abroad] was that we wanted to have a laboratory where we were selling our products because the research laboratory was supporting the submission of drug to the authorities. Nowadays global companies are well placed if they have sites in Europe, the US and Japan. We want to access the available knowledge from the US universities'.

Similarly the manager of a therapeutic area said:

'The head of [the therapeutic area dealing with the] central nervous system has to be based in the US, because in the US is where the science is evolving. In the area of neurology a lot of the basic research is done in the US'.

From this interview with the head of a therapeutic area it also appeared that the reason for being physically close to sources of knowledge such as universities and research centres, is not only to have a easy access to this pool of knowledge, but also to be able to hire qualified personnel and in this way to become embedded in the local knowledge network:

- We would like to harvest early projects in all continents. To do that more efficiently it is better to have people located in each continent and be able to get in contact as fast as possible with the researchers there. We have people especially devoted to make contacts with biotech firms. This gives us access to companies in all three continents very fast. In addition since we have people doing research in these continents there are natural contacts with local academic institutions through the employees that are mainly American, Japanese and European graduates. It is not only important the network between the ex-PhD. students and their university professors, but it is also a matter of co-location: collaboration works easily if you can casily see each other. 
The importance of being socially embedded in the US scientific and academic community also explains the practice of cmploying researchers with post-doc experience in the US. ${ }^{82}$ As a senior R\&D manager said: "the main reason is not only the type of expertise acquired in the US but also the fact that they bring along relationships'.

However. although not always acknowledged. the actual organisational setting is in most cases the legacy of M\&A and the outcome of the rationalisation of resources, more or less drastic, that followed them. It was not by chance that Glaxo-Smith-Kline. AstraZeneca, and Aventis implemented their current R\&D organisation structures after mergers, or that Schering adopted a global R\&D organisation after acquiring a Japanese company (Mitsui Pharmaceuticals) specialised in oncology.

As can be seen from Table 6.3, overseas R\&D centres are actively engaged in drug discovery activitics in one or more therapeutic areas. It is interesting to note that US R\&D centres are specialised in some therapeutic areas such as oncology, the central nervous system, immunology and cardiovascular. Some of these discase areas, mainly oncology and immunology, are building on advances in bio/gene technologies developed in regional clusters in the US (Reger 2000). However the apparently similar distribution across companies in their US therapeutic area alignments may hide differences in their approaches to a particular discase. As pointed out by an R\&D manager in the area of oncology:

- Each site focused on oncology is specialised in a particular treatment paradigm: the functional treatment paradigm (i.e. hormones), and the anti-angio-genesis paradigm (i.e. we try to block the nutrition of the cancer cells) are investigated in Europe. while in the US they are more exploring the use of gene therapy and immunology to fight cancer'.

The therapeutic alignment of each location is also determined by the pre-existing capabilities of the research units, especially for those companies that have recently merged (c.g. GSK. Aventis and AstraZeneca).

Although all the companies in the sample have an R\&D presence in several continents, the actual distribution of research phases varies across companies. In particular they have chosen different points of the drug discovery process on which to centralise resources to achieve economies of scales and on which to decentralise to achieve specialisation.

\footnotetext{
: Although not officially stated such experience is practically mandatory. if you want to have a reasonable chance to get employed".
} 
Since the merger of (Blaxo Welleome and Smith Kline Beecham in 2000, the carly phase of their discovery process has become a global function located in the UK. US. Italy and Spain, although $90 \%$ of the activity is concentrated in rescarch sites in the US and the UK. Once molecules have been identified and optimised they are passed over to the Centres of Excellence of Drug Discovery (CEDDs) which are aligned by therapeutic areas; and chemists and biologists. expert in the disease in question. can work closely to bring the compound to the proof of concept phase (Phase 2 of clinical development). According to an R\&D manager the CEDDs are almost set up like independent operations if they were small biotechnology. companies. They compete for the resources that are distributed aceording to how close their molecules are to the market and how well they have performed. Once the compound has reached the proof of concept stage, it is transferred to other global functions that might be located elsewhere, to be further developed.

In Aventis there are three drug-discovery sites (Paris, Frankfurt and Bridgewater. US) that are set up as entrepreneurial units and compete on a global basis for resources. Each site has responsibilities from the early phase of a project up to the proof of concept phase, but the project team gets support from the so-called Global Functions of: 1) Lead Generation, which provides support for genomic technologies, high through-put screening technologies and chemical libraries; and 2) Lead Optimisation, which provides support for drug metabolism, pharmacokinetics, drug safety, clinical discovery, human pharmacology and laboratory animal and welfare. There is a Global Drug Development centre in Bridgewater from where all clinical development activities subsequent to the proof of concept stage are coordinated. Clinical trials are carried out all over the world, monitored by regional development centres in Paris for Europe, in Tokyo for Japan, in Bridgewater for the US. This R\&D organisation has been in place sinec the creation of Aventis, which resulted from the merger of Hocchst and Rhone-Poulenc in 2000.

In Schering since 2001 there have been five Research Business Arcas (RBAs) (In vivo diagnostic, Neurology/Immunology/Cardiovascular. Dermatology, Gender Health Care and Oncology) which are attached to three research sites. The target identification phase is carried out in all three locations, but the studies of lead identification and lead optimisation are only undertaken in Berlin and Richmond. The activity of each research site is supported by three regional research centres in Europe. Japan and the US which mainly work on pharmacology, medicinal chemistry, compound logistics, pharmakokinetics, physicochemistry, computational chemistry and enabling technologies (i.c. high throughput screening, assay 
development. genomics, bio-informatics, protein chemistry and structural biology). The preclinical development phase is concentrated in Berlin while the four phases of clinical development take place both in Berlin and in the US.

In the last three years Roche has organised its R\&D activity across four research sites where all drug discovery functions are carried out until they reach the pre-clinical development phase. Pre-clinical and clinical studies are concentrated in Basel and Nutley in the US. Similarly in Novartis, established by a merger between Sandoz and Ciba-Geigy in 1997. all the phases of the drug discovery process up to the pre-clinical stage are performed in each of the research sites. The compound is further developed in Basel, the US and the UK.

Likewise in AstraZeneca, the company resulting from a merger between Astra and Zeneca in 1999, each site is a fully-fledged R\&D facility engaged in activitics which range from carly discovery to life-cycle management in a particular therapeutic area. However the research activity is organised by therapeutic area and not geographic location. This implies that more than one R\&D unit is normally involved in different phases of the drug discovery process with the support of centres of excellence in enabling technologies. 


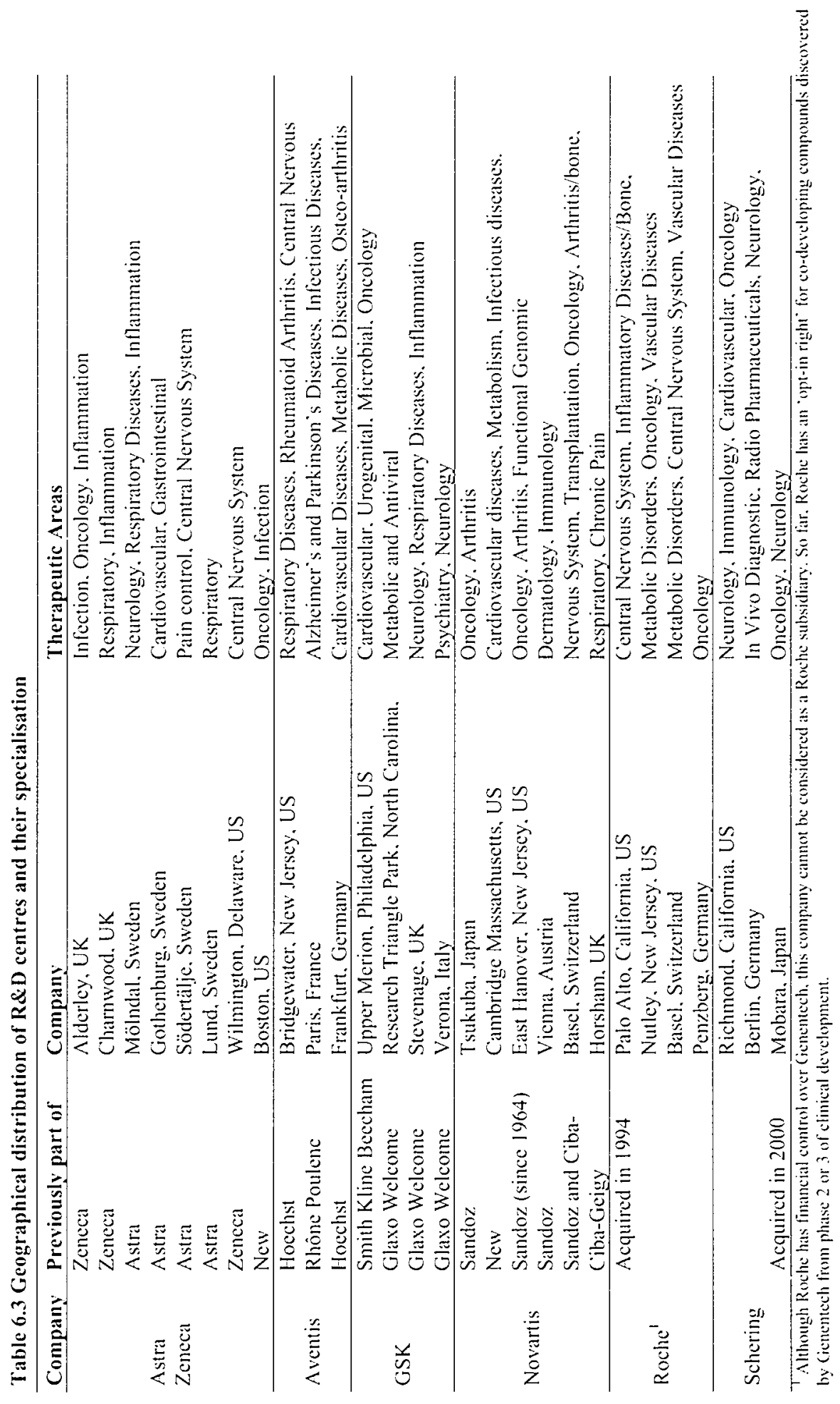


Figure 6.1 R\&D organisational structure

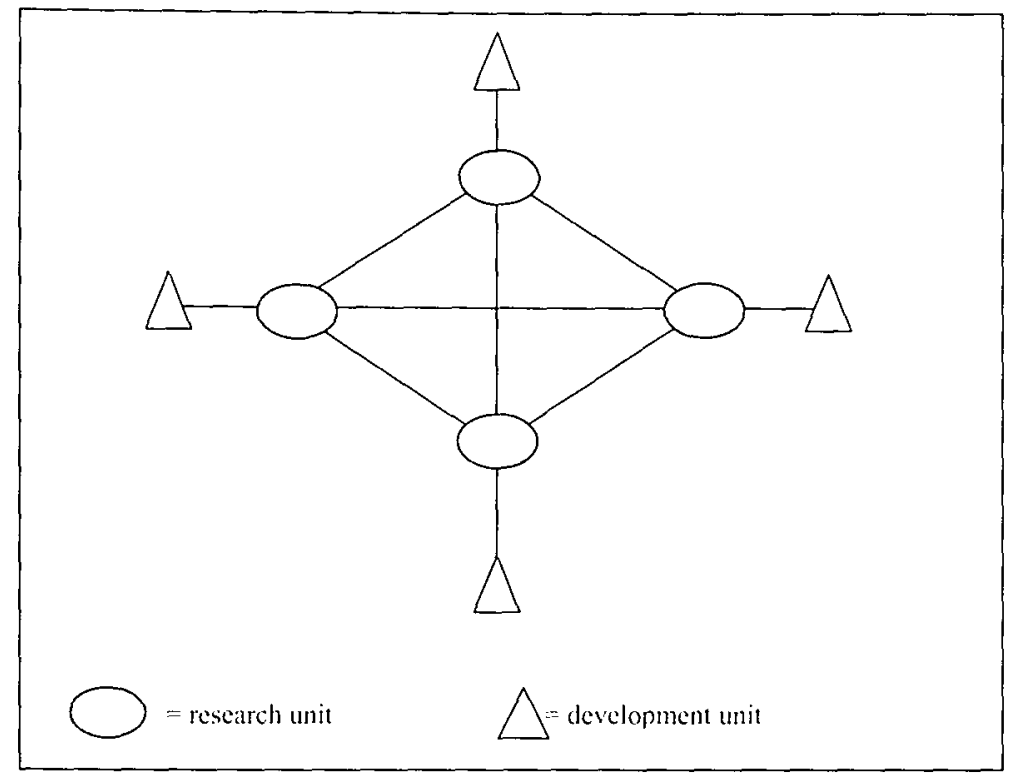

The taxonomy proposed by Gassmann and von Zedtwitz (1999) and illustrated in Figure 6.1 illustrates the organisational differences of the research and development functions. Drug discovery can be seen as being organised in an integrated-network structure. In each location a critical mass of scientists and technicians specialised in a set of targets for a discase area are brought together, facilitating personal interaction and the exchange of tacit knowledge. The activity of each centre is supervised by a central research unit, which could either be in the home country or in the US (as, for example, in Aventis and Novartis), to avoid duplication and favour knowledge integration. As pointed out by Ramirez (2003), the organisation of research activities according to therapeutic areas has been made possible by a new heuristic in drug discovery. This more systematic method has allowed scientists to focus on specific groups of targets in particular centres of expertise. This international division of labour allows the firm to access multiple external knowledge sources from centres of excellence around the world and/or internal knowledge sources from research units with a strong technological background within the organisation. At the same time the firm's innovative efforts are enhanced by greater interaction among researchers, which is necessary for succeding in tasks that rely heavily on tacit abilities and trial-and-error activities. The following comments illustrate this point: 
It is important and easy to have pharmacology and chemistry in the same location. because the work of these two departments is very much interconnected".

We prefer to have a project in one site within the domain of the project from synthesis. to analytics and screening. All these functions are more casily and efficiently done in one site*

Centres of excellence for a particular enabling technology (such as genomics, high throughput screening. combinatorial chemistry and bio-informatics) support the activity of these research units." These centres can serve the needs of various research units specialised in different therapeutic areas. The implementation of these centres is made possible because of the generic nature of the technologies. As Ramirez (2003) points out, the output of these research support functions is highly standardised and codified and therefore can be casily transferred from one location to another. The concentration of these activities in a few locations is designed to achicve critical mass, the rational use of resources, the full exploitation of specialised assets and cost reductions.

However, according to one R\&D manager the costs of managing and coordinating the network of integrated laboratories are extremely high and they are mainly connected with moving key project members from one site to another rather than with the project itself. In order to reduce these costs, GSK and Aventis have concentrated certain phases of the drug discovery process in centres of excellence (the CEDDs in the case of GSK). As a result, inside the integrated network structure there are small, autonomous, and flexible units able to take decisions more rapidly and frecly as regards the allocation of resources and the establishment of collaborations with external partners.

The diug development process (from pre-clinical development to registration) is organised as a polveentric decentralised structure with a regional focus and less intense inter-unit communication. These phases of the drug discovery process are concentrated in a few locations in order to achieve critical mass and the economies of scale needed to carry out studies in the drug development process. These development units tend to be located in both the home country and the US with the aim of being near the largest markets and the regulatory authorities. They usually confine themselves to developing the results from research units located in the same region and are coordinated by a global development centre (for example Bridgewater for Aventis). The degree of interaction among the development entres is not as intense as among the research network although they frequently carry out studies for other development centres whenever these have problems of insufficient capacity.

\footnotetext{
"For example, in GSK the bulk of high through-put screening is performed in Spain.
} 
The existing R\&D organisational setting has evolved from a structure characterised by a lower degree of integration and interaction among different units. Although each location was previously specialised in eertain therapeutic areas. cach eentre was organised as a completely self-sulfieient R\&D unit, where most of the phases of the drug discovery and development process were carried out. Each R\&D centre was fairly independent and there was an element of competition among the different units. In general communication among the different sites was not very intense and cross-border team projects were not often implemented. Using the taxonomy proposed by (iassmann and von Zedtwitz (1999), the R\&D organisation was a hubstructure where each centre had the responsibility to pursue research in certain therapeutic areas under the coordination of the headquarters.

\subsection{SOCIALISATION MECHANISMS EMPLOYED TO ACHIEVE KNOWLEDGE TRANSFER AND INTEGRATION}

The existing organisation of research activities is quite complex and involves a high degree of lateral communication among geographically dispersed research centres that operate in an integrated way during the drug discovery process. The complexity of the knowledge diffusion process inside the network derives from the fact that both intemational vertical and horizontal flows need to be achieved. Knowledge acquired in a particular therapeutic area has to be transmitted to other units working in the same therapeutic area (horizontal intra-disciplinary. flows) and also to other therapeutic areas where it could be employed (horizontal interdisciplinay flows). Results from the drug discovery process must also be transferred to the units carrying out development activities (vertical flows). Knowledge transfer within the different development centres is less complex sinee it does not involve horizontal knowledge flows, but the centres still have to manage vertical knowledge flows with the research units. One of the potential problems inherent in this structure is the lack of integration of knowledge produced in geographically distant units. This could result in a decrease in the firm's innovation performance and lack of cross-fertilisation of knowledge across different therapeutic areas.

The Glaxo-Smith-Kline drug discovery organisation seems to be the one most prone to these problems duc to the geographical. technological, and organisational distance among the CEDDs. As an interviewee stated:

-The CEDDs are almost like separate companies, they have their own budget, their own ways of working. One of the dangers of the CEDDs is that they might end up not sharing best practices. Among them there is a minimum level of communication. mostly based on personal 
relationships. Most of the people in Upper Marion do not know the people in North Carolina because they used to belong to different companies and they are also geographically separated. The CEDDs have various levels of communication, but it is pretty poor, because they have been set up almost like small companies. They are almost in competition, they are evaluated based on the value that the particular (EDD delivers to the business. In addition people de not move between CEDDs because they hese expertises in a specific theropeutic area (emphasis added).

The problem of technological distance among R\&D centres also emerged from the interviews with scientists. The increased specialisation of knowledge used in investigating specific therapeutic targets and, within these, particular methodological approaches is the main cause behind this process, as shown by the comments of a chemist and a toxicologist:

'I communicate very rarely with scientists in other locations because the therapeutic area I am working on is only located here. I do not have formal contacts with other colleagues. Before, the therapeutic area I am working on was also studied in New York and at that time I had very frequent contacts. But once the research facility was closed down all these contacts were interrupted' ... 'other colleagues working in other therapeutic areas have completely different structures, different chemistry, we hardly can ever help each other".

'I would use very little the R\&D results from other subsidiaries, because our projects are very separated, they have different target indications as compared to what we are doing. so I would not have very much exchange of data, because we do not overtap" (emphasis added).

Both vertical and horizontal transfer of information can be facilitated by the use of ICT. All the firms made extensive use of ICT applications such as intranets, portals, project websites, internal databases of compounds and intermediates, and they acknowledged the importance of having a globally standardised ICT system. The implementation of an ICT infrastructure plays a fundamental role in supporting communication and coordination in this R\&D organisational structure. Without ICT, the management and implementation of such a geographically dispersed R\&D network would not be possible. However ICT applications cannot completely overcome technological, organisational and geographical barriers inherent in the implemented network structure. These barriers can be reduced by creating a onecompany culture that can be encouraged through socialisation mechanisms such as frequent personnel rotations. Personal interaction can contribute to building a common language, shared values and cross-border networks, and allow the exchange of more tacit form of knowledge. ICT applications cannot substitute for face-to-face communication, especially for transferring tacit knowledge.

Thus to avoid compartmentalisation along disciplines firms try to increase the level of communication among scientists working on different therapeutic areas and in distant locations using some of the social mechanisms discussed above. Cross-border and crossdisciplinary projects are frequently employed. Due to the organisational setting of the R\&D 
function it is often the case that researchers from different locations are involved at different stages in a drug discovery project. However cross-border team projects are seen more as an unavoidable consequence of the R\&D organisation than as a strategic means for increasing knowledge diffusion inside a geographically dispersed R\&D network. This clearly emerges from the comments of an R\&D manager:

'The onc-location team is the preferable model because it is the more efficient, but the reality of our organisation is that most of our teams have members based in at least two countries and some of them three. My personal view is that if you can have one location team you are going to be better off. if you can have all sitting in one corridor is going to work better. But this is the exception to the rule'.

Temporary assignments appear to be the preferred socialisation mechanism when firms aim to achieve vertical transfers of know-how from the discovery to the development phase. Rescarchers from the development function will work closely with the discovery team for up to one year before the compound has been identified.

International horizontal transfers of know-how are more difficult to achieve especially when they are interdisciplinary. Companies try to stimulate intedisciplinary knowledge flows by promoting and officially supporting communities of scientists and technology councils. These communities are formed by people with expertise in a target family, such as kinesis or protease, or in a discipline such as molecular biology, chemistry, phamacology. The task of this group of experts is to integrate and diffuse the knowledge across different locations and therapeutic areas. ${ }^{8-7}$ The members of these communities interact regularly through intranet. meetings and formal workshops. Technology councils are set up to discuss problems faced in using particular technologies, such as those used in combinatorial chemistry or high throughput screening. These councils provide a forum where individuals can share best practice and some of the challenges they face in using a particular technology. ${ }^{55}$ An organisational measure adopted by one company is cross-disciplinary project proposal review boards. These boards are composed of peer reviewers from different areas and from different R\&D units who facilitate the cross-fertilisation of knowledge across therapeutic arcas and locations.

In general it seems that companies rely heavily on the ability and private initiative of individual scientists to span the boundaries of their own area of specialisation, to interact with

\footnotetext{
" They are also supposed to span outside the firm's boundaries and follow the developments of their scientific fields outside the firm.

ss In certain cases these technology councils involve people from other companies. In this case the object of these communities is to share their experience of use of a particular piece of equipment.
} 
other scientists and to generate, share and disseminate knowledge. A manager confirmed that one mechanism to ensure the recombination of knowledge across disciplines and rescarch sites is to choose the right people: people who have fun working with another culture and other poople, will make this happen?

\subsubsection{The role of international assignments}

Although these firms acknowledge the crucial role of scientists in the international diffusion of knowledge, the use of international assignments is very limited. mainly because of high costs and family ties. On average in 2003 only $1 \%$ of the R\&D staff employed was on secondment to another unit in the same company and secondments are generally organised only when needed. Only in one division of one particular company is there an organised exchange programme where a scientist from the European division spends one year in the US facilities while a scientist from the US replaces her/him at the European site. This programme has only been in place for the past two years and is an attempt at replacing the less popular sabbatical option", where a scientist goes to a foreign R\&D laboratory but is not replaced by another scientist.

These assignments last from as little as 6 months to up to 2 years and they can either be imposed by the management to acquire or transfer competences across sites, or they can be proposed by the scientist because he/she considers the experience to be useful part of his/her personal development. In this study 1 found evidence of both types of international assignment experiences. For example one scientist I interviewed spent 6 months in the US as a visiting scientist in a dedicated bio-informatics group formed as a result of a joint venture with an American company. This assigmment was aimed at acquiring new technological expertise in the field of genomics that was missing in the European R\&D facility and was needed to undertake gene-chip experiments in the European site. In another company, sabbatical visits were used for transferring expertise (i.e. in combinatorial chemistry. automation technologies) from one site to another, as well as for stimulating networking between groups from particular sites using similar or different approaches.

In two cases the exchange of scientists was aimed at improving relations between R\&D locations.

'Historically. communication and cooperation between European and US sites have been difficult due to the different research philosophies. During the mid 1990s there was more competition than cooperation with them. During that time it was even difficult to exchange knowledge. To overcome cultural differences and to increase a common understanding among 
colleagues from different continents staff exchange programs have been established. Now, after the first exchange of staff, things are improving ... People taking part in the exchange programme should be the bridge between the two sites. It is important to know people, it is much easier to deal with them if you have worked with them'.

Similarly in another company a scientist said:

'The R\&D facility where I went was part of a company we just acquired the year before and people there were not very happy about this unfriendly take over. One of the purposes of this exchange was to overcome the initial reservation and try to build a collaboration that would make us colleagues rather than competitors'.

In all instances the international assignment enabled researchers to have better interaction and communication with the people they met in the other facility. Interaction with colleagues inside the company appeared to be the most important source of leaming, which confirms the main purpose of these assignments: network building among researchers working in geographical distant R\&D centres and increasing awareness of 'who knows what' in other centres. These relationships are in most cases maintained once the scientist has returned to his/her home laboratory. In contrast, very little interaction seems to take place between the scconded researchers and other host country firms, universities, or scientists.

If an assignment was not aimed at acquiring specific knowledge, researchers nevertheless picked up technical expertise, but it was not always easy to implement and apply it once they returned to the their permanent job.

-When I was in the US I developed a completely new class of drugs. I wanted to work more on that class of compounds. but I did not. because it would have meant implementing here a different program?

However it is possible to identify a longer-term potential for cross-fertilisation arising from these exchanges of personnel.

'Coming from traditional medicinal chemistry it was my first chance to get in touch with automated chemistry. After staying three months in the automated chemistry group in our US subsidiary I was aware of the scope and limitations of the approach which helped a lot in contributing to a global technology strategy".

-While I was in the US I had started a collaboration with a company expert in gene-chip technology. This experience improved my innovation activity because we are trying to work more and more in my field with this micro-areas and this time in the US was a trigger for me to think very hard on how I could use these tools".

Researchers who had been on secondment seemed to have gained a better understanding of the R\&D organisation and management adopted in the US centre. This appears to be one of 
the primary goals attributed to this type of socialisation mechanism by the top management of the companies. According to the head of a therapeutic area:

\begin{abstract}
For me, in terms of delivering projects globally, it is important that people [when sent in another R\&D centre] understand what it takes to deliver things in a different country and how to do it most effectively. When these people go back to their original site they actually strengthen the site they eame from because they know how this organisation works globally rather than knowing only how it works based on what they have seen in one site" ... "when you send someone in another R\&D site you have to make sure that [the international assignment] is seen as a family thing not an individual thing' (emphasis added).
\end{abstract}

While scientists perceive the foreign experience as a chance to broaden their knowledge and acquire new skills, the top management see it as an opportunity to increase the productivity of the company by getting the researchers acquainted with how the R\&D function is managed in other facilities.

\title{
6.7 Conclusion
}

This chapter has analysed the R\&D organisation in six of the largest European pharmaceutical companies and the mechanisms in place to ensure the integration and cross-fertilisation of technical knowledge produced in geographically dispersed R\&D units. In the centralised hub' R\&D structure there was no necessarily to stimulate network building among researchers and exchange managerial solutions because each centre was working in isolation with very little interaction with other R\&D units, but in the integrated multi-hub R\&D structure this was essential.

The companies I interviewed had similar organisational structures characterised by different configurations for the drug discovery and drug development functions. The innovative efforts in the drug discovery phase are carried out in an integrated network of research facilities, supported by centres of excellence in enabling technologies, while the organisational structure of the development activities is organised as a polycentric decentralised structure characterised by a lower level of inter-unit interaction. I would argue that the new sciencedeductive method in drug discovery has allowed the adoption of this international division of labour, which is characterised by elements of concentration both in the development phases and in the implementation of new enabling technologies, and by elements of dispersion in the drug discovery phases. This network structure cnables companies to leverage knowledge from pockets of excellence around the world and to cxploit existing specialised assets within the organisation, but at the same time it allows them to maintain a critical mass of resources in the development phases of the drug discovery process. 
The intervicw data in this chapter indicate that a major drawback of the integrated network structure is the high cost involved in coordinating the innovative efforts of these units and in ensuring cross-pollination of the knowledge produced in physically distant units. Geographical, technological, and organisational distances seem to significantly affect technology transfer and knowledge integration in this R\&D network. In this study I have focused on socialisation mechanisms and in particular on international assignments of researchers as one of the possible means for overcoming these barriers and fully exploiting the benefits of this organisational form.

From the data gathered in the interviews it appears that cross-border team projects are quite often used, but mainly as a result of the organisation of the drug discovery and development process more than as a way of achieving inter-personal relationships between researchers. Technology councils and project-proposal peer reviews boards are the main socialisation mechanisms employed to foster inter-disciplinary and intra-disciplinary knowledge flows among technologically and geographically distant units. The use of international assignments is quite limited (on average only $1 \%$ of R\&D staff is seconded to another research unit) even though companies rely heavily on the initiative of individual researchers to interact with other colleagues and to enhance R\&D synergies across projects. This socialisation mechanism is used to achicve three main aims. First, rescarchers are seconded to another R\&D unit to transfer technical knowledge from the headquarters or to acquire technical knowledge from another research facility. Second, international assignments are used for individual leadership development. In this instance, technology transfer is not the primary goal and scientists find it difficult to apply what they have learnt during their experience abroad, to their work. However the secondment experience appears to increase their overall understanding of the R\&D organisation and management in the other unit, help them identifying "who knows what', and foster the creation of personal relationships with other researchers. Third, assigning researchers to other $R \& D$ units is employed as a means of reducing organisational distance through social interaction among researchers.

The recent nature of this re-organisation of the $R \& D$ functions, mostly as a result of $M \& A$ strategies, and the long delay between $R \& D$ and the commercialisation of new drugs, make it difficult to evaluate the impact of these organisational changes and of the adoption of these social mechanisms on the firms' cconomic performance. Future research should address this issue. However this study has highlighted a few potential problems from the adoption of a geographically dispersed R\&D network structure. The principal ones are increased inter-unit 
technological distance as each unit becomes more specialised in a particular disease area and/or methodological approach, and the difficulty of exploiting synergies across disciplines. 


\section{CHAPTER 7}

\section{INTER-FIRM REVERSE TECHNOLOGY TRANSFER THE CASE OF EUROPEAN CHEMICAL AND PHARMACEUTICAL SECTORS}

\subsection{INTRODUCTION}

Chapter 5 provided empirical evidence that US forcign subsidiarics of high-tech European MNEs draw on localised soures of knowledge to an important extent. The case study reported in Chapter 6 confirmed and enriched the findings of the quantitative analysis for a sample of European pharmaccutical MNEs. These results suggest that R\&D internationalisation entails not only an outflow of knowledge from the parent company to the foreign subsidiary, as assumed in Vernon's (1966) product life cycle and in the traditional model of the multinational company, but also an inflow of technological knowledge from the foreign subsidiaries to the home part of the MNE (intra-firm RTT) and to other home country firms (inter-firm RTT). This chapter builds on these findings. The discovery that the R\&D activities of foreign subsidiaries have a significant asset-augmenting component motivates these research questions: Do firms located in the MNE home country benefit fiom the technological knowledge developed in foreign subsidiaries of their inational champions"? And if so which home county firms benefit more from this technology transfer process?

As discussed in Chapter 3, the idea of lcarning from forcign subsidiaries was initially postulated and tested by Reddaway et al. (1968) in their report on the impact of outward FDI on the UK economy: however a more systematic analysis of this phenomenon was provided by Mansfield (1984) and Mansfield and Romeo (1984). More recently, the increasing importance of asset-augmenting $R \& D$ activities has led researchers to investigate to what extent knowledge diffuses inside the MNE and in particular from forcign-based R\&D facilities to the home part of the MNE (intra-firm RTT). MNEs have to ensure that the knowledge acquired abroad is then transmitted to the rest of the organization. The evolutionary theory of the multinational (Chesnais 1988, Cantwell 1989, Kogut and Zander 1993 ) and the more recent knowledge-based theory of the firm (Grant 1996) have emphasized the strategic role of knowledge in the creation and sustainability of a firm's competitive advantage. Kogut and Zander define MNEs as 'social communities that specialise in the 
creation and internal transfer of knowledge' and. according to them. "an MNE arises not out of the maket failures for the buying and selling of knowledge but out of its superior efficiency as an organisational vehicle by which knowledge is transferred across borders' (p. 625). Thus the process of "reverse technology transfer". as defined by Mansfield. has generally been examined as a means of improving the MNE's portfolio of knowledge and technological assets on the one hand (see Frost 1998. Branstetter 2000, Gupta and Govindarajan 2000, Hákanson and Nobel 2000, 2001. Zhou and Frost 2001), and its productivity on the other (Fors 1997. Castellani 2001. Barba Navaretti and Castellani 2003). But RTT maly also have significant effects on the home country, if the knowledge and resources that are transferred back to the parent firm spill over to the rest of the economy. through its linkages to domestic firms. As shown in Chapter 3, this process has been less well researched. Studies on the impact of outward FDI on domestic productivity growth within the international R\&D spillovers literature (i.e. $\mathrm{Xu}$ and Wang 2000. Pottelsberghe and Lichtenberg 2001, Braconier et al. 2002) can be regarded as empirical evidence of the effects of imer-firm RTT, although they do not analyse this phenomenon directly.

Following the approach proposed by Globerman, Kokko and Sjöholm (2000), I therefore decided to test for the existence of inter-firm RTT using patent citation analysis to capture knowledge flows from foreign R\&D units to other firms located in the home of the MNE. In particular 1 examine in this chapter the geographical distribution of citations received by patents granted by the USPTO to US subsidiaries of 24 European chemical and pharmaceutical MNEs over the period 1980-99 using data from the NBER patent citations dataset (Hall et al. 2001). If foreign subsidiaries work as a channel for transmitting host country knowledge back to units in the home country then firms located in the home country of the multinational should show a learning advantage over firms located in other countries. Technological knowledge may diffuse more rapidly and easily in the home country - where the multinational lies at the centre of a dense network of relationships with suppliers, customers, competitors, research institutes, universities, financial institutions, and industry associations, where their core productive and innovative activities are concentrated, where their linkages with external actors are strongest, but also historically defined (Sally 1996). Thus home country firms should show a higher propensity to cite patents developed by US subsidiaries of their national "champions'. so

\footnotetext{
*t For example. lechnology transfer from an R\&D laboratory set up or acquired by Bayer in the US to other firms operating in Germany. via Bayer's headquarters.
} 
As found in the previous chapters, European MNEs operating in these sectors, and in particular pharmaceuticals firms, have substantially increased their R\&D activities in the US, and, more importantly, these investments have a significant asset-augmenting component. As shown also by a number of other empirical investigations (Allansdottir et al. 2002. Senker 1998. Shan and Song 1997. Sharp 1999). European chemical and pharmaceutical companies have been particularly engaged in tapping into the US knowledge base, the source of many new products and technological competences. The increasing number of asset-augmenting facilities can be attributed to the comparative advantage that the US has in the new biotechnology areas relative to the more traditional pharmaceutical fields. The US is the preferred location for asset-augmenting activities not because of its technological infrastructure per se, but because of the existence of a large number of small specialist research firms which are extremely dynamic and embedded in networks of collaborative relationships with universities, large firms and both public and private research centres (Gambardella et al. 2000). European multinationals are attracted to these biotech clusters in order to benefit from the external economies generated by the concentration of production and innovation activities, and to get access to highly skilled workers and to the rescarch of "star" academic scientists. The tacit nature of knowledge in the new technological areas such as biotechnology explains both spatial agglomeration and the need for geographical proximity to benefit from localised spillovers.

The internationalisation of R\&D activity and, above all, the creation of asset-augmenting R\&D sites reinforce the role of multinational firms in promoting cross-border knowledge flows in these technological areas. Of course, home country firms may access knowledge developed abroad by other means, especially if they are themselves part of a company with units in the foreign location (in the empirical analysis I tried to control for this, by looking at the home-country firm's international presence). However, as pointed out by Veugelers and Cassiman (2004), the role of multinationals in the cross-border transfer of knowledge becomes crucial when the know-how that home country firms are trying to access is localised and 'sticky'. This strategy may therefore represent a potential source of RTT, which may benefit other firms located in Europe and enhance the competitiveness of Europe in fast growing technological areas. However the reliance on MNEs as a channel for international technology transfer may fade as the knowledge frontier evolves and knowledge becomes more codified. 
The remainder of this chapter is organised as follows. Section 7.2 discusses some of the limitations of the data. presents an analysis of the innovative activity of MNEs in my sample in order to assess the nature of their foreign-based R\&D efforts, and provides descriptive statistics of the patent citation database used in the empirical model. Section 7.3 presents the econometric model and the explanatory variables used to test the research questions. Section 7.4 reports and comments on the results. Finally, section 7.5 makes policy suggestions drawn from the empirical evidence.

\subsection{DESCRIPTION OF THE DATABASE}

The existence of inter-fim RTT was explored using a database of the patenting activities of 24 chemical and pharmaceutical European MNEs (a list of the company names is contained in Table A7-1 in the appendix). Patents and patent citation data are taken from the NBER database (Hall et al. 2001), which contains patents granted from 1963 to the end of 1999 and citations made to other USPTO patents by patents granted in 1975-99. From the almost 3 million patents in the NBER database I selected those granted between 1980 and 1999 to US affiliates of the companies in the sample. As in previous chapters, I used the address of the first inventor to identify the location of the invention and the name of his organisational affiliation ('assignee name') to relate each patent to the corporation that owns it. To be able to attribute all patents to a specific multinational company I used the Dun and Bradstreet Linkages database which contains the company ownership structure as it was in 1996. I used this structure to construct patent data for each MNE during the period 1980-99. A major drawback of this procedure is that it does not take into consideration changes in the corporate structure due to M\&A that have occurred before or after 1996. Most of the effects of M\&A after 1996 are mitigated by the fact that there are few patent applications in the database after this year (because the database lists patents by the year they were gramed, finishing in $1999) .87$

As discussed at length in previous chapters, there are some limitations to the use of patents and patent citations to capture knowledge flows. Two points in particular need to be stressed here. First, although it is true that not all inventions are patented, because firms can follow other means of appropriating the innovation benefits, patents are appropriate for exploring the innovation activity in the chemical and pharmaceutical sectors. Recent studies using data from

\footnotetext{
"In addition this problem is alleviated by the fact that 1 am analysing citations received by this set of patents. most of which naturally occur with a certain time lag.
} 
innovation surveys have shown that both large and SMEs operating in these industries have a high patent propensity (Arundel and Kabla 1998, Brouwer and Kleinknecht 1999), and patents are more widely used than alternative methods to protect the returns from R\&D investments. In addition, dedicated biotechnology firms that are heavily engaged in R\&D collaboration agreements may have a high rate of patenting in order to protect and define their knowledge base because of future collaboration with other firms. Second despite the fact that. as shown in Chapter 4. USPTO patents are not able to capture to same extent as EPO patents R\&D activities undertaken in Europe. I decided to use this data source because I wanted to measure fully the innovative efforts of European MNEs in the US. As a result my analysis may underestimate the patenting performance of European firms, especially SMEs and public rescarch institutes, and it may therefore be biased against finding cvidence of inter-firm RTT, given that I am tracking this knowledge flow using patent citations contained in EU-invented patents. However in using USPTO rather than EPO patents I may be better able to capture the innovative efforts in the area of biotechnology because, as shown in Chapter 4, patents in this technology field do not tend to be extended for protection in other patent offices (see Table A4-2 in the appendix of (hapter 4 ).

\subsubsection{The patenting profile of US subsidiaries}

The overall number of patents granted to US subsidiaries over the period 1980-99 is 11,672. which corresponds to almost $21 \%$ of the total number of patents granted to the MNEs under analysis. Some companies are more technologically active in US locations than others: more than $60 \%$ of the patents granted to the BOC Group, for example, originate from US sites, with

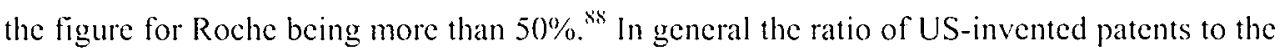
total number of patents granted to phamaceutical companies increased from $19 \%$ in 1980 to $36 \%$ in 1997. The ratio for chemical companies has increased from $9 \%$ in 1980 to $23 \%$ in 1997. Thus, although increasing, the US R\&D activities of chemicals companies are less significant than those of pharmaceutical companies.

Even though the results provided in the previous chapters have already shown that the US R\&D efforts of European MNEs in these sectors have a significant asset-augmenting component, it is interesting to assess whether, and to what extent, the patenting activities of US subsidiaries have diverged from the patenting activities of their home country R\&D facilities. As already pointed out, the process of RTT is connected to asset-augmenting R\&D

\footnotetext{
${ }^{4 x}$ The high share of US-invented patents in Roche's patent portfolio is largely due to the patenting activities of the US based Genentech, which was acquired by Roche in 1990.
} 
activity, with the multinational firm aiming to acquire or create completely new technological alssets that are location specific. Thus, one would expect to observe greater differences in the technological specialisation of US subsidiaries and their headquarters, if the asset-augmenting component of foreign R\&D investment dominates the asset-exploiting component. Frost (1998) measures the evolution of US subsidiaries' patenting activities with respect to the home base units using phi-square distance measures, which capture dissimilarities between vectors of patents granted to the two groups of firms. ${ }^{\text {(6) }}$ The formula used is:

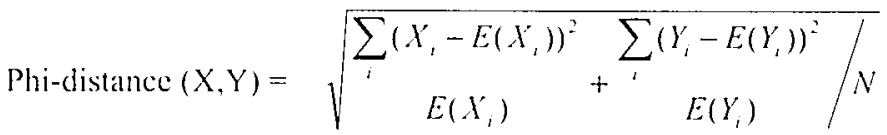

where $X$ and $Y$ are respectively the patents applied for by the home part of the MNE and the US-located subsidiaries; $i=1 . .36$ technological classes ${ }^{90}$, and $N$ is the total number of patents in the two vectors. This index varies between 0 and 1 and higher values indicate greater distance.

Table 7.1 Phi-square measures between US subsidiaries and headquarters of most technologically active MNEs

\begin{tabular}{lcc}
\hline Parent company & $\mathbf{1 9 8 0 - 8 7}$ & $\mathbf{1 9 8 8 - 9 9}$ \\
\hline BASF AG & 0.18 & 0.34 \\
Bayer AG & 0.27 & 0.31 \\
Ciba-Geigy AG & 0.29 & 0.27 \\
Glaxo Wellcome Plc & 0.11 & 0.27 \\
Henkel & 0.37 & 0.28 \\
Hoechst AG & 0.29 & 0.26 \\
ICI Plc & 0.28 & 0.28 \\
Rhonc-Poulenc S.A. & 0.35 & 0.36 \\
Roche Holding AG & 0.37 & 0.50 \\
Sandoz AG & 0.22 & 0.44 \\
SmithKline Beecham Plc & 0.38 & 0.38 \\
Solvay S.A. & 0.45 & 0.59 \\
The BOC Group Plc & 0.29 & 0.34 \\
\hline Average & $\mathbf{0 . 2 9}$ & $\mathbf{0 . 3 5}$ \\
\hline
\end{tabular}

Table 7.1 reports the results of the distance measure calculated for those MNEs with the highest share of US invented patents and for two sub-periods. On average the technological

\footnotetext{
s* The phi-square measure is a dissimilarity index, which together with the chi-square measure is specifically designed for frequency count data. The main differenee between these wo indicators of dissimilarity is that the phi-square index does not depend on the total frequencies of the two vectors whose distance is computed.

These are the 36 technological sub-categories in the NBER database.
} 
distance between the US subsidiaries and the home part of the multinational has increased over time, with some firms exhibiting a more evident pattern in this direction (see for example the pattern of BASF, (jlaxoWelleome, Roche, and Sandoz). These results are in line with the evolution of the three technology classes in which US subsidiaries specialise most. Although not reported, US affiliates patent in technical fields not previously emphasised in the home country R\&D portfolio or they specialise in different areas, maybe as a result of the MNE's acquisition strategy." In particular biotechnology (class 435 . 800) appears among the top three technology classes of specialisation for the US subsidiaries of most companies, both chemical and pharmaceutical (i.e. Solvay, Roche, Glaxo Wellcome, SmithKline Beccham, Novo Nordisk, Akzo Nobel, Bochringer Ingelheim International, and Zeneca).

To assess whether these subsidiaries focus on the areas of expertise of the US states in which they are located, I calculated what percentage of affiliates' patents are in fields where the host state appears to be specialised. I then compared this with the proportion of US subsidiaries' patents in technical areas where the MNE home country is specialised. To measure the technological specialisation of a particular location, I constructed a tevealed technological advantage' (RTA) index. This index, first applied in the country context by Socte (1987), is analogous to the index of 'revealed comparative advantage' used in the trade literature (Balassa 1965) and represents the extent to which a particular location accounts for a disproportionate share of patents in a technical field relative to its share of patents in all technical fields. The index will vary around unity, with values above one indicating a RTA whereas values below one point to a relative technological disadvantage. I calculated the RTA as:

$$
R T A_{i n}=\left(P_{i n} / \sum P_{i n}\right) /\left(\sum P_{i n} \sum_{n} \sum_{i} P_{i n}\right)
$$

where $P_{i n}$ stands for the number of patents granted to inventors located in state $i$ in field $n$ (3digit level as classified in the NBER (ataset). The host state RTA is calculated using $\sum_{n} \sum_{i} P_{i n}$ as the total number of patents granted to all US states to avoid the problem of constructing the RTA index using a small number of patents.

\footnotetext{
"This is particularly true for Roche with its acquisition of Cenentech. i.e. biotechnology is the top teclmical ficld of Roche US subsidiaries. while it does not appear in the top three of the home base units.
} 
Table 7.2 Specialisation of US subsidiaries' patenting activities

\begin{tabular}{lcccc}
\hline \multirow{2}{*}{ Parent company } & \multicolumn{2}{c}{ Home country (\%) } & \multicolumn{2}{c}{ Host country (\%) } \\
\cline { 2 - 5 } & $\mathbf{1 9 8 0 - 8 7}$ & $\mathbf{1 9 8 8 - 9 9}$ & $\mathbf{1 9 8 0 - 8 7}$ & $\mathbf{1 9 8 8 - 9 9}$ \\
\hline BASF AG & 76.71 & 77.66 & 57.53 & 64.36 \\
Bayer AG & 74.51 & 57.27 & 70.00 & 56.82 \\
Ciba-Geigy AG & 66.13 & 63.89 & 61.29 & 62.64 \\
Glaxo Wellcome Plc & 65.00 & 71.43 & 35.00 & 54.17 \\
Henkel & 71.59 & 79.78 & 51.14 & 59.55 \\
Hocchst AG & 75.00 & 74.32 & 59.62 & 51.89 \\
ICI Ple & 50.00 & 59.05 & 64.52 & 54.29 \\
Rhone-Poulene S.A. & 43.60 & 69.30 & 69.01 & 59.29 \\
Roche Holding AG & 55.77 & $\mathbf{6 5 . 7 9}$ & 63.46 & 55.41 \\
Sandoz AG & 62.90 & 58.16 & 62.90 & 58.16 \\
SmithKline Beecham Plc & 66.67 & 79.59 & 55.56 & 61.22 \\
The BOC Group Plc & 40.38 & 59.71 & 44.23 & 46.04 \\
\hline Average & $\mathbf{6 8 . 0 3}$ & $\mathbf{7 4 . 1 8}$ & $\mathbf{6 3 . 1 2}$ & $\mathbf{6 2 . 1 7}$ \\
\hline
\end{tabular}

The pattern shown in Table 7.2 reveals an increasing trend in the proportion of US subsidiaries' specialisation towards fields of home country expertise, and a stable pattern towards ficlds of host state specialisation: US subsidiaries of six MNEs have substantially moved their technical activities towards areas of host state specialisation.

I therefore conclude that, in line with the findings in the previous chapter and those from other studies (Allansdottir et al. 2002, Gambardella et al. 2000), the US is attracting an increasing amount of research efforts from European chemical and pharmaccutical multinationals especially in biotechnology. These R\&D activities are being conducted in technological areas that differ in part from those explored in home country laboratories, which is consistent with an asset augmenting $R \& D$ strategy.

\subsubsection{A descriptive look at the citations data}

The total number of citations received by the patents granted to US subsidiaries during the entire sample period is 38,887 , of which only 5,783 (less than 15\%) are citations made by patents whose first inventor is located in a European country." ${ }^{2}$ This is a very small number compared to the citations made by US located inventors $(28,825)$, but big enough to allow a consistent empirical analysis. Among the citations made by inventors resident in Europe onefifth are intra-firm citations $(1,129)$. This is not a very high proportion, but it does not imply that the European units of these MNEs do not deploy the knowledge produced in US subsidiaries. Knowledge flows within the company may occur without giving rise to patent citations. However it is worth noting that intra-firm citations occur more quickly than inter-

\footnotetext{
"Is in previous chapters with Europe 1 refer to the 15 countries belonging to the European Union (prior to May $2004)$ plus leeland. Liechtenstein. Norway, and Switzerland.
} 
firm citations: the average citation lag (the difference between the application year of the citing patent and the application year of the eited patent) for intra-group citations (4.8 years) is less than the overall average citation lag $\left(5.5\right.$ years). ${ }^{93}$ This reflects the fact that technological knowledge flows more easily within a multinational company. Another important fact about this group of citations is that half of the patents cited by MNEs' European subsidiaries are also cited by other European firms. This suggests that to a certain extent the knowledge flowing outside the boundaries of the firm is also exploited internally. Because intra-firm citations capture knowledge flows within the multinational, I eliminated them from the analysis.

Among the remaining citations. I identified 1.219 home-country citations, i.c. citations made by inventors located in the country of origin of the cited subsidiary (for instance citations made by patents invented in Germany to patents granted to a US affiliate of Bayer). corresponding to almost one-third of total citations. I also identified three groups of citing firms that differ in their international profile:

1. subsidiaries or headquarters of European MNEs (European firms with at least one subsidiary in the US):

2. European subsidiaries of US MNEs;

3. domestic firms and institutions, defined as assignees without either patenting activities or subsidiaries in the US.

According to this last definition, domestic firms may have subsidiaries in other European countries but not in the US, while business units in group (1) may never have patented in the US directly, but may be part of a European MNE with a US subsidiary. I classified the citing companies into these groups to control for the fact that multinational firms might have acquired the knowledge developed in the US directly through their presence in the US or indirectly through their organisational network. In contrast, domestic firms and institutions would most probably have to rely on their linkages with the relevant MNE in order to access technological knowledge accumulated in the US. It is for this group of firms that multinational companies may be important in the international transfer of knowledge.

\footnotetext{
"2. I carried out a one-sample t-test to statistically support this conclusion. The t-statistic for the test of equality of mean of the intra-fim citation lag with the overall citation lag is -6.553 implying that the intra-firm citation lag is significanty shorter than the sample average at $99 \%$ level of confidence.
} 
As shown in Table 7.3, only 16\% of all citations originate from domestic firms and institutions, white almost three-quarters of citations to US subsidiaries' patents are made by other Europan MNEs. Another interesting feature of those patents granted to the sample of US subsidiaries and subsequently cited by European firms is their technological and economic value. Following the approach used in Chapter 4 . I took the number of forward citations as a proxy for the impact of a particular invention. Table 7.3 shows the percentage of patents lying above the $75^{\text {th }}$ pereentile of the distribution of citations received by patents granted in the same year. Overall, just over $40 \%$ of patents are highly cited and there are no significant differences in patent importance across the three groups of citations. This figure is quite high if compared with the proportion of highly eited patents in the overall sample of US-invented patents granted to the MNE under analysis $(28 \%)$. This may therefore indicate that the knowledge flowing back to Europe is quite valuable. There are some modest differences in patent importance and citation lag across the three groups of citing firms. One interesting difference that distinguishes citations made by European MNEs is the high share of homecountry citations. Almost one-third of these citations are made by inventors located in the country of origin of the cited subsidiary's parent company. The last column of Table 7.3 presents some statistics on the technological diversity of the pair of citing and cited patents. Although indicative of the type of knowledge developed by US subsidiaries and used by European firms, these figures do not reveal whether it is consistent with the citing firm's technological specialisation. To assess this I calculated the share of patents that are in the same 3 -digit technology class as the cited patent in the citing firm's patent portfolios. In $24 \%$ of cases the citing firm had never patented in the cited technology area suggesting that the knowledge flowing back from the US is new to the citing firm. This is confirmed by the analysis of the shares of patents in the same technology class of the cited patent: in $84 \%$ of cases the share is less than $25 \%$. 
Table 7.3 Descriptive statistics of citations made by EU-invented patents to US subsidiaries' patents (excluding intra-firm citations)

\begin{tabular}{|c|c|c|c|c|c|c|c|}
\hline Citing firms & $\begin{array}{l}\text { Number } \\
\text { of cited } \\
\text { Patents }\end{array}$ & $\begin{array}{c}\text { Average } \\
\text { 'importance' } \\
\text { of the cited } \\
\text { patent }\end{array}$ & $\begin{array}{c}\text { Number } \\
\text { of } \\
\text { citations }\end{array}$ & $\begin{array}{c}\% \\
\text { Total } \\
\text { citations }\end{array}$ & $\begin{array}{c}\% \\
\text { Home- } \\
\text { country. } \\
\text { citations }\end{array}$ & $\begin{array}{c}\text { Mean } \\
\text { citation } \\
\text { lag }\end{array}$ & $\begin{array}{c}\% \\
\text { Citations } \\
\text { to the } \\
\text { same } \\
\text { class }\end{array}$ \\
\hline Units of US & 330 & 42.4 & 636 & 14.2 & 20.3 & 6.05 & 43.9 \\
\hline Units of EU & 1594 & 36.9 & 3293 & 73.6 & 31.0 & 5.58 & 53.4 \\
\hline Domestic firms & 310 & 40.5 & 543 & 16.1 & 12.3 & 5.68 & 49.9 \\
\hline Overall & 2234 & 40.1 & 4472 & 100 & 27.2 & 5.66 & 51.6 \\
\hline
\end{tabular}

Citations made by inventors located in the country of origin of the eited subsidiary.

Percentage of eited patents above the $75^{\text {th }}$ pereentile of the distribution of citations received by patents granted in the same year.

Perentage of total citations that have the same 3-digit patent class as the cited patent.

Another important issue is whether the patents eited by European inventors originate from asset-augmenting units. The findings presented in the previous section suggest that US subsidiaries engage in asset-augmenting R\&D activities, but to what extent the results of these efforts are exploited by firms in their home countries or in other European countries is not known. If European firms draw on knowledge originating from asset-augmenting R\&D units they should cite patents in ficlds of host state specialisation (host state RTA>1, calculated for each 3-digit patent class). Almost $65 \%$ of all US subsidiaries' patents cited by European inventors are in fields of host state specialisation. ${ }^{4 / 4}$ These results clearly show that the knowledge produced in the US and flowing back to Europe is related to fields of host state specialisation.

\subsection{EMPIRICAL MODEL}

The main aim of the empirical analysis is to test whether firms located in the MNE home country benefit from the technological knowledge developed in foreign subsidiaries of their 'national champions'. The key to answering this research question is establishing whether home country firms show a learning advantage over firms located in other European countries, i.e. do they have a higher than average propensity to cite patents applied for by foreign subsidiaries of their own 'national champions'. I tested for the presence of this technology transfer process by carrying out a multivariate regression analysis. This analysis allowed me to consider the relationship between the citation rate and the country of origin of the citing firm, while controlling for other important variables, such as the technological proximity of the cited and citing firms, the technological specialisation of the citing firm's

\footnotetext{
This share is equal to $68 \%$ for the sample of eited patents granted to pharmaceutical MNEs and $61 \%$ for the sample of patents owned by chemical MNEs.
} 
country. and the citing firms international profile. For example, if I found many German patents citing patents applied for by a Bayer subsidiary in the US, before I could take this as evidence of inter-firm RTT. I would have to rule out a number of competing hypotheses. German firms may operate in similar technological areas to the Bayer subsidiary, and/or the cited patents may happen to be very important in that particular field. Alternatively, it could be the case that the citing firm was itself part of a multinational with business units in the US and that this was the actual conduit for the knowledge flow. Finally. Germany as a nation may be specialised in the technological field of the cited patent and therefore German firms would be the most likely firms to cite patents in this field, no matter where these patents came from. In other words. if the citation rate is linked to factors other than the embeddedness of the MNE in its home country, I would observe a higher citation rate by home country firms, without there being any true RTT.

Therefore to be able to control for the technological characteristics of the innovation activity of the cited subsidiary, I did not aggregate the data at the level of the firm and instead used the number of forward citations received by patents applied for by a particular subsidiary in a given year $t$ and class $n$ as the unit of analysis. The dependent variable - denoted by $C_{z m}-$ is thus the number of eitations made by firm (j) located in Europe to patents applied for by a US subsidiary $(i)$ at time $t$ and in technological class $n$, where $i$ is not a subsidiary of $j$ (i.e. I exclude intra-group citations). I identified cach cited firm $i$ as a pair of assignee name and state of the first inventor (for instance Bayer Corporation - NY state) and the citing firm $j$ as a pair of assignee name and country of the first inventor (for instance L'Oreal SA - France). ${ }^{95}$

Table 7.4 illustrates how the citation count variable is computed from the initial dataset of citation pairs. The sample reported in Table 7.4 shows how the dependent variable $C_{i t m}$ is calculated for a set of citations made by patents granted to three firms (firm A located in the UK, firm B operating in Germany, and firm $C$ based in Italy) to patents granted to two subsidiaries of Bayer, one in California and the other in New York. As can be seen in the lower part of the table, the result of this computation is a dataset with a combination of application year, technology class, cited subsidiary and citing firm in each row, allowing me to introduce other dependent variables with these dimensions. However, as shown in Figure

\footnotetext{
"In this way 1 should capture the patenting activity of a specific foreign subsidiary and control for the practice of assigning patents to the headquarters, even if developed in other locations. The information contained in the NBIER database on the address of the inventor was not useful in identifying the exact location of the cited US inventor (the ZIP code was missing for most patents in the sample). Similarly I should also be able to identify the patenting activity of a particular eiting firm. although not with the same degree of certainty because if an inventor has an address outside the US only the country of residence is provided.
} 
7.1, the result of maintaining this level of aggregation is that the citation count variable is in $76.6 \%$ of cases equal to one. I try to account of this very large number of 'ones' (and, of course, no zeros) in the count variable in the empirical estimation of the model.

Table 7.4 An example of how the citation count variable is derived

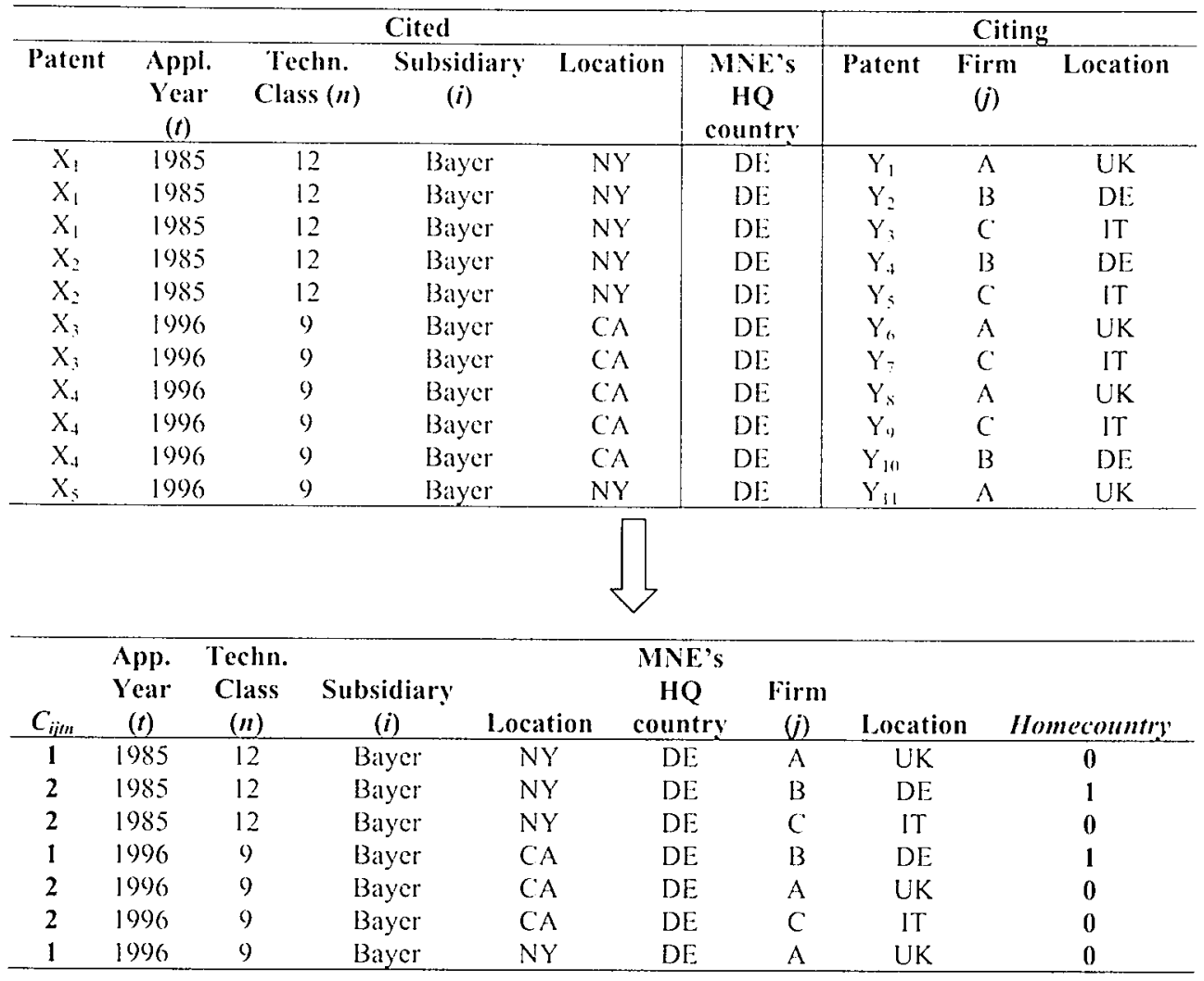

Since here I am analysing forward citations to a set of patents applied for between 1980-99 I need to correct for various factors that may change citation intensities over time and across sectors (Hall et al. 2001). As explained in Chapter 5, I need to correct for the truncation cffect or 'cohort effect': patents applied for in 1980 may receive more citations than patents applied for in 1995. simply because of the longer citation history. In addition, the increasing trend observed in the USPTO data in both patent applications and the average number of citations received by patents may introduce another potential bias. And finally the number of citations a particular patent receives may vary across technology classes. In order to control for the 
variability arising from year and techmology class fixed effects I introduced year and technology dummies in the regression."

Figure 7.1 Frequency table of the citation count variable $\left(C_{i j m}\right)$

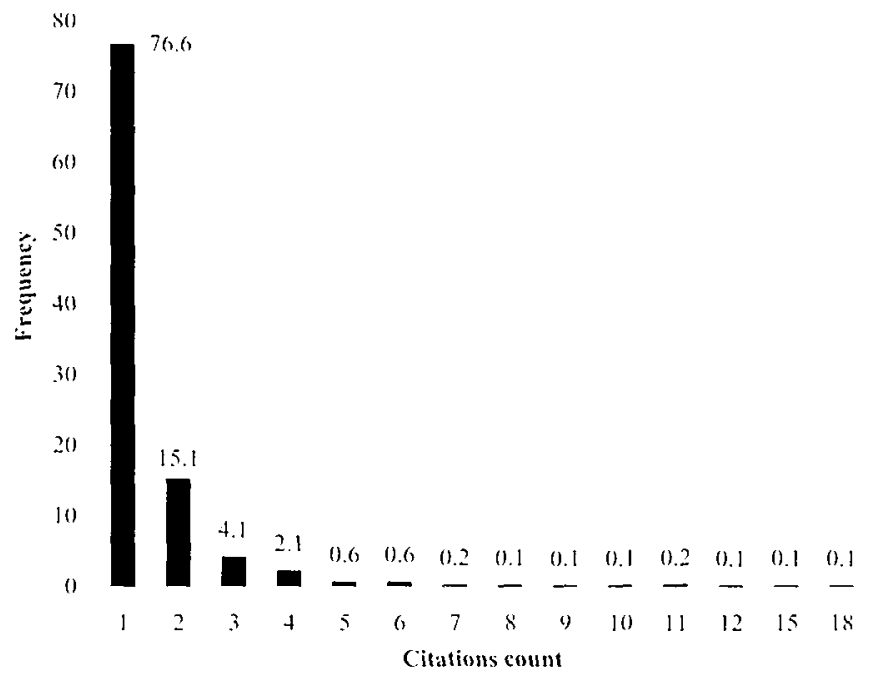

I regressed the dependent variable on a number of control variables to take account of the factors discussed above:

$C_{i m n}=\beta_{0}+\beta_{1}$ Homecounmy $+\beta_{2} T Y P E_{1}+\beta_{3} \ln \left(P_{i l}\right)+\beta_{4} \ln \left(P_{n}\right)+\beta_{5} P R O X_{i}+$ $\beta_{t} S O P H_{n}+\beta_{7} R T A_{n}+$ year dummies + tech. class dummies + citing country dummies

Homecounmy is a dummy variable that takes the value of 1 if the citing patent assigned to firm $j$ originates from the home country of the cited subsidiary. Table 7.4 illustrates how this variable was computed for a set of citation pairs. A positive and statistically significant coefficient indicates that the citation rate to US subsidiaries' patents is higher for firms located in the same country as the headquarters of the multinational cited. This dummy variable is supposed to pick up inter-firm RTT.

\footnotetext{
"The technological class $n$ corresponds to one of the 36 two-digit technological calegories in the NBER dataset. I adopted this technological classification because the 3-digit patent class would have implied too many technological dummies and not enough degree of freedom in the regression.
} 
$T Y P E_{i}$ stands for a set of dummy variables that identify the threc groups of citing firms located in Europe listed in the previous section: subsidiaries of European multinationals (EUMNE), subsidiaries of US multinationals (USMNE), and domestic firms and institutions $(E U)$. In the empirical analysis I also investigated the relationship between the citation rate and the multinational nature of the citing firm, introducing a dummy variable ( $M N E$ ) which is 1 if the citing firm is a European or American multinational and zero if it is a domestic company. Finally I reclassified the firm as being a multinational only if it has a patent originating from an US location and introduced a dummy variable (USR\&D) that takes the value of 1 if this condition is verified. ${ }^{47}$ This set of variables is designed to control for other channels through which technology transfer may have occurred. At the same time they allowed me to investigate whether domestic firms in the home country can benefit from this reverse knowledge transfer process to the same extent as multinational companies.

$\ln \left(P_{i f}\right)$ denotes the logarithm of the number of patents granted to the cited firm $i$ in the application year $t$. This represents the number of potentially cited patents. $\ln \left(P_{j l}\right)$ is the logarithm of the number of patents granted to the citing firm $j$ between year $t$ and the final year of the sample (1999). This variable defines the number of potential citing patents. ${ }^{98}$ Citations between two firms depend on their patent activities and therefore I expect a positive sign on the coefficients of both of these variables.

$P R O X_{i j}$ is a technology distance measure between the cited firm $i$ and the citing firm $j$ which is given by the degree of similarity in their patent portfolio, as in Jaffe (1986). More precisely, the distance in the technology space between two firms, $i$ and $j$, can be approximated by the un-centred correlation coefficient of the vectors, $F_{i}$ and $F_{j}$, of patent counts in each of the 36 technology classes over the entire sample period:

$$
\operatorname{PROX}_{i j}=\frac{F_{i} F_{j}^{\prime}}{\sqrt{\left(F_{i} F_{i}\right)\left(F_{i} F_{j}\right)}} .
$$

This proximity measure is bounded between 0 and 1 and is closer to unity the greater is the degree of overlap in the firms' research interests. I introduce this variable to control for the

\footnotetext{
"It may not be enough for a multinational to have a presence in the United States in order to get a leaming advantage: it may need to patent there too.

"Strictly speaking, the number of potentially citing patents should be equal to the number of patents applied for by the citing firm starting from the groming year of the cited patents. since in the USPTO patents are publicly available only once they have been granted. Considering that the average lag in the sample between application and granting year is less than 2 years. my variable can be considered to be a good approximation.
} 
fact that firms operating in similar activities have a higher probability of citing each others' patents and I would expect it to be positively related to the citation rate.

SOPH $H_{t}$ measures the distance of the cited firm's innovative activity from the technological frontier and is equal to the average across the 36 technological classes of the ratio of the forward citations received by the cited firm's patents to the number of forward citations received by the average patent in that class (MacGarvie 2002):

$$
S O P H_{u}=\frac{1}{N_{i t}} \sum_{n=1}^{n} \frac{\overline{c_{m t}}}{\overline{c_{m t}}},
$$

where $N_{i t}$ is the number of technological classes in which the cited firm has patented in year $t$, $\overline{c_{i n}}$ is the average number of forward citations received by patents applied for by firm $i$ in year $t$ in class $n, \overline{c_{n t}}$ is the average number of forward citations received by patents in class $n$ in year $t$. This variable is supposed to account for the importance and value of patents granted to the cited firm relative to the overall average, correcting for the differences in citation frequencies across technological classes. A value of $S O P H_{i t}$ greater than 1 suggests that the firm is a technological leader, and a value less than 1 suggests the firm is a technological follower. A priori, I had not specific expectations about the sign of this coefficient. On the one hand. one would expect a greater number of citations to patents of firms doing cutting-edge innovation, but on the other hand the lack of technological congruence between the activity of the citing firm and the eited firm may negatively affect the citation frequency.

$R T A_{n}$ is a dummy variable equalling 1 if the standardised RTA index ${ }^{(9)}$ of the country of residence of the citing inventor is positive for the technological class of the cited patent. and 0 otherwise. This variable controls for the technological specialisation of the country in which the citing firm is located and thus is a proxy for the citing country's absorptive capacity. I expected a positive coefficient for this dummy variable. This variable is crucial in identifying RTT since if Homecountry remains significant and positive when RTA is included, then this confirms that this effect exists over and above any inherent technological capabilitics of the home country.

Finally I included year and technology dummies for each of the 36 classes to control for year and technology class fixed effects, and country dummies for each country where a citing

\footnotetext{
w) The standardised RTA index is equal to: (RTA-1)/(RTA +1$)$
} 
patent originates to control for unobserved country specific fixed effects. Summary statistics of the data used to estimate the model are given in Table 7.5. and Table A7-2 in the appendix presents the correlation matrix. There are several important aspects to Table 7.5. First, the dependent variable is truncated alt zero, because I have data only on European firms that cite at least once patent granted to a US subsidiary in the sample. Second. the mean of the citation count is almost equal to the variance. Third, on average the patent portfolio of the citing firm is fairly dissimilar to that of the cited subsidiary, which is in line with the evidence reported in the previous section showing that the knowledge cited by European firms is not in areas on which they themselves focus on. Fouth. foreign subsidiaries eited by European firms secm to be quite involved in cutting-edge research: on average the $S O P H_{i t}$ variable is greater than 1. This is consistent with the finding that the patents eited have a high value (see Table 7.3).

Table 7.5 Summary statistics

\begin{tabular}{lcccc}
\hline Variable & Mean & $\begin{array}{c}\text { Standard } \\
\text { Deviation }\end{array}$ & Max & Min \\
\hline$C_{\text {iim }}$ & 1.435 & 1.215 & 18 & 1 \\
Homecounty & 0.245 & 0.430 & 1 & 0 \\
$\ln P_{\text {it }}$ & 2.428 & 1.357 & 5.142 & 0 \\
$\operatorname{In} P_{i t}$ & 8.336 & 1.649 & 10.951 & 0 \\
PROAij & 0.394 & 0.330 & 1 & 0 \\
SOPH & 1.563 & 1.507 & 0.086 & 32.480 \\
MNE & 0.895 & 0.307 & 1 & 0 \\
USMNE & 0.147 & 0.354 & 1 & 0 \\
EUMNE & 0.748 & 0.434 & 1 & 0 \\
EU & 0.105 & 0.307 & 1 & 0 \\
USRCD & 0.675 & 0.469 & 1 & 0 \\
RTA & 0.763 & 0.425 & 1 & 0 \\
\hline
\end{tabular}

To summarise, the Homecounty variable captures the RTT process and the other explanatory variables control for different factors that are likely to affect the citation rate between two firms, not only at the level of the firm $\left(P_{i t}, P_{i t}, P R O X_{i j} . T Y P E_{j}, S O P H_{i t}\right)$, but also at the level of the country of residence of the citing inventor $\left(R T A_{n}\right)$.

I estimated the model presented in equation (1). pooling all citations over all years in the period. In theory I could have estimated the model using panel data, regression techniques, but the panel would have been very unbalanced because most subsidiaries' patents in particular technologies receive no citations from European firms in any given year.

The discrete nature of my dependent variable requires a count data model to estimate equation (1). In addition I had to account for the fact that my data were truncated at zero, because I 
only observe citations greater or equal to one, as can be seen from Figure 7.1. Given that the mean of the citation count variable is only 1.435, truncation may have an important effect on the estimates and the goodness of fit of my model. I therefore specified a Poisson regression to model the probability of citations between a foreign subsidiary. $i$, and a European firm. $j$ (a more detailed and technical explanation of count data models is provided in the appendix). The idea behind the model is that a European firm $j$ learns about the innovative activities of the US subsidiary $i$ in a particular technology class $n$ at a rate $i_{j i m}$ per year. $C_{i j m}$ a a proxy for the inter-firm knowledge flows that influence the innovative activity of firm $i$, comes from a Poisson distribution with intensity $\lambda_{i j m}$. Thus the arrival rate of patent citations depends on the explanatory variables, $x$, through the functional form:

$E\left(C_{i j m} \mid i_{i j m}\right)=i_{i j m}=\exp \left(\beta x_{i j m}\right)$

\subsection{ECONOMETRICS RESULTS}

Column (1) in Table 7.6 presents the estimation results of the truncated Poisson model. To reduce the number of estimates to be reported, I only presented the results of the model using the $M N E$ dummy variable to capture the international profile of the citing firm. No important differences were found in the estimates of the coefficients using the other dummy variables to control for this characteristic of the citing firm. Also, to increase the readability of this and the following tables, the coefficients on the year, country and technology dummy variables were not reported. To control for the likely correlation of the citation behaviour of firms located in the same country I corrected standard errors for heteroskedasticity by clustering on citing countries. ${ }^{100}$

The coefficient of the home country variable is positive and significant, which scems to confirm the hypothesis of a RTT process. Firms located in the home country show a higher propensity to cite patents developed by US subsidiaries of their national 'champions'. The role of multinational companies in cross-border technology transfer appears to be significant after controlling for the technological characteristics of the cited patent, the firms and the country where the citing firms is located. However, as shown in Figure 7.2, the comparison of

\footnotetext{
${ }^{l(k)}$ Usually robust standard errors are calculated using the White-Huber estimator of the variance, which is equal to $\hat{v}=\hat{V}\left(\sum_{j=1}^{N} u_{j} u_{j}\right) \hat{V}$ where $\left.\hat{l}=(-\partial)^{2} \ln L / \partial \beta^{2}\right)^{-1}$ is the conventional estimator of the variance and $u_{i}$ is the contribution from the $j$ th observation to the scores $\partial \ln L / \partial \beta$. This estimator assumes that the observations are independent. while the robust cluster estimation of the variance requires only that the observations are independent across clusters. i.c. that the observations may be correlated within the clusters. (I am grateful to John $V$ an Reneen for suggesting this heteroskedasticity structure to me.)
} 
fitted probabilities with actual frequencies shows that the truncated Poisson has a tendency to under-predict the number of one counts and over-predicts the other outcomes. Therefore the truncated Poisson is inadequate due to its inability to model the relatively high number of ones in the sample.

One way of dealing with the large number of ones is to reseale the citation count variable ( $Z_{i j m}$ $\left.=C_{i j m}-1\right)$ and estimate equation (1) using either a standard version of the count data model (Poisson or Negative Binomial) or the Zero Inflated Poisson (ZIP) or Negative Binomial (ZINB) model. This class of models allows for additional over-dispersion via a splitting process that models the probability of a zero outcome by logistic regression, while the continuous count outcome is modelled using a Poisson or negative binomial distribution (see the appendix for an explanation of these models). The transformed citation count variable $\left(Z_{i j m}\right)$ presents quite significant evidence of over-dispersion (the standard deviation, 1.215, is almost three times the mean 0.435 ). The source of over-dispersion in the data may be either the extreme values on the right of the distribution of the citation count variable (see Figure 7.1) or the very large number of zeros. If the former were the cause for the over-dispersion then a negative binomial model would be appropriate to describe the data, but if the latter were the source of over-dispersion then a ZIP or ZINB would be more appropriate.

Figure 7.2 Histogram of the predictions of the truncated Poisson model

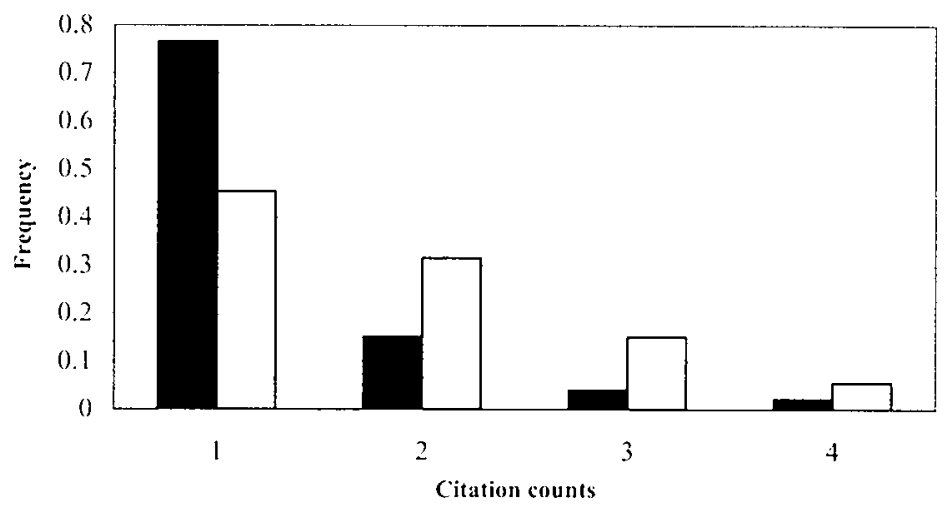

Observed counts $\square$ Predicted values

I therefore estimated equation (1) using these count data models. Results from the Poisson model and the Negative Binomial models are reported in columns (2) and (3) of Table 7.6 respectively, while column (4) shows the estimates of the ZIP. The ZINB model could not be 
estimated because the maximisation of the log-likelihood function did not converge. The Poisson and the negative binomial yield substantially similar estimates and robust standard errors for the main parameter of interest. while the estimates and, above all, the standard errors from the ZIP model are considerably different. The results of various tests for overdispersion ${ }^{101}$ suggest that the Poisson is not appropriate for the data. This is confirmed by the results of the Vuong (1989) statisties $(b)$ which is a test for non-nested models used to discriminate between a zero-inflated and a regular Poisson or negative binomial model. A large positive value of $Y$ favours the zero-inflated version, while the test supports neither model over the other (e.g.. ZIP w. Poisson) if $|V|<1.96$. The value of this statistic for the ZIP model is $V=6.77$ which implies that the ZIP model fits better than the Poisson model.

Another way to assess which model is more appropriate for the data is to examine how well they predict the share of zero outcomes. In this case, too, the Poisson model performed worst with only $67.0 \%$ of zeros predicted (recall that the observed proportion of $z$ cros was $76.6 \%$ ) while the ZIP $(76.5 \%)$ and negative binomial $(76.9 \%)$ predictions are very close to the observed counts. Thus the negative binomial and the ZIP have a better fit for zero observations than the Poisson. However, if one compares the predictions of outcomes different from zero, the negative binomial predictions appear to outperform the ZIP predictions (sec Figure 7.3). The ZIP model under-predicts outcome 1 and over-predicts the tail. Thus the negative binomial appears to describe the data more adequately.

The coefficient on the Homecoumery variable estimated with the negative binomial is only significant at the $20 \%$ level. Thus, the estimates for the overall sample do not appear to support strongly the existence of a RTT process, i.e. firms in the home country of the cited multinational do not seem to cite the US-invented patents of their 'national' champions more often than other European firms. Rather the main determinants of the citation frequency are that the citing firm is a multinational with a subsidiary in the US and the citing and cited firms are technologically proximate.

\footnotetext{
${ }^{101}$ Both $\alpha$ and $\beta$ respectively in equation (a5) and (a6) in the appendix are significantly different from zero at the $1 \%$ level. indicating that the Poisson model is not appropriate for the data and that the negative binomial model should be estimated. The presence of over-dispersion is contirmed by the LR test for $\alpha=0$ ) (presemed in the appendix). This statistic is equal to $\chi^{2}(1)=903.86$. which corresponds to a $p$-value of 0.00 .
} 
Table 7.6 Estimates from the citation count model

\begin{tabular}{|c|c|c|c|c|}
\hline & $\begin{array}{l}\text { Truncated } \\
\text { Poisson } \\
\text { (1) }\end{array}$ & $\begin{array}{c}\text { Poisson } \\
(2) \\
\end{array}$ & $\begin{array}{l}\text { Negative } \\
\text { Binomial } \\
\text { (3) }\end{array}$ & $\begin{array}{l}Z P^{: 1} \\
(4)\end{array}$ \\
\hline Variable Name & $C_{i j m}$ & $Z_{i j n}$ & $Z_{i j m}$ & $Z_{i j m}$ \\
\hline Homecount? & $\begin{array}{l}0.268 \\
(1.71)^{\circ}\end{array}$ & $\begin{array}{l}0.305 \\
(1.69)^{\circ}\end{array}$ & $\begin{array}{l}0.202 \\
(1.36)\end{array}$ & $\begin{array}{l}0.268 \\
(1.17)\end{array}$ \\
\hline MNE & $\begin{array}{c}0.672 \\
(4.55)^{\cdots}\end{array}$ & $\begin{array}{c}0.740 \\
(4.64)^{\cdots}\end{array}$ & $\begin{array}{c}0.672 \\
(4.11)^{\cdots}\end{array}$ & $\begin{array}{l}1.056 \\
(2.20)^{\circ}\end{array}$ \\
\hline $\ln P_{11}$ & $\begin{array}{c}0.158 \\
(3.29)^{\cdots}\end{array}$ & $\begin{array}{c}0.177 \\
(3.24)^{\cdots}\end{array}$ & $\begin{array}{c}0.176 \\
(5.19)^{\cdots}\end{array}$ & $\begin{array}{l}0.075 \\
(0.94)\end{array}$ \\
\hline $\ln P_{n}$ & $\begin{array}{c}0.108 \\
(2.84)^{\cdots}\end{array}$ & $\begin{array}{c}0.121 \\
(2.84)^{\cdots}\end{array}$ & $\begin{array}{c}0.154 \\
(3.50)^{\cdots}\end{array}$ & $\begin{array}{l}0.114 \\
(0.95)\end{array}$ \\
\hline$S O P H_{t}$ & $\begin{array}{c}0.087 \\
(4.71) \cdots\end{array}$ & $\begin{array}{c}0.101 \\
(4.57) \cdots\end{array}$ & $\begin{array}{c}0.149 \\
(3.59)^{\cdots}\end{array}$ & $\begin{array}{c}0.02 \\
(0.59)\end{array}$ \\
\hline$P R O X_{i \prime}$ & $\begin{array}{c}0.518 \\
(9.50)^{\cdots}\end{array}$ & $\begin{array}{c}0.585 \\
(9.34)^{\cdots}\end{array}$ & $\begin{array}{c}0.586 \\
(8.47)^{\cdots}\end{array}$ & $\begin{array}{c}0.527 \\
(3.85)^{\cdots}\end{array}$ \\
\hline$R T A_{n}$ & $\begin{array}{c}0.392 \\
(2.84)^{\cdots}\end{array}$ & $\begin{array}{c}0.438 \\
(2.82) \cdots\end{array}$ & $\begin{array}{c}0.408 \\
(2.52)^{\circ}\end{array}$ & $\begin{array}{c}0.344 \\
(2.42)^{\circ}\end{array}$ \\
\hline Constant & $\begin{array}{c}-2.591 \\
(6.00)^{\cdots}\end{array}$ & $\begin{array}{r}-3.441 \\
(7.18)^{\cdots} \\
\end{array}$ & $\begin{array}{c}-3.683 \\
(7.12)^{\cdots}\end{array}$ & $\begin{array}{r}-2.26 \\
(1.80)^{\circ}\end{array}$ \\
\hline Observations & 2891 & 2891 & 2891 & 2891 \\
\hline $\begin{array}{l}\text { Log-likclihood } \\
L R \chi^{2}\end{array}$ & $\begin{array}{l}-2636.80 \\
435.60\end{array}$ & $\begin{array}{l}-2768.67 \\
485.43 \cdots\end{array}$ & $\begin{array}{l}-2314.73 \\
198.27^{\cdots}\end{array}$ & $\begin{array}{l}-2465.01 \\
233.16^{\cdots}\end{array}$ \\
\hline$\alpha$ & & & 2.700 & \\
\hline \multicolumn{5}{|c|}{$\begin{array}{l}\text { Robust t-statistics in brackets, crrors clustered on citing countries } \\
\text { significant at } 20 \% ; \text { significant at } 10 \%:{ }^{\circ} \text { significant at } 5 \%: \cdots \text { significant at } 1 \% \\
\text { "Year, technology ficld and country dummies are not included in the Logit part of the Zero- } \\
\text { Inflated Poisson because inclusion resulted in non-concave likelihood. }\end{array}$} \\
\hline
\end{tabular}

This model assumes that the effect of the explanatory variables is the same across the two sectors. However if chemical and pharmaceutical MNEs differ in their innovative activities, their patents may be more or less likely to be cited by European firms. It is possible, for example, that the extent of asset augmenting R\&D and home-country embeddedness may vary between the two. If inter-firm RTT is more likely to occur when foreign subsidiaries are engaged in asset-augmenting activities, it is crucial that the home country laboratory retains a dominant role in the production of new knowledge and that the R\&D activities are strongly rooted in the national innovation system. 
Figure 7.3 Histogram of models' predictions

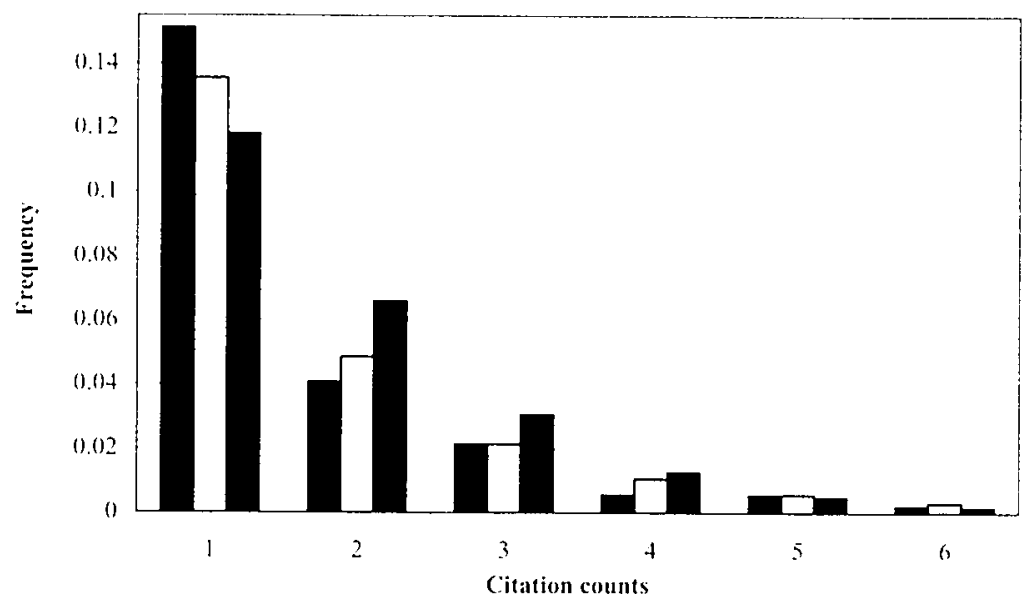

Observed counts $\square$ Negative Jinomial predicted values $\mathbf{Z}$ ZIP predicted valtes

The results reported in Chapter 5 indicate that both chemical and pharmaceutical European MNEs are involved to the same extent in asset-augmenting and asset-exploiting R\&D activities in the US, mainly because both groups of firms appear to focus on biotechnology, as shown in section 7.3.1, and in Chapter 6 with reference to pharmaceutical MNEs. This suggests that the differences between the two sectors should not be significant in terms of their involvement in asset-augmenting R\&D activities. Interview data discussed in Chapter 6 clearly show the high degree of R\&D internationalisation of pharmaceutical companies and the emergence of a multi-hub R\&D network where the home country has lost the dominant role in the innovation process. As shown by other studies (Owen-Smith and Powell 2002). recent trends in the pharmaceutical sector seem to suggest that the number of collaborations with physically distant partners is increasing as firms attempt to access cutting-edge technologies. They may not therefore draw as extensively as before on domestic sources of technological knowledge. Chemical companies instead, as reported by the studies of von Zedtwitz and Gassmann $(1999,2002)$ and Chiesa (1996b), tend to adopt an R\&D-hub model where the home country laboratory is the most important R\&D unit for all research and advanced development activities. As pointed out by Chiesa, in chemical companies the implementation of an international division of R\&D labour is made difficult because different phases of the research process cannot be divided and carried out in geographically dispersed units. As a result chemical companies may be more embedded in their national innovation system than pharmaceutical companies. Furthermore, ineffective intra-firm RTT in an 
integrated R\&D network may hinder the potential benefit for home country firms of foreign R\&D activities by pharmaceutical MNEs. As shown in chapter 6 , geographical, organisational and technological distance represents significant barriers to internal knowledge transfer in these companies.

I explored this hypothesis by estimating equation (1) separately for the sample of cited patents granted to pharmaceutical MNEs and for the sample of chemical MNEs. The results are reported in columns $I p$ and $1 \mathrm{c}$, respectively, of Table 7.7 . I also tested the validity of the restrictions of the model in column (3) in Table 7.6 using a likelihood ratio test. This test rejects the validity of the restricted model relative to the unrestricted models of columns ( $1 p$ ) and (1c). ${ }^{102}$ The other columns of Table 7.7 report the individual estimates for the two samples.

A comparison of the results in columns ( $1 p$ ) and (lc) suggests that the results for the overall sample are driven by the chemicals sector and that inter-firm RTT is a phenomenon stemming mainly from the activity of US subsidiaries of chemical companies rather than the US units of pharmaceutical companies. The estimated coefficient on the Homecountry variable for the sample of cited patents owned by chemical companies is positive and statistically significant and whether the citing firm operates intcrnationally cannot by itself explain the citation pattern. This reinfores the findings in favour of the role of chemical MNEs in the crossborder transfer of technology, since it seems that the hypothesis that the citing firm would have acquired the citing knowledge from its presence in the US can be discarded. In column (lc) the technological specialisation of the country where the citing firm is located $\left(R T A_{n}\right)$ has a large and significantly positive impact on the citation frequency, which supports the idea that absorptive capacity, i.c. prior knowledge, is crucial in the technology transfer process. This result holds only partially for the sample of pharmaceutical patents: the coefficient of $R T A_{n}$ is positive but significant at the $20 \%$ level. In both columns ( $1 \mathrm{p}$ ) and ( $1 \mathrm{c}$ ) the coefficient on the technological proximity variable $\left(P R O X_{i j}\right)$ is also statistically significant, suggesting that firms with a similar technological portfolio are more likely to cite each other. The coefficient on the potentially-citing patents variable is significant in both columns, whereas the coefficient on the potentially-cited patents is only significant for the sample of chemical patents, confirming in part that citations occur when both firms are patenting. Finally the

\footnotetext{
102 The likelihood ratio test is calculated as -2 times the difference between the fitted log-likelihood of the restricted model and the sum of the fitted log-likelihoods of the unrestricted models. This statistic is equal to 90.72 . corresponding to a $p$-value of 0.00 for the $\chi^{2}(49)$ distribution; thus the restricted model is rejected.
} 
technological sophistication $\left(S O P H_{i t}\right)$ of the cited firm is positive and significant indicating that European firms exploit the knowledge developed by foreign subsidiaries that perform cutting-edge research.

Columns $(2 p)$ to $(4 p)$ and $(2 c)$ to $(4 c)$ of Table 7.7 check the robustness of these results. Columns (2p) and (2c) measure the international profile of the citing firm by an R\&D presence in the US (US R\&D), rather than simply through a subsidiary presence ( $M N E$ ) as in columns ( $1 p$ ) and (1c). In column (2p) the coefficient on the US R\&D dummy is significant at the $1 \%$ level, while in column (lp) the coefficient on MNE is only significant at the $20 \%$ level. This may suggest that in this sector reverse knowledge flows are not significantly correlated with where the eiting firm is located and whether it has subsidiaries in the US. but rather with whether it has a US R\&D unit. The magnitude and the significance of the Homecountm remain virtually unchanged. The robustness of this result is also confirmed in columns $(3 p)$ and $(3 \mathrm{c})$ where the distinction is made between European and US citing multinationals (EU MNE, US MNE). Thus for the sample of eited patents owned by chemical MNEs the Homecount? variable is always significant and neither the international operation of the citing firm, whether it be through a technologically active site in the US or simply through a subsidiary presence. nor the nationality of the parent company can on its own explain the citation pattern. In columns (4p) and (4c) I estimate a model with dummies for each of the MNEs whose patents were cited. ${ }^{103}$ This should account for unobserved firmspecific characteristics that explain the citation patterns; for example MNEs may differ in their degree of home-country embeddedness or on the type of linkages they have with other agents and institutions in their home country. The inclusion of firm fixed effects reduces the coefficient and decreases the significance level of the Homecountry variable, leaving the sign and the statistical significance of the other explanatory variables unchanged. This suggests that the observed citation pattern is in part explained by unobserved MNE characteristics, which were earlier captured by the Homecountry variable.

Finally the specifications in columns $(5 p)-(5 c)$ and $(6 p)-(6 c)$ address the rescarch question of who benefits from this technology transfer. In columns (5p) and (5c) I included an interaction term between the Homeconmty and the $E U$ dummies to capture the effect of being a domestic

\footnotetext{
111: I did try to include dummy variables for each of the cited subsidiaries. but this resulted in a non-concave loglikelihood function. A similar problem emerged when l tried to estimate the model with dummy variables for each of the citing firms or citing firm-cited subsidiary combinations.
} 
company in the home country of the cited MNE. ${ }^{104}$ For the sample of eited patents granted to pharmaceutical companies, this interaction term is negative and not statistically significant, while the coefficient on the MNE is positive and significant at the $10 \%$ level. This result suggests that non-multinational firms and institutions do not benefit from the RTT process generated by US subsidiaries of pharmaceutical MNEs. For the chemical sample, the interation $1 \mathrm{~cm}$ and the coefficient on the $M N E$ dummy are positive and highly significant. This supports my a priori expectations of sectoral differences in the way MNEs operate and innovate in their home countries. I investigated this issue further using only the sample of citations made by multinational companies (columns (6p) and (6c)). These estimates confirm what 1 found in the previous specifications. For the sample of chemical patents Homecoum ry is positive and significant implying that MNEs in the home country show a lcarning advantage relative to other MNEs not operating in the country of origin of the cited subsidiary. In contrast MNEs in the home country do not appear to benefit from the US R\&D activities of their co-national pharmaceutical MNEs.

104 To lest whether domestic companies in the home country are accessing the knowledge produced abroad by their national champions a regression using only the citations made by these types of firms would be needed. However due to the small number of observations in this sample the model does not converge. 


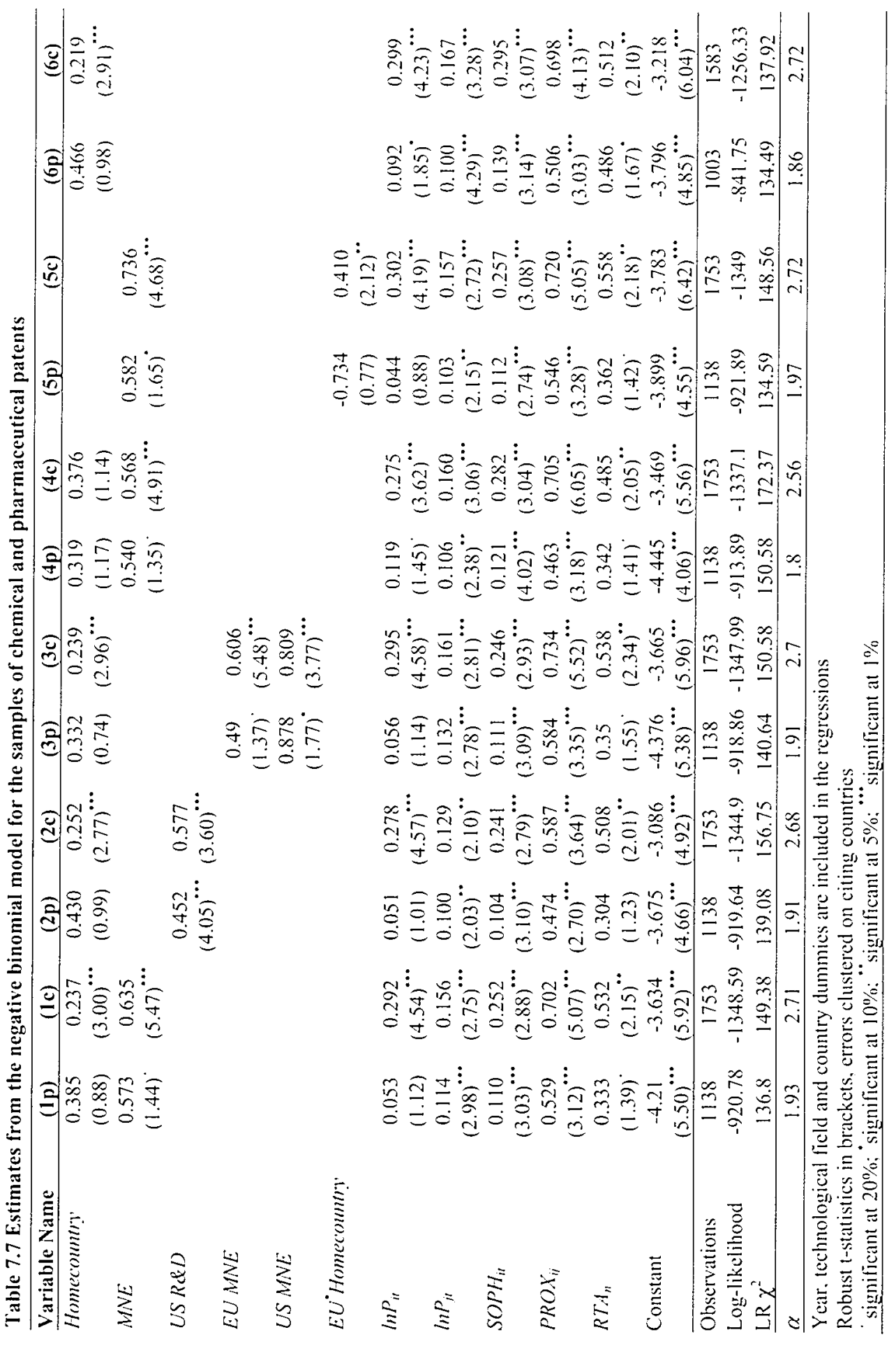




\subsection{Conclusion}

This chapter described the test for the existence of inter-firm RTT. i.e. the existence of a technological knowledge flow from foreign R\&D facilities of a multinational company to home country firms. This implies that there is a feedback effect from outward R\&D investment: subsidiaries abroad first internalise localised technologies then transfer them back to the MNE's operations in the home country and over time this body of knowledge becomes available to other home country firms. I argued in Chapter 3 that this process would be mainly confined to those (high-tech) sectors where there is an important component of assetaugmenting R\&D activity and that the strong embeddedness of MNEs in their home countries would allow the spillover potential from the parent company to other actors in the home country to be realised.

I tested for the existence of this technology transfer process using patent ciation analysis as an indicator of technological knowledge flows from US subsidiaries of pharmaceutical and chemical European MNEs to firms located in Europe. In order to test for the role of MNEs in the international transfer of knowledge, I introduced a variable, Homecountry, which in a very crude way takes account of the MNE's embeddedness in its home country, distinguishing between citing firms in the home country and other firms. ${ }^{105}$ Having controlled for the intemational profile of the citing firm, the importance of the cited patent, the patenting activity of the citing and cited firm, the technological specialisation of the citing country, I found statistically significant differences between the samples of cited patents granted to chemical and pharmaceutical MNEs. In the chemical sector home-country firms tend to cite US-invented patents more often than other European firms do. In the pharmaceutical sector home-country firms do not show this learning advantage with respect to firms located in other countries. Furthermore, for the chemical sector this result applies not only to citing firms with an international engagement, but also for domestic firms and institutions. However these results are not fully robust to the inclusion of firm-specific fixed effects.

A possible explanation for these different sectoral patterns may be the different degree of home country embeddedness of the R\&D activities of chemical firms compared to pharmaceutical firms. Although the asset-augmenting component of US R\&D activities of

\footnotetext{
105 An ideal measure of embeddedness would take into account the development and the strength of the reciprocal linkages between MNEs' business units and home country suppliers. customers and public research institutes. These linkages may also cut across geographical borders particularly when companies originate in small countries.
} 
both chemical and pharmaceutical MNEs in the US is as strong as the asset-exploiting component (as shown in (hapter 5), the R\&D activities of pharmaceutical firms are more internationalised than those of their chemical counterparts, as evidenced by the percentage of patents invented in the US and also by the number of collaborations with physically distant partners (Owen-Smith and Powell 2002). These different patterns of R\&D internationalisation are also reflected in the emergence of the different R\&D organisation structures adopted by these two groups of firms. As discussed in Chapter 6, pharmaceutical MNEs have adopted a multi-hub R\&D structure where forcign units are as important as home-country units in the generation of new innovations. In contrast, in chemical MNEs, the home country laboratory still retains a dominant role in the performance of R\&D. Thus for inter-firm RTT to take place it is not only important that foreign R\&D units carry out asset-augmenting activities, but that the MNE innovative efforts continue to be rooted in the home country.

An important implication of these results is that the increasing trend in the transfer of R\&D activities may not be completely detrimental to the home country knowledge base. The relocation of research activities to centres of excellence can have a positive fecd back effect if MNEs' innovative activities are strongly rooted in their home-country innovation system. Policy makers have tended so far to encourage domestic multinationals to maintain their R\&D activity at home and have disapproved of the re-allocation of this investment to foreign countries, ignoring the possibility of RTT. My findings offer an alternative understanding of foreign direct R\&D investment and its implications, both for the home country's technological activity and for its competitive performance in general. National policies on international technology transfer have so far disregarded the role that MNEs might play in this process.

As was pointed out in the description of the citation data, only a small proportion of citations to patents applied for by US subsidiaries in the sample come from patents originating in Europe. I would not therefore claim that inter-firm technology transfer is the principal source of technology transfer. However given the increasing trend in the asset-augmenting nature of foreign R\&D activities, the role of MNEs in the transfer of knowledge back to the home country may acquire a significant dimension, especially at the carly stages of emerging technologies when knowledge is 'sticky' and tacit. 


\section{APPENDIX}

\section{Count Data Model Framework}

\section{Poisson Model}

The Poisson regression model is the basic model used to analyse count data ( seminal studies on the estimation of count data models are Hausman et al. 1984, and Cameron and Trivedi 1986. For a survey of recent developments see Winkelmann and Zimmermann 1995). This model postulates that a response variable $y_{i}$ denoting the $i^{\text {th }}$ observation of a non-negative discrete random variable $Y$, is Poisson distributed with density function:

$$
\operatorname{Pr}\left(Y=y_{i}\right)=f\left(y_{i} \mid \lambda_{i}\right)=\frac{e^{-\lambda} \lambda_{i}^{y_{i}}}{y_{i} !} \quad, y_{i}=0,1,2, \ldots
$$

and mean parameter:

$$
\lambda_{i}=\exp \left(\beta^{\prime} x_{i}\right)=e^{\beta_{i}+\beta_{2} x_{i}+\ldots+\beta_{i} x_{i}}
$$

where $\operatorname{Pr}\left(Y=y_{i}\right)$ is the probability of $y$ occurring for sample observation $i, \lambda$ is the Poisson parameter distribution, $x$ is the vector of explanatory variables, and $\beta$ a parameter vector. The parameters can be estimated using a maximum likelihood estimator.

However the Poisson model has the unattractive feature that the conditional mean and variance are equal. This makes it an inappropriate model when there is over-dispersion, i.e. when the conditional variance is greater than the conditional mean. If there is over-dispersion, estimates of the Poisson model are inefficient with standard errors biased downwards (Cameron and Trivedi 1986). Accordingly it is important to test for over-dispersion following one of the procedures illustrated below.

\section{Negative Binomial Model}

The negative binomial model generalises the Poisson model by allowing for unobserved heterogencity and over-dispersion. It can be specified by introducing a random component in the specification of the arrival rate $\lambda_{i}$ to account for an additional source of variance. Let $v_{i}$ be an error term in equation 2 , and write $\tilde{\lambda}_{i}$ instead of $\lambda_{i}$ since it is now random: 
$\tilde{\lambda}_{i}=\exp \left(\beta^{\prime} x_{i}+v_{i}\right)=\exp \left(\beta^{\prime} x_{i}\right) \exp \left(v_{i}\right)$

where $v_{i}$ captures unobserved heterogencity and is uncorrelated with the explanatory variables.

It can be shown that if $v_{i} \sim$ Gamma $(\alpha, \alpha)$ then a closed form negative binomial model can be specified. The conditional mean and variance of the negative binomial model are calculated as

$E\left(y_{i} \mid x_{i}\right)=\lambda_{i}$ and $\operatorname{Var}\left(y_{i} \mid x_{i}\right)=\lambda_{i}+\alpha_{i} \lambda_{i}^{p}$

The parameter $\alpha$ represents the over-dispersion parameter and the constant $p$ determines the form of over-dispersion and usually takes the value of one or two. Accordingly the negative binomial model is labelled NBI or NB2 in Cameron and Trivedi's (1986) terminology. Since both models are equal to the Poisson model if the over-dispersion parameter, $\alpha$, is zero, one can assess the adequacy of the negative binomial over the Poisson model testing the hypothesis that $\alpha=0$ against the hypothesis that $\alpha \neq 0$ using a likelihood ratio (LR) test. The LR test uses -2 times the difference between the fitted log-likelihood of the two models. A significant chi-square statistic suggests that the Poisson model is inappropriate and that there is evidence of over-dispersion.

\section{Over-dispersion Test}

Cameron and Trivedi (1990) propose another way to check for the presence of overdispersion. They suggest using a simple regression-based procedure for testing the null hypothesis of equi dispersion against the alternative of over-dispersion. After estimating $\lambda$ from the Poisson model, one can regress $z_{i}$ on $\hat{\lambda}_{i}$,

For NBl: $\Sigma_{i}=\alpha+\varepsilon_{i}$

For NB2: $z_{i}=\beta \hat{\lambda}_{i}+\varepsilon_{i}$,

where $z_{i}=\left\lfloor\left(y_{i}-\hat{\lambda}_{i}\right)^{2}-y_{i}\right\rfloor /\left(\hat{\lambda}_{i} \sqrt{2}\right)$

The test statistic for $\alpha$ and $\beta$ determines whether the Poisson model is appropriate for the data. 


\section{Truncated Poisson}

However if the dependent variable is truncated, Grogger and Carson (1991) show that coefficients estimates will be inconsistent. This problem can be removed by using a truncated count data model which is derived from the truncated models used for continuous data. The truncated-at-zero version of the Poisson model is obtained by rescaling the probabilities of strictly positive outcomes so that the density function is cqual to:

$\operatorname{Pr}\left(Y=y_{t}\right)=\left\{\begin{array}{cc}\frac{\operatorname{cxp}\left(-\lambda_{i}\right) \lambda_{i}}{y_{1} !\left(1-\exp \left(-\lambda_{t}\right)\right)} & y_{i}=1,2 \ldots \\ 0 & y_{i}=0\end{array}\right.$

and the new mean and variance are equal to:

$$
\begin{aligned}
& E\left(y_{i} \mid x_{i}, y_{i}>0\right)=\frac{\lambda_{i}}{1-\operatorname{cxp}\left(-\lambda_{i}\right)} \\
& V a r\left(y_{i} \mid x_{i}, y_{i}>0\right)=E\left(y_{i} \mid x_{i}, y_{i}>0\right)\left(1-\frac{\lambda_{i} \exp \left(-\lambda_{i}\right)}{1-\exp \left(-\lambda_{i}\right)}\right)
\end{aligned}
$$

\section{'Zero-Inflated' Poisson Model}

When there are a large number of zero counts the Poisson or the negative binomial models may not be appropriate for the data. One way of dealing with excess zeros (compared to the Poisson model) is to apply a 'Zcro-Inflated' Poisson (ZIP) distribution. It is assumed that different underlying mechanisms can be involved in generating zero and non-zero counts. A Poisson process generates both zero and positive counts, and in addition, zero counts can arise separately through a logistic process. In other words the distinction lies between structural zeros, which are inevitable, and sampling zeros, which occur by chance.

Thus if one assumes that $y_{i}=0$ with probability $\varphi_{i}$ and $y_{i} \sim$ Poisson $\left(\lambda_{i}\right)$ with probability $\left(1-\varphi_{i}\right)$ then:

$$
\begin{aligned}
& \operatorname{Pr}\left(Y=y_{i}\right)=\varphi+\left(1-\varphi_{i}\right) \exp \left(-\lambda_{i}\right) \text { if } y_{i}=0 \\
& \operatorname{Pr}\left(Y=y_{1}\right)=\left(1-\varphi_{i}\right) \exp \left(-\lambda_{i}\right) \frac{\lambda_{i}^{y_{i}}}{y_{1} !} \text { if } y_{i}>0
\end{aligned}
$$

Different formulations can be used for the probability $\varphi_{i}$, such as the probit or logit model. 
The ZIP model not only models an excess of zeros, compared to the Poisson model. but also yields in a variance that is greater than the mean, thus allowing for over-dispersion. The ZIP model can easily be extended to the negative binomial distribution, yiclding the so-called Zero Inflated Negative Binomial model (ZINB). 
Table A7-1 List of companies in the sample

\begin{tabular}{|c|c|}
\hline Chemical MNEs & Home country \\
\hline Akzo Nobel N.V. & NL \\
\hline$B \wedge S F \wedge G$ & DE \\
\hline Bayer $\mathrm{AG}$ & DE: \\
\hline Boehringer lngelheim International & \\
\hline (imbH & DE \\
\hline DSM N.V. & NL \\
\hline Degussa $A G$ & DI: \\
\hline E. Merck Chemische Fabrik OHG & DE: \\
\hline llenkel & DE \\
\hline Hoechst $A G$ & DE \\
\hline Imperial Chemical Industries Plc & $\mathrm{GB}$ \\
\hline L'Air Liquide S.A. & FR \\
\hline Reckitt \& Colman Plc & GB \\
\hline Solvay S.A. & BE: \\
\hline The BOC Group Ple & $\mathrm{GB}$ \\
\hline Pharmaceutical MNEs & Home country \\
\hline Astra $A B$ & $\mathrm{SE}$ \\
\hline (Ciba-Geigy $\wedge \mathrm{G}$ & $\mathrm{CH}$ \\
\hline Glaxo Welleome Ple & GB \\
\hline Novo Nordisk A/S & DK \\
\hline Rhone-Poulenc S.A. & FR \\
\hline Roche Holding AG & $\mathrm{CH}$ \\
\hline Sandoz AG & $\mathrm{CH}$ \\
\hline Schering $\wedge G$ & $\mathrm{DE}$ \\
\hline SmithKline Beccham Ple & GB \\
\hline ZENECA Group PIC & GB \\
\hline
\end{tabular}




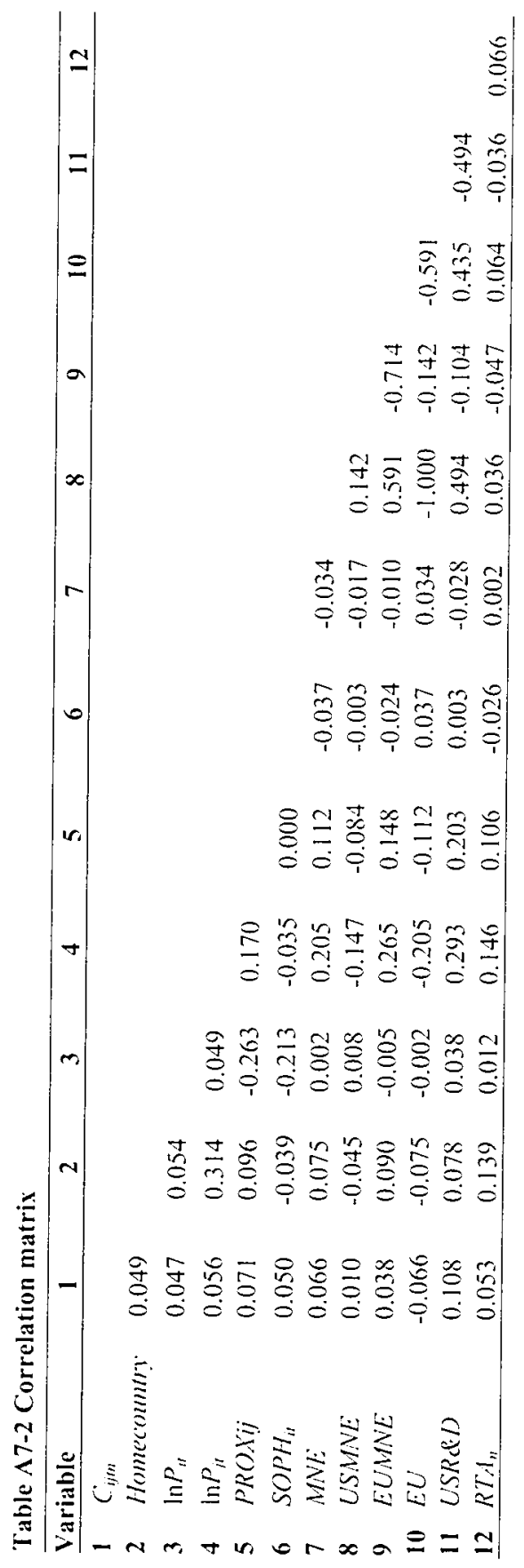




\section{CHAPTER 8 \\ SUMMARY AND CONCLUSIONS}

\subsection{INTRODUCTION}

The main objective of this work was twofold. First I wanted to determine what the impact was of R\&D internationalisation on the organisational structure and on the internal knowledge diffusion process in MNEs. Second I wanted to test for the presence of technology-related externalities stemming from R\&D activities performed abroad by MNEs. Chapter 6 focused essentially on the first objective, Chapter 7 on the second. Alongside these two principal themes, I also addressed a methodological issue concerning patents and patent citation indicators. Chapters 4 and 5 assessed to what extent the 'home advantage' effect distorts R\&D internationalisation indicators based on patent data on the one hand, and patent citation analysis carried out to measure the degree of asset-exploiting and asset-augmenting activities of foreign R\&D facilities on the other. Chapter 5 also presented an analysis of forcign R\&D activities of US MNEs in Europe and EU MNE subsidiaries in the US, which aimed to identify the extent of asset-augmenting and asset-exploiting R\&D in the two regions. Chapters 2 and 3 provided the theoretical background for the empirical analysis based on the literatures on inward-FDI related spillovers, R\&D internationalisation, and strategic management. Although the main objective of this thesis was to provide original empirical evidence on the private and public effects of R\&D internationalisation, it also aimed to contribute to theoretical debates in these areas.

The purpose of this concluding chapter is to summarise the main results of the study, outline some of its limitations, and suggest possibilities for further research. Finally I discuss some of the implications of my findings from an economic policy and managerial perspective.

\subsection{Principal Research Findings}

\subsubsection{Assessing the limitations of patent and patent-citation indicators in the analysis of R\&D internationalisation}

Chapters 4 and 5 analysed the limitations of using patent and patent-citation statistics to examine the R\&D internationalisation strategy of multinational companies. More specifically, I questioned the use of USPTO data in analysing R\&D internationalisation and compared them with EPO data which, due to the regional nature of this particular patent system, should 
be less affected by the 'home advantage' effect. Important findings emerged from this empirical analysis.

First. contrary to what is suggested by other authors (c.g. Archibugi 1992), both USPTO and EPO data (the fatter to a lesser extent), show evidence of a 'home advantage' effect. This means that using EPO data to analyse the internationalisation strategies of MNEs will underestimate the R\&D activities of multinational companies originating from US locations. while using USPTO patents will underestimate the innovative efforts made outside the US. Therefore the choice between the two datasets should be determined by the specific geographical focus and rescarch questions. I amalysed a sample of EPO and USPTO patents protecting the same invention and found that of those US inventions patented with, and granted by, the USPTO only $13 \%$ were also patented with, and granted by, the EPO. In contrast, the bias for EU inventions is less strong: on average $45 \%$ of EPO-granted patents have a corresponding patent in the USPTO. These results confirm, in part, the claim that the EPO is more international with less home country bias, but they contradict the assumption that large non-US firms tend to file their patents in the USPTO even when the innovative activity did not take place in the US. Filing a patent in more than one patent office is an expensive procedure and therefore, even for large firms with significant financial resources, external patent protection will be sought only when the expected commercial value and exploitation of the invention justify it.

Second, this home country bias also affects the geographical pattern of citations made by EPO and USPTO patents. I found that within the EPO system $64 \%$ of backward citations made by patents invented in the EU are to other EU-invented patents, while the proportion is only $23 \%$ for citations within the USPTO system. This result suggests that using USPTO patent citations underestimates the technology sourcing behaviour of foreign and domestic firms outside the US and vice-versa for EPO data. One should be cautious therefore when interpreting patent citation analyses that attempt to examine the geographical dimension of knowledge flows that go beyond the area protected by a particular patent office. However I showed that the inclusion of citations made by EPO patents to USPTO patents significantly reduces the difference between the geographical patterns of citations in the two patent systems.

Third, it emerged that not only do EPO and USPTO data suffer from the bias introduced by the "home advantage' effect, but they also capture different technological activities of MNEs, 
with a degree of overlap that changes depending on the geographical origin of the patent. For example, almost $45 \%$ of patents owned by EU MNEs and invented in the US are filed with and granted by the EPO alone. i.e. they have no equivalent patent within the USPTO. One reason put forward to explain this surprising result is the existence of different patentability in the patent offices; the findings for biotechnology patents are one area where this explanation may be relevant.

Overall. this study seems to suggest that even large firms with multinational operations and extensive financial resources adopt a case-by-case patenting strategy and do not appear to systematically protect their inventions in both the EPO and the USPTO. At the same time they also point towards a more careful interpretation of patent family size as an indicator of the economic value and technological impact of inventions, an approach initially suggested by Putnam (1996). Although further research is needed on this issue, from the results obtained in this study it appears that the propensity to file a patent in more than one patent office is correlated with factors such as the different patentability standards across patent offices that are not related to the potential economic and technological value of an invention.

\subsubsection{Identifying the extent of asset-augmenting and asset-exploiting R\&D activities}

Chapter 5 analysed the extent of the asset-augmenting and asset-exploiting R\&D activities of EU and US MNEs' foreign subsidiaries in the US and in Europe respectively. This chapter contributes to the international business literature both theoretically and empirically. From a theoretical point of view, I have proposed a new 'macro' perspective on asset-augmenting R\&D activity. I argued that as asset-augmenting activities can only be undertaken near the sources of knowledge they seck to acquire, asset-cxploiting activities draw not just from the parent company's technological resources, as has been assumed in other studies, but also from other home country technological assets. From an empirical point of view, this study provides an analysis of US R\&D investment in Europe, while many of the existing studies on assetcxploiting and augmenting activitics of MNEs have concentrated on forcign-owned R\&D in the US.

By applying the techniques proposed in the literature on localised knowledge spillovers, I identified asset-augmenting and asset-exploiting R\&D activities through patent citation analysis. The purpose of the patent citation analysis was twofold. It aimed to assess the relative propensity for US and European MNEs to undertake assct-exploiting and assetaugmenting activities. It also examined whether European affiliates in the US have a higher 
propensity to exploit their assets than do their US counterparts in Europe. I found that assetaugmenting activity is largely a phenomenon associated with European firms' activities in the US. The asset-augmenting component of this R\&D investment is in several cases even stronger than theit asset-exploiting component and that of their American counterparts. American subsidiaries in Europe still rely extensively on home-region knowledge sources. The significant asset-exploiting nature of US MNEs is also evident when compared with European R\&D investment in the US: in all sectors, apart from industrial machinery \& transportation. American MNEs operating in the EU tend to exploit their home-country technology base more than their European counterparts.

\subsubsection{The impact of R\&D internationalisation on the organisation of innovative active and the internal diffusion of knowledge}

Chapter 6 described a case study of six European pharmaceutical MNEs to analyse how MNEs firms implement their international R\&D strategy and how they manage knowledge transfer across physically distant R\&D facilities. In particular 1 focused on the role of researcher mobility as a technology transfer channel. This qualitative analysis yielded threc principal findings.

First, in all these companies rescarch efforts are organised differently from development activities. While the drug development process takes place in a much looser network of large units organised in a decentralised polveentric structure, the drug discovery process is organised in a multi-hub integrated network of laboratories specialised in different therapeutic arcas. I argued that this dichotomy was the result of the adoption of a new scientific-deductive method in the drug discovery process, which has made it possible to carry out rescarch in relatively small experimental units, highly specialised and geographically dispersed. In contrast the drug development process still requires a large amount of both human and financial resources and its efficiency relies on the achievement of a critical mass to carry out highly standardised large-scale activities.

Second, although this organisational structure aimed to capture and leverage technological knowledge from pockets of excellence around the world, I showed that the adoption of this R\&D organisation might hinder the transfer and integration of knowledge due to increased inter-unit geographical, organisational, and technological distance. In addition, the knowledge diffusion process is quite complex because it involves a high degree of lateral communication among dispersed research centres that need to operate in an integrated way during the drug discovery process, and because both international inter-disciplinary and intra-disciplinary 
knowledge flows need to be achieved to exploit the full potential of this organisational structure.

Third, despite the important weight given to initiatives that allow individual researchers to interact with other colleagues and enhance R\&D synergies across projects, the use of international assignments is quite limited (on average only $1 \%$ of R\&D staff are seconded each year to another research unit). Moreover, I found that this technology transfer mechanism is not only employed to achieve inter-unit knowledge transfer but fulfils two other objectives. It aims to reduce organisational distance through social interaction among researchers and it is used for individual leadership development. In both these cases knowledge transfer does not represent the primary motivation for the secondment though the experience often increases researchers' understanding of the R\&D organisation as a whole and management in the other unit in particular, and helped them identify 'who knows what' in the other location.

This investigation contributes to the international business and to the strategic management literatures in two respects. First, the evidence gathered in this research challenges the view advanced within these bodies of literature that the existence of a dispersed R\&D structure necessarily implies real knowledge-exchange and networking abilities. This study shows that knowledge diffusion in such an organisational structure could be hindered by a number of obstacles. Second, it provides a first insight into what mechanisms are adopted by firms to achieve knowledge integration. Despite the growing interest in this process in the strategic management literature, there is little empirical cvidence about how to attain cross-fertilisation of knowledge produced in physically distant R\&D facilities.

\subsubsection{Testing for the presence of inter-firm reverse technology transfer}

The empirical analysis presented in Chapter 7 tested for the existence of a fcedback effect from US R\&D facilitics of European chemical and pharmaceutical MNEs to other home country firms. I have argued that this phenomenon might arise from asset-augmenting R\&D units that produce knowledge that is more basic in nature, less context-specific, and with no particular development purpose. I also postulated that the main factor favouring the realisation of these spillovers is the high degree of embeddedness of multinational enterprises in their home countries, where their core productive and innovative activities remain concentrated, and where their linkages with external actors are strongest and also historically defined. 
By tracing knowledge flows using patent citations, 1 found that the flow of knowledge going back to Europe. though limited, is of significant economic and technological value. is generated by asset-augmenting R\&D activities and appears to complement the knowledge base of the firms that exploit it. Having controlled for the international profile of the citing firm. the importance of the cited patent, the patenting activities of the citing and eited firms, and the technological specialisation of the citing country, I found that home country firms, whether active internationally or only domestically, tend to cite US-invented patents from chemical subsidiaries more often than firms in other European countries: while this does not hold true for the sample of patents granted to pharmaceutical companies. I have argued that these findings might be explained by the different levels of R\&D internationalisation and the different roles that home country laboratories play in the R\&D organisation of the two sectors. While in pharmaceutical MNEs foreign R\&D facilities are becoming as important as home country R\&D units, in chemical MNEs home country R\&D laboratories retain the dominant role in the creation of new technological assets. As a result. the innovative activities of chemical MNEs are still strongly rooted in the home country. whereas pharmaceutical MNEs seem not to draw as extensively on domestic sources of technological knowledge. Thus, the main conclusion from Chapter 7 is that RTT can occur whenever the asset-augmenting R\&D activities of foreign subsidiaries are coupled with strongly embedded home country R\&D activities.

This investigation can be seen as original in two respects. First, the international business literature on R\&D internationalisation and the outward FDI literature are somewhat reconciled by the incorporation of a reverse knowledge flow into FDI flows and by the specification of the determinants of this phenomenon. Second, this study has provided the first direct empirical investigation of this phenomenon.

\subsubsection{Some common themes}

Although the results of this study have been presented as separate themes in separate chapters. two issues cut across them: the geographical and social dimensions of R\&D spillovers. This thesis has demonstrated the importance of geography in explaining both MNEs' R\&D internationalisation strategies and their R\&D organisation. As shown in Chapter 6, one of the factors driving the relocation of $R \& D$ activities abroad is the need to access cutting-edige science and technology from host-country R\&D resources such as local science communities, local pools of scientists and competing firms. Usually the type of knowledge to be sourced is general and basic in nature and has a significant tacit element; thus it can be acquired more 
efficiently and accurately through close interaction with local knowledge pools. By having a foreign R\&D unit in these centres of excellence MNEs are better able to communicate with local researchers. to establish collaborative research with local counterparts, to hire local scientists and engineers, and to learn about the seeds of potential technologies. The R\&D organisation has thus cvolved from a highly centralised structure to a less hicrarchical network of R\&D facilities, each tapping into a distinctive national technological advantage and cach comprising a critical mass of scientists and technicians to guarantec informal interaction and the exchange of more tacit forms of knowledge.

However, although the geographical dimension of knowledge spillovers may explain the emergence of these patterns, the social dimension is much more important for knowledge exchange. Spillovers are not only spatially bounded, but are also channelled through personal interaction and rooted in a social context, i.e. they are locally embedded. In this thesis the social aspect of R\&D spillovers has been examined in two ways. In Chapter 6 inter-unit mobility of rescarchers was considered as a technology transfer channel because it facilitates personal interaction and creates the opportunity for building personal relationships, which should persist not only across time but also across space. Results from the case study confirmed that international assignment of researchers worked as a technology transfer channel and as a means to bridge between distant R\&D units, but its limited use and the crosssectional nature of my analysis did not allow me to assess its effectiveness. Chapter 7 explained the diffusion of knowledge ereated abroad from MNEs to other home country firms and institutions, by the presence of socially and historically constructed networks of relationships with local counterparts. The different sectoral pattems emerging from the empirical analysis confirmed the importance of this factor in the RTT process. The concept of embeddedness was also at the centre of the new 'macro' perspective on asset-augmenting R\&D activities proposed in Chapter 5.

\subsection{LIMITATIONS OF THE STUDY AND SUGGESTIONS FOR FURTHER RESEARCH}

This research has highlighted significant areas within the international business and the knowledge management which, because of their theoretical and empirical relevance, deserve further cxploration.

First, our knowledge of the patenting strategy of multinational firms needs to be expanded. We need to explore further the factors contributing to the decision to file a patent in more than one patent office. Qualitative research could be performed to shed light on the determinants of 
the pattems emerging from the quantitative exercise carried out in this thesis. A detailed case study of a sample of companies or a survey, similar to Bertin and Wyatt (1988), could be conducted to gather information about the firm and the patented imnovation. This type of investigation could provide a deeper understanding of the relationship between patent family size and the economic value and technological impact of inventions. Furthermore, from a more methodological perspective, the empirical analysis undertaken in this study could be improved by using information from USPTO applications which has recently become available rather than considering only data on granted patents. This would allow firms' patenting propensities and thus their patenting strategies to be captured better.

Second, analysis of the mechanisms of knowledge integration would also provide grounds for future investigation. In this study I focused on socialisation mechanisms as a way to achicve international cross-fertilisation within individual technologies and/or the recombination of knowledge across related technologies. This research can be taken further in two directions. On the one hand it would be interesting to complement the cross-sectional study with a timeseries analysis of inter-unit mobility of researchers. This would allow an assessment to be made of how the use of technology transfer mechanisms has evolved with the R\&D organisation and how effective it is for achieving knowledge diffusion and integration. On the other hand, it would also be useful to conduct some research on the structural and formal mechanisms employed to achieve this.

Third, more attention should be devoted to analysing the consequences of M\&A for firms' technological performance. As has emerged from the case study, the geographical dispersion of R\&D activities is often the result of a merger or acquisition leading to an organisation characterised by a significant amount of inter-unit attrition and the lack of a common culture. Thus M\&A may hinder the internal transfer of knowledge and reduce R\&D efficiency.

Fourth, in this thesis I used the concept of embeddedness as the main factor explaining the occurrence of inter-firm RTT transfer but did not directly measure it, assuming that the innovative activity of MNEs is still strongly rooted in their home countries. What has emerged from the results of this thesis, however, is that the increasing level of R\&D internationalisation in certain sectors may lead to looser ties with the home country's national innovation system. Thus it would be worthwhile to measure the degree of home country embeddedness of this function. The centrality of multinational companies in their home 
country innovation system could be measured by using social network analysis, as done by Verspagen (1999) for the case of Philips.

Finally, attention could be given to how knowledge developed abroad spills over to other home country firms. The method used in this study, patent citation analysis, was appropriate for identifying the presence of these reverse knowledge flows, but it did not shed light on the channels and mechanisms through which the flows take place. Information on these could be extremely helpful for public policy aimed at supporting and stimulating the reverse transfer process. Research in this direction could include analysing the diffusion process of a particular innovation invented abroad by a foreign subsidiary in the MNE's home country.

\subsection{IMPLICATIONS FOR ECONOMIC AND TECHNOLOGY MANAGEMENT POLICY}

In spite of the desirability of extending this research, several implications both for R\&D policy makers and R\&D managers are nonetheless apparent.

The findings on inter-firm RTT have provided an alternative view of foreign direct R\&D investment. The relocation of R\&D activities abroad does not entail only an erosion of national technological competitiveness; it may also improve the overall innovative performance of the investing firm and of other home-country firms and institution by transferring back technological assets developed in foreign locations. Foreign R\&D activities can thus serve as technological conduits for home country firms, be they suppliers, customers, collaborators, or competitors. European governments have so far tended to encourage domestic multinationals to maintain their R\&D activity at home and have disapproved of the re-location of this investment to foreign countries, ignoring the possibility of RTT. If R\&D abroad were restricted by formal or informal barriers it is possible that not only the investing firms but also other home-country players could be excluded from important developments in products and processes, which could lead to competitive disadvantage. Particularly in R\&Dintensive and technologically complex industries, innovation sources have become much more dispersed than in the past and in order to remain internationally competitive firms require access to foreign technological developments. Thus it would be detrimental to an economy if its major companies were not able to undertake R\&D activities abroad, given the high degree of specialisation in the generation of technological knowledge and the growing importance of critical pockets of excellence abroad. 
However, as has emerged from the empirical analysis presented in Chapter 7, to reap greater local benelits from R\&D performed abroad. policy makers should ensure that the multinational's R\&D function is well embedded in the home country. On the one hand this can be achieved by strengthening the ties between home-country firms and institutions and the multinational firms undertaking R\&D investment abroad through enhanced inter-firm cooperation and inter-firm mobility of highly qualified workers. At the same time R\&D managers of domestic firms. especially those without the resources to establish foreign subsidiarics with technical and/or monitoring capabilities, should actively pursue collaborations with international companies. On the other hand this goal could be achieved by mainaining and enhancing the attraction of the home country as a location for undertaking R\&D activities. A highly skilled labour force and strong research base are key conditions for making a country technologically and scientifically attractive. The availability of highly qualified scientists and engineers is one of the most important determinants in the MNEs" decisions of where to locate its R\&D facility. The role of the education system is not only to provide a well-educated work force: it must also foster high-quality basic research and development in universities and public research institutes. To increase the attractiveness of a country as a location for R\&D policy makers must foster scientific excellence through the creation of both scientific and technological networks of public and private rescarch not only within the boundaries of a country but also with distant partners. Another objective of science policy should be the integration and concentration of resources to reach an internationally competitive critical mass.

Such policies would achieve the objective of attracting foreign $R \& D$ investments aiming at the creation of forefront technology. As the results in Chapter 5 have shown, Europe does not appear to attract significant amounts of research-related R\&D activitics from US MNEs. These types of foreign $R \& D$ investments could be more beneficial to the European technology base than the ones driven to exploit the results of home base innovations, because they would serve as a bridge between the domestic innovation system and the international scientific and technological community. As with policies directed at increasing the potential effects of RTT, policy makers should not only target the amount and type of R\&D investment, but they should also ensure that these investments are embedded into local innovative networks and are actively contributing to the national knowledge base. Several fiscal instruments can be implemented to attract foreign industrial $R \& D$ such as tax credits or R\&D subsidies. Financial instruments can also be used to integrate foreign companies into the 
national innovation systcm, for example including forcign companies in public-private partnerships co-financed with public money. Governments could increase the R\&D expenditures of foreign subsidiaries by imposing a certain minimum level of technological involvement as a condition for accessing the domestic market.

Thus governments could strengthen their national systems of innovation in order to prevent the overseas flight of R\&D investment of domestic firms and to attract $R \& D$ investment from foreign firms, while capturing greater local benefits from both inward and outward FDI R\&D. To what extent a passive internationalisation strategy, i.e. one encouraging $R \& D$ investment from foreign firms, is better than a 'active' one, i.e. encouraging R\&D investment abroad, will be country and sector specific. As pointed out by Van Pottelsberghe de la Potteric and Lichtenberg (2001) the trade-off between these two strategies is like choosing what is the best way to learn a foreign language: talking with forcigners living in one's home country or choosing to live in a foreign country. The latter seems more appropriate if one considers also the fact that the former strategy has the problem that, to a great extent, foreign companies cannot be chosen, and in particular it is very difficult to select the amount and the quality of technology they are willing to transfer. In addition foreign companies might displace domestic R\&D by competing for limited specialised resources, such as highly-skilled workers. However the 'active' internationalisation strategy has other drawbacks. A policy that subsidises the relocation of $R \& D$ activity abroad needs to assess to what extent the technological knowledge acquired abroad is completely internalised by the investing firm or spills over to other domestic firms, generating positive externalities for the domestic cconomy. Another cost of this intcrnationalisation strategy may arise if MNEs stop interacting with the domestic innovation system and instead turn exclusively to co-operation with forcign partners. Therefore it is important to stress that a policy aiming to encourage $R \& D$ investment abroad should be coupled with a policy aiming to capture greater local benefits from these investments.

The results of this investigation also have important managerial implications. The evidence presented in Chapter 6 showed that the adoption of a geographically dispersed R\&D organisation entails significant managerial challenges in relation to internal knowledge diffusion. The increasingly international division of labour among R\&D laboratories, the establishment of centres of excellence, the need for integration and coordination of the knowledge produced in globally dispersed R\&D units all require significant changes to the management of innovative activities. 
While MNEs have accumulated a substantial amount of experience in coordinating productive activities in distant locations, the coordination of $R \& D$ across different countries raises specific challenges associated with the tacit nature of the knowledge involved in these types of activities. Creative activities require personal interaction to resolve ambiguities in communication. However the ability to manage international innovation processes well is one of the most important soures of competitive advantage. Multinational companies need to find a balance between dispersion and centralisation. R\&D centres need to be spread around the world to acquire local competences, but at the same time, in each location, there must be a critical mass of resources to guarantec informal interaction and communication among $R \& D$ personncl. This may cxplain the finding that many organisations are becoming increasingly globalised and concentrating their R\&D resources, and also continuously changing their R\&D organisation. Global R\&D structures may be a creation of the top of an organisation, fostering more complex networks and global cooperation, but they simultaneously raise major problems at the operational level in integrating dispersed teams.

Thus the critical issues for management practice relate to the design and use of intra-firm knowledge management systems. While firms have made huge strides in the use of ICT to transfer information and to support communication worldwide, they need to focus managerial attention on creating a common culture and building cross-border internal innovation networks. To this end, global R\&D managers should encourage the formation of technology interest groups to bring together from across the organisation people with similar expertise. They should also use international assignments of researchers to achieve technology transfer and to promote the creation of networks across the company. The high cost involved in seconding a researcher to another $R \& D$ unit or in gathering researchers from different units sometimes limits the use of these instruments, and technologically supported communication may seem more cost-efficient than personal interaction: however it may not lead to the most effective outcome. Thus, global R\&D managers need to balance personal interactions with technologically supported communications to achieve their strategic knowledge management goals. Human resource managers are also faced with the reluctance of engineers and scientists to leave family and lifestyles behind to take on assignments abroad. Thus, capital and resources can be relatively easy to transfer to another location while people are not. R\&D managers must take into account of this constraint when making strategic R\&D decisions such as the establishment or the relocation of an R\&D laboratory. 
The results of the case study described in this thesis also showed that M\&A have significant consequences both for the R\&D organisation structure and for the internal flow of knowledge. In most companies the geographical dispersion of activities was prompted by the need to rationalise resources after a merger or acquisition. However, because of the difficulties of transferring researchers to other locations, a merger often leads to a duplication of R\&D activities (see for example the therapeutic specialisation of AstraZeneca research centres). Furthermore mergers introduce high levels of attrition and organisational distance. increasing the difficulties of achieving efficient inter-unit knowledge flows. Although M\&A is often driven by market and financial considerations, the results of this study point to the challenges that R\&D managers face in trying to achieve global learning in a new organisational structure. 


\section{REFERENCES}

Abramovit\%, M. (1986). "Catching up, forging ahead and falling behind", Jommal of Economic History XLVI(2): 385-406.

Acs, Z. J., D. B. Audretsch and M. P. Feldman (1992). "Real effects of academic research: comment", American Economic Review 82(1): 363-367.

Acs. Z. J., D. B. Audretsch and M. P. Feldman (1994). "R \& D spillovers and recipient firm size". Review of Economics and Statistics 76(2): 336-340.

Adler, M. (1971). "The impact of the U.S. direct investment controls", Joumal of Imternational Business Studies 2(1): 1-14.

Agrawal, A., I. Cockburn and J. McHale (2003) Gone but not forgotten: labour flows, knowledge spillovers, and enduring social capital, NBER Working Paper No. 9950.

Aitken, B. and A. Harrison (1999). "Do domestic firms benefit from direct foreign investment? Evidence from Venezucla", American Ecomomic Review 89(3): 605-618.

Akers, N. (2000). "The referencing of prior art documents in European patents and applications", World Patent Information 22(3): 309-315.

Allansdottir, A., A. Bonaccorsi, A. Gambardella, M. Mariani, L. Orsenigo, F. Pammolli and M. Riccaboni (2002) Innovation and competitiveness in European biotechnology, Enterprise papers No. 7.

Allen, T. J. (1970). "Communication networks in R\&D laboratories", R\&D Management 1(1): 14-21.

Allen, T. J. (1977). Managing the Flow of Technology. Cambridge, MA, MIT Press.

Almeida, P. (1996). "Knowledge sourcing by foreign multinationals: patent citation analysis in the U.S. semiconductor industry", Strategic Management Journal 17(Winter Special Issue): 155-165.

Almeida, P. and B. Kogut (1999). "Localization of knowledge and the mobility of engineers in regional networks", Management Science 45(7): 905-917.

Almeida, P.. J. Song and R. M. Grant (2002). "Are firms superior to alliances and markets? An empirical test of cross-border knowledge building", Organization Science 13(2): 147-161.

Amin. A. (2000). Organizational leaning through communities of practice. Paper presented at the workshop 'The firm in Economic Geography', 9-11 March, University of Portsmouth. 
Angel, D. P. (1991). "High-technology agglomeration and the labour market: the case of Silicon Valley", Emironment and Plamning A 23: 1501-1516.

Archibugi, D. (1992). "Patenting as an indicator of technological innovation: a review". Science and Public Policy 19(6): 357-368.

Archibugi. D. and M. Pianta (1992). "Specialization and size of technological activities in industrial countries: The analysis of patent data". Research Policy 21(1): 79-93.

Arora, A. and A. Gambardella (1994). "The changing technology of technological change: general and abstract knowledge and the division of innovative labour". Research Policy 23(5): 523-5.32.

Arundel, A. and I. Kabla (1998). "What percentage of innovations are patented? Empirical estimates for European firms". Research Policy 27(2): 127-141.

Atkinson, A. and J. Stiglitz (1969). "A new view of technological change". The Economic foumal 79(315): 573-578.

Audretsch, D. B. and M. P. Feldman (1996). "R\&D spillovers and the geography of imnovation and production", American Economic Revierl 86(3): 630-640.

Audretsch. D. B. and P. E. Stephan (1996). "Company-Scientist Locational Links: The Case of Biotechnology". The American Economic Review 86(3): 641-652.

Balassa, R. (1965). "Trade liberalisation and 'revealed' comparative advantage", The Manchester School of Economics and Social Studies 33(2): 99-124.

Barba Navaretti. G. and D. Castellani (2003) Investments abroad and performance at home. Evidence from Italian multinationals. Centro study Luca D' Agliano. Development Studies Working Paper No. 180.

Barba Navaretti, G., D. Castellani and A. Zanfei (2002). Investimenti all'estero e produttività. Un'analisi comparata di Italia, Francia e Spagna, in Rapporto sulla competitività dell'ralia: le imprese Milano, Il Sole 24 Ore.

Bartlet, C. A. (1986). Building and managing the transnational. The new organizational Challenge, in Competition in global industries. M. E. Porter (Ed.) Boston, MA, Harvard Business School Press.

Bartlet, C. A. and S. Ghoshal (1990). Managing innovation in the transnational corporation, in Managing the Global Firm. C. Bartlett, Y. Doz and G. Hediund (Eds.) London, Routledge.

Basberg, B. L. (1987). "Patents and the measurement of technological change: a survey of the literature". Research Policy 16(2-4): 131-141. 
Belderbos, R.. G. Capannelli and K. Fukao (2001). "Backward Vertical Linkages of Foreign Manufacturing Affiliates: Evidence from Japanese Multinationals", World Development 29(1): 189-208.

Bernard, A. and J. B. Jensen (1999). "Exceptional exporter performance: cause, effect or both?". Jommal of Inemational Economics 47(1): 1-25.

Bertin, G. V. and S. Wyatt (1988). Meltinationals and hndustrial Property. The Control of the World's Techmologl; Atlantic Highlands, N.I, Humanities Press.

Bhagwati, J. N. (2004). In Defence of Globalization, New York. Oxford University Press.

Birkinshaw. J. and N. Hood (1998). "Multinational subsidiary evolution: capability and charter change in foreign-owned subsidiary companies", Academy of Management Review 23(4): 773-795.

Blalock, G. and P. J. Gertler (2003). Technology from foreign direct investment and welfare gains through the supply chain. Cornell University, mimeo.

Blanc, H. and C. Sierra (1999). "The internationalisation of R\&D by multinationals: a tradeoff between external and internal proximity", Cambridge Jounal of Economics 23(2): 187-206.

Blömstrom, M. (1986). "Foreign investment and productive efficiency: the case of Mexico", Sournal of Industrial Economics 37: 315-328.

Blömstrom, M. and A. Kokko (1998). "Multinational corporation and spillovers", Journal of Economic Sulveys 12(3): 247-277.

Blömstrom. M. and H. Persson (1983). "Foreign direct investment and spillovers efficiency in an underdeveloped economy: evidence from the Mexican manufacturing industry", World Development 11(6): 493-501.

Borensztein, E., J. D. Gregorio and J. W. Lee (1998). "How does FDI affect economic growth", Journal of International Economics 45(1): 115-135.

Braconier, H. and F. Sjöholm (1998). "National and international spillovers from R\&D: comparing neoclassical and an endogenous growth approach", Weltwirtschaftiches Archiv 134(4): 638-663.

Braczyk, H., P. Cooke and M. Heidenreich (1998). Regional Innovation Sy stems, London, UCL Press.

Branstetter, L. G. (2000) Is foreign direct investment a channel of knowledge spillovers? Evidence from Japan's FDI in the United States, NBER Working Paper No. 8015.

Breschi, S. and F. Lissoni (2001). "Knowledge spillovers and local innovation systems: a critical survey", Industrial and Corporate Change 10(4): 975-1005. 
Breschi. S. and F. Lissoni (2003) Mobility and social networks. Localised knowledge spillovers revisited, CESPRI Working Paper No. 142.

Brouwer. E. and A. Kleinknecht (1999). "Innovative output, and a firm's propensity to patent. An exploration of (IS micro data". Research Policy 28(6): 615-624.

Brown, J. and P. Duguid (1996). Organizational learning and communities of practice, in Organizational Learning. M. D. Cohen and L. S. Sproull (Eds.) London, Sage.

Cameron, A. C and P. K. Trivedi (1986). "Econometric models based on count data: comparisons and application of some estimators and tests", Journal of Applied Econometric:s 1(1): 29-53.

Cameron, A. C. and P. K. Trivedi (1990). "Regression-based test for overdispersion in the Poisson model", Jommal of Econometrics 46(3): 347-364.

Cantwell, J. (1989). Technological innovation and multinational corporations, London, Basil Blackwell.

Cantwell, J. (1995). "The globalisation of technology: what remains of the product cycle model?" Cambridge Journal of Economics 19(1): 155-174.

Cantwell, J. (2001). Innovation and information technology in MNE, Oxford, Oxford University Press.

Cantwell, J. and C. Hodson (1991). Global R\&D and UK competitiveness, in Global Research Strategy and International Competitiveness. M. Casson (Ed.) London, Basil Blackwell.

Cantwell, J. and J. Odile (1999). "Technological globalisation and innovative centres: the role of corporate technological leadership and locational hicrarchy", Research Policy 28(23): $119-144$.

Castellani, D. (2001) Export behaviour, foreign direct investments and firm's productivity. Ph.D thesis, University of Ancona, Ancona.

Castellani, D. (2002). "Export Behavior and Productivity Growth: Evidence from Italian Manufacturing Firms", Weltwirtschaftliches Archiv 138(4): 605-28.

Castellani, D. and A. Zanfei (2003a). Innovation, foreign ownership and multinationality. An empirical analysis on Italian manufacturing firms. Paper presented at the 29th EIBA conference "MNC as a Knowing Organization", 11-13 December, Copenhagen.

Castellani, D. and A. Zanfei (2003b). "Technology gaps, absorptive capacity and the impact of inward investments on productivity of European firms", Economics of Innovation and New Technologies 12(6): 555-576. 
Caves, R. (1974a). Effects of international technologl transfers on the US economy. The Effects of Intcmational Technology Transfers on US Economy, Washington DC:

Caves. R. (1974b). "Multinational firms. competition, and productivity in host-country markcts". Ecomomica 41(162): 176-193.

(hiesa, V. (1996a). "Human resource management issues in global R\&D organisation: a case study". Jownal of Engineering and Technologr Management 13(2): $189-202$.

Chiesa, V. (1996b). "Managing the intemationalisation of R\&D activities". IEEE Transactions on Engineering Management 43(1): 7-23.

Chiesa, V. (1996c). "Separating research from development: evidence from the pharmaceutical industry", European Management Journal 14(6): 638-647.

Chiesa, V. and R. Manzini (1996). "Managing the transfer of knowledge within multinational firms", International Joumal of Technology Management 12(4): 462-476.

Chung. W. (2001). "Identifying technology transfer in FDI: influence of industry conditions and investing firm motives", Journal of International Business Studies 32(2): 21 1-229.

Clerides, S. K., S. Lach and J. R. Tybout (1998). "Is learning by exporting important? Microdynamic evidence from Colombia, Mexico, and Morocco", Quarter/y Joumal of Economics 113(3): 903-947.

Coc, D. and E. Helpman (1995). "International R\&D spillovers", European Economic Review 39(5): $859-887$.

Coc, D., E. Helpman and A. Hoffmaister (1997). "North-South R\&D spillovers", The Economic Joumal 107(440): 134-149.

Cohen, W. M. and D. A. Levinthal (1990). "Absorptive capacity: a new perspective on learning and innovation", Administrative Science Quarterly 35(1): 128-152.

Cooke, P. (1992). "Regional innovation systems: competitive regulation in the new Europe", Geoforum 23: 365-382.

Cooke, P., M. G. Uranga and G. Etxebarria (1998). "Regional systems of innovation: an evolutionary perspective", Environment and Planning A 30: 1563-1584.

Cowan, R., P. David and D. Foray (2000). "The explicit economics of knowledge codification and tacitness", Industrial and Corporate Change 9(2): 211-253.

Criscuolo, P., R. Narula and B. Verspagen (2004). "The role of home and host country innovation systems in R\&D internationalisation: a patent citation analysis". Economic of Imovation and New Technologies forthcoming. 
Criscuolo, P. and P. Patel (2003). Large firms and internationalisation of Rd D: 'hollowing out' of national technological capacity? Paper presented at SETI workshop, May $15-$ 16. Rome.

Cyert, R. (1995) Management of knowledge, Newsletter of the Carnegie Bosch Institute for Applied Studies in Management.

Dahl. M. (2002). Embedded knowledge flows through labour mobility in regional clusters in Demmark. Paper presented at the DRUID Summer Conference, Elsinore, Copenhagen. Dahlam, C. and R. Nelson (1995). Social absorption capability, national innovation systems and economic development, in Social Capability and long-term growth. D. H. Perkins and B. H. Koo (Eds.) Basingstoke, Macmillan Press.

Dalton, D., M. Serapio and P. Yoshida (1999). Globalizing industrial R\&D. U.S. Department of Commerce. Technology Administration, Office of Technology Policy.

Das, S. (1987). "Externalities, and technology transfer through multinational corporations. A theoretical analysis", Jomnal of International Economics 22(1-2): 171-182.

De Meyer, A. (1991). "Tech talk: how managers are stimulating global R\&D communication", Sloan Management Review 33(3): 49-58.

De Mcycr, A. (1993). "Internationalising R\&D improves a firm technical learning", Research Technology Management 36(4): 42-49.

Dernis, H. (2003). OECD Wiadic patent families. OECD methodology: an overview. WIPOOECD workshop on statistics in the patent field, Geneva.

Dicken, P., M. Forsgren and A. Malmberg (1994). The local embeddedness of transnational corporations, in Globalization, Institutions, and Regional Development in Europe. A. Amin and N. Thrift (Eds.)

Duguet, E. and M. MacGarvie (2003). "How well do patent citations measure flows of technology? Evidence from French innovation surveys", Economics of Innovation and New Technologies forthcoming.

Dunning, J. (1977). Trade, location of economic activity and the multinational enterprise: a search for an eclectic approach, in The international allocation of economic activity. B. Ohlin, P. Hesselborn and P. Wijkman (Eds.) London, Macmillan.

Dunning, J. (1986). Japanese Participation in British Inchustry, London, Croom Helm.

Dunning, J. and J. Cantwell (1986). The changing role of Multinational Enterprise in the international creation, transfer and diffusion of technology. Paper presented at the conference on 'Innovation Diffusion', 17-22 March, Venice,. 
Dunning, J. and R. Narula (1995). "The R\&D activities of foreign firms in the United States", Imernational Studies of Mandrgement and Organization 25(1-2): 39-73.

ETAN (1998). Internalisation of research and technology: trends, issues, and implications for S\&T policies in Europe. Brussels/Luxembourg, European Commission Directorate General XII.

European Commission (1997). Second European Report on S\&T Indicators. Bruxelles, European Commission.

European Commission (2002) More research for Europe. Towards 3\% GDP, Communication from the Commission No. COM(2002) 499 final.

Faust, K. and H. Schedl (1982). International patent data: their utilisation for the analysis of techological developments. Workshop on Patent and Innovation Statistics, Paris, OECD.

Findlay, R. (1978). "Relative backwardness, direct foreign investment and the transfer of technology: a simple dynamic model", Quaterly Jounal of Economics 12(1): 42-56.

Florida, R. (1997). "The globalisation of R\&D: results of a survey of foreign affiliated R\&D laboratories in the USA", Research Policy 26(1): 85-103.

Fors, G. (1997). "Utilization of R\&D results in the home and foreign plants of multinationals", Joumal of Industrial Economics XLV(2): 341-358.

Fosfuri, A., M. Motta and T. Ronde (2001). "Foreign direct investment and spillovers through workers mobility", Joumal of International Economics 53(1): 205-222.

Frost, T. (1998) The geographic sontes of imnovation in the multinational enterprise: U.S. subsidiaries and host country spillovers, 1980-1990. Ph.D thesis, MIT, Cambridge, MA.

Frost, T. (2001). "The geographic sources of foreign subsidiaries' innovation", Strategic Management Joumal 22(2): 101-123.

Gambardella, A., L. Orsenigo and F. Pammolli (2000) Global competitiveness in pharmaceuticals. A European perspective, Report prepared for the Directorate Gencral Enterprise of the European Commission.

Gassmann, O. and M. von Zedtwitz (1999). "New concepts and trends in international R\&D organization", Research Policy 28(2-3): 231-250.

Gerschenkron, A. (1962). Economic Backwardness in Historical Perspective ${ }_{2}$ Massachusetts, Belknap Press of Harvard. 
Gertler, M., D. Wolfe and D. Garkut (2000). "No place like home? The embedededness of innovation in a regional economy", Review of Intemational Political Economy 7(4): 688-718.

Ghoshal, S. and D. E. Westney (1993). Introduction, in Organization Theory and the Multinational Corporation. S. Ghoshal and D. E. Westney (Eds.) London, The Macmillan Press.

Girma, S. (2003) Absorptive capacity and productivity spillovers from FDI: a threshold regression analysis, European Economy Group No. 25/2003.

Gittleman, M. and E. Wolff (1995). "R\&D activity and cross-country growth comparisons", Cambridge Jounal of Economics 19(1): 189-207.

Glaser, B. G. and A. L. Strauss (1967). The discovery of grotunded theory: Strategies for qualitative research ${ }_{2}$ New York, Aldine De Gruyter.

Globerman, S. (1979). "Foreign direct investment and "spillovers" efficiency benefits in Canadian manufacturing industries", Camadian Jommal of Economics XII( 1 ): 42-56.

Globerman, S. (1994). The public and private interests in outward direct investment, in Canadian-Based Multinationals. S. Globerman (Ed.) Calgary, University Calgary Press.

Globerman, S., A. Kokko and F. Sjöholm (2000). "International Technology Diffusion: evidence from Swedish patent data", Kyklos 53(1): 17-38.

Gordon, I. R. and P. McCann (2000). "Industrial clusters: complexes, agglomeration and/or social networks?" Urban Studies 37(3): 513-532.

Görg, H. and D. Greenaway (2003). "Much ado about nothing? Do domestic firms really benefit from foreign direct investment?" World Bank Research Observer forthcoming.

Görg, H. and E. Strobl (2001). "Multinational companies and productivity spillovers: a meta-analysis", The Economic Jounal 111 (475): F723-F739.

Görg, H. and E. Strobl (2002) Spillovers from foreign firms through worker mobility: An cmpirical investigation, IZA Discussion paper No. 591.

Grabher, G. (1993). Rediscovering the social in the economics of inter-firm relations, in The Embedded Firm: On the Socio-economics of Industrial Networks. G. Grabher (Ed.) London, Routledge.

Granovetter, M. (1985). "Economic action and social structure: the problem of embeddedness", American Jounal of Sociology 91(3): 481-510.

Granstrand, O. (1998). "Towards a theory of the technology based firm", Research Policy. 27(5): 465-490. 
Granstrand, O., P. Patel and K. Pavitt (1997). "Multi-technology corporations: why they have 'distributed' rather than 'distinctive core' competencies", Califormia Management Revieri 39(4): 8-25.

Grant, R. (1996). "Toward a knowledge-based theory of the firm", Strategic Management Journal 17(Winter Special issue): 109-122.

Griliches, Z. (1990). "Patent statistics as cconomic indicators: a survey". Joumal of Economics Literanure 28(4): $1661-1707$.

Griliches, Z. (1992). "The search for R\&D spillovers", Scandinavian Joumal of Economics 94(Suppl.): S29-S47.

Grilliches, Z. (1979). "Issues in Assessing the Contribution of Research and Development to Productivity Growth". The Bell Journal of Economics 10(1): 92-116.

Grogger, J. T. and R. T. Carson (1991). "Models for truncated counts", Journal of Applied Econometrics 6(3): 225-238.

Grupp, H. and U. Schmoch (1999). "Patent statistics in the age of globalisation: new legal procedures, new analytical methods, new economic interpretation", Research Policy 28(4): $377-396$.

Guellec, D. and B. Pottelsberghe-de-la-Potteric (2002). "The value of patents and patenting strategies: countries and technology arcas patterns", Economics of Imovation and New Technologies 11(2): 133-148.

Guerrieri, P. (1999). Patterns of national specialisation in the global competitive environment, in Imovation Policy in a Global Economy. D. Archibugi, J. Howells and J. Michie (Eds.) Cambridge, Cambridge University Press.

Gupta, A. K. and V. Govindarajan (2000). "Knowledge flows within multinational corporations", Strategic Management Journal 21(4): 473-496.

Haddad, M. and A. Harrison (1993). "Are there positive spillovers from direct foreign investment? Evidence from pancl data for Morocco", Journal of Development Economics 42(1): 51-74.

Hagedoorn, J. and J. Schakenraad (1994). "The effect of strategic technology alliances on company performance". Strategic Management Journal 15(4): 291-311.

Håkanson, L. (1990). International decentralization of R\&D. The organizational challenges, in Managing the Global Firm. C. A. Bartlett, Y. Doz and G. Hedlund (Eds.) London, Routledge. 
Hakanson. L. (1992). Locational determinants of forcign R\&D in Swedish multinationals, in Technology management and international business: internationalisation of RePD and technology. O. Grandstand, L. Hakanson and S. Sjölander (Eds.) Chichester. Wiley.

Hakanson, L. and R. Nobel (2000). "Technology characteristics and reverse technology transfer". Management International Review 40(Special issue): 29-48.

Hákanson, L. and R. Nobel (2001). "Organization characteristics and reverse technology transfer". Management International Review 41(Special issue): 392-420.

Hall, B., A. Jaffe and M. Trajtenberg (2001) The NBER patent citations data file: lessons, insights and methodological tools, NBER Working Paper No. 8498.

Hansen, B. E. (2000)). "Sample splitting and threshold estimation", Ecomometrica 68(3): 575 603.

Harhoff, D., F. M. Scherer and K. Vopel (2003). "Citations family size, oppositions and the value of patent rights", Reseench Policy 32(8): 1343-1363.

Hausman, J., B. Hall and Z. Griliches (1984). "Econometric models for count data with an application to the patent - R\&D relationship", Ecometrica 52(4): 909-938.

Hausman. I. and D. MacFadden (1984). "Specification tests for the multinomial logit model", Econometrica 52(5): 1219-1240.

Hedlund, G. (1986). "The hypermodern MNC - A heterarchy?" Human Resonice Management 25: 9-35.

Hedlund, G. (1994). "A model of knowledge management and the N-form corporation". Strategic Management Journal 15(Summer Special Issue): 73-90.

Hejazi, W. and E. Safarian (1999). "Trade, foreign direct investment, and R\&D spillovers". Journal of International Business Studies 30(3): 491-508.

Helpman, E. and P. Krugman (1985). Mater Structure and Foreign Trade, Cambridge, MA, MIT Press.

Henderson, R. (1994). "The evolution of integrative capability: innovation in cardiovascular drug discovery". Industrial and Corporate Change 3(3): 607-630.

Henderson, R. and I. Cockburn (1994). "Measuring competence? Exploring firm effects in pharmaceutical rescarch", Strategic Management Journal 15(Winter Special Issue): 63-84.

Henderson, R. and I. Cockburn (1996). "Scale, Scope, and Spillovers: The Determinants of Research Productivity in Drug Discovery", The Rand Joumal of Economics 27(1): 32 59. 
Hingley. P. and W. Park (2003). Patent family data and statistics at the Europecm Patent Office. WIPO-OED workshop on statistics in the patent field. Geneva.

Hood, N. and S. Young (1982). "U.S. multinational R\&D: corporate strategies and policy implications for the UK". Multinational Business 2: 10-23.

Howells. J. (1995). "Going global: the use of ICT networks in research and developments". Research Policy 24: 169-184.

Howells, J. (2002). "Tacit knowledge, innovation and economic geography". Urban Studies 39(5-6): $871-884$.

Hu, Y. (1992). "Global corporations are national firms with international operations", California Management Review 34(2): 107-126.

Hymer, S. (1960) The international operations of national firms: a study of direct imestment. Ph.D thesis, Department of Economics, Cambridge MA.

Jaffe, A. and M. Trajtenberg (2002). Patents, Citations and Innovations: A Window on the Knowledge Economy; Cambridge. MA, MIT Press.

Jaffe, A., M. Trajtenberg and M. Fogarty (2002). The meaning of patent citations: report on the NBER/Case-Western Reserve survey of patentecs, in Patents, Citations, and Imnovations: A Window on the Knowledge Economy. A. Jaffe and M. Trajtenberg (Eds.) Cambridge, Massachusetts, The MIT Press.

Jaffe, A. B. (1986). "Technological opportunity and spillovers of R \& D: evidence from firms' patents, profits, and market value", The American Economic Review 76(5): 984-1001.

Jaffe, A. B. (1989). "Real Effects of Academic Research", The American Economic Review 79(5): $957-970$.

Jaffe, A. B., M. S. Fogarty and B. A. Banks (1998). "Evidence from patents and patent citations on the impact of NASA and other federal labs on commercial innovation". Jounal of Industrial Economics 46(2): 183-205.

Jaffe, A. B. and M. Trajtenberg (1996) Flows of knowledge from universities and federal labs: modelling the flow of patent citations over time and across institutional and geographical boundaries, NBER Working Paper No. 5712.

Jaffe, A. B. and M. Trajtenberg (1999). "International knowledge flows: evidence from patent citations." Economics of Imnovation and New Techmologies 8(1): 105-136.

Jaffe, A. B., M. Trajtenberg and R. Henderson (1993). "Geographic localization of knowledge spillovers as evidenced by patent citations", The Quarerly Joumal of Economics 108(3): $577-598$. 
Javorcik Smarzynska. B. K. (200)3a). "Composition of foreign direct investment and protection of intellectual property rights in transition economies", European Economic: Review forthcoming.

Javorcik Smarzynska. B. K. (2003b). "Does foreign direct investment increase the productivity of domestic firms:? In search of spillovers through backward linkages". American Economic Review forthcoming.

Katz, R. and T. J. Allen (1982). "Investigating the not invented here (NIH) syndrome: a look at the performance, tenure, and communication patterns of 50 R\&D project groups", R\&D Management 12(1): 7-19.

Kim. L. (1995). Absorptive capacity and industrial growth: a conceptual framework and Korea's experience, in Social Capabilities and Long-term Growth. D. H. Perkins and B. H. Koo (Eds.) Basingstoke, Macmillan Press.

Kindleberger, C. (1969). American Business Abroad. Six Lectures on Direct Imestment, New Haven and London, Yale University Press.

Kinoshita, Y. (2000) R\&D and technology spillovers via FDI: innovation and absorptive capacity, CEPR Discussion Paper No. 2775.

Kogut, B. and S. Chang (1991). "Technology capabilities and Japanese forcign direct investment in the United States", Review of Economics Statistics: 401-413.

Kogut, B. and U. Zander (1992). "Knowledge of the firm, combinative capabilities, and the replication of technology", Organization Science 3(3): 383-397.

Kogut, B. and U. Zander (1993). "Knowledge of the firm and the evolutionary theory of the multinational corporation", Journal of International Business Studies Fourth Quarter: 625-645.

Kokko, A. (1994). "Technology, market characteristics, and spillovers", Joumal of Development Economics 43(2): 279-293.

Kokko, A., R. Tansini and M. C. Zejan (1996). "Local technological capability and productivity spillovers from FDI in the Uruguayan manufacturing sector", Joumal of Development Studies 32(4): 602-611.

Kuemmerle, W. (1996) Home Base and Foreign Direct Investment in R\&D. Ph.D thesis, Boston, MA.

Kuemmerle, W. (1999). "Foreign direct investment in industrial research in the pharmaceutical and electronics industries: results from a survey of multinational firms", Research Policy 28(2-3): 179-193. 
Lall. S. (1979). "The intemational allocation of rescarch activity by U.S. multinationals", Oxford Bulletin of Economics and Statistics 41(4): 313-331.

Lall, S. (1980). "Vertical inter-firm linkages in LDCs: an empirical study". Oxford Bulletin of Economics and Statistics 42: 203-226.

Lanjouw, J. O. and M. Schankerman (1999) The quality of ideas: measuring innovation with multiple indicators, NBER Working Paper No. 7345.

Lanjouw, J. O. and M. Schankerman (2004). "Patent quality and research productivity: measuring innovation with multiple indicators". Economic Journal 114(4): 441-465.

Lankhuizen, M. (1998) Catching-up, absorption capability and the organization of human capital, MERIT Research Memoranda No. 17.

Lapan, H. and P. Bardhan (1977). "Localized technical progress and transfer of technology and economic development", Jommal of Economic Theory 6(6): 585-595.

Le Bas, C. and C. Sicrra (20)2). "Location versus country advantages in R\&D activities: some further results on multinationals' locational strategies", Research Policy 31(4): $589-609$.

Lichtenberg, F. and B. van Pottelsberghe de la Potteric (1996) International R\&D spillovers: a re-examination, NBER Working Paper No. 5668.

Lichtenberg, F. and B. van Pottelsberghe de la Potteric (1998). "International R\&D spillovers: a comment", European Ecomomic Review 42(8): 1483-1491.

Lipsey, R. E. (2002) Home and host country effects of FDI, NBER Working Paper No. 9293.

Lipsey, R. E. and F. Sjöholm (2001) Foreign direct investment and wages in Indonesian manufacturing, NBER Working Paper No. 8299.

Luintel, K. B. and M. Khan (2003) The dynamics of international R \& D spillovers, CERF (Public Policy and Department of Economics and Finance) Discussion Papers No. 0327.

Lundvall, B. (1992). National system of innovation: towards a theory of imovation and interative leaming. London, Pinter.

Lyons, D. (2000). "Embeddedness, milieu, and innovation among high-tech firms", Emiromment and Plaming A 32: 891-908.

MacGarvic, M. (2002). Do firms learn from international trade? Evidence from patent citations and micro data. Department of Economics, University of California, Berkeley, mimeo.

Malmberg, A. (1997). "Industrial geography: location and learning", Progress in Human Geography. 21(4): 573-582. 
Mansfield. E. (1975). "International technology transfer: forms, resource requirements, and policies". American Economic Review Paper and Proceedings: 372-376.

Mansficld, E. (1984). R\&D and innovation: some cmpirical findings, in R\&D. Patents, and Productivity. Z. Griliches (Ed.) Chicago and London. The University Chicago Press and NBER.

Mansfield, E. (1994) Intellectual property protection, foreign direct investment, and technology transfer. International Finance Corporation Discussion paper No. 19.

Mansfield, E. and Associates (1982). Technology Transfers, Productivity and Economic Policy. New York. W. W. Norton.

Mansfield. E. and A. Romeo (1984). "'Reverse' tansfers of technology from overseas subsidiaries to American firms", IEEE Transactions on Engineering Mandgement EM-31(3): 122-127.

Mansficld. E., A. Romeo and S. Wagner (1979). "Foreign Trade and U. S. Research and Development", The Review of Economic Statistics 61(1): 49-57.

Marin, A. and M. Bell (2003). Technology spillovers from foreign direct investment (FDI): an exploration of the active role of $M N C$ subsidiaries in the case of Argentina in the 1990)s. Paper presented at the workshop 'Understanding FDI-Assisted Economic Development', 22-25 May, TIK centre, University of Oslo.

Markusen, J. (1984). "Multinationals, multi-plant economics and the gains from trade", Jounal of International Economics 16(3-4): 242-261.

Markusen, J. (1995). "The boundaries of multinational firms and the theory of international trade", Joumal of Economic Perspectives 92(2): 169-189.

Markusen, J. R. and A. J. Venables (1999). "Foreign direct investment as a catalyst for industrial development", European Economic Review 43(2): 335-356.

Marshall, A. (1891). Principles of Economics. An Introductory Volume, London, Macmillan.

Maurseth, P. and B. Verspagen (2002). "Knowledge spillovers in Europe. A patent citations analysis", Scandinavian Joumal of Economics: 104(4): 531-545.

Meyer. M. (2000). "What is special about patent citations? Differences between scientific and patent citations", Scientometrics 49(1): 93-123.

Meyer-Krahmer. F. and G. Reger (1999). "New perspectives on the innovation strategies of multinational enterprises: lessons for technology policy in Europe", Research Policy 28(7): $751-776$.

Michel, J. and B. Bettles (2001). "Patent citation analysis. A closer look at the basic input data from patent search reports", Scientometrics 51(1): 795-816. 
Mohen, P. (1995). Some estimates of international ReD spillovers. Paper presented at the Tip Conference 'The Emerging Knowledge-based Society', September 21-22, Vienna.

Morgan. K. (2004). "The exaggerated death of geography: learning, proximity and territorial innovation systems", Journal of Economic Geographỵ 4(1): 3-21.

Mowery, D., . Oxley and B. Silverman (1996). "Strategic alliances and inter-firm knowledge transfer", Strategic Management Jommal 17(Winter Special Issue): 77-91.

Nadiri, M. I. and S. Kim (1996) International R\&D spillovers, trade and productivity in major OECD countries, NBER Working Paper No. 5801.

Nahapiet, J. and S. Ghoshal (1998). "Social capital, intellectual capital and the organisational advantage". Academy of Management Review: 23(2): 242-266.

Narin, F., M. Rosen and D. Olivastro (1988). Patent citation analysis: new validation studies and linkages statistics, in Science Indicators: Their Use in Science Policy and Their Role in Science Suclies. A.F.J. van Raan, A. J. Nederhof and H. F. Moed (Eds.), DSWO Press, The Netherlands.

Narula, R. (2002). "Innovation systems and 'inertia' in R\&D location: Norwegian firms and the role of systemic lock-in", Research Policy 31(5): 795-816.

Narula, R. and J. Dunning (2000). "Industrial development, globalisation and multinational enterprises: new realities for developing countries", Oxford Development Studies $28(2): 141-167$

Narula, R. and A. Marin (2003) FDI spillovers, absorptive capacities and human capital development: evidence from Argentina, MERIT Research Memoranda No. RM2003016.

Narula, R. and A. Zanfei (2004). Globalisation of innovation: the role of multinational enterprises, in Handbook of Innovation. J. Fagerberg, D. Mowery and R. Nelson (Eds.) Oxford, Oxford University Press.

Nash, M. (2003). Making patents less costly and more efficient: how to patent more for less. PATINNOVA \& EPIDOS Annual Conference 2003, 10-12 November, Luxembourg.

Nelson, R. and S. Winter (1982). An Evolutionary Theory of Economic Change, Cambridge, MA. Harvard University Press.

Nightingale, P. (2000). "Economies of scale in experimentation: knowledge and technology in pharmaceutical R\&D", Industrial and Corporate Change 9(2): 315-359.

Nonaka, I. and H. Takeuchi (1995). The Knowledge-Creaning Compan: Oxford. Oxford, Oxfort University Press.

OECD (1999). Globalisation of industrial R\&D: policies issues. 
Ohmae, K. (1990). The Bordless World, London, Collins.

OTA (1993). Multinationals and the National Interest: Playing by Different Rules.

Washington DC, U.S. Congress, Office of Technology Assessment.

OTA (1994). Multinationals and the US Technology Base. Washington DC. U.S. Congress,

Office of Technology Assessment.

Owen-Smith, J. and W. Powell (2002). Knowledge nerwork in the Boston biotechnology community. Paper presented at the National Academy of Sciences STEP Board Conference 'The Operation of the Patent System: Insights from New Research'.

Patel, P. (1997). Localised production of technology for global markets, in Techmology: glohalisation and economic performance. D. Archibugi and J. Michie (Eds.) Cambridge, Cambridge University Press.

Patel, P. and K. Pavitt (1991). "Large firms in the production of the world's technology: an important case of non-globalisation". Joumal of International Business Sudies 22(1): $1-21$.

Patel, P. and M. Vega (1999). "Patterns of internationalisation of corporate technology: location vs. home country advantages", Research Policy 28(2-3): 145-155.

Pauly, L. and S. Reich (1997). "National structures and multinational corporate behaviour: enduring differences in the age of globalisation", International Organization 51(1): 131.

Pavitt, K. (1985). "Patent statistics as indicators of innovation activities: possibilities and problems", Scientometrics 7(1-2): 77-99.

Pavitt, K. (1988). Uses and abuses of patent statistics, in Handbook of Quantitative Studies of Science and Technology. A.F.J. van Raan (Ed.) Amsterdam, Elsevier.

Pavitt, K. and P. Patel (1994). "Uneven (and divergent) technological accumulation among advanced countrics", Industrial and Corporate Change 3(3): 759-787.

Pavitt, K. and P. Patel (1999). Global corporations and national systems of innovation: who dominates whom?, in Innovation Policy in a Global Economy. D. Archibugi, J. Howells and J. Michie (Eds.) Cambridge, Cambridge University Press.

Pearce, R. and S. Singht (1992). Globalising research and development, London, Macmillan.

Perez, T. (1997). "Multinational enterprises and technological spillovers: an cvolutionary model". Journal of Evolutionary Economics 7(2): 169-192.

Perlmutter, H. (1965). "L'enterprise internationale - trois conceptions", Revae Economique et Sociale 23. 
Persaud, A., U. Kumar and V. Kumar (2001). "Harnessing scientific and technological knowledge for the rapid deployment of global innovations", Engineering Management Joumal 13(1): 12-18.

Porter. M. E. (1986). Competition in globat industries: a conceptual framework, in Competition in Global lindustries. M. E. Porter (Ed.) Boston, Harvard Business School Press.

Porter. M. E. (1990). The Competitive Advantage of Nations, New York. The Free Press.

Putnam, J. (1996) The value of international patent rights. Ph.D thesis, Yale.

Ramires. P. (2003) Globalisation. techology and organizational change in the phamaceutical industry. Ph.D thesis, Manchester School of Management,

Reddaway, B., S. Potter and C. Taylor (1968). Effects of U.K. direct investment orerseas. Final Report, Cambridge, Cambridge University Press.

Reger, G. (2000). Internationalization of research and development in pharmaceuticals, in Changing Innovation in the Pharmaceutical Indusmy. A. Jungmittag, G. Reger and T. Reiss (Eds.) Berlin, Springer-Verlag.

Reich, R. (1990). "Who is us?" Haverd Business Review January/February.

Reiss, T. and S. Hinze (2000). Innovation process and techno-scientific dynamics, in Changing Imovation in the Pharmacentical Industry. A. Jungmittag, G. Reger and T. Reiss (Eds.) Berlin, Springer.

Rodriguez-Clare. A. (1996). "Multinationals, linkages, and cconomic development", American Economic Review 86(4): 852-873.

Rogers, M. (2004). "Absorptive capability and cconomic growth: how do countries catchup?" Forthcoming in Cambridge Journal of Economics.

Rosenkopf, L. and P. Almeida (2003). "Overcoming local search through alliances and mobility". Management Science 49(6): 751-766.

Sally, R. (1994). "Multinational enterprises, political economy and institutional theory: domestic embeddedness in the context of internationalization", Review of International Political Economy: 1(1): 161-192.

Sally, R. (1996). Public policy and the Janus face of the multinational enterprise: national embeddedness and international production, in Globalization and Public Policy. P. Gummett (Ed.) Cheltenham, Edward Elgar.

Saxenian. A. (1990). "Regional networks and the resurgence of Silicon Valley", California Management Revien 33(1): 39-112. 
Saxenian, A. (1994). Regional Adrantage: Culture and Competition in Silicon Valley and Route 128. Cambridge. MA. Harvard University Press.

Saxenian. A. and H. Jinn-Yuh (2001). "The Silicon Valley-Hsinchu connection: technical communities and industrial upgrading". Industrial and Corporate Change 10(4): 8939) 20.

Schmoch, U. and T. Schoöring (1994). "Technological strategics of telecommunications equipment manufacturers". Telecommmanications Policy 18(5): 397-413.

Senker. J. (1998). Biotechology and Competitive Adrantage, Cheltenham, Edward Elgar.

Serapio, M. and D. Dalton (1999). "Globalization and industrial R\&D: an examination of foreign direct investment in R\&D in the United States", Research Policy 28(2-3): 303316.

Servan-Schreiber, J. J. (1968). The American Challenge, London, Hamish Hamilion.

Shan, W. and J. Song (1997). "Foreign direct investment and the sourcing of technology advantage: an evidence from the biotechnology industry", Joumal of Intemational Business Studies 28(2): 267-284.

Sharp, M. (1999). "The science of nations: European multinationals and American biotechnology", International Journal of Biotechnology 1(1): 132-159.

Shaver, M. and R. Solomon (2003). Learning fiom exporting: new insights from examining firm imnovation. Paper presented at the annual AIB conference 'The Power of Ideas and International Business', July $5-8$. Monterey, CA.

Singh, J. (2004a). Multinational firms and knowledge diffusion: evidence using patent citation data. Harvard Business School and Department of Economics, mimeo.

Singh, J. (2004b). Social networks as determinants of knowledge diffusion patterns. Harvard Business School and Department of Economics, mimeo.

Sjöholm, F. (1996). "International transfer of knowledge: the role of international trade and geographic proximity", Welwirtschafiliches Archiv 132(1): 97-115.

Sjöholm. F. (1999). "Technology gap, competition and spillovers from direct foreign investment: evidence from establishment data", Journal of Development Studies 36(1): 53-73.

Small. K. and C. Hsiao (1985). "Multinomial logit specification tests", International Ecomomics Review 26(3): 619-627.

Smith, P. J. (2001). "How do foreign patent rights affect U.S. exports, affiliate sales, and licenses?" Joumal of International Economics 55(2): 411-439. 
Socte, L. (1981). "A general test for the technology gap theory". Welwirtschafiliches Archiv 17: 638-660.

Soetc, L. (1987). "The impact of technological innovation on intemational trade patterns: the evidence reconsidered". Research Policy 16(2-4): 101-130.

Socte. L. and S. Wyatt (1983). "The use of foreign patenting as an international comparable science and technology output indicator", Scientometrics 5(1):31-54.

Sölvell, O. and I. Zander (1995). "Organization of the dynamic multinational enterprise", International Studies of Management and Organization 25(1-2): 17-38.

Sölvell, O., I. Zander and M. E. Porter (1991). Advantage Sweden, Stockholm, Norstedts.

Sousa, N. (2001). Multinationals and technology transfer through labour training. University of Nottingham, mimeo.

Stolpe, M. (2002). "Determinants of knowledge diffusion as evidenced in patent data: the case of liquid crystal display tcchnologies", Research Policy 31(7): 1181-1198.

Swedenborg, B. (1985). Sweden, in Multinational enterprises, economic structure and international competitiveness. J. Dunning (Ed.) Chichester, John Wilcy \& Sons.

Szulanski, G. (1996). "Exploring internal stickiness: impediments to the transfer of best practice within the firm", Strategic Management.Jommal 17(Winter Special Issue): 27-43.

Teece, D. (1976). The Multinational Corporation and the Resource Cost of International Technology Transfer: Cambridge MA, Ballinger.

Tecec, D. and G. Pisano (1994). "The dynamic capabilities of firms: an introduction", Industrial and Corporate Change 3(3): 537-556.

Teigland, R., C. Fey and J. Birkinshaw (2000). "Knowledge dissemination in global R\&D operations: an empirical study of multinationals in the high technology clectronics industry", Management International Review 40(1): 49-78.

Trajtenberg, M. (1990). "A penny for your quotes: patent citations and the value of innovations", RAND Jommal of Economics 20(1): 172-187.

Trajtenberg, M., A. Jaffe and R. Henderson (1997). "University versus corporate patents: a window on the basicness of invention", Economics of Innovation and New Technology' 5(1): $19-50$.

Tsai, W. and S. Ghoshal (1998). "Social capital and value creation: the role of intra-firm networks", Academy of Managemen Jownal 41: 474-476.

UNCTAD (2001). World Investment Report 2001 - Promoting Linkages, New York and Geneva. United Nations Conference on Trade and Development. 
van Pottelsberghe de la Potterie, B. and F. Lichtenberg (2001). "Does foreign direct investment transfer technology across borders?" Review of Economics Statistics 83(3): 490-497.

Venables, A. (1999). "Fragmentation and multinational production", European Economic Review 43(4-6): 935-945.

Vernon, R. (1966). "International investment and international trade in product cycle", Quarterly Journal of Economics 80(2): 190-207.

Vernon, R. (1977). Storm over multinationals: the real issues, London, Macmillan.

Vernon, R. (1979). "The product cycle hypothesis in a new international cnvironment", Oxford Bulletin of Economics and Statistics 41(4): 255-67.

Vernon, R. (1992) Are forcign-owned subsidiaries good for the United States?, Occasional paper. Group of Thirty No. 37.

Verspagen, B. (1993). Uneven Giowth Between Independent Economies, Aldershot. Avebury.

Verspagen, B. (1994). Technology and growth: the complex dynamics of convergence and divergence, in The Economics of Growth and Technical Change. G. Silverberg and L. Soete (Eds.) Aldershot, Edward Elgar.

Verspagen, B. (1997). "Estimating international technology spillovers using technology flow matrices", Welmirtschaftliches Archiv 133(2): 226-248.

Verspagen, B. (1999). "Large firms and knowledge flows in the Dutch R\&D system: a case study of Philips Electronics", Technology Analysis and Strategic Management 11(3): $211-233$

Verspagen, B. and W. Schoenmakers (2000) The spatial dimension of knowledge spillovers in Europe: evidence from firm patenting, MERIT Research Memoranda No. 2000-016.

Verspagen, B. and W. Schoenmakers (2004). "The Spatial dimension of patenting by multinational firms in Europe", Jounal of Economic Geography forthcoming(1).

Veugelers, R. and B. Cassiman (2004). "Importance of international linkages for local knowhow flows: some econometric evidence from Belgium", European Economic Review forthcoming.

Von Hippel, E. (1987). "Cooperation between rivals: informal know-how trading". Research Policy 16(6): 291-302.

Von Hippel. E. (1994). "'Sticky information' and the locus of problem solving: implications for innovation", Management Science 40(4): 429-439. 
von Zedtwit\%. M. and O. (jassmamn (20)2). "Market versus technology driven in R\&D) internationalisation: four different patterns of managing research and development". Reserarch Policy 31(4): 569-588.

Vtong. Q. (1989). "Likelihood ratio tests for model selection and non-nested hypothesis", Ecomometrica 57(2): 307-333.

Wang. Y. and M. Blömstrom (1992). "Foreign direct investment and technology transfer: a simple model", Europesun Economic Review 36(1): 137-155.

Wenger, E. C. (1998). Communities of Practice: Leaning. Meaning and ldentity: Cambridge, Cambridge University Press.

Westney, D. E. (1993). "Cross-Pacific internationalization of R\&D by U.S. and Japanese firms". R\&D Managemem 23(2): 171-181.

Winkelmann, R. and K. F. Zimmermann (1995). "Recent developments in count data modelling: theory and applications", Journal of Economic Surveys 9: 1-22.

Winter. S. (1987). Knowledge and competence as strategic assets, in The Competitive Challenge-Strategies for Industrial Innovation and Renewal. D. Teece (Ed.) Cambridge MA. Ballinger.

Xu, B. (2000). "Multinational enterprises, technology diffusion, and host country productivity growth". Joumal of Development Economics 62(2): 477-493.

Xu, B. and J. Wang (2000). "Trade, FDI and International technology diffusion", Joumnal of Economics Integration 15(4): 585-601.

Yamin, M. (1999). An Evolutionary Analysis of Subsidiary Innovation and Reverse Transfer, in International Business Organization: Subsidiany Management. Entry Strategies and Emerging Markets. F. Burton, M. Chapman and A. Cross (Eds.) Basingstoke, Macmillan.

Zander. I. (1999). "How do you mean 'global"? An empirical investigation of innovation networks in the multinational corporation", Research Policy: 28(2-3): 195-213.

Zander, U. (1991) Exploiting a technological edge-Voluntary and involuntary dissemination of technology: Ph.D thesis, Institute of Intemational Business, Stockholm.

Zanfei, A. (2000). "Transnational firms and the changing organisation of innovative activitics", Cambridge Journal Economics 24(5): 515-542.

Zeira, Y. (1976). "Management development in ethnocentric MNCs". California Management Review 18(4): 34-42.

Zcira, Y. and M. Banai (1984). "Present and desired methods for selecting expatriate managers for international assignments", Personnel Review 13(3): 29-35. 
Zeira. Y. and E. Harari (1979). "Host country organisation and expatriate managers in Europe". California Management Revie' 21(3): 40-50.

Zhou, C. and T. Frost (2003). Centrifugal forces, ReD co-practice, and reverse knowledge flows in multinational firm. Paper presented at the annual AIB conference 'The Power of Ideas and International Business', July 5-8, Montercy, CA.

Zucker, L. G., M. R. Darby and M. B. Brewer (1998). "Intellectual human eapital and the birth of U.S. biotechnology enterprises". American Economic Review 88(1): 290-306. 


\section{SamenVatTing (Sumiary IN DUTCH)}

De internationalisering van $R \& D$ door multinationale ondernemingen brengt een aantal uitdagingen met zich mee, zowel voor managers van die ondernemingen, als voor beleidsmakers. Op micro-niveau is de uitdaging voor R\&D managers om voor hun wereldwijde activiteiten gebruik te maken van kennis afkomstig uit locaties die verspreid zijn over de wereld. Dit betekent dat zij methodes moeten ontwikkelen om binnen hun organisatic kennis over te dragen en te integreren. Op macro-niveau moeten beleidsmakers zich in eerste instantic bekommeren om de aard en omvang van R\&D-werkzaamheden dic naar het buitenland worden verplatatst. Voor hen is het wellicht niet zorgwekkend indien lokaal ontwikkelde kennis naar het buitenland wordt geëxportecrd met het doel die kennis aan te passen aan de buitenlandse lokale onstandigheden en marktbehoeftes, maar meer beleidsandacht is op zijn plats indien er een meer substantiële verplaatsing van $R \& D$ naar het buitenland plaatsvindt. Het gaat daarbij niet zozeer om de omvang van de naar het buitenland verplaatste R\&D, maar vooral om de mate waarin de nationale economie voordeel kan behalen uit die verplaatsing, als dat al gebeurt. Verplaatsing van $R \& D$ naar het buitenland kath het nationale technologische concurrentievermogen versterken indien de in het buitenland opgedane kennis naar andere binnenlandse bedrijven stroomt.

In dit procfschrift heb ik op basis van een casestudy van zes Europese farmaceutische ondernemingen onderzocht hoc multinationals hun internationale R\&D-laboratoria organiseren en kennis verspreiden. Uit uitvoerige interviews met R\&D managers en wetenschappers is gebleken dat de ontwikkeling van medicijnen voornamelijk is georganiseerd in een netwerk van grote eenheden met een regionale focus, die relatief los ten opzichte van elkaar staan. Daarentegen wordt het meer fundamentele gedeelte van het ontdekkingsproces verricht in een sterker geïntegrecrd netwerk van relaticf kleine cenheden, die gespecialiseerd zijn in therapeutische gebieden van algemene aard. In dit complexe netwerk van eenheden die geografisch, organisatorisch en technologisch gezien ver uit elkaar liggen. lijkt internationale mobiliteit van onderzockers bij te dragen aan de overdracht en integratie van kennis; hiervan wordt echter niet op grote schaal gebruik gemaakt, en het lijkt er eerder op dat ondernemingen leunen op het initiatief van een enkele onderzoeker om voordeel te halen uit een internationaal uitgebreid R\&D-netwerk.

Ten tweede wordt in dit proefschrift onderzocht in welke mate buitenlandse dochterondernemingen gebruik maken van locale kennisbronnen in het land waarin ze 
gevestigd zijn (hetgeen Dunning en Narula, 1995. 'asset-augmenting' activiteiten nocmen), en daarnalast of ondernemingen in het thuisland van de multinational die niet tot de multinationale groep behoren, ook kunnen profiteren van de kennis dic de multinational via haar dochterondernemingen in het buitenland vergalt (hetgeen ik hier inter-firm reverse technology transfer' zal noemen, ofwel omgekeerde technologicoverdracht tussen bedrijven). In dit procfschrift wordt gebruik gemaakt van octrooi-citaticanalyse voor een steekprocf van 94 Europese en Amerikaanse multinationals dic actief zijn in een high-tech sector. De resultaten hiervan tonen allereerst aan dat de 'asset-augmenting' activiteiten van Europese dochterondernemingen in de VS in een aantal gevallen belangrijker zijn dan zowel de 'assetexploiting' activiteiten van die bedrijven, alsook dan de 'asset-augmenting' activiteiten van hun Amerikaanse tegenhangers. Dochters van Amerikaanse multinationals in Europa zijn nog steeds sterk afhankelijk van kennisbronnen uit hun thuisland. Verder is uit de analyse van ontvangen citaten van octrooien die zijn toegekend aan 24 chemische en farmaceutische multinationals gebleken dat in het thuisland gevestigde bedrijven (of deze nu international of puur nationaal actief zijn) inderdaad lijken te profiteren van de Amerikaanse R\&D-activiteiten van chemische dochterondernemingen (van niet-Amerikaanse multinationals), terwijl dit lijkt niet op te gaan voor de Amerikaanse dochterondernemingen van farmaceutische multinationals. Het lijkt crop dat 'inter-firm reverse technology transfer' uitsluitend kan platsvinden wanneer de 'asset-augmenting' R\&D-activiteiten van buitenlandse dochterondernemingen samengaan met sterk ingebedde R\&D-activiteiten in het thuisland.

Een afgeleid thema van dit proefschrift is het meten van de omvang van het effect van het 'thuislandvoordecl' bij het tellen van octrooi-aanvragen als innovatie-indicator (d.w.z. dat nationale aanvagers, evenredig aan hun innovatieve activiteiten, vergeleken met buitenlandse aanvragers, meer octrooien aanvragen in hun thuisland); en na te gaan of dit effect even sterk merkbaar is in de databases van de twee belangrijkste octrooibureaus wiens gegevens worden gebruikt in de literatuur over R\&D internationalisering: het Amerikaanse octrooibureau USPTO en het Europese octrooibureau EPO. Een analyse van de EPO- en USPTOoctrooiportefeuilles van 131 Europese, Amerikaanse en Japanse multinationals actief in de high-tech sector, alsmede de octrooifamilies van deze portefeuilles (dat wil zeggen, soortgelijke octrooien die in meerdere landen aangevraagd zijn), wijst uit dat dit effect in beide octrooistelsels aanwezig is - zij het in mindere mate bij EPO - cn ook de octrooicitatieanalyse beïnvloedt. De conclusie van deze analyse is dat zelfs grote bedrijven met multinationale activiteiten en aanzienlijke financiële middelen voor iedere uitvinding 
afzonderlijk een afweging maken waar een octrooi an te vagen, in plaats van simpelweg iedere uitvinding te octrooieren in zowel Europa (EPO) als de VS (USPTO). 


\section{Curriculum Vitae}

Paola Criscuolo was born in Siena on 14 May 1972. She graduated cam laude in Economics from the faculty of Scienze Economiche e Bancaric of the University of Siena in 1998, having completed a dissertation. supervised by Prof. A. Vercelli and Prof. F. Coricelli. on "The diffusion of technology as a condition for the convergence process: a possible synthesis between neo-classical models and the technological gap approach." She went on to do an MSc in International Economics and Finance at the Catholic University of Milan and, thanks to a fellowship from the Einaudi Foundation, an MSc in Economics at the University of Warwick. Paola graduated from Warwick in September 1999, having been awarded a distinction for her thesis on "An endogenous growth accounting analysis of the Asian miracle" supervised by Prof. Stephen Broadberry.

She commeneed her work on this thesis at the Maastricht Economic Research Institute on Innovation and Technology (MERIT), part of the University of Maastricht, in autumn 1999. partly funded by a Marco Fanno fellowship from Mediocredito Centrale. During her doctoral studies she has spent a year as visiting Ph.D. student at the Clore Management School, Birkbeck College, University of London, where she lectured in managerial economics, and three years at the Science and Technology Policy Research Unit (SPRU) at the University of Sussex, first as a Marie Curie fellow, funded by the European Commission, and then as a Research Officer. Since October 2004 she has been a Research Associate at the Innovation Studies Centre in Tanaka Business School, part of Imperial College London.

Paola has been a member of several intemational collaborative projects on innovation issues and has published two articles in refereed joumals and several working papers, and has also presented her work on numerous occasions to conferences.

She is married to her husband, Fergal Shortall. 